MANAGING THE NATURAL RESOURCE SECTOR:

\title{
A CASE STUDY OF THE LIQUEFIED NATURAL GAS (LNG) PROJECT IN PAPUA NEW GUINEA
}

by

\section{ELLY KINKIN}

\author{
A thesis \\ submitted to Victoria University of Wellington \\ in fulfilment of the requirements for the degree of \\ Doctor of Philosophy
}

Victoria University of Wellington 


\begin{abstract}
This research is a study of the Papua New Guinea (PNG) Liquefied Natural Gas (LNG) project, the country's biggest single investment in the extractive industry. The focus of the research is on understanding the impact and effect of the project on the country and in particular the distribution of the revenue and the influences on the distribution of the revenue. An additional area that was also looked at was the financial transparency and accountability of these distributions.

The research arose in direct response to the fact that Papua New Guinea (PNG), which is well endowed with a wide range of natural resources, does not seem to use its natural wealth effectively to improve the human development of its people. The exploitation of these resources has in fact been associated with recurring fiscal and monetary crises, concentrations of investment in the minerals and petroleum sector, no improvement in the basic public services, and corruption at all levels of government. There has also been a persistent rising level of socio-economic inequality in the immediate communities hosting major resource projects and increasing poverty in the urban areas and pockets of rural areas.
\end{abstract}

The research took a case study approach and used a multi-disciplinary lens by looking at the political, economic and anthropological literature and gleaning from them propositions about the influences on the distribution of revenues. In particular the case was used to investigate propositions related to the "resources curse" hypothesis that, in the absence of good governance, developing country governments are at risk to economic and fiscal mismanagement and corruption from the availability of resource rents from extractive industries. The research gathered evidence from people from project-specific documents made available largely through social media, accessible budget papers, parliamentary proceedings (Hansard), Acts of Parliament, government policy edicts, statements and press releases and websites of key government departments, state owned enterprises and the companies involved in the project, and some interviews of key informants. The Extractive Industry Transparency Initiative (EITI) reports on PNG were also specifically examined.

The project has been exporting LNG now since 2014. While the construction of the project had a significant effect on economic growth, wages and prices and the exchange rate, the longer-term effects are more contestable. Returns to the economy and government revenues have been lower than forecast due to lower prices but also the effect of tax concessions and debt servicing leading to flows offshore larger than forecast. The government and landowners were making decisions based on a flawed projection and information to the extent that the government has been unable to sequester any revenues in a Sovereign Wealth Fund.

Continued volatility in petroleum prices has affected government budget planning but overoptimistic forecasting of revenues including from the PNG (LNG) project, particularly in 2014-16, led to ballooning deficits. For short-term political reasons, government budgeting has tended to over-commit to new spending during the commodity booms and be forced in the downswings into cutbacks damaging to public services and investment or to rapid increases in broadly defined public debt. Budgets also pre-committed project revenues to new 
public expenditure project. The key point was the lack of attention being given to the downside risks of revenue projections supplied by the operator.

The politics of access to resource rents have played out in the form of relations between local landholders and the government and in how the executive power has been able to structure access to project revenues nationally. The project also has had a destabilizing effect on local society where local-national relations have influenced the national politics of resource rent distribution and conversely have been put under pressure over contestation of the project impacts and access to benefits. Further, landholders have to date not received their full financial entitlements from the project despite the promises being made by successive governments since 2009. There has been ongoing discontent amongst landholders. The lack of transparency about the use of project revenues, particularly those not accruing directly to the Public Account, has contributed to this discontent.

The research also found the few key project agreements have been officially released but much information has found its way into the public domain via social media. Budget-related information has been more plentiful but the EITI has been hampered by poor financial reporting by public organisations receiving and managing revenues. When project information does enter the public and government is forced to acknowledge it, it can influence how government conducts its business and makes decisions. 


\section{Acknowledgement}

I want to thank the Government of New Zealand for the scholarship which allowed me the privilege to undertake the doctoral study at the Victoria University of Wellington. I would also like to extend my gratitude to the people of New Zealand for my stay in this beautiful country.

I received a lot of support from the Victoria University of Wellington and in particular from the School of Government. I want to acknowledge and thank the Head of School of Government: Professor Girol Karacaoglu who gave me all the support including supervisory assistance to complete the thesis.

I want to thank my supervisor Rob Laking who provided invaluable insights, shared his wealth of experience and critically questioned a lot of my assumptions. He inspired me and instilled in me a positive approach to work and life. I am greatly indebted to him for guiding me and encouraging me on this extraordinary journey.

A lot of people encouraged and supported me along the way and include: Professor Robert Gregory of the School of Government and Associate Professor Jane Bryson of the Victoria Business School who wanted to see me succeed. I would also like to extend my gratitude to Associate Professor Hon. Lumanuvao Winnie Laban, who as Assistant Vice-Chancellor continuously supported me in the early part of my studies.

I am grateful for the support I received from Clemmie Newton, the Coordinator - New Zealand Aid Scholarship for her advocacy and confidence in me.

I also want to acknowledge and thank my employer the University of Papua New Guinea for granting me the study leave to pursue the PhD program. I want to thank the Pro Vice Chancellor Vincent Malaibe for his encouragement. I am also greatly indebted to Professor Lekshmi N. Pillai, the Executive Dean of the School of Business and Public Policy for his support and confidence in my ability to complete the study.

The following people loved and supported me regardless of the outcome of this journey and to them I am forever grateful:

My great friends: Dr Hengene Payani and Alphonse Kona

My parents: Elias and Maria Waninara

My Beautiful wife: IaJosephine Kinkin

My walk and faith in Christ Jesus was strengthened in this journey. 


\section{Contents}

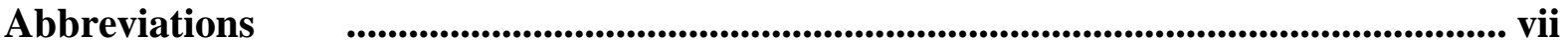

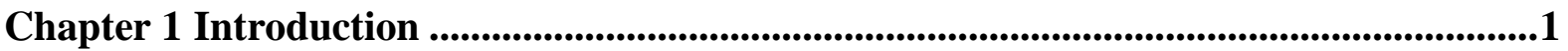

1.1 The basis for this research ..................................................................... 1

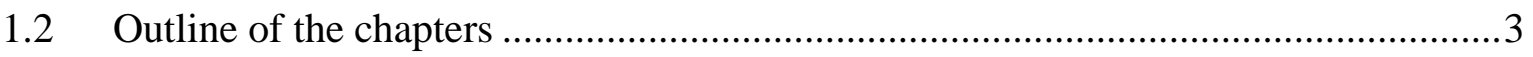

Chapter 2 Problem Statement and Research Questions .....................................................7

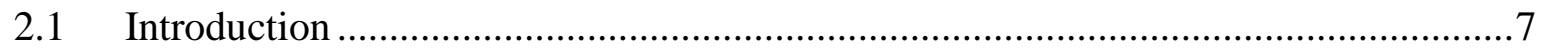

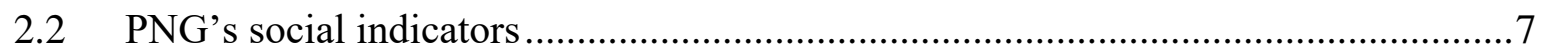

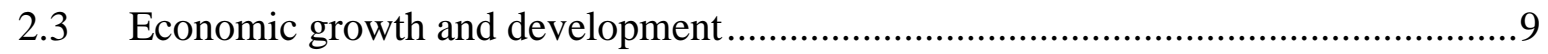

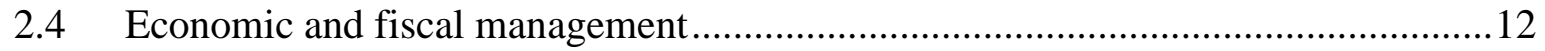

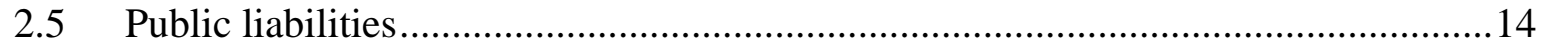

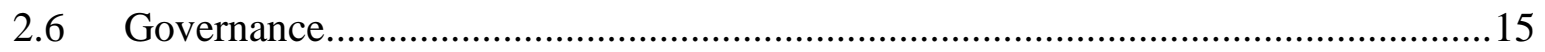

$2.7 \quad$ Problem Statement and Research Questions ....................................................... 18

Chapter 3 International Literature Review ....................................................................21

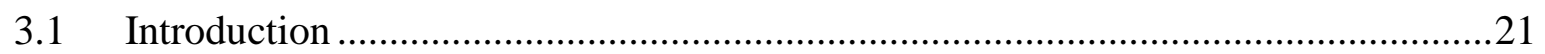

3.2 Relationship between natural resource dependence and development ...................21

3.3 Explaining the effects of natural resource dependence ..........................................21

3.4 Causes and mechanisms for natural resource / development relationship ...............25

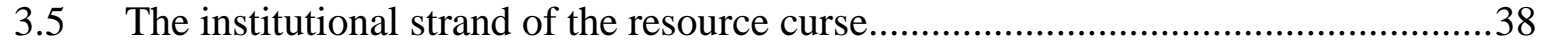

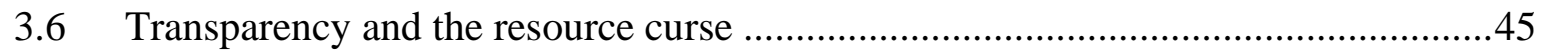

3.7 Conclusions on the resource curse and the role of governance..............................48

Chapter 4 Natural resource dependence: the case of Papua New Guinea ........................50

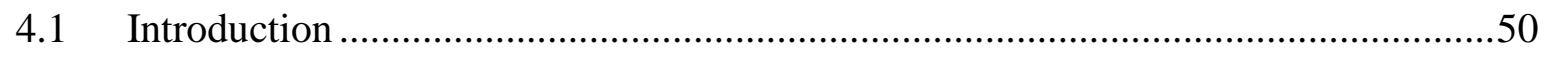

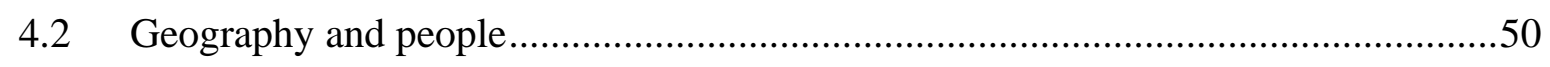

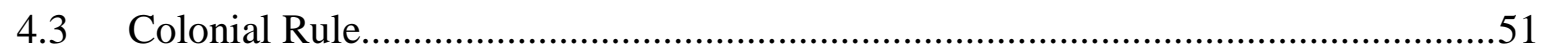




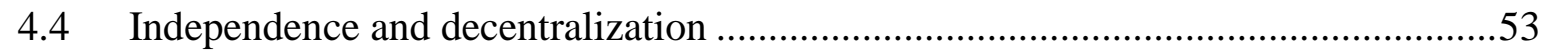

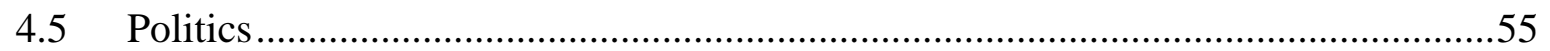

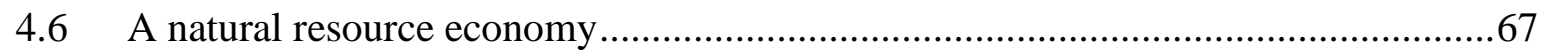

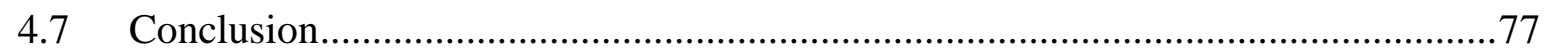

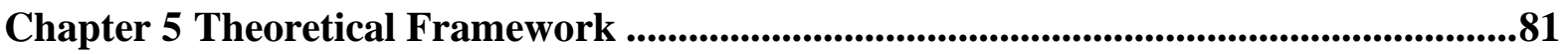

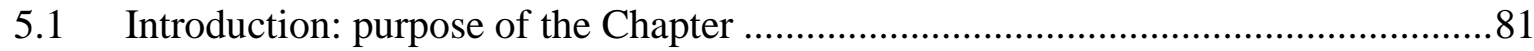

5.2 A political economy approach to modelling NR rents ......................................... 81

5.3 Conclusion: implications for analysis of the PNG LNG case ...............................103

Chapter 6 Methodology and Evidence Gathering ................................................................106

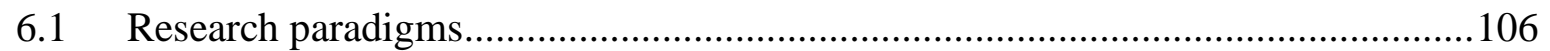

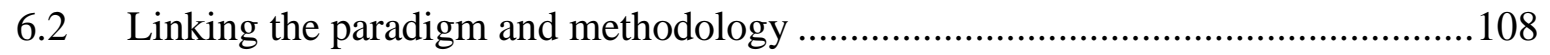

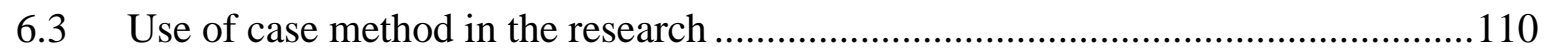

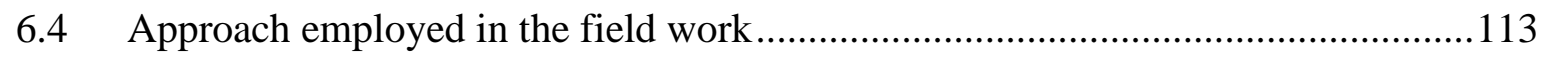

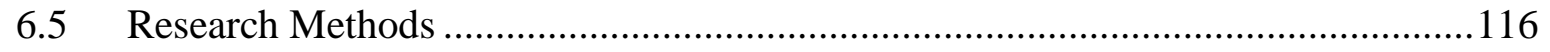

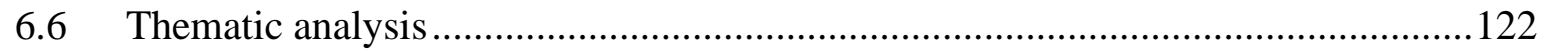

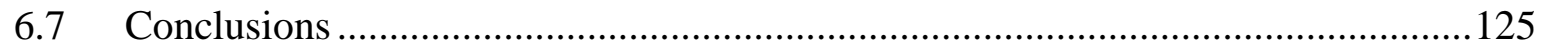

Chapter 7 The PNG LNG Project and its context ..............................................................127

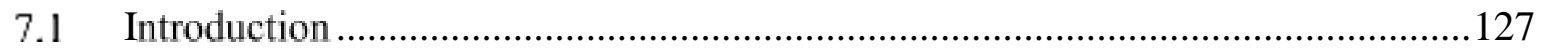

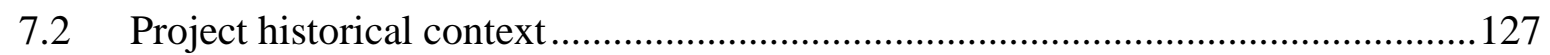

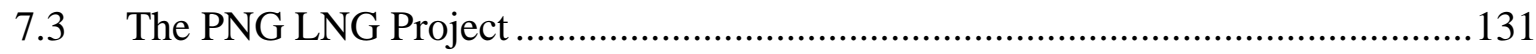

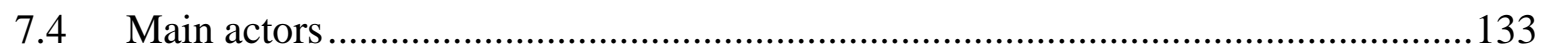

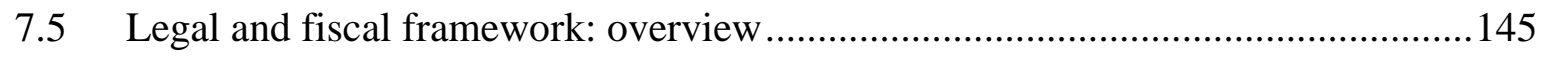

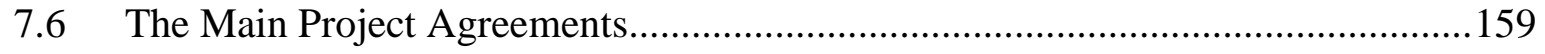

7.7 Conclusions: the PNG LNG main project agreements and their legal and institutional framework 
8.1 Introduction: Benefit Sharing Agreements - development and implementation....172

8.2 State-landowner relations following the benefit-sharing agreements 182

8.3 Conclusions on benefit sharing..... 191

Chapter 9 The project and government fiscal planning and budgeting 195

9.1 Introduction: emergence of the PNG LNG project in fiscal planning 195

9.2 The ACIL study 196

9.3 The evolution of budget expectations and policy 201

9.4 Summary: the effects on budgetary and fiscal policy of expectations about the PNG LNG project .228

Chapter 10 Transparency and its effects............................................................231

$10.1 \quad$ Introduction: Availability of information and its effects ...............................231

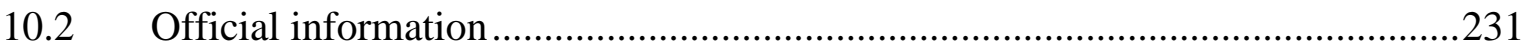

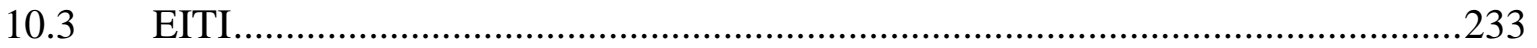

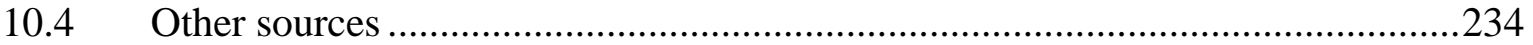

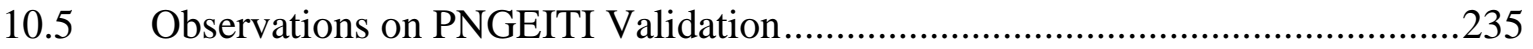

10.6 Weaknesses in public sector accountability framework ...................................2.238

10.7 Conclusion: How did availability of information influence the discourse? ........241

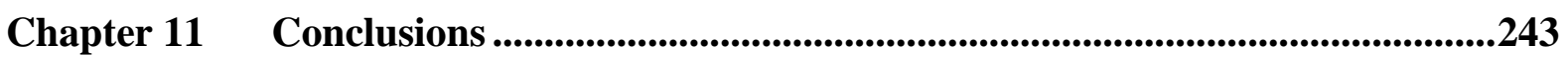

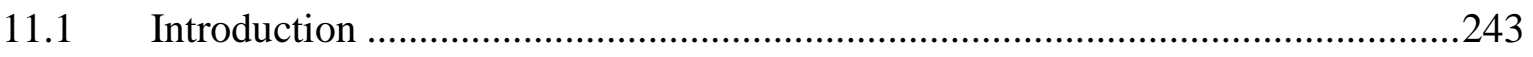

11.2 How have the research questions been addressed? .........................................243

11.3 Implications for future PNG governance and policy .......................................251

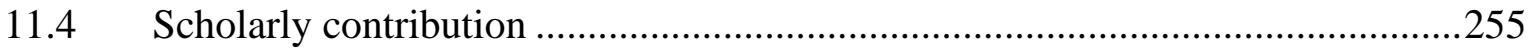

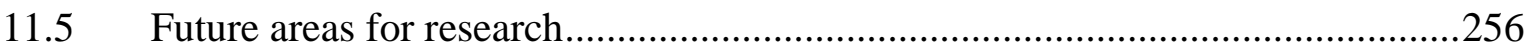

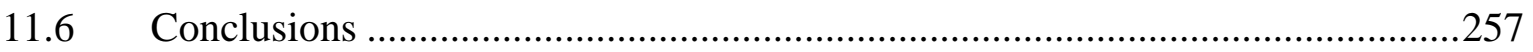


Annex: Sovereign Wealth Fund Rule Changes

References

Note on referencing.

Bibliography 


\section{Tables}

Table 2:1 PNG: Percentile Ranking in World Governance Indicators ..................................16

Table 3:1 Political system characteristics and natural resource dependence ...........................34

Table 3:2 World Bank: Worldwide Governance Indicators ...............................................40

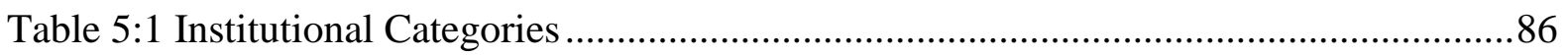

Table 5:2 Phases of Project-Related Processes..................................................................92

Table 5:3 Propositions about impacts of resource dependence in PNG ................................. 105

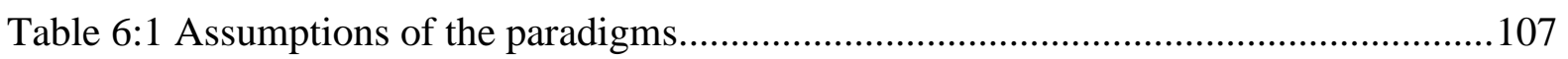

Table 6:2 Methodological Differences, Qualitative and Quantitative ..................................116

Table 6:3 Main documentary sources for the research .................................................... 118

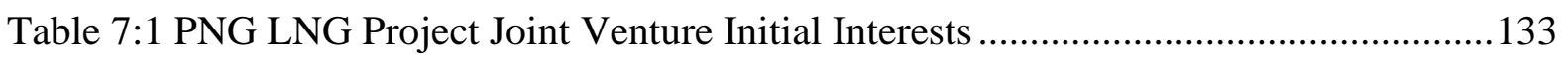

Table 7:2 PNG LNG Project: Main Agreements .............................................................. 159

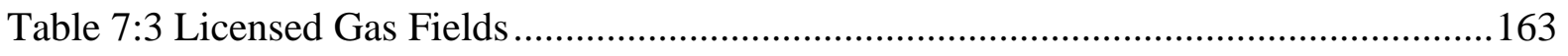

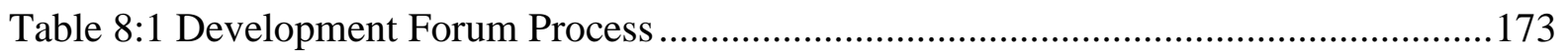

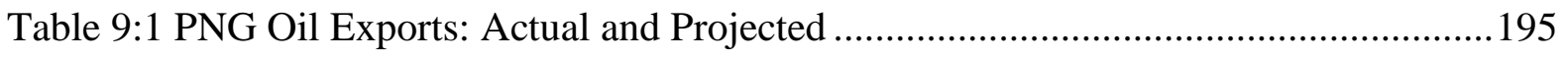

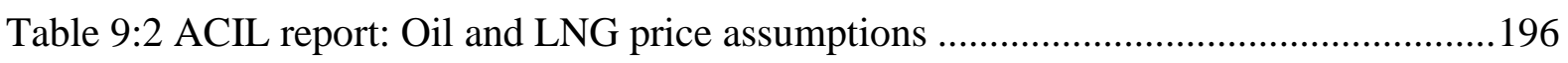

Table 9:3 ACIL forecast: Total net cash payments to GoPNG, ACIL forecast, 2008-2042 .197

Table 9:4 ACIL forecast: net cash payments to government, 2008-2032 ............................. 197

Table 9:5 2015 and 2016 Budget forecasts (PGK m) ......................................................217

Table 9:6 Budget 2016: Projected Sovereign Wealth Fund Transactions (m Kina)..............218

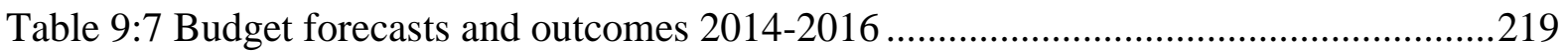

Table 9:8 EITI: Payments to government and landowners from PNG LNG project (PGK).224 Table 9:9 Average annual early project revenues for government: forecast and actual (20152017) 225 


\section{Figures}

Figure 2:1 PNG: Human Development Index 1990-2017 _.................................................

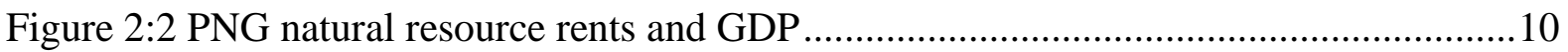

Figure 2:3: Falling government share of total resource rents ............................................ 11

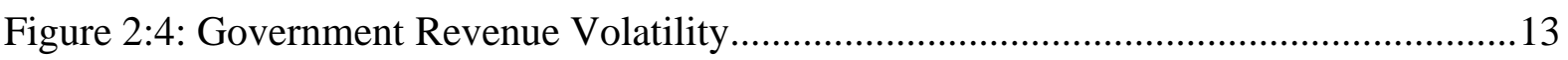

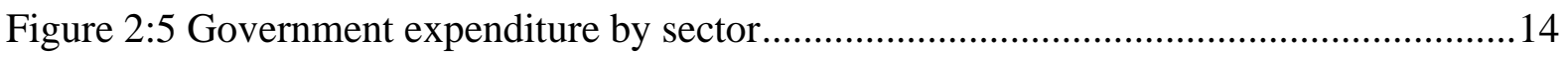

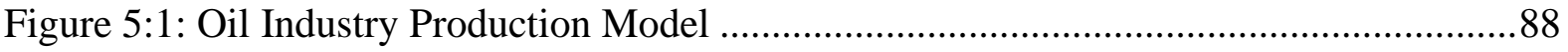

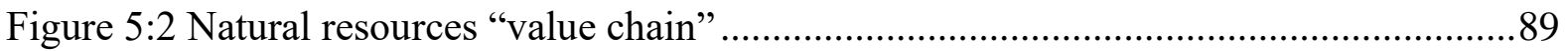

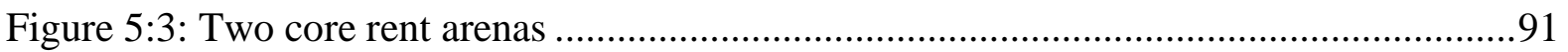

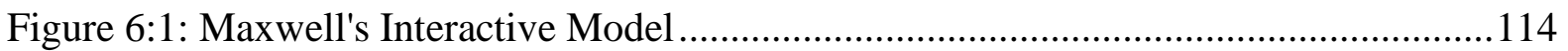

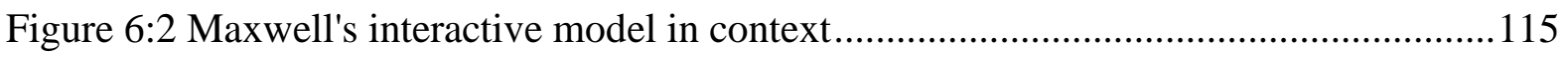

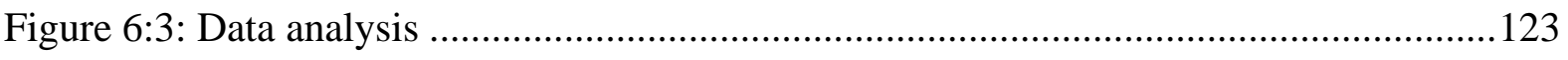

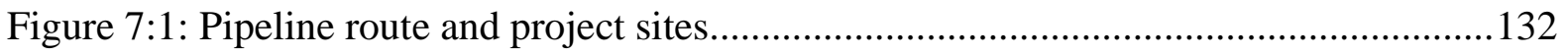

Figure 7:2: PNG LNG Project:- State Coordination Mechanism ........................................ 136

Figure 7:3: Kumul Petroleum Holdings Ltd Interests..................................................... 156

Figure 7:4: Legal structure of the PNG LNG Project .......................................................... 161

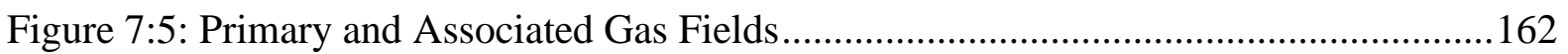

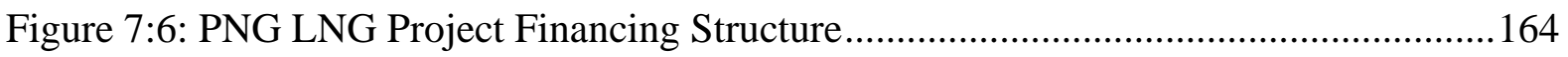

Figure 9:1: ACIL Forecast of total net revenue plus dividends ......................................... 197

Figure 9:2: Budget 2009 forecast oil and gas production ................................................. 199

Figure 9:3: Budget 2009 forecast total direct activity from LNG project ...........................200

Figure 9:4: 2011 Budget - Forecast government revenue plus dividends from PNG LNG

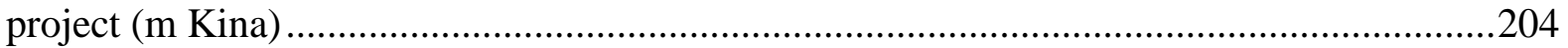

Figure 9:5: 2012 and 2011 Budgets - Forecast government revenue plus dividends from PNG

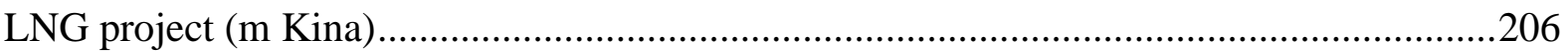

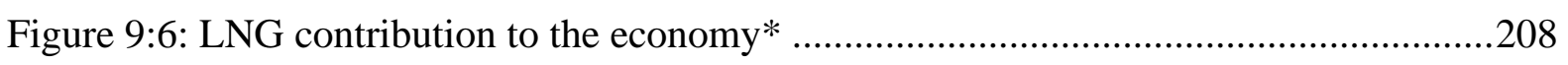

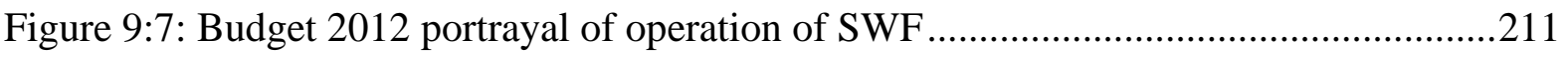

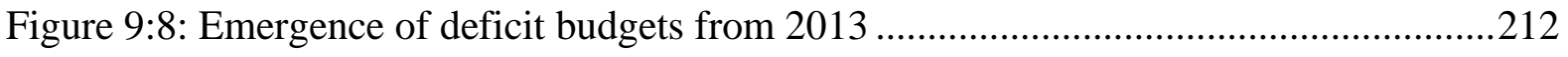

Figure 9:9: Sovereign Wealth Fund: Treasury forecast of accumulations ..........................213

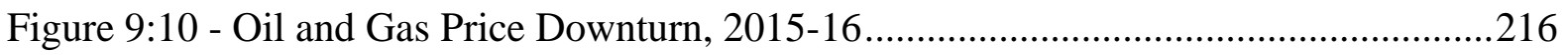

Figure 9:11: Budget 2019 Forecast of Revenue from PNG LNG Project (US\$m) ..............227 


\section{Abbreviations}

ADB Asian Development Bank

ADR Alternative Dispute Resolution

APT Additional Profits Tax

BCL Bougainville Copper Limited

BPNG Bank of Papua New Guinea

BSA Benefit Sharing Agreements

CDOA Coordinated Development and Operating Agreement

CEPA Conservation and Environment Protection Authority

CPI Corruption Perceptions Index

CSA Cost-Sharing Agreement

CSR Corporate Social Responsibility

DEC Department of Environment and Conservation

DFAT Department of Foreign Affairs and Trade (Australia)

DPE Department of Petroleum and Energy

DSIP District Services Improvement Program

DSP Development Strategic Plan

ECA Export Credit Agency

EHL Esso Highlands Limited

EIA Environmental Impact Assessment

EIR Environmental Inception Report

EIS Environmental Impact Statement

EITI Extractive Industries Transparency Initiative

FBO Final Budget Outcome

FDI Foreign Direct Investment

FEED Front-End Engineering and Design

FSA Fiscal Stability Agreement

GDP Gross Domestic Product

GloCo PNG LNG Global Company LLC

GoPNG Government of Papua New Guinea

GTE Gas to Electricity 


\begin{tabular}{|c|c|}
\hline HDI & Human Development Index \\
\hline IBP & International Budget Partnership \\
\hline IFC & International Finance Corporation \\
\hline IFI & International Financial Institution \\
\hline ILG & Incorporated Land Group \\
\hline IMF & International Monetary Fund \\
\hline IPBC & Independent Public Business Corporation \\
\hline IRC & Internal Revenue Commission \\
\hline ITC & Infrastructure Tax Credits \\
\hline $\mathrm{JCC}$ & Japan Crude Cocktail \\
\hline KCHL & Kumul Consolidated Holdings Limited \\
\hline KPHL & Kumul Petroleum Holdings Limited \\
\hline LA & Landowner Association \\
\hline LBBSA & License Based Benefit Sharing Agreement \\
\hline LNG & Liquefied Natural Gas \\
\hline LPG & Liquefied Petroleum Gas \\
\hline MCES & Ministerial Committee for Economic Sector \\
\hline MDG & Millennium Development Goal \\
\hline $\mathrm{MNC}$ & Multi-National Corporation \\
\hline MOA & Memorandum of Agreement \\
\hline MP & Member of Parliament \\
\hline MRDC & Mineral Resources Development Company \\
\hline MRSF & Mineral Resources Stabilisation Fund \\
\hline MTDP & Medium Term Development Plan \\
\hline MTDS & Medium Term Development Strategy \\
\hline MTFS & Medium Term Fiscal Strategy \\
\hline MTPA & Million tonnes per annum \\
\hline MYEFO & Mid-Year Economic and Fiscal Outlook \\
\hline NGO & Non-Government Organisation \\
\hline NR & Natural Resources \\
\hline NRD & Natural Resource Dependence \\
\hline ODA & Official Development Assistance \\
\hline
\end{tabular}


OECD Organisation for Economic Cooperation and Development

OGA Oil and Gas Act 1998

OSL Oil Search Limited

PDL Petroleum Development Licence

PERR Public Expenditure Review and Rationalisation

PFMA Public Finances (Management) Act 1995

PGK Papua New Guinea Kina

PMMRA Public Money Management Regularisation Act 2017

PNG Papua New Guinea

PNG IPA Papua New Guinea Institute of Public Administration

PNG LNG Papua New Guinea Liquefied Natural Gas (Project)

PPL Petroleum Prospecting Licence

PRL Petroleum Reservation Licence

PSIP Provincial Services Improvement Program

SAP Structural Adjustment Program

SPA Sale and Purchase Agreement

SIA Social Impact Assessment

SMLI Social Mapping and Landholder Identification

SWF Sovereign Wealth Fund

TI Transparency International

TIPNG Transparency International PNG

TNC Transnational Corporation

UBSA Umbrella Benefit Sharing Agreement

UNDP United Nations Development Program

USA United States of America

WGI Worldwide Governance Indicators 


\section{Chapter 1 Introduction}

\subsection{The basis for this research}

This research is based on a case study of the development of the Papua New Guinea Liquefied Natural Gas Project (PNG LNG) and distribution of its revenues. It arose in direct response to the fact that Papua New Guinea (PNG), which is well endowed with a wide range of natural resources, does not seem to use its natural wealth effectively to improve the human development of its people. The exploitation of these resources has in fact been associated with recurring fiscal and monetary crises, concentration of investment in the minerals and petroleum sector, no improvement in basic public services, and corruption at all levels of government. There has also been a persistent rising level of socio-economic inequality in the immediate communities hosting major resource projects and increasing poverty in the urban areas and pockets of rural areas.

A common explanation from the international literature is that PNG is subject to the "resource curse" of economies dependent on natural resources for their development and growth. In addressing these problems, the Government of Papua New Guinea (GoPNG) has relied heavily on the prescriptions of international donors without questioning the rationale of some of the recommended remedial measures (Chand, 2004). During severe debt crises of the last forty years there have been numerous attempts especially by donor agencies to improve economic and fiscal management and governance of state institutions (particularly their transparency and accountability) but with little success (ADB, 2012; Chand, 2004; World Bank, 2018). Corruption in its various forms and at different levels of government is perceived to be rampant (ADB, 2012; Chand, 2004; World Bank, 2018).

The author's personal interest in PNG's natural resource development arose in part because of his interest and involvement (through a social mapping and socio-economic impact assessment) with the Papua LNG project, a further LNG project following PNG LNG, and also for the need to understand how a major resource project such as PNG LNG can transform not only local communities but also the national economy. PNG LNG is also the single largest investment project in the country's petroleum sector: it began in 2008 and is now in its fourth year of production. The investment in this project, totalling US $\$ 19 \mathrm{bn}$, is also the largest ever in PNG's history, and the project is expected to be a major impact on both PNG's Gross Domestic Product (GDP) and the revenues of the Government of PNG. 
The institutional settings and specific contractual commitments for this project was widely held to represent best practice at the time, in areas like equity participation, ownership structure, taxation regimes, corporate social responsibility (CSR), foreign direct investment (FDI) and benefit sharing agreements (BSA). A detailed study of the development and implementation of the PNG LNG project can offer insights particularly into how these settings affect the generation, distribution, and use of revenues from a natural resource development and how this might in turn affect the socio-economic and human development of the country. A related question arising from the research has been the accessibility of information about the project and its effects, and the influence of publicly available information on decision-making about the project and revenue use. The project offered particular opportunities for the study of transparency and accountability because the GoPNG and investors committed themselves to the international Extractive Industries Transparency Initiative (EITI), which promised a full accounting for all revenue flows associated with the project.

The research here takes a political economy approach by looking at these resource flows in terms of the natural resource sector value chain, from initial investment to distribution and use of revenues, assessing the influences of institutions, actors, and government policies on these flows and assessing the impact of the "rents" on the economy and society (particularly landowning groups). An historical perspective will also be employed to see what lessons, if any, were learned for the PNG LNG project from the policies of various governments in the last four decades. The role and the influence of the various stakeholders will also be assessed against the prevailing institutional structures that set the parameters of the natural resource sector in the country. The institutional structures and their links with development outcomes will be assessed against the backdrop of the country's political economy.

The subsidiary question on transparency asks whether, in the case of the LNG project, an international initiative like the EITI, a multi-stakeholder initiative focusing on the participation of civil society and the use of voluntary mechanisms to secure compliance from powerful multi-national corporations (MNCs), bears out its promise to reduce corruption and civil conflict and to mitigate the adverse economic impacts of the resource curse. PNG as a developing country presents an opportunity to test many propositions including the application of transparency in the resource sector and the use of technology (social media) and participation by civil society in the policy formulation and implementation of transparency initiatives. 


\subsection{Outline of the chapters}

\section{Chapter 2: Problem statement and research questions}

Chapter Two details the background of the problem statement and research questions. The starting point is the perennial question of why PNG, which is rich with natural resources and is strategically located within the Asia-Pacific region, has relatively poor human development and governance outcomes. The poor development outcomes can be seen by the poor socioeconomic indicators from which the root causes can be highlighted and analysed. Academic critiques have drawn particularly on the theory of the "resource curse" in poor, resource rich economies to explain these effects. There have been many major resource development projects within the extractive sector. There has been widespread criticism of many of these investments for their environmental and social impacts, distorting effects on economic development, inequitable distribution of benefits, and corruption of the political process. The negative effects of these projects are attributed to the process for their selection and approval and their development and operation. The main fundamental influences on the processes cited are the complex and fragmented nature of PNG's society and politics and the fragility of governance institutions, including the lack of transparency and political accountability at all stages of the projects.

These propositions about PNG are tested by analysis of a case study of the PNG LNG project, in terms of three research questions:

(1) How have revenues from the PNG LNG project been distributed?

(2) What have been the major influences on this distribution?

(3) Subsidiary question: what effects have there been on distribution from the initiatives for financial transparency and accountability associated with the project?

\section{Chapter 3: International Literature Review}

This Chapter reviews the international literature on the economic and social impacts of natural resource development generally; and the underlying theories of politics, society and economy espoused by these writers. It specifically discusses the resource curse as a phenomenon associated with natural resource rich countries; how developing countries have managed their natural resources; rent-seeking behaviour of governments (and individuals); relationships between natural resources and economic growth; and key institutions and their role in the 
extraction industry. The themes that will be covered include governance, corruption, and conflict, and specifically the effects that greater transparency about the generation and use of extractive industry revenues can have on political decision-making.

\section{Chapter 4: Natural resource dependence: the case of PNG}

This Chapter discusses the case of PNG with specific reference to the writing on effects of natural resource development. The effects cited by scholars are summarised under the headings of: PNG's natural endowments; colonial and post-colonial history; cultural, social, and political institutions; principal actors with influence: corporations, government, traditional leaders, foreign governments, and international organizations, and local and international nongovernment organisations (NGOs).

\section{Chapter 5: Theoretical Framework}

This chapter outlines the framework for analysing the PNG LNG Case based on the constructs and explanations in the existing scholarship on natural resource dependence (NRD) as discussed in Chapter 3 and Chapter 4. Further, the chapter discusses:

(1) Explanations for the effects to be found in the characteristics of the minerals and energy sector; the contest for access to the rents arising from exploitation of natural resources;

(2) The use of a political economy and institutional approach to analyse natural resource rents by identifying the activities that lead to generation and distribution of rents and how they are shaped to determine the distribution of rental income; including identification of the principal arenas, actors and institutions influencing distribution.

The theoretical framework for the case analysis uses eight principal propositions in the literature on resource dependence and governance in PNG to be tested against the case evidence.

\section{Chapter 6: Methodology and evidence gathering}

This chapter details the methodology used and how evidence was collected for this thesis. The first part of the chapter gives the philosophical basis for the research, followed by how evidence was collected, and the last part details how evidence was organized and presented. The Chapter also: 
(1) Discusses the strengths and limitations of the case method and how they apply in the PNG LNG case;

(2) Outlines the evidence base for the case, its methodological underpinning, and its strengths and limitations;

(3) Discusses the researcher's position in relation to the study, particular problems faced by the researcher in developing the evidence base, how they were handled, and how they modify the inferences that were drawn from the evidence.

\section{Chapter 7: PNG LNG project}

The first part of the Chapter covers some of the history leading up to the PNG LNG Project dealing with development of petroleum resources in the Southern Highlands Province and the policy and legal framework that evolved in response. The second part provides a description of the PNG LNG Project itself covering the principal institutions and actors in the Case, particularly the legal framework in the mineral and petroleum sectors. The third part discusses the formation of the main project agreements and how the legal and policy framework responded.

\section{Chapter 8: Benefit Sharing Agreements}

This chapter discusses the project benefits sharing agreements with local landowners and subnational governments and traces the processes leading up to the Development Forum, culminating in the Development Agreement specified in s.50 of the Oil and Gas Act (OGA). The Umbrella Benefit Sharing Agreement (UBSA) and the associated License Based Benefit Sharing Agreements (LBBSAs) are highlighted, as they form the basis of the distribution of benefits. The chapter also explains the difficulties encountered analysed in terms of social relations and land rights, reasons for the delay of the distributions of the benefits, and the emerging landowner discontent in the sharing process.

\section{Chapter 9 Influences of the project on government fiscal planning and budgetary policy}

This Chapter looks at government fiscal and financial policy during the construction and operating phases of the project. The discussion and analysis focus on the various influences, issues, and events that have an impact on revenue distribution with a focus on the public debate surrounding the project, landowner relationships, and dissent. An analysis of the various 
budgets handed down between 2009 and 2018 is also captured in this chapter and offers insights into the government's fiscal positions and planning. The perspectives of some of the key players are also highlighted.

\section{Chapter 10 Transparency and its effects}

This Chapter looks at transparency, focussing on the quality and extent of information on the project and revenue flows and evidence for its effect on public debate. The evidence gathering has in itself identified both the strengths and gaps in public transparency and accountability in PNG and its effects on this Case. An important area observed during the field work was the PNGEITI Validation exercise conducted in Port Moresby which is captured in this chapter.

\section{Chapter 11 Conclusion}

This Chapter analyses the findings from the case study in relation to the research questions and the underlying propositions about revenue distribution and the effect of transparency. The Chapter also makes some observations about the implications of these findings for PNG's future public policy and governance and suggests directions for future research.

This chapter concludes the thesis by:

(1) Reviewing the findings from the research in the light of the original research questions together with the propositions developed in Chapter 5 and discussing the contribution of the research to the understanding of the effects of major natural resource projects in a resource rich developing economy;

(2) Making suggestions for further research into this topic;

(3) Discussing the implications for PNG government policy on natural resource development. 


\section{Chapter 2 Problem Statement and Research Questions}

\subsection{Introduction}

PNG is a developing country that is well endowed with natural resources to develop to improve the well-being of its citizens. In the last decade, despite all the wealth and strong if uneven economic growth, the country continues to have a low ranking on most indicators of human development. The studies undertaken by scholars and donors in PNG tend to agree that the problems with development are those of governance and management (see ADB, 2012; Hayward-Jones, 2016; UNDP, 2015; World Bank, 2018).

\subsection{PNG's social indicators}

PNG's social indicators are below those of other countries with similar per capita incomes. The United Nations Development Program (UNDP) uses a Human Development Index (HDI) a composite indicator combined into a single measure to compare human development progress across countries.

Figure 2:1 PNG: Human Development Index 1990-2017

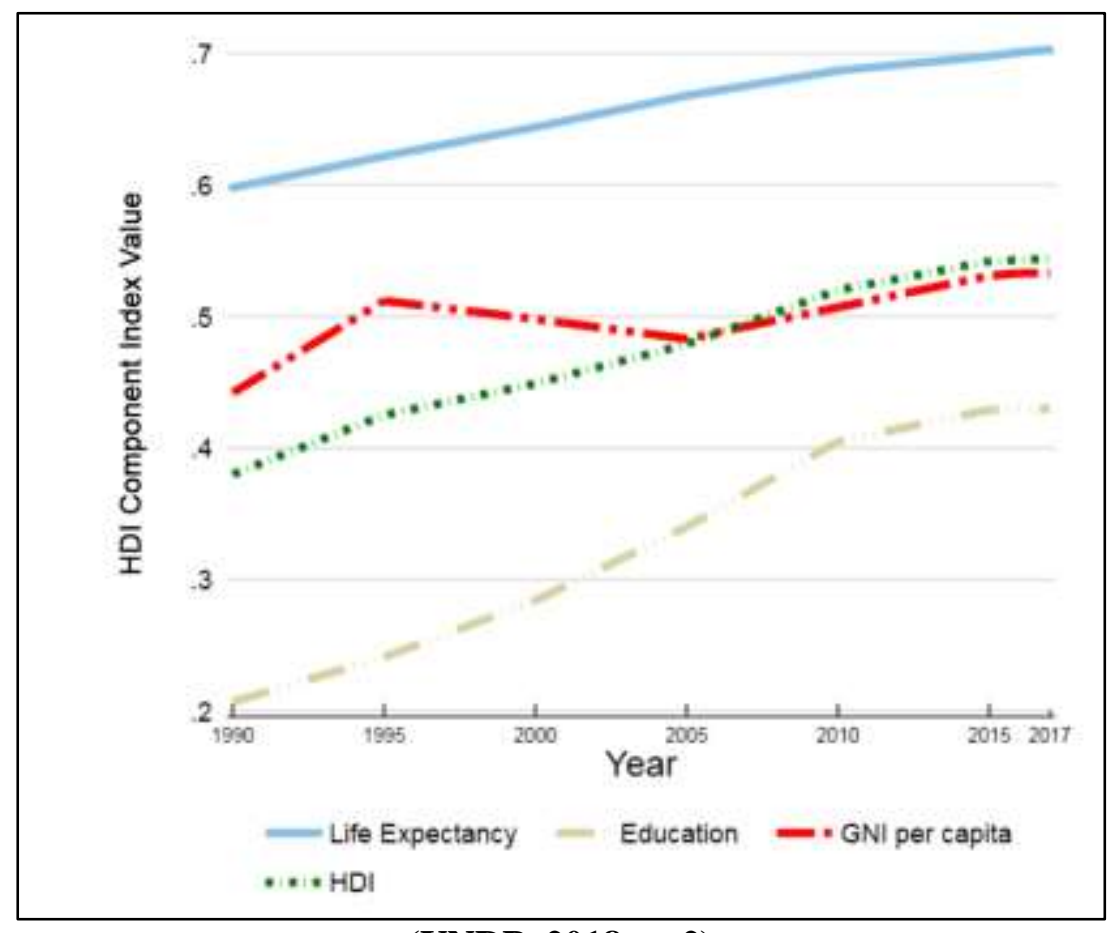

(UNDP, 2018, p. 2)

The country's overall HDI has improved over the last three decades but PNG remains currently 153rd out of 189 countries (UNDP, 2018). This is little different to several years ago when it 
was ranked $156^{\text {th }}$ out of 186 countries in the $2013 \mathrm{HDI}$, at the height of the country's resource boom. Life expectancy at birth is 65.7 years and has not changed much in the last decade. There has been some improvement in expected years of schooling, from 8 to 10 years, in last decade but the country has a low literacy rate (one of several indicators used in the HDI) compared to other countries within the region (UNDP, 2018).

PNG's population is demographically young: $76 \%$ are under 35 years old and $40 \%$ are under the age of 15 years. The population growth rate in 2011 was 2.3\% (PNG National Statistical Office, 2013). Although PNG therefore has a relatively low dependency ratio, most youth are either not educated to tertiary level or lack the experience and skills required by a lot of the industries. This demographic reality will continue to affect the various HDIs.

\subsubsection{Health status of PNG}

A good measure of a country's development is the various health indicators. In the case of PNG, there remain major challenges including: vaccine-preventable diseases such as tuberculosis which is prevalent; a high maternal mortality rate at 230 per 100,000 live births, more than double the UN Millennium Development Goal target set for PNG; and the increasing number affected by non-communicable diseases, including cardiovascular and respiratory disease, cancer, and diabetes (Hayward-Jones, 2016, p. 7). Data from the Department of Health in 2013 also showed that the level of antenatal care has declined, with an extreme shortage in skills in the field except the Highlands region (ibid). Further, compounding this is the "very low level numbers of medical professionals per capita. According to WHO, there are 5.3 nurses and midwives and fewer than 1 doctor per 10,000 people" (ibid:10).

The country did not meet any of the Millennium Development Goals (MDGs) in 2015. There continues to be pervasive gender inequality and gender based violence, with a low rate of prosecution of offenders because of cultural factors (UNDP, 2015, p. 54). Maternal and child mortality is the highest in the Pacific region and is compounded by the fact that $85 \%$ of the population live in rural areas with poor or minimal access to health services. (UNDP, 2018)

Despite increased funding to the health sector by the government and donors, there is still a lot that needs to be done. Rural health services are relatively sparse. The churches continue to play a very important role in some of the remotest parts of the country where there are no government services. 


\subsubsection{National education system}

The educational system of the country continues to suffer from a host of adverse factors including poor access to facilities and services (lack of classrooms, materials that either arrive late or never arrive, teachers who do not take up their posts, and the poor working conditions). The numbers are also very concerning: adults achieve an average four years schooling, and only $20 \%$ of students completing grade 12 in 2015 went on to higher education in 2016 (Hayward-Jones, 2016, p. 11). The government of Peter O'Neill sought to address the low level of education with tuition free education and to encourage students completing grade 12 to pursue further studies in the technical and vocational fields. The government is also trying to create more opportunities for school leavers by encouraging and giving incentives to industries through tax breaks. Facilities and working conditions for teachers in remote areas need to be improved.

\subsection{Economic growth and development ${ }^{1}$}

PNG's real GDP growth rate improved to an average 5.0\% per annum over the past decade to 2017 compared with the previous ten years' rate of $1.9 \%$ per annum. However, real growth in per capita GDP has been much lower, being virtually nil in the decade to 2007 and $2.7 \%$ p.a. in the decade to 2017. Moreover, from independence in 1975 until the present day, growth has been strongly cyclical, with short periods of accelerating growth alternating with sharp contractions, including several periods of negative growth. Annual growth rates have ranged from $-3.9 \%$ to $18.2 \%$ over this period.

A major driver of growth performance has been investment and revenues in the extractive minerals and energy sector. Although resource rents as a share of GDP have been falling in recent years, PNG still ranks in the top 30 countries in the world. The petroleum and mining sectors have been significant contributors to the economic growth in PNG over the last forty years. In 2017, these two sectors accounted for an estimated $86 \%$ of exports and $29 \%$ of GDP (Ernst \& Young, 2018, pp. 36-38). Fluctuating commodity prices in the sector have had a major impact on GDP, the balance of payments, exchange rates, and government revenues.

\footnotetext{
${ }^{1}$ Data in this section from World Bank (2019d) unless otherwise indicated.
} 
Figure 2:2 PNG natural resource rents and GDP

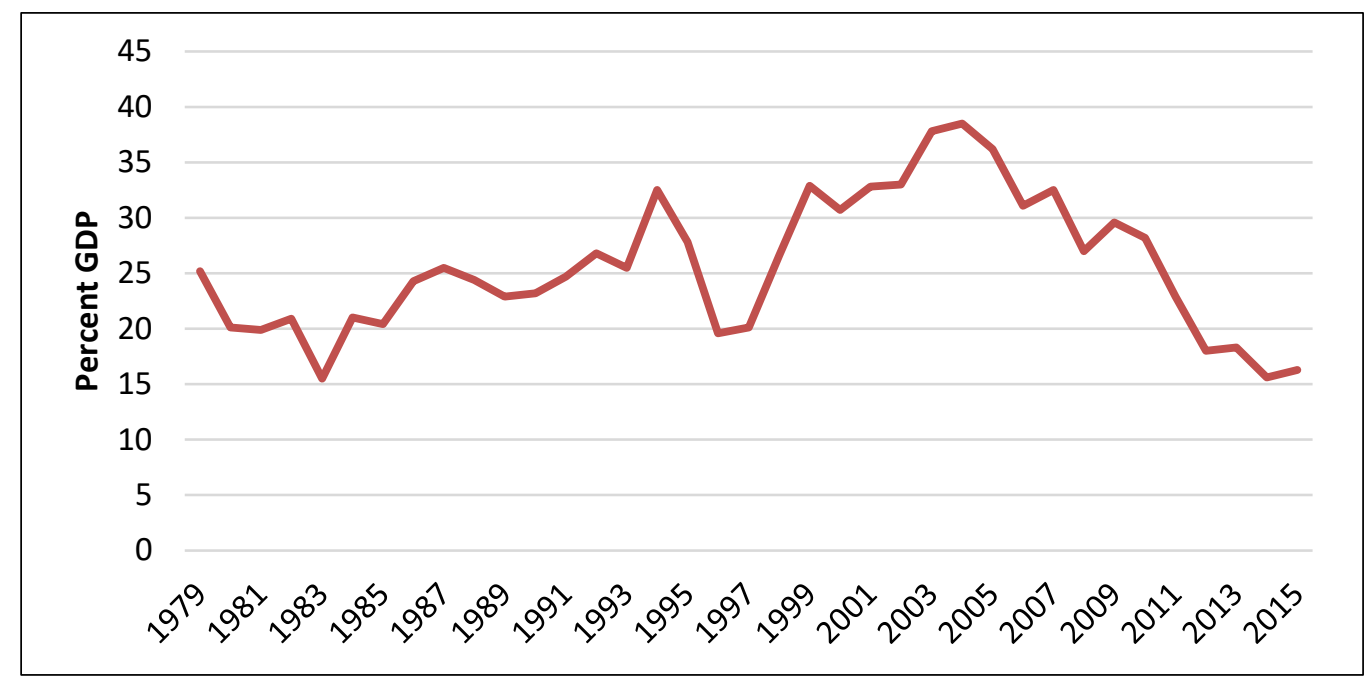

Data from World Bank (2019a)

Within these fluctuations, resource sector contributions to the national government budget have fallen considerably in recent years. The World Bank estimated that "resource revenues have also fallen, from 11.9 percent to 3.8 percent [of total revenues] between 2012 and 2016 ". (World Bank, 2018, p. 61). This is at a time when total resource sector GDP has been rising rapidly: "Petroleum and minerals revenues have fallen from 18 percent of resource sector GDP in 2012 to only 2.3 percent in 2016, despite large increases in resource sector GDP over this time ...." (ibid). Despite the recent decline in resource revenues, current government projections of the major sources of revenue discussed in this thesis assume that the resource sector will continue to make a major contribution for the next decade. Based on the various government plans such as Vision 2050 (GoPNG, 2009b) and the PNG Strategic Plan (GoPNG, 2014 a) ${ }^{3}$ there will be a continued reliance on the resource sector to finance a lot of the development needs of the country and the infrastructure and agriculture sectors.

\footnotetext{
${ }^{2}$ Revenues from natural resources in excess of their cost of production. From the World Bank source: "The estimates of natural resources rents are calculated as the difference between the price of a commodity and the average cost of producing it. This is done by estimating the world price of units of specific commodities and subtracting estimates of average unit costs of extraction or harvesting costs (including a normal return on capital). These unit rents are then multiplied by the physical quantities countries extract or harvest to determine the rents for each commodity as a share of gross domestic product (GDP)." For detailed methodology and analysis see also Lange et al. (2018).

${ }^{3}$ Successive strategic policy documents of the Somare government (GoPNG, 2009b) and the O'Neill government (GoPNG, 2014a).
} 
Figure 2:3: Falling government share of total resource rents

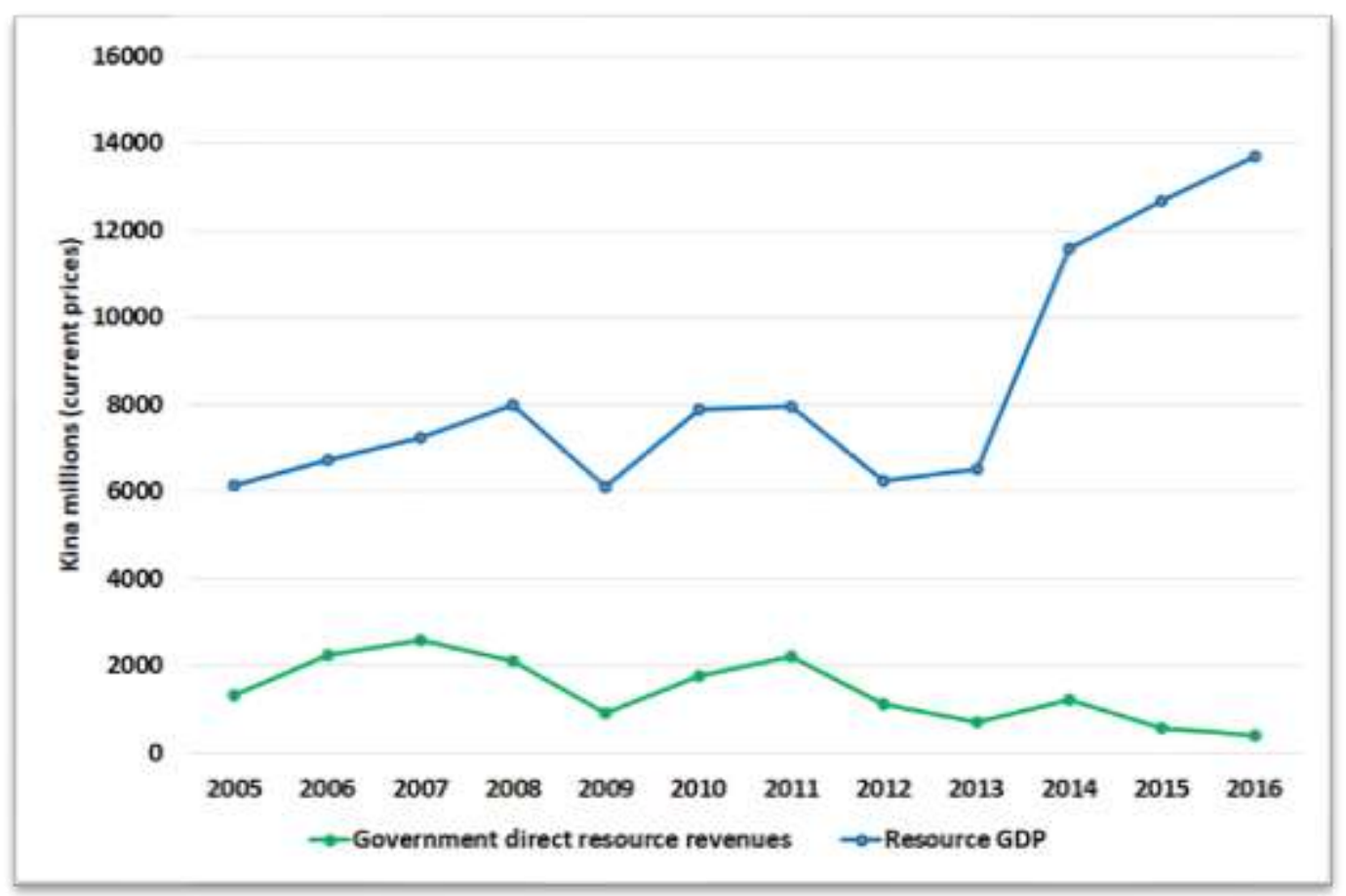

Data from World Bank (2018, p. 35)

In contrast to minerals and petroleum, other productive sectors such as agriculture, tourism and fisheries industries have grown more slowly. The share of agriculture, forestry, and fishery in GDP fell from $32 \%$ in 1997 to $18 \%$ in 2015 ; that of manufacturing from $9 \%$ to $2 \%{ }^{5}$. Successive governments since independence have taken few policy measures aimed at diversification. There has also been very little investment in human resources: there have been capacity, skills, and knowledge gaps where training is required not only at the managerial level but also at the technical level. More physical institutions - vocational and technical colleges - need to be built as well. Development of infrastructure has been uneven: there has been significant investment in upgrading major roads but inadequate investment in rural access roads. Priorities have been distorted by leaving it up to local politicians, who tend to favour bigger flashier projects. Access roads in a lot of rural areas of the country have been left to local politicians to fund through their District Services Improvement Program (DSIP) ${ }^{6}$. PNG has not been entirely without investment in social services such as health and education although outcomes in both are still

\footnotetext{
${ }^{4}$ Sourced to "Budget documents (various years), National Statistics Office"

${ }^{5}$ World Bank (2019d): 2015 data is the most recent available.

${ }^{6}$ DSIP is a fund given to each of the 89 "open" (district constituency) members of parliament. The other 22 MPs represent the PNG provinces. Total DSIP disbursements are about K10 million (NZ\$4.5 million).
} 
lagging behind many other lower middle-income countries. Law and order have been neglected.

On balance, therefore, gains from the various resource and agricultural commodity booms over the last forty years have been significantly offset by factors such as the two global oil crises, natural disasters including adverse weather conditions, the Bougainville conflict (10-year war between the government and the people of Bougainville over the copper mine), high population growth rates, poor fiscal management, and political instability (ADB, 2012, pp. 6-7; UNDP, 2018).

\subsection{Economic and fiscal management}

The resource sector has been a "very highly volatile" source of revenue over which the government has very little control. Government spending plans have tended to be influenced by actual or expected changes in resource revenues. The fiscal crises currently being experienced are caused principally by the government assuming that high oil and gas prices would continue with guaranteed windfall revenue in the coming years, which has led to excessive government spending before these revenue streams were being realized.

An analysis of PNG budget data from the Australian National University for the period 19892016 (Devpolicy, 2019) shows that:

- Government revenue has been volatile, with annual percentage changes ranging from about $-5 \%$ to $+25 \%$. The variance is so big that it has severe implications for any budget.

- Government expenditure fairly closely tracked government revenue until 2011, indicating that most of the revenue variance was matched by equally large fluctuations in expenditure. From 2011 however, expenditure rose significantly faster than revenue, leading to a significant increase in debt. This is also the period when there was a change of government and an election the following year. In election years governments have tended to expand spending, including funding of populist programs such as free primary and secondary education. 
- Public debt as a percentage of GDP fell from nearly $70 \%$ in 2002 to between $28 \%-32 \%$ in the last decade. The decade from 2000-2009 was characterised by heavy borrowing by the various governments.

Figure 2:4: Government Revenue Volatility

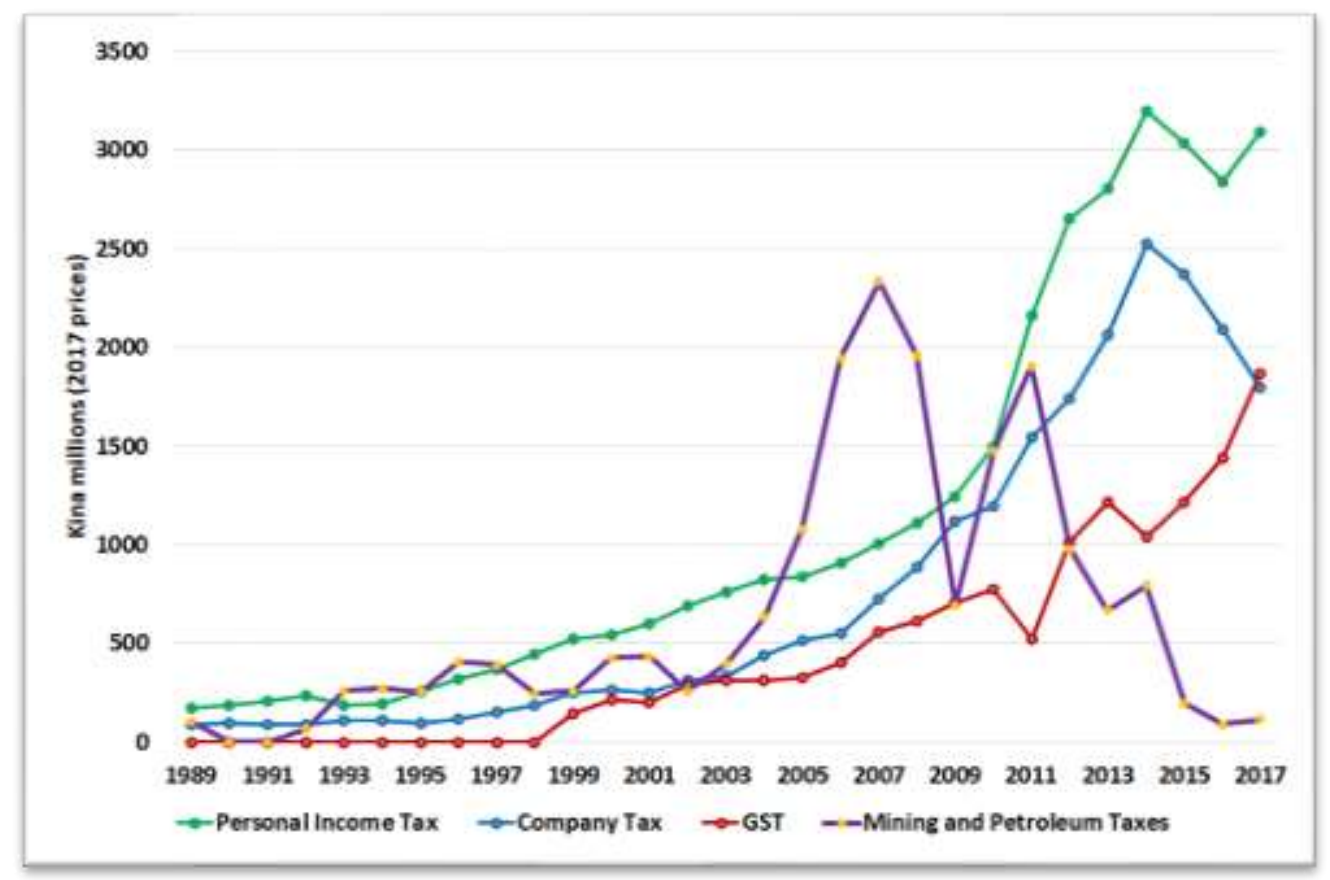

Data from Devpolicy (2019)

Like many other resource rich countries, PNG has therefore struggled to transform short term resource revenue windfalls into long term economic and development investments (ADB, 2012). It has also failed to diversify its economic base and shift away from the mineral and petroleum sectors and to invest in the agriculture and tourism sectors (ibid).

Figure 2:5 below shows the breakup of sectoral allocations from 2012. The biggest spending is sub-national (which covers the provinces). The biggest increase in sub-national spending has been the funds given to Members of Parliament (MPs) in the form of the Provincial and District Services Improvement Programs (PSIP and DSIP), for which there is little accountability. At the same time there have been cuts in other sectors such as education, health, and infrastructure, in some sectors to 2012 levels (Fox et al., 2017). 
Figure 2:5 Government expenditure by sector

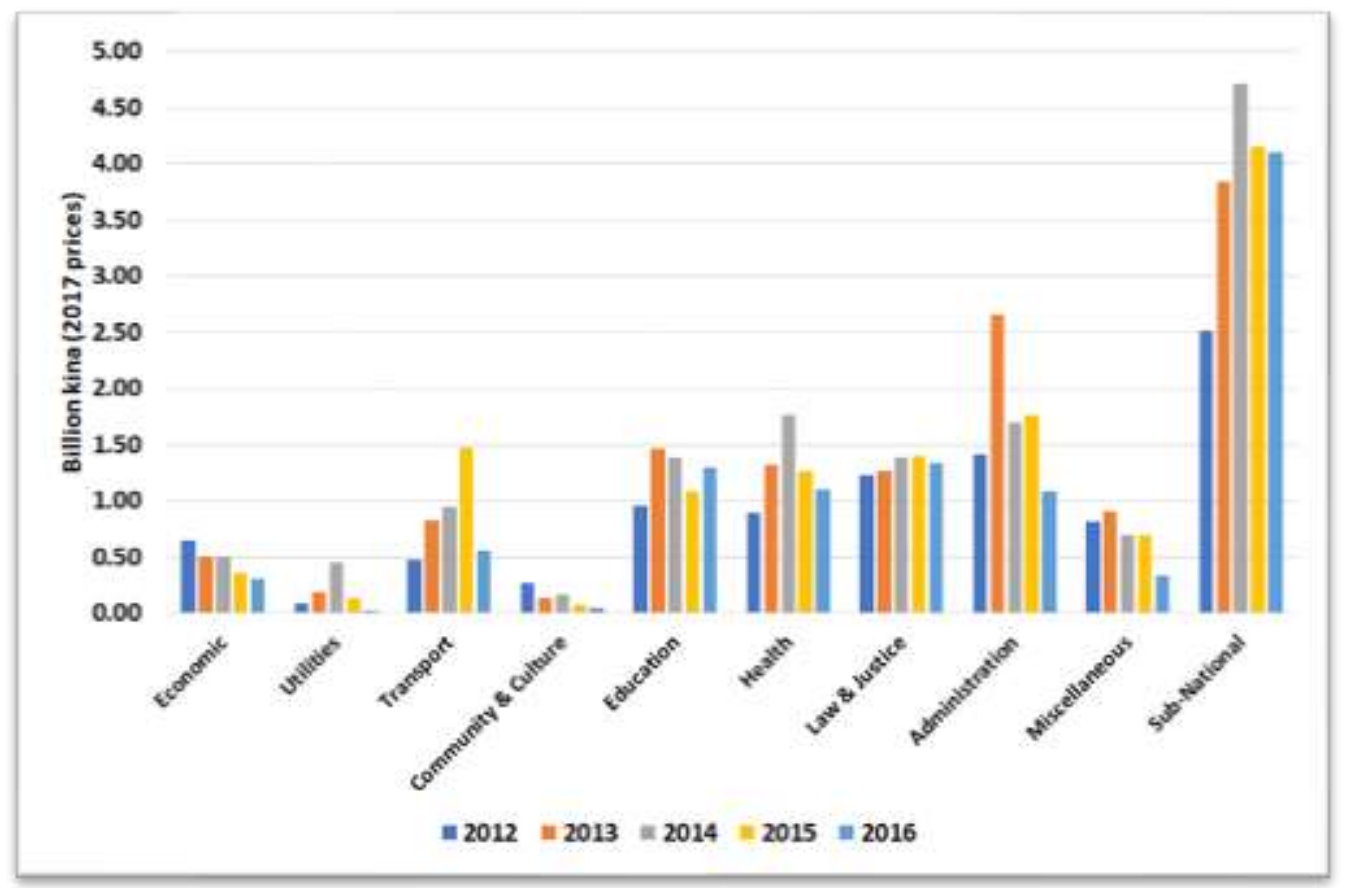

Data from Fox et al. (2017, p. 14)

\subsection{Public liabilities}

The government's mismanagement of the most recent resources boom and subsequent budget crisis $^{8}$ has underlined the risk of its over-reliance on the extractives industry. The various quarterly reports from the Bank of Papua New Guinea (BPNG) (Bank of PNG, 2015 (20152018)) and the recent ADB Outlook (ADB, 2018) for the Pacific including PNG point to a worsening debt crisis and slow economic growth, instead of the much talked about "windfall".

The rapid growth in the government deficit as of 2016 increased the debt/GDP ratio above $30 \%$, the legislated limit for government borrowing both internally and offshore. According to the IMF the estimated overall public debt to GDP ratio was $37.5 \%$ of GDP in 2017, "well above the long-term target" of $30 \%$ (IMF, 2018, p. 17). More critical was the fact that there the government made other commitments outside the budget. A major example was the approximately US\$7 billion that the GoPNG borrowed from the international financial markets in 2014/2015, not captured in the budget. Other more recent liabilities have been carried by

\footnotetext{
${ }^{7}$ From PNG Treasury budget documents.

${ }^{8}$ The 2017 budget is a deficit budget because of the government's commitments (including entitlements) that must be met.
} 
Kumul Petroleum Holdings Limited, the state-owned company that holds the government's $16.58 \%$ equity in the PNG LNG project. The PNG Treasury's 2017 Mid-Year Economic and Fiscal Outlook (MYEFO) shows "state guaranteed loans now being serviced by the state" have contributed to the increase in public debt (GoPNG, 2017, p. 29). There are also other state liabilities such as mandatory superannuation payments and court cases with default judgments against the state.

\subsection{Governance}

\subsubsection{Weaknesses}

Four multilateral agency studies in the last decade - ADB (2012), IMF (2015), UNDP (2015) and World Bank (2018) - have agreed on some of the critical development constraints faced by PNG. As summarised in the ADB report they include:

- poor infrastructure and infrastructure services, particularly in the case of transport, electricity and water supply;

- shortages of skilled human capital and poor and unequal access to affordable and quality education;

- lack of and unequal access to affordable and quality health services.

At the root of these constraints lie weaknesses in governance and institutions, particularly those relating to delivery of public services, maintaining law and order, controlling corruption, and managing land and land titles.

The Australian government has spent between a third and a fifth of its total aid budget for the government of PNG on governance over the past 18 years with little improvement on the various governance indicators (Hayward-Jones, 2016, pp. 3-4). The World Bank's Worldwide Governance Indicators (WGI) (Table 2:1 below) show a deterioration in PNG's ranking on all six indicators but especially government effectiveness, rule of law, and corruption. 
Table 2:1 PNG: Percentile Ranking in World Governance Indicators ${ }^{9}$

\begin{tabular}{|l|c|c|c|c|}
\hline Dimension & $\mathbf{2 0 0 2}$ & $\mathbf{2 0 0 7}$ & $\mathbf{2 0 1 2}$ & $\mathbf{2 0 1 7}$ \\
\hline Control of Corruption & 20 & 20 & 16 & 13 \\
\hline Government Effectiveness & 38 & 32 & 29 & 22 \\
\hline Political Stability and Absence of Violence/Terrorism & 28 & 29 & 28 & 20 \\
\hline Regulatory Quality & 29 & 26 & 21 & 17 \\
\hline Rule of Law & 19 & 13 & 18 & 17 \\
\hline Voice and Accountability & 45 & 42 & 36 & 39 \\
\hline
\end{tabular}

Data from World Bank (2019d)

A manifestation of the weak governance is the prevalence of corruption at all levels of government. As shown in Table 2:1, PNG is in the highest quartile of corrupt nations in World Bank governance indicators. The 2017 Transparency International (TI) Corruption Perception Index (CPI) shows PNG ranked $135^{\text {th }}$ out of 180 countries. (Transparency International PNG, 2017, p. 5).

The study by Hayward-Jones also points out that the devolution of funding to provinces via the District Service Improvement Program (DSIP) through the individual members of parliament for the delivery of basic services in their districts has been done with little transparency and accountability. The devolution of funding has in fact given rise to fraud and corrupt practices, as there is little capacity at the provincial and district level to deliver basic goods and services (Hayward-Jones, 2016, p. 5). A UNDP report in 2014 referred to the obvious "politicisation of development" exemplified by the lack of accountability for funds disbursed through the DSIP (UNDP, 2015, p. 92).

Arising out of the weak governance and poor delivery of services is the deteriorating law and order in the country. The levels of crime and violence have increased in all the urban centres of the country. The decision to expand or invest by PNG businesses was based in part on the law and order situation (Hayward-Jones, 2016, pp. 5-6). The rising crime levels have not been met by increasing resources to the law and justice sector of the country. While the population has tripled since independence, the number of police personnel has barely increased. Forty years ago there were 4,100 officers, by 2013 there were only 5,724 with a low police to population ratio of 78:100,000 (Hayward-Jones, 2016, p. 6).

\footnotetext{
${ }^{9}$ For definitions, see World Bank (2019d).
} 


\subsubsection{Resource dependence and other factors in governance}

The 2018 World Bank report (World Bank, 2018) summarises the relationship between resource rents and institutional and governance weaknesses as follows:

- Resource dependence which is an important feature of PNG's economy can also be its most vulnerable area, especially when there is 'price volatility' of commodities that are exported. There is also no guarantee that sustained economic growth can be relied upon.

- "Unlike taxation revenues, resource rents are rarely attached to strong political accountabilities, such as for the provision of health or education services. Rents arrive at both central and local levels into the hands of elites with high political discretion over expenditure. They are commonly channelled to the local level via development budget projects, rather than recurrent spending. They travel into institutional arrangements dominated by individual leaders, enabling return of political favours and rents (kickbacks) to office holders and patrons."

- "Resource revenue flows were increasingly institutionalized into top-down, fragmented expenditure arrangements. These booming rents led to rapid expansion of development budgets: the ratio of development to recurrent spending rose from 30:70 to peak at 70:30. ... As development budget grant transfers expanded, the share of budget properly allocated to provinces and lower administrative levels through recurrent function grants fell to just 3 per cent.” (World Bank, 2018, pp. 100-101)

There are other institutional factors also cited by the World Bank. The Westminster parliamentary system leaves governments susceptible to votes of no-confidence, which has been an obstacle to political stability, policy predictability and coherence, and the delivery of public services. However, in addition, PNG's ethnic diversity gives rise to a highly fragmented political landscape, adding to and exacerbating the political economy challenges that arise from resource dependency.

For its population, PNG is ethnically an extraordinarily diverse society. There are more than 800 ethnic groups with distinct languages (ADB, 2012, p. 7). An important aspect of the social and cultural fabric of PNG is the fact that about $97 \%$ of the land is customarily owned and governed by traditional rules and laws making it difficult for commercial development to take place (Connell \& Howitt, 1991). Transactions such as outright sale or leases require clan 
agreements. The significance of local cultural institutions in understanding PNG's governance is unevenly treated in the reports of international institutions and in some scholarly literature, as discussed in Chapter Four. A 2009 ADB Evaluation Report did highlight the need to account for cultural factors:

Cultural traditions permeate society and social processes that affect decision-making and actions of public servants; particularly where newly proposed systems clash with traditions (example wantok systems of social obligations towards kinsmen). Culturally, sensitive participatory approaches to introduce reform measures are needed (ADB, 2009, p. 9)

The conclusion from the ADB study is that while modern institutions and processes are the basis of governing, the solutions for a lot of the problems that afflict public sector organizations can be found by looking more closely at cultural values.

\subsection{Problem Statement and Research Questions}

\subsubsection{Summary}

In comparison with other countries with similar income levels, PNG exhibits relatively poor performance on a range of social indicators.

Writers on PNG's human development and governance attribute the country's problems to a complex of factors, including the geography of the country, its cultural diversity, political competition for access to state resources, weakness of state institutions, post-colonial dependence on international capital and metropolitan states, and economic dependence on mineral and petroleum resources. As will be discussed in Chapter 4, most of the literature on PNG's development acknowledges the complex origin of its problems. However, both in PNG's public discourse and in academic writing, considerable attention has been directed at the oil, gas, and mining industries. Important questions are raised about the adequacy of benefits that accrue to local landowners, businesses, and government; the ongoing and sometimes violent struggle for shares of these benefits; the excessive focus of investment on resource sector projects; and the way that large overseas-financed projects reinforce PNG's post-colonial dependence. The public sector's limited capability to negotiate complex agreements and, subsequently, to monitor and enforce their provisions, the associated limited transparency of the agreements that are reached, and the mechanisms for distributing revenues 
also play their part. Poor governance arrangements and a lack of transparency can create opportunities for graft, misappropriation, and resource sector outcomes that do not serve the best interests of the Papua New Guinean public.

In summary, granted that PNG, particularly given its extraordinary cultural diversity, is a uniquely constituted economy and society, most of the sources discussing its development assign an important role to resource dependence, and in particular how large-scale mining and petroleum projects have been developed, and how the rents flowing from extraction of these resources have been distributed.

\subsubsection{Problem Statement}

The problem statement for this thesis is then:

"How has the governance and management of revenues from the extractive industries influenced the country's development?"

The status of the PNG LNG project as the largest single extractive industry development in the country's history, and the abundant references to it in government fiscal policy and planning, provide an opportunity to study this question through a case study of the project's development and implementation.

\subsubsection{Research questions}

The discussion above leads to three basic questions for the PNG LNG project and some specific propositions to be investigated. The basic questions are:

(1) How have revenues from the PNG LNG project been distributed?

(2) What have been the major influences on this distribution?

(3) Subsidiary question: what effect has there been from the initiatives for financial transparency and accountability associated with the project?

The next two chapters lead to a framework for analysis of evidence from the case study. Chapter Three discusses the international literature on the effects of natural resource dependence on economy and society, and Chapter Four discusses writing on the case of PNG, with specific reference to its extractive industries. Chapter Five develops a framework for analysis, and concludes with specific implications for analysis of the evidence from the PNG 
LNG case, including a set of propositions derived from the literature on resource dependence, which can be tested by the case study evidence. 


\section{Chapter 3 International Literature Review}

\subsection{Introduction}

The previous Chapter discussed problems with PNG's human development and governance challenges as identified in academic and official writing. What is common in all this writing is the acknowledgement that the country is comparatively well-endowed with mineral and energy resources and that exploitation of this natural wealth is a significant factor both in its development and in the associated problems.

This Chapter reviews the literature on the economic and social impacts of natural resource development generally and the underlying theories of politics, society and economy espoused in this writing. Chapter Four then discusses the case of PNG with specific reference to the writing on effects of natural resource development. Based on this critical evaluation, Chapter Five identifies a model for analysis of the PNG LNG case.

\subsection{Relationship between natural resource dependence and development}

In the 1950s and 1960s many development economists argued that countries with abundant mineral resources "would grow much faster than their resource-poor counterparts precisely because their mineral wealth would provide them with the necessary capital to industrialize and diversify their exports" (Weinthal \& Luong, 2006, p. 36). Development economists viewed natural resources as a platform for investment to "take off" into self-sustaining growth. This thinking was challenged in the 1970s when the Dutch Disease showed the negative consequences of the exploitation and export of a resource product. By the 1990s "a scholarly consensus emerged that these countries' vast wealth is the root cause of their severe political and economic problems." (Ibid., p. 37).

\subsection{Explaining the effects of natural resource dependence}

\subsubsection{Dutch disease and commodity price volatility}

The term "Dutch Disease" refers to the unintended negative impact of a resource boom on a country's non-resource tradeable sector (for example agriculture and manufacturing) caused by a substantial rise in the value of exported minerals and energy resources, resulting in an appreciation of the local currency, a rise in government expenditure beyond longer-term revenue capacity, increases in prices of non-tradeable goods, and rising current account 
deficits. The "natural resource exploitation leads to the appreciation of a country's currency, resulting in deterioration in the terms of trade and a contraction of the manufacturing sector" (Kolstad \& Søreide, 2009, p. 216). The debate on the Dutch Disease arose in the aftermath of the rapid escalation in world oil prices in the 1970s and focused on the effects on higher income countries with exploitable reserves of petroleum and natural gas, such as the Netherlands, Norway, and the United Kingdom.

The Dutch Disease hypothesis began with the presumed negative effects on manufacturing and other non-resource sectors in the Netherlands. Some higher-income countries avoided the Dutch disease: Norway, Australia, Canada, and the United States of America (USA) (Melhum et al., 2006, pp. 1-20). The most common cited counter-case was the success story of Norway (R. M. Auty, 2001; Weinthal \& Luong, 2006) where the government channelled much of the windfall profits from development of oil and gas into a Sovereign Wealth Fund for more broadly-based development. Norway's example thus re-focused debate on good economic management as a means of countering the short and long-term effects of rapidly increasing resource rents (Canuto \& Cavallari, 2012).

The Dutch disease was originally viewed as a problem for wealthier countries, but the diagnosis was extended to developing countries exploiting mineral and energy resources. Many empirical studies conducted by economists show the Dutch disease in resource-abundant developing countries. Alan Gelb looked at the management of resource revenue in six oil exporting countries - Algeria, Ecuador, Indonesia, Trinidad, Tobago and Venezuela - and concluded that:

- The non-mining tradable sectors - agriculture and manufacturing - were neglected during the booms;

- All the countries increased debt during the booms by using their oil revenue as collateral for loans;

- There was unsustainable consumption by all countries. (Gelb, 1988)

Some studies (e.g. Leite \& Weidmann, 2002; Subramanian \& Sala-i-Martin, 2003) concluded that the empirical evidence amassed over the previous forty years did support the Dutch Disease thesis as a sufficient explanation of relatively poor development performance in these poorer resource-rich countries. It is generally argued that a few developing countries - among 
them Botswana, Malaysia, and Indonesia -avoided the Dutch Disease. The main difference was in how these countries managed the resource boom by increasing the rate of national savings. A lot of developing countries who are dependent on resource revenue increased expenditure on non-tradable goods and experienced higher prices caused by higher wages in the resource sector (Leite \& Weidmann, 2002).

On the other hand, Bulte et al. and Gylfason argued that the expansion of the natural-resource sector would have little effect on economic growth by simply affecting the performance of the manufacturing sector and/or the industrialization stages in a country (Bulte et al., 2005; Gylfason, 2001). Gerelmaa and Kotani found that in the period from 1970 to 1990, the hypotheses of a resource curse and Dutch disease were supported. However, in the period from 1990 to 2010, these hypotheses no longer held, because manufacturing sectors grew sufficiently even in resource-rich countries (Gerelmaa \& Kotani, 2016). Further, in their test on an abundance of natural resources they found that the natural resource abundance in 1990 had positive impacts on economic growth between 1990 and 2010.

The Dutch Disease hypothesis has been used in PNG to explain the relative neglect of sectors other than minerals and petroleum. Although PNG does not have a manufacturing base nor is it on the path to industrialization, it is argued that the agriculture sector has been neglected by successive governments because the booming mining and energy sector draws skilled personnel, credit facilities and other resources away from the agriculture, tourism, and other non-resource sectors, causing them to decline. (Avalos et al. 2015).

However the general conclusion is that the Dutch Disease thesis has very little explanatory power when it comes to how and why a natural resource abundance negatively affects economic growth in some countries (Bulte et al. 2005), which has led to the development of other models.

\subsubsection{Resource curse in developing countries}

Beginning in the late 1980s, there was a second iteration of the debate on the effects of mineral and petroleum wealth on development. Findings, initially by economists investigating country cases (e.g. R. M. Auty, 1990; R. Auty \& Mikesell, 1998; R. Auty \& Warhurst, 1993; Davis \& Tilton, 2005; Gelb, 1988), seemed to confirm a relationship between a relative abundance of natural resources and relatively slow economic growth. 
Richard Auty is widely credited with coining the phrase resource curse in the early 1990s to describe this inverse relationship. The findings showing the negative relationship were confirmed by a number of empirical cross-sectional studies undertaken from 1995 to 2001 by Sachs and Warner (e.g. 1995, 2001) covering a five year period and using different country samples. The Sachs and Warner studies reported that a high ratio of natural resource exports to gross domestic product (GDP) was correlated with lower economic growth, controlling for other factors.

Since the Sachs and Warner studies, a number of other econometric studies using cross-country datasets have been published, with some re-analysing the original datasets employed by Sachs and Warner, but using new statistical techniques. There were varying conclusions reached. A number of studies confirming the resource curse phenomenon include, on the economic side, Brückner (2010) and Arezki and Van der Ploeg (2011) and, on the political side, Ramsay (2011) and Tsui (2010). Other studies have questioned the original findings and conclusions. For example Brunnschweiler and Bulte (2008) and Alexeev and Conrad (2009) both conclude that there is a positive relationship between resource endowments and growth. Political and social studies (e.g. Cotet \& Tsui, 2013; Haber \& Menaldo, 2011) have reached similar conclusions.

Badeeb, Lean, and Clark et al. (2017) reviewed the empirical studies that identified the mechanisms through which resource wealth might slow economic growth and show other factors that are associated with growth. They argue that the evidence that resource dependence negatively affects growth remains convincing, particularly using factors closely associated with growth in developing countries. They concluded however that future research should better "address endogeneity of dependence measures, and expand the years of study and range of empirical methodologies used" (ibid., p. 1) The level and intensity of the transmission mechanisms varied between different countries and seemed to be dictated in part by factors such as the stage of socio-economic development ${ }^{10}$, weak institutions, and economic policies. Badeeb et al. point out that none of the writers cited on the resource curse effects advocate leaving the resources in the ground but do discuss how the negative effects might be mitigated.

\footnotetext{
${ }^{10}$ For example, the "Dutch Disease" thesis may not be relevant to many developing countries, including PNG, which do not have a significant industrial/manufacturing base to be "crowded out".
} 


\subsection{Causes and mechanisms for natural resource / development relationship}

\subsubsection{Introduction}

The studies so far show that estimates of simple relationships between resource dependence and indicators of development such as growth in GDP have several problems. The most obvious one is that they capture very little of the actual variance in performance, and the cases reveal a wide range of outcomes in similarly resource-dependent countries.

The next step then is to try to explain why the outcomes of similarly resource dependent (or endowed) countries are so different. There are two strategies: the first is statistical, classifying these countries according to indicators of characteristics that might produce different paths for those with similar resource bases so as to try to capture more of the variance (e.g. is the relationship between resource dependence and outcomes a better fit for sub-groups of countries classified by "quality of governance"?); the second is case based: trying to identify what might differ between these countries through detailed narratives of the linkages between resource sector development and overall country development.

Both depend on theory to begin with, but the connection between resource sectors and outcomes must be made and then must be tested, either statistically or with cases that might lead on to further ideas about what the connections are.

The approach taken here combines evidence from both statistical and case-based approaches on the major explanatory factors but is broadly to view the explanations through the lenses first of economic theory and then political theory. The dividing line is somewhat arbitrary: in particular, both economics and political theory recognise the importance of institutions in modifying the behaviour of decision-makers.

\subsubsection{The characteristics of mineral and energy resources}

The characteristics of the natural resources under discussion (minerals and energy) can be analysed using the political economy framework. The following are the main characteristics identified as important in the literature.

- These natural resources are non-renewable and exhaustible over time which has led to normative arguments about their sustainability and the desirability of replacing depleted resources with other forms of capital (Atkinson \& Hamilton, 2003; World Bank, 2018). 
- The exploitation of these resources generates rents (value in excess of cost of exploitation). The distribution of resource rents which are viewed as "free goods" and as the source of easy money shapes the political behaviour of decision makers when viewed through the political economy lenses (Avalos et al. 2015). Badeeb et al. argue that "[r]eady access to resource rents may relieve pressures on governments regarding tax collection and the need for fiscal discipline", and that "... the windfall of resource revenues increases the power of elites, who have the capacity to widen income inequalities" [and is] "also considered a main cause for conflict between domestic stakeholders such as politicians, local tribes, and citizens more broadly" (Badeeb et al., 2017, p. 126).

- A distinction may be made in analysis between natural resource abundance (availability of natural resources, exploited or still in the ground) and natural resource dependence (the relative importance in the national economy and government revenues of resource rents flowing from exploitation). Natural resources generate revenues only in exploitation but expectations of natural resource abundance as an asset may influence decision-making (Cust \& Mihalyi, 2017a, 2017b) - the so-called "presource curse". Badeeb et al. (2017) provide an overview of both approaches in modelling NRD. Earlier approaches starting with Sachs and Warner (1995) defined NRD as the share of natural resources in economic activity (a "flow" concept). Badeeb et al. argue that later approaches "show that if resource abundance (proxied by a measure of natural resource wealth [a "stock" concept]) is used in place of measures of resource dependence, the effect of natural resources on growth performance is positive" (2017, p. 130). They reference Brunnschweiler and Bulte (2008) who found that "resource abundance has a positive effect on growth, an effect which is not transmitted through resource dependence or institutional quality, and that resource dependence has no significant effect" (Ibid.).

- Natural resources are usually subject to commodity price cycles, a determining variable in investment decision-making and government budgetary decision-making; e.g. "Empirical studies suggest that price volatility can adversely affect the economy by increasing overall macroeconomic fluctuations." ... "As commodity prices directly affect the share of exports in GDP, these findings imply that the volatility of commodity prices appears to be a key element of the NR curse." (Avalos et al., 2015, p. 347) 
- Large minerals and energy projects are capital-intensive and have a characteristic profile: an initial high investment with associated financing requirements and employment in construction and associated services, significantly reducing over time. This profile has financing effects in the investment phase. Firstly, at the macro-level there will usually be substantial capital inflows during investment booms. Major projects in developing countries frequently involve significant inflows of foreign capital and technology during the investment phase, followed by associated outflows of profits during the production phase. Secondly, at the micro-level major capital-intensive projects have dislocating effects, particularly at the local level. There can be an initial high demand for labour and services which attracts migrants to the locality but jobs disappear once operations start. Because there is limited demand in the production phase for goods and services from other sectors, these projects are relatively enclaved: they have few longer-term linkages to other sectors.

- Finally, because of these characteristics of large natural resource projects, they usually have significant environmental and social impacts.

\subsubsection{Economic effects}

Economic explanations of the effects are based on incentives and the assumption of selfinterested behaviour by economic actors, but economists recognise the importance of institutions in modifying economic behaviour. The following sections discuss mechanisms based fundamentally on relative prices: exchange rate effects, "crowding out" and concentration of investment in enclaves, and uncertainty due to commodity cycle instability; but also political economy explanations (e.g. rent seeking behaviour based upon access to political or market power).

\section{Relative price effects}

The "Dutch Disease" effect on prices is explained by Badeeb et al. in terms of "spending" and "pull" effects:

- The "Spending effect" "occurs when natural resource booms increase domestic income and the demand for goods. This increase generates inflation and appreciation of the real exchange rate. As a result, the relative prices of non-resource commodities increase, and their export becomes expensive relative to world market prices. This leads to a decrease in 
the competitiveness of these non-resource commodities, and in the investment they attract". (2017, p. 125)

- The "Pull effect" occurs when "... internal domestic inputs such as labor and materials are shifted to the natural resource sector. The prices of these inputs rise in the domestic market. As a result, the production costs of other traditional export sectors such as manufacturing and agriculture increase, contracting these sectors." (Ibid.) In PNG, highly skilled and educated personnel (medical doctors, engineers, accountants/economists etc.) from resource rich provinces tend to forego their professions and use their qualifications and standings in the community to become consultants or advocates for the landowners and lower level governments - a gain for local communities but a loss for the national economy.

Badeeb et al. conclude that "[p]articularly if non-resource sectors such as manufacturing generate more positive spillovers for growth than resource sectors, the 'spending' and 'pull' effects of growth in resource output could then partially or more than partially crowd out nonresource output, and growth overall." (2017, p. 125)

Market volatility is also a major source of concern for resource rich developing countries who rely on primary exports. Fluctuating future price expectations can adversely affect investment decisions; and the unpredictable stream of government revenues creates problems for government fiscal planning and budgeting.

Some writers have argued the case that discovery of a major new petroleum resource will affect expectations and therefore economic decision-making and performance even before the resource is exploited. Arezki et al. estimated the economic effects of "giant" discoveries ${ }^{11}$ and concluded that

After an oil or gas discovery, the current account and saving rate decline for the first five years and then rise sharply during the ensuing years. Investment rises robustly soon after the news arrives, whereas GDP does not increase until after five years. Employment rates fall slightly and remain low for a sustained period. (2017, p. 103).

\footnotetext{
${ }^{11}$ E.g. Horn (2019), the most recent version. The Southern Highlands Hides field is the only PNG discovery included in the database.
} 
Some of this effect may be attributable to the typical cycle of oil and gas exploitation, covering discovery, field development (on average 2-5 years after discovery), and then a production period. For developing economies, the investment period is likely to be characterised by significant current account deficits financed by foreign capital inflows. The authors are also modelling the effect on expectations following "discovery", rather than from "development", which arguably would start with the effect on expectations of news that a major investment is planned.

Cust and Milyahi used the same database of "giant" oil and gas discoveries to estimate the effect of major discoveries on expected and actual growth following discoveries (Cust \& Mihalyi, 2017a, 2017b). Actual GDP growth was compared with IMF staff projections from World Economic Outlook (IMF, 2019). They found that "On average around the world, after major discoveries, growth has underperformed the post-discovery forecasts. For certain countries, such discoveries have led to significant growth disappointments, even compared with pre-discovery trends." (Cust \& Mihalyi, 2017b, p. 37). The authors dubbed this phenomenon the "presource curse".

\section{Fiscal policy effects}

Several studies focus more specifically on the challenges of fiscal policy in dealing with the high volatility of natural resources (Bleaney \& Halland, 2009; Davis, 2013). Fiscal volatility affects growth when natural resource export shares fall, controlling for institutional variables (Bleaney \& Halland, 2009). For a lot of developing countries, the curse is manifested through the inability of governments to manage large revenues sustainably (Atkinson \& Hamilton, 2003). They stress the cases where the combination of natural resources and macroeconomic and public expenditure policies has led to a low rate of genuine savings (ibid.). According to Tornell and Lane (1999), rent seeking activities contribute to governments misallocating revenues to less productive industries, as is the case in a lot of countries including PNG. This misallocation can be caused by several factors including trying to appease and please special interests, populist policies, corrupt practices, the absence of proper planning, and weak institutions that do not do proper screening of investments (see also Gylfason, 2001; Ross, 2013; Tornell \& Lane, 1999). "The empirical literature on the resource curse consistently emphasize that resource dependent economies and resource booms seem to lead to highly 
dysfunctional state behaviour, particularly large public sectors and unsustainable budgetary policies" (Robinson et al., 2006, p. 448).

Torvik was able to show that an increase in natural resources leads to lower welfare because "[i]n a model with rent seeking, a greater amount of natural resources increases the number of entrepreneurs engaged in rent seeking and reduces the number of entrepreneurs running productive firms" (Torvik, 2002, p. 1). In resource rich countries, they can benefit more from lobbying for a share of resource rents than from starting business in another field.

By limiting the need for other forms of government revenue generation, such as tax collection, natural resources can lead to the weakening of state administrative and institutional capacity building. Easy revenue can also weaken prudence and due diligence by both bureaucratic and political leaders. Hence a core set of the political effects of the resource curse derives from what Mick Moore has dubbed the "fiscal sociology" paradigm (Moore, 2004). This paradigm was shown by Robert Bates in his examination of state failure in Africa: "if political elites calculate that their own best interests are served by collecting tax revenues and protecting producers with the rule of law to maximise tax base, they will establish bureaucratic infrastructure to enable them to do so; if not, they will be prone to turning the state apparatus into a predatory instrument that extracts rent from society and dispenses that rent through patronage networks" (Bates (2008) quoted in Shaffer and Ziyadov (2011, p. 331)).

At the political decision-making level, when a lot of the revenues are channelled through the state, the capacity of governments in most developing countries is lacking. Karl (1997) focusses on the impact of the "petrodollar" and the euphoria it generates, which weakens the government's ability to build a strong state.

\section{Rent-seeking}

The availability of natural resource rents is an incentive for their acquisition and control through market and state power. They thereby influence fiscal decision-making but also patronage, clientelism, and corrupt practices, especially without the benefits of controls and safeguards (Kolstad \& Wiig, 2009; Sachs \& Warner, 1995). A big part of the resource curse kicks in when the revenues from the resources are misused.

The rent seeking argument posits that the negative economic growth is caused by rent seeking activities and behaviour (Robinson et al., 2006; Torvik, 2002). Torvik (2002, 2009) has argued 
that natural resource abundance increases the rewards that civil servants, politicians, or landowners can gain from rent-seeking, which in turn provides them with greater incentive to engage in unproductive activities. In a country with weak institutions this can be the difference between success or failure, peace or civil strife, and blessings or a curse.

Furthermore, resource rents induce patronage behaviour, or the rent-seeking of political influence for economic gain (Karl, 1997, p. 56). Rents also generate an incumbency advantage: the prize associated with political control is large so that there is a constant battle to take control of the government (Ibid.). A government's dependence on resource rents tends to weaken its bargaining power with developers. In other words, governments will tend to give huge concessions to companies who in turn support the incumbents. With large rents accruing to the state, public office or access to those in public office becomes the most valuable commodity in a resource-dependent country's political economy.

\section{Rentier state and accountability}

In the rentier state, rents often accrue to the government directly from the natural resource sector. There are only a few actors in society involved in the generation of the rent and many more in distributing or using it (Karl, 1997). Furthermore, the state will be politically dependent on the sector: to the extent that it can finance its activities from rents rather than taxes it is popular with citizens (Moore, 2004).

The following are what Ross (2001) labelled the "rentier effect":

- The state collects rents and allocates them in ways that maintains power. The state uses both budgetary and off-budgetary allocations.

- The state ensures that the institutions remain weak so that it avoids accountability and there is also resistance to reforms that alter the status-quo.

- The opposition is either coerced or paid off in terms of pet projects or awarding of contracts.

- There is a move away from democracy or a strengthening of authoritarian regimes with policies and laws to stay in power.

- The patronage network grows throughout the public sector.

In short, rentier states are characterized by weak institutions and corrupt practices (Ross, 2001) and lack the capacity to perform development tasks. In a lot of developing countries like PNG, the governments spend a lot of time and resources trying to stay in power and neglect the 
important functions of developing and supporting the private sector and undertaking important and necessary reforms to improve the public sector. Even worse is the situation where business elites arrange with local politicians to capture resource rents and work to either weaken or maintain a weak institutional infrastructure and become entrenched obstacles to reforms and transformative measures.

The rentier state perspective holds that natural resource rents may weaken accountability of governments to citizens. Rent is used by those in power to remain in power. By controlling substantial oil revenues, governments can reduce pressures for accountability (Karl, 1997; Ross, 2001). In most instances the governments lower domestic taxes, making them popular with the people; the people in return will be less likely to demand accountability. In a worstcase scenario, revenues may be used to oppress and suppress opposition and social groups that may pose a challenge to government (Ross 2012). Furthermore, incumbent governments will not try to strengthen institutions to improve public sector performance and so the rent acts in a counter-productive manner by weakening those institutions meant to ensure good governance (Auty $(1994,2001))$.

Despite the primacy of the state, all power does not rest with government officials and institutions. Rather, ruling elites of individual and groups within and outside government work together to assert a monopolistic control of wealth and power. The political, social, and economic outcomes are therefore the manifestation of a "legacy of oil led development" (Karl, 1997, p. 16).

\subsubsection{Political and institutional perspectives}

There are two sets of public problems that economists say are associated with NRD: mismanagement of the economic effects (Dutch disease, price volatility), and misuse of the rents themselves (patronage, clientelism, corruption). But why are these responses seen more strongly in some countries than in others? We must look to a country's politics and society for the answers. An associated question will be to what extent NRD influences a country's political and social relationships: are these relationships an exogenous factor that moderates how NRD affects outcomes, or are the relationships in turn affected by NRD?

Gylfason and Zoega review the literature and available evidence on the relationship between institutions, natural resource abundance and economic growth, using data from 85 countries 
from 1965-1998. They conclude that NRD may be viewed as an exogenous factor that impedes economic growth and investment, but that "economic and structural reforms leading to more efficient capital markets, increased investment and a better allocation of capital across sectors may help start growth in countries that are well endowed in terms of natural resources." (Gylfason \& Zoega, 2006, p. 30).

On the other hand, Ross (2001) analysed NRD research focussing on the different political systems of governments and concluded that higher NRD correlated with less democracy, controlling for other factors (Fearon \& Laitin, 2003; Collier \& Hoeffler, 2004). In other words, an abundance of natural resources would tend to move governments towards dictatorial and authoritarian regimes (Ross 2001). Even in countries with democratic processes and systems such as regular elections and a plurality of political parties there is a tendency for those in power to weaken democratic institutions, rig elections, suppress the media, and use the rent to stay in power at the cost to the economy. As pointed out by Stevens, Lahn, and Kooroshy, "this is a self-reinforcing mechanism in which centralized wealth serves to consolidate the political hold of the ruling elite" (2015, p. 9).

In making a distinction between "developmental" and "predatory" states, Peter Evans argued that the rentier state was not an inevitable result of the contest for rents (Evans, 1989). Evans contrasted Taiwan and Korea development states with Zaire as the archetypal predatory state. These two types of state might both be authoritarian "but the former has a bureaucratic structure and an elite that will develop the country while the latter has an elite that is organized around sucking out the state's wealth and resources and thus makes little attempt at development" (Stevens et al., 2015, p. 9).

Thus, the argument that NRD determines political institutions is contested: factors such as patronage and corruption exist in non-NRD countries as well and some NRD countries have low levels of these conditions. Badeeb et al. argue:

For political factors such as rent seeking and corruption, we somewhat agree with the sceptics' arguments that these factors are endemic to many poor economies whether they have natural resources or not. However, the predominant view in 'rentier state' theory is that natural resource economies experience a higher level of such factors than non-resource economies .... Resource dependence may then augment the negative impact of political factors already affecting growth in poorer countries. (2017, p. 125) 
Barma (2014) and Barma et al. (2012) offer a typology to suggest the political conditions that may increase the risk of "predation" as above. This is on two dimensions: (1) credible intertemporal commitments: the ability of states to make and enforce commitments that persist into the future; and (2) political inclusiveness, the extent to which governments are responsive to the needs and interests of all their citizens. Table 3:1 below is a typology developed by Barma (2014) of political regimes and their effects on NR generation and distribution.

Table 3:1 Political system characteristics and natural resource dependence

\begin{tabular}{|l|l|l|}
\cline { 2 - 3 } \multicolumn{1}{c|}{} & $\begin{array}{l}\text { Less credible intertemporal } \\
\text { commitment }\end{array}$ & $\begin{array}{l}\text { More credible intertemporal } \\
\text { commitment }\end{array}$ \\
\hline $\begin{array}{l}\text { Less political } \\
\text { inclusiveness }\end{array}$ & $\begin{array}{l}\text { Patrimonial rentier state } \\
\text { Rent generation low; rent distribution } \\
\text { dominated by concentrated elite }\end{array}$ & $\begin{array}{l}\text { Hegemonic rentier state } \\
\text { Productive rent generation; rents } \\
\text { distributed among small elite }\end{array}$ \\
\hline $\begin{array}{l}\text { More political } \\
\text { inclusiveness }\end{array}$ & $\begin{array}{l}\text { Clientelist rentier state } \\
\text { Rent generation relatively low; rent } \\
\text { distribution benefits client networks }\end{array}$ & $\begin{array}{l}\text { Pluralist rentier state } \\
\text { Rent generation and distribution } \\
\text { sustainably provide collective goods } \\
\text { and services }\end{array}$ \\
\hline
\end{tabular}

Adapted from Barma (2014, p. 260)

According to Barma:

Rent generation becomes optimal when a government can make credible intertemporal commitments to both extractive companies and its citizens; and rent distribution becomes optimal in inclusive political regimes where governments have the incentive to use resource rents to provide public goods that enhance collective welfare. ... In hegemonic rentier states, natural resource rents are generated productively on the basis of credible extractive bargains; rents, however, are distributed in a concentrated way among the dominant elite. In pluralist settings, political elites compete in elections on the basis of programmatic commitments to collective welfare enhancement, with an emphasis on society wide public goods provision. ... In resource-dependent developing countries with weak intertemporal credibility and low political inclusiveness, elites are able to channel resource rents to benefit themselves and their clientelist networks and away from investment in broad-based public goods and social welfare. Factors that lengthen time horizons enhance the potential for favourable extractive deals and hence rent generation for society; and improving dimensions of political inclusiveness makes it more likely that rents will be distributed to enhance collective welfare." (2014, p. 269) 
Other writers have addressed the potential for NRD to be a source of societal conflict (Collier \& Hoeffler, 2004; Ross, 2013). Large resource revenues and rents "create a pot" worth fighting for - for the simple reason "that whoever is in power is better able to plunder that pot" (Stevens et al., 2015, p. 11). There will also be a tendency for the wealthy regions to demand more revenues and financial benefits which can lead to secessionist threats and eventual conflict within countries, as has been the case with the Bougainville crises in PNG.

In the framework developed by Barma, PNG is apparently in the bottom left hand cell: a high degree of political inclusiveness but (because of rapidly shifting coalitions) a low reliability of intertemporal commitments. A prime driver of rent distribution is then the need for political leaders to reward their clients. An example will be used here to illustrate. Sir Julius Chan, a former Prime Minister of PNG, has been quoted remarking about two sets of politicians in two different contexts (institutional settings):

In Dorney $(2000)^{12}$, we see former PNG Prime Minister Sir Julius Chan talk about the pressure on big men to deliver resources to supporters ... : "Ideology is a luxury marginal members cannot afford. It becomes a case of delivering the goods - a pragmatic approach... The Australian parties play Santa at every Federal and State election. For us it is a full-time job!” (Duncan, 2011, p. 165)

\subsubsection{Alternative perspectives on the effects of resource dependence}

In identifying the factors important for the effects of the resource curse, some writers have started from a different perspective altogether. The two to be addressed here are the Marxist critique, emphasising the importance in determining distribution of rents of foreign capital and post-colonial dependence and transnational corporations as actors, and the anthropological perspective, emphasising the significance of traditional society and its relationship to the other actors.

\section{Dependency theory and related critical perspectives}

Alternative political economy explanations for the effects of resource dependence draw on structuralist and neo-Marxist theories of growth and modernisation ${ }^{13}$. They include the

\footnotetext{
12 Citing Dorney (2000, p. 47)

${ }^{13}$ An overview is available in Martinussen (1997).
} 
"underdevelopment" theorists like Prebisch, Singer, Myrdal, Baran, Sweezy and others and embrace structuralism, dependency, and world-systems theories. "Underdevelopment" is defined as "a situation in which resources are being actively used, but used in a way which benefits dominant states and not the poorer states in which the resources are found." (Kuwimb (2010) quoting Ferraro (2008)). As summarised by Kuwimb:

- Structuralist theory assumes that existing domestic and international political economic structures are the immediate cause of underdevelopment, and recommends structural changes through domestic manufacturing, self-sufficiency, and other policies to assert economic independence.

- Dependency theory agrees with structuralism but adds that since the wealthy nations of the world need peripheral countries to remain wealthy, the economies of the peripheral countries are made dependent on the rich countries. The obstacle to "national development" is caused by "cultural dependence of the elite" on the "colonizer" and the intrusion of transnational corporations (TNCs) in the peripheral economy. Political revolution to sever the colonial and neo-colonial connections is required to break free from this dependence.

- World systems theory posits that because the world economy is a single world capitalist system (not dual economies as assumed by modernization theory), even if industrial growth did occur in the peripheral countries, their economies remain dependent on the capitalist "centres" for access to markets, finance and technology. Growth in the periphery is "developed" by the world capitalist system so that the peripheral economy remains in a state of "under-development". (2010, pp. 133-134).

\section{The anthropological perspective}

Analysis later in this thesis, particularly of the triangular relationship between local traditional communities, corporate developers, and government, draws extensively on the research and analysis of anthropologists. David Lewis has identified three positions of anthropologists with respect to capital-intensive development projects in general:

(1) "Antagonistic observer" - similarly to the critical perspectives outlined above, maintaining a "critical distance and a basic hostility towards both the idea of development and the motives of those who seek to promote it" (Lewis, 2005, p. 2). Development is regarded as a contested term: a subjective evaluation of well-being of communities or individuals, a 
value judgement about movement of societies from traditional to modern; a programme or policy of interventions to achieve social change; or a tool of the hegemony of colonial or rich capitalist societies to dominate poorer countries.

(2) "reluctant participation" - there are strong financial incentives to offer services to policy makers and development organisations related to local communities affected by resource projects; the tools of ethnography are used to map relevant social systems, and also to advise on the impacts on, and responses of, those communities in relation to "issues such as local customs, dispute settlement and land rights." (Ibid.) ${ }^{14}$

(3) "advocacy support" - combining "community or agency-level interactions with people at the level of research with involvement with or on behalf of marginalised or poor people in the developing world"; thus, Castro and Brokensha (2015, p. 307) argue that, based on their contacts with and knowledge of local communities, anthropologists may also represent the interests of these communities in negotiations with developers and government.

Broadly speaking, when analysing capital-intensive natural resource projects in terms of their impacts on local social structures and livelihoods, anthropologists have tended to assume an imbalance of power between governments and developers on the one hand and local communities on the other so that, while there may be some mutual adaptation going on, most of the social changes have been forced on the locals. Castro and Brokensha observe that

... applied anthropologists were often initially assigned the task of explaining local resistance to development projects. Given the discipline's predominant ideas in the 1950s and 1960s, they often did so by emphasizing local values and cultural patterns. (2015, p. 306)

Gilberthorpe and Rajak argue also however that the tools of an anthropologist can be also turned on the other actors to analyse these mutual effects: “... the ethnographic interest in agency is not only or chiefly concerned with the agency of subaltern or marginalised actors (as

\footnotetext{
${ }^{14}$ For contrasting positions on co-optation, see Castro and Brokensha: "Arturo Escobar (1995) used discourse analysis to expose development as a discourse and institutional practices that perpetuate domination of the Third World. He argued that anthropologists should not be involved with development agencies. In contrast, Katy Gardner and David Lewis (1996) agreed with many of the criticisms of the development industry, but reached a different conclusion: contending that the insights of discourse analysis, combined with ethnographic research, offered new possibilities for supporting effective participatory efforts.” Op. cit., (2015, p. 307), citing Escobar (1995) and Gardner and Lewis (1996).
} 
is commonly assumed to be the province of anthropology), but with the elite agencies of the powerful actors and institutions driving processes of mineral investment and extraction." (2016, p. 190) $)^{15}$. Anthropologists, they argue, can study these relations by

... applying anthropological tropes such as kinship, gift and reciprocity as heuristic devices to analyse how resource extraction generates and reshapes social relations between corporate actors, state officials, and their wider 'stakeholders' (to borrow from corporate jargon), and to investigate how the economies of extraction create new domains for the exercise of power, and new struggles over authority, at the micro-level as much as the macro. (Ibid. p 194).

This summary anticipates further discussion later in this thesis of the role of anthropologists and their analysis. However the more general writing on their role highlights some features of their role in PNG: reporting from a critical stance on the impacts of resource projects on local communities, extensive involvement in the social mapping and landowner identification precursors to benefit sharing agreements, and a significant contribution to the political economy analysis of resource development.

\subsection{The institutional strand of the resource curse}

In a 1995 essay, Douglas North defined institutions in the most general terms as the "rules of the game":

... the constraints that human beings impose on human interaction. They consist of formal rules (constitutions, statute law, common law, regulations) and informal constraints (conventions, norms and self enforced codes of conduct) and their enforcement characteristics. (North, 1995)

There is a growing scholarship about the role of institutions in the resource curse literature. Acemoglu and Robinson (2012) have shown empirically the importance to economic growth of good quality institutions and policies.

There is also a general consensus about the importance of institutions in explaining the resource curse (Harford \& Klein, 2005). Subramaniam and Sala-i-Martin (2003) also point out that

\footnotetext{
${ }^{15}$ See also Gilberthorpe and Banks (2011), cited later in this thesis, who apply this mode of analysis to the actual effects of developers' corporate social responsibility policies in their relations with local affected communities.
} 
institutional quality does matter and has an influence on economic growth (using selected indicators of institutional quality and policies to confirm the link). In other words, an abundance of natural resources does not translate to economic growth without the support of quality institutions. In a lot of resource rich developing countries, it is argued, weak institutions continue to be a major limitation on capacity to manage the newfound wealth.

Cust and Milyahi filtered their "presource curse" effect by an estimate of strength of national political institutions ${ }^{16}$ and concluded:

We see the biggest effects in countries with weaker political institutions, such as ineffective constraints on the executive. These countries not only fail to meet IMF forecast growth, but their average growth rate is lower than before a discovery. On the other hand, countries that had strong political institutions at the time of a discovery fare well - growth continues at the same rate and keeps pace with IMF projections. (2017b, p. 38)

The institutional approach and its emphasis on the institutional environment has been neglected until recently when a number of studies (Frankel, 2012; Hodler, 2006; Mehlum et al., 2006; Robinson et al., 2006) showed the influence of the institution on economics and politics. All these scholars have included institutional analysis in their work and discussions on the resource curse thesis. It is widely agreed amongst economists and politics scholars that natural resources have different effects on a country (and economy) depending on the quality of institutions. However, the definition of institutions and how they are summoned up in analysis varies widely. Although North included "informal constraints" in his essay quoted above, he confined these to "informal means of exchange" within or between organizations. Most economic analysis of the resource curse would not include the institutions of traditional society, such as kastom in PNG village communities. We would need to look for these to the broader definitions of sociologists and anthropologists.

\footnotetext{
${ }^{16}$ Various sources including Augmented Freedom House index of Political Rights (Freedom House, 2019) and the various components of the Polity IV scores (Center for Systemic Peace, 2009) together with sovereign credit scores from the database of Institutional Investor Ratings, compiled by Reinhart and Rogoff (2011).
} 


\subsubsection{Governance and institutions}

\section{"Good" governance and natural resource dependence}

Actors and institutions are brought together in governance: "the exercise of public authority with regard to society through the agencies of government ... in the context of the institutional and policy framework in place. It is about the processes by which bargains between state and society are made (including policies and institutions) and how they are subsequently implemented and monitored (by organizations)." (Barma et al. 2012) The term is usually deployed in the normative sense of "good governance", of political and administrative qualities of the state which, it is argued, are positively associated with human development. Measures of governance qualities have been developed into indices for use in estimating a governancedevelopment relationship and checklists for assessment of the quality of country governance; the World Bank's indicators (shown in Table 3:2) are the most often cited.

Table 3:2 World Bank: Worldwide Governance Indicators

Control of Corruption captures perceptions of the extent to which public power is exercised for private gain, including both petty and grand forms of corruption, as well as "capture" of the state by elites and private interests.

Government Effectiveness captures perceptions of the quality of public services, the quality of the civil service and the degree of its independence from political pressures, the quality of policy formulation and implementation, and the credibility of the government's commitment to such policies.

Political Stability and Absence of Violence/Terrorism measures perceptions of the likelihood of political instability and/or politically motivated violence, including terrorism.

Regulatory Quality captures perceptions of the ability of the government to formulate and implement sound policies and regulations that permit and promote private sector development.

Rule of Law captures perceptions of the extent to which agents have confidence in and abide by the rules of society, and in particular the quality of contract enforcement, property rights, the police, and the courts, as well as the likelihood of crime and violence.

Voice and Accountability captures perceptions of the extent to which a country's citizens are able to participate in selecting their government, as well as freedom of expression, freedom of association, and a free media.

\section{Definitions from World Bank (2019d)}

Measurement of "good" governance and its use for country governance assessment has come under attack technically for its reliance on correlations between governance and development without a theory of how they are connected, together with the endogeneity of the individual sub-measures, and their basis in essentially subjective "expert" assessment. ${ }^{17}$ At a political

\footnotetext{
${ }^{17}$ Kaufmann, Kraay, and Mastruzzi (2007) is a response to some of the more technical criticisms with references to the articles addressed.
} 
level it has been criticised for its development of an idealistic "one size fits all" agenda which exists nowhere in the developed world (Andrews, 2008); or its embodiment of a supposed "neo-liberal" agenda frequently associated with the Washington Consensus.

Paralleling the earlier discussion in 3.4.4 above on the relationship between NRD and politics and society, the political economy literature postulates that natural resources interact with governance and state institutions in two interrelated ways. First, extraction of natural resources might induce a deterioration in governance. Some writers (e.g. Karl, 1997; Mehlum et al., 2006; Weinthal \& Luong, 2006) attribute a deterioration of institutions to the resource rents from the mineral or oil sectors. One line of logic is that dependence on revenues from natural resource wealth correspondingly reduces the need for other taxation. This in turn can lead to a decline in administrative and institutional capacity building, particularly as the core tax-accountability linkage between state and society is weakened. Karl (1997) articulates this as the core logic of the "petro state" and Moore (2004) further explains the link between fiscal sources and accountability (see also Basedau \& Lacher, 2006). Additionally, resource wealth might adversely affect governance quality by provoking more intense political or bureaucratic battles between powerful interest groups for control of natural resource rents and the state institutions responsible for collecting and distributing them (Barma et al. 2012).

Second, even if resource dependence does not worsen governance, the quality of institutions and governance will most likely condition the quality of the economic and natural resource management policies adopted as well as their implementation. From this viewpoint, institutional quality and the government's ability to make policy effectively, minimizing discretion and rent-seeking, affect outcomes in the natural resource sector more than they affect other development outcomes. In addition, because natural resources generate revenue windfalls, governments may be tempted to make policy and public spending decisions with adverse long-term consequences.

Political and economic issues of power, bargaining, and social injustices have formed longstanding and institutionalised patterns that are at the heart of the resource curse (Frankel, 2012; Ross, 2013). These institutions, shaped by MNCs, their host governments, and foreign lenders, as well as by private actors in exporting countries, need to be considered in their totality (Barma et al. 2012). 
On the political side, depending on the quality of institutions, the presence of an abundance of resources can either support or undermine political regimes, whether they are authoritarian or democratic. More specifically, Robinson et al. (2006) and Mehlum et al. (2006) point out that the key to understanding the resource curse is to look at the political system, political institutions, and the actors. Barma et al. (2012) argue that the politicians discount the future through over-exploitation and use their positions to stay in power by misallocating resources; and that the quality of the institutions will determine whether the resource boom will benefit the country or be a curse (see also Robinson et al., 2006; and Mehlum et al., 2006).

\section{Corruption and NRD}

Corruption is another conspicuous symptom of the resource curse. Although accurately quantifying prevalence of corruption is very difficult, the current evidence discussed earlier suggests a probable correlation between natural resource dependence and corruption.

Corruption is defined as the abuse of public or private office, position, or power for private gain. Corruption has been established as a major impediment for economic growth and development in resource-rich countries. Patronage and rent seeking are ways in which corruption is spread and sustained in resource rich countries (North 2005).

At the most abstract level, corrupt practices take place when agents given power to act on their principal's behalf pursue their own interests (Klitgaard, 1988, p. 24). In a more specific term as it relates for the purposes of this research, here:

Corruption occurs when politicians use the power that has been entrusted upon them by voters for example by accepting bribes to push legislation favourable to the briber, awarding government contracts in exchange for a kickback or embezzling public money for personal use (Hellmann, 2015, p. 3)

The capture and distribution of natural resource rents - defined as returns in excess of costs including normal returns to capital - are common mechanisms for corruption. Corruption can be centralized in the form of patronage networks and decentralized in the form of rent seeking (Kolstad \& Wiig, 2009). Both forms are prevalent in countries with significant revenues from oil and mineral exports, especially if they are controlled by the public sector or a small number of firms. The mainstream consensus is that corruption has a negative impact on development outcomes: it reduces growth, reduces foreign direct investment, increases income inequality, 
and deters foreign aid. Finally, the facilitation of corruption by international commercial banks and the "supply side" role of transnational resource corporations have been underemphasized.

\subsubsection{Transparency and governance}

"Secrecy means deliberately hiding your actions; transparency means deliberately revealing them" (Florini, 1988, p. 50).

Transparency has been a neglected area of focus by scholars and practitioners when it comes to reforming public sector organizations and yet it remains an important component of governance, accountability, and the fight against corruption (Kolstad \& Wiig, 2009).

Finel and Lord provide the most comprehensive definition of transparency in the context of this research:

In states, we define transparency as legal, political, and institutional structures that make information about the internal characteristics of a government and society available to actors both inside and outside of the domestic political system. ... In general, transparency is increased by any mechanism that leads to the public disclosure of information such as a free press, open government hearings, and the existence of nongovernmental organizations with an incentive to release objective information about the government. (1999, p. 316).

Balkin (1999) identified three related types of transparency: informational, participatory, and accountability. Transparency efforts of organizations need all three qualities to build trust and confidence with key stakeholder: information that is truthful and useful with the participation of stakeholders who identify information they need so that the organization is accountable for its policies and activities.

Transparent organizations are those whose actions, words, and decisions can be evaluated by others. There are two ways in which transparency affects organizations: firstly, it enables organizations to be held accountable for their policies and activities; secondly, it recognizes the rights of individuals to information that affects their lives.

Stirton and Lodge (2001, p. 476) propose four basic transparency mechanisms in the relationship between citizens and public services. Two are output-oriented: information about service provision and about choices available for provision. Two are input oriented - the ability of individuals to influence service provision directly ("voice") and collectively through 
political leadership ("representation"). In a democratic state the government must be held accountable for the decisions it makes (Bannister \& Connolly, 2011, pp. 2-3). As pointed out by Bannister and Connolly, "accountability without transparency is of little value - people cannot be held accountable, if we do not know what they are doing" $(2011$, p. 6). It is therefore important that transparency facilitates the open relationship between those governed and those governing. Good governance is promoted through increased transparency, when public administration values such as efficiency, fairness, integrity, honesty and so on are seen to be at work (Rhodes, 1997; Bovaird \& Löffler, 2003; Bannister \& Connolly, 2011). Transparency is therefore viewed as means of improving the governance process within the public sector through the combination of ensuring accountability, increasing confidence in state institutions, and promoting effective functioning by the state (Heald, 2003).

Meyer (2003) argues that advances in technology such as social media have created a platform where transparency can be enforced. "Technology has both created the expectation and also produced the tools to deliver greater organizational transparency. Access to information through the internet has shifted the balance of power toward the customer rather than the supplier" (2003, p. 6). The internet raises transparency to a new level by providing means previously not available to facilitate transparency requirements.

\subsubsection{Budget transparency}

Budget transparency is defined as "the full disclosure of all relevant fiscal information in a timely and systematic manner". (OECD, 2002, p. 1) Transparency is being used here as a means of improving economic governance through a combination of mechanisms, strengthening accountability and legitimacy as well as facilitating policy consistency and predictability and ensuring the better functioning of government (Heald, 2003). Furthermore, budget transparency enables understanding and participation in budget policy decisions by the public and serves to build trust in government (OECD, 2019; Ramkumar \& Shapiro, 2010).

In general, the empirical literature on budgets has followed a variety of avenues that range from the transparency of the budget (and budgeting process) itself, through to the consequences of transparency on other economic outcomes. For example, Alt and Dreyer Lassen (2003), using OECD countries as their sample, found that greater fiscal transparency was associated with lower debt and smaller budget deficits. Golwitzer (2010) found a similar result in a sample of African economies. 
Although civil society would seem to offer considerable potential for bringing about a strengthening of institutions for more accountable and effective fiscal management (Petrie, 2003), its increased role is quite recent in promoting fiscal transparency alongside that of other accountability institutions such as legislatures and audit institutions.

\subsection{Transparency and the resource curse}

\subsubsection{Transparency for extractive industries}

Transparency within the context of this study focusses on making available and releasing information and by extension looking critically at the role of institutions. It is argued that transparency will have the effect of holding government agencies along the natural resource management value chain more responsible and accountable for their actions, which has been lacking (Mitchell, 1998). In other words, regardless of the level of a county's development and the type of political and economic systems in place, transparency, if fully enforced and complied with, will reduce corrupt practices and wastage among other inefficiencies within the natural resource sector.

In this argument, the accountability condition of transparency is what makes it very critical to the extractive industry and in countries like PNG with very weak institutions. Given the complexity of the extractive sector and the political, social, and economic contexts in which resource extraction takes place, fostering accountability is not an easy process. There are many points to push for transparency of information from publication of contracts, through to revenues paid or received, to how revenues are shared, to how they are invested or spent and to evaluation of their impacts.

There is also a global promotion of transparency in the extractive industry. Although these initiatives are in their early stages, developing countries with resources such as oil, gas and mining stand to benefit from improved governance, more accountability, and better use of revenues. A remedy for the resource curse has been the promotion of transparency by the international community such as the World Bank, International Monetary Fund and the United Nations and advocacy groups to increase accountability and improve governance in the natural resource sector of developing countries. It is important to state here that although transparency appears simplistic, it means that if there is full information disclosure then it would produce an 
informed and interested public who would demand accountability and good governance (Kolstad \& Wiig, 2009).

In a parliamentary democracy such as PNG, transparency would have the effect of assisting the citizens to elect better political leaders. At the bureaucratic level, transparency would ensure that institutions provide information about their activities and be more accountable to the people whom they are serving. At the operational level the civil/public servants would be under close scrutiny and prevented from corrupt practices. The next part of this section will look at the model that will be used to discuss the relationship between the citizens and the government and where and how transparency fits in.

Within the context of natural resources - the people (principal) are the owners of the natural resources and expect the government (agent) to properly manage these resources. However, with little information the people are unable to properly hold accountable the political leaders and bureaucratic officers within the resource sector. In short, the lack of proper information and a more transparent process in using the "rent" or revenue from the resources could be an explanation for the resource curse and the lack of development in resource rich developing countries like PNG.

The central argument on transparency as a means to avoid the resource curse is deeply rooted in the principles of good governance. Transparency supposedly works by generating responsiveness among public office holders and organisations by making information about their activities publicly available. Here, the information itself is not necessarily important, but rather how the potential release of this information causes agents to essentially "do the right thing". And so, transparency is often quite closely related to the issue of corruption.

\subsubsection{The EITI}

The EITI which was launched in 2003 became an international standard for the extractive industry ${ }^{18}$. The EITI has in fact been successful in setting up standards for auditing, reporting, and civil society involvement, it has also been widely accepted and recognized as a brand that

\footnotetext{
${ }^{18}$ For the global EITI, see EITI (2019). For EITI in PNG, see EITI PNG (2019) .
} 
is promoting transparency as an international norm. There is a lot of debate about its success and also why it has failed in some countries (Rustad, Le Billon, \& Lujala, 2017).

As of 2015 there were 31 EITI Compliant countries and another 49 EITI candidates ${ }^{19}$. The EITI now sets a standard in extractive industry revenue transparency in 46 countries. The total disclosed payments and revenues were about $\$ 1.67$ trillion with some of the biggest global oil gas and mining companies committed to EITI. Further, 84 global investment institutions that manage \$16 trillion in energy assets have fully endorsed the EITI. Perhaps more importantly is the fact that the G8, G20 and the United Nations have all fully supported the EITI (Sovacool et al., 2016). EITI has been defined by its push for transnational standards in revenue disclosure and its link to socio-economic development.

Sovacool et al. (2016) undertook a comprehensive econometric examination of the EITI's effectiveness in improving governance and economic development in its member countries using data from the World Bank. The examination covered the economic performance of 16 countries which attained full EITI compliance during the period 1996-2014 (Ibid). The study found that none of the countries that were assessed performed better during compliance than before compliance. The authors suggested four explanations for the weakness of EITI: its limited mandate; its voluntary nature; stakeholder resistance; and the weakness of the civil society on which it relies for holding developers and governments to account (Ibid). The counterargument is that, although membership of EITI is not a cure for all the problems or a guarantee of good governance in the resource sector it builds a culture of transparency and engagement with civil society especially in developing countries.

EITI works under the assumption that the industry and government will comply with these requirements (Öge, 2016). This is underwritten by a unique format that requires an active civil society to be part of the resource management process, but the question remains: can the EITI successfully incorporate civil society groups into the decision-making process in resource rich countries? In fact NGOs are having difficulty playing their role in monitoring the companies and government agencies (including SOEs) due to political, technical, financial, and

\footnotetext{
${ }^{19}$ A new standard for EITI was introduced in 2016. As at 2019, 61 countries are listed in the EITI database and are assessed as follows on progress towards the standard: satisfactory progress (8), meaningful progress (26), suspended (inadequate progress or missed deadline) (5), yet to be assessed (19), and "other" (not regarded as EITI countries) (3). PNG's latest validation in 2018 was "meaningful progress". (EITI, 2019: summary data.)
} 
bureaucratic constraints (Öge, 2017). Van Alstine's overall conclusion on experience with EITI is that:

While transparency itself is insufficient in addressing the multifaceted problems resourcerich countries face, revenue transparency can be viewed as an 'entry point' into a conflicting conversation between companies, governments and civil society where trust and consensus can be built on issues beyond revenue. $(2017$, p. 2)

\subsection{Conclusions on the resource curse and the role of governance}

The current state of the empirical and theoretical literature can best be described as "mixed": there is a demonstrable case for the resource curse and there is also a case against the resource curse thesis. At this stage of the research it is reasonable to suggest that the weight of the empirical and theoretical literature favours the resource curse hypothesis.

What is clear is that none of these writers are advocating leaving mineral resources in the ground as a means of avoiding the resource curse. (This leaves aside arguments that the environmental impacts of mining need to be properly managed and that exploitation of carbon resources such as fossil fuels needs to be phased out as part of the global response to the risks of climate change.) There is recognition of the classical argument that, properly managed, exploitation of natural resource assets is a platform for more diversified and sustainable development paths.

In summary, the debate in the literature is implicitly or explicitly about the appropriate policy and institutional settings to avoid the immiserising risks of the "resource curse":

- Managing the "Dutch disease" with the standard "neo-liberal" prescription based on economic management (including the establishment of sovereign wealth funds) and the investment and development of the non-resource sectors of the economy; and alternative Neo-Marxist prescriptions based on state ownership of resource industries and greater autarky in trade policy.

- The broader prescriptions aimed at the "resource curse-governance" linkage primarily aimed at strengthening executive accountability (through mechanisms such as transparency and the EITI) and state capacity (to improve quality of economic management) and regulating the resource sector more effectively. 
- Managing the expectation of all stakeholders in large resource discoveries and the need for governments to approach them more cautiously (see Cust \& Mihalyi, 2017b, p. 38). 


\section{Chapter 4 Natural resource dependence: the case of Papua New Guinea}

\subsection{Introduction}

The previous Chapter concluded with observations about the effects of natural resource dependence based on the international literature. This Chapter first outlines relevant features of PNG in terms of its history, politics, institutions, and people and then reviews the discussion in the literature on the specific case of PNG in relation to the resource curse thesis and its connection to governance. To summarise, the literature identifies the existence of substantial resource rents and strong cycles in commodity prices as a source of economic and political instability in PNG, through Dutch disease effects, pro-cyclical government policies, rentseeking behaviour of individuals, and the struggle for shares of the expected rents. Explanations also emphasise the unique features of PNG society and state-society relations as a significant factor in the socio-economic consequences of natural resource dependence.

\subsection{Geography and people}

PNG's geography and people have both had a significant impact on the development of its natural resources.

Papua New Guinea (PNG) is in the South Pacific and occupies the eastern half of the island of New Guinea. It is the largest country in the region in both land and population size, except for Australia. The country's population is estimated at between 7.5 and 8 million people with a land mass of 461,690 $\mathrm{km}^{2}$. The rugged topographic terrain and impenetrable mountain ranges has prevented the building of infrastructure to link the scattered hamlets (Bourke \& Allen, 2009). Physical isolation and a lack of connectivity continue to pose major challenges to expanding access to basic social services, further compounded by underlying state fragility and weak bureaucracy.

PNG is also one of the world's most ethnically diverse countries, with over 850 indigenous languages and at least as many traditional societies and is considered one of the most heterogeneous countries in the world (Reilly, 2008, p. 13). The country is predominantly a rural agrarian society with a small but rapidly growing urban population. Eighty-five per cent of the population live in rural areas and seventy-five per cent of households depend on subsistence agriculture. The fact that it is substantially a non-cash economy poses a lot of challenges in terms of encouraging commercial activities. 


\subsection{Colonial Rule}

Papua New Guinea, like a lot of developing countries especially in Africa, emerged from colonial rule with its system of government, many of its laws, and its foreign policy influenced by the colonial powers. PNG had two separate jurisdictions - Papua was ruled by the British, then Australia; New Guinea was ruled by Germany from 1884 to 1914; by 1942 the combined territory came under Australian rule, where it remained until 1975 when the country gained independence (Reilly, 2008, p. 13).

Prior to colonialism, there was no history of state-like organization in what is now PNG: "instead society was made up of thousands of small, acephalous and largely independent tribal units" (Reilly, 2008, p. 13). As one academic pointed out: "if ethnic communities are understood to be groups possessing a distinctive language, custom and memories - traits that give its members a sense of unity and cause them to distinguish themselves (and be distinguished by others) - then PNG may have more than one thousand such ethnic groups within its borders" (Levine, 1997, p. 479; quoted in Reilly, 2008, p. 13). "Membership of even the smallest primary groups was unstable - as people married in and out, disputes arose between rival leaders, and inter-group warfare forced some members of each group to choose between the claims to their loyalties of, say, their residential or their kin group" (Parker \& Wolfers, 1971; cited in Reilly, 2008).

The colonial state made an important contribution through the suppression of tribal fights and the acquisition of land by conquest, and the overall maintenance of law and order. There was also a move to establish a new political order with the rule of law and establishment of a state apparatus to enforce laws.

Colonial rule, among its other objectives, was also "aimed quite consciously at laying the foundations of capitalism in Melanesia (PNG). The policies included introduction of indentured labour system, head tax, and educational institutions, which all paved the way for a gradual incorporation of indigenous people into the sphere of capitalism" (Imbun, 2008, p. 4). The colonial administration while advocating for plantation (coffee, cocoa, copra, tea and rubber) and mining development, including the introduction of labour laws, land policies and other administrative regulations, paradoxically did not allow for large scale employment of indigenous labour "because of its associated potential adverse impacts of uprooting of traditional village life and adaptation into an alien urban milieu" (Ibid, p. 5). While it is 
debatable, the approach by the colonial administration developed what is now referred to as the dual economy which characterises the economy of PNG. This dual economy, made up of the cash and subsistence economies, contributed to movement of labour into the plantations and estates and population concentration which has had an influence in political contestation. "The dispersed and unevenly developed economy, as well as social divisions rooted in the people's social structures and cultures, heighten developmental inequities and hence political discontent" (Standish, 2007, p. 135). Insofar as native custom was concerned:

The Australian colonial authorities in PNG were primarily interested in the substance of "native custom" because of their compulsion to eliminate those customs deemed repugnant to the values of Western civilisation (Filer, 2006, p. 67).

The colonial administration also started establishing and building institutions necessary to carry out its responsibilities. The Australian colonial administration introduced the public service and ran it with a high level of professionalism. However, although the system of government and its various institutions were serving the colonial administration well, it was in effect an extension of the Australian bureaucracy. It also meant that there was no demarcation between politics and administration within PNG: policy was made in Australia and administration (the implementation of policy) was done in PNG. The colonial administrative culture was paternalistic and authoritarian, based on the Weberian model of bureaucracy. Its primary purpose at that time was to serve the colonial administration in maintaining law and order and to provide basic services.

\subsubsection{Post-Colonial State in PNG}

"PNG ... (was) in many ways a state in search of a nation” (Reilly, 2008, p. 13)

In the lead up to independence, there was a lot of scepticism about the newly independent state's ability to bring under control all the people and territory under its jurisdiction. There were also threats of secession by different groups of people, most notably Bougainville. The country at independence was divided ethnically, socially, politically, and geographically: lack of accessibility through poor communication and transportation isolated thousands of communities.

In fact, the newly independent state began with some optimism. The World Bank in 1978 noted that: 
In the four years after its elections, the Somare government showed an impressive ability to deal with the young country's financial, economic, and political problems. An effective set of institutions for economic and financial management has been created. These include a strong ministry of finance that has developed a tight system of budget controls, operating through a budget priorities committee; a planning office; and a central bank that, with International Monetary Fund assistance, has organized a set of international accounts (World Bank, 1978, p. 5; cited in Chand \& Yala, 2009, p. 43).

However, the work ethic and professional culture began to dissipate following independence until it was totally dysfunctional (Ronald James May, 2003). The Weberian features of a modern bureaucracy were replaced with cultural values such as loyalty to kinsmen and reciprocity which undermined the capability of the bureaucracy to deliver. The result was a breakdown in administrative systems and procedures characterised by political corruption, cronyism, and nepotism (Standish, 2007). Furthermore, the weaknesses in the bureaucracy were exploited by the various governments that came to power in terms of making political appointments (appointment of unqualified personnel), abusing the tendering process (giving contracts to unqualified companies), and engaging in corrupt practices with impunity.

\subsection{Independence and decentralization}

\subsubsection{Authority of the state}

The capacity of the state in developing countries to exert its authority over its people rests not only on its legitimacy but also on the recognition by the people of the state's authority. The question then becomes how does an independent state as PNG go about establishing its authority? Munro identifies challenges with transiting from colonialism to an independent sovereign state:

- The state as the final arbiter of property rights: the new state must be able to demonstrate that the courts are able to implement and enforce the laws of the land and more importantly the people including corporate entities must have confidence in the state's ability to do so, but there is limited coercive capacity particularly in the remotest parts of the country.

- The importance of transforming and regulating social relations and the establishment of common ethico-political values. (1996, p. 45) 
Munro goes on to point out the state's authority in asserting its powers over the people rests on its legitimacy and the need for the community to be brought into the state and the state must be brought into the community (1996, p. 141). This is brought home succinctly by Ballard who points out that where "the institutions of the state have little or no presence, material or symbolic, in the village, the ability of the state to insist upon its sovereignty - its voice - is open to challenge." (1997, p. 49)

There is a consensus that the post-colonial state in PNG has lacked the capacity to deliver goods and services to the hinterland and remote areas of the country. In fact, there has been a decline in the maintenance of law and order and an increasing challenge to its authority (Standish, 1994; A. Strathern, 1993). The colonial government may have imposed a military style of governing where the use of force was applied to secure compliance and enforce the laws for the purposes of "pacification" but under a post-colonialist state the use of force (fire power) was increasingly being challenged (Filer, 1997).

There were secessionist threats from different groups around the country, the most notable being the Bougainville people (North Solomon Province which also hosted the giant Panguna mine). (Reilly, 2008, p. 13)

In Papua and in Bougainville there were unilateral declarations of independence. Neither movement had great impact on the inevitable transition to independence, the leaders of both groups becoming members of the National Parliament in the independent state of Papua New Guinea. Provisions to accommodate the demands of the Bougainvilleans, however, provided the basis, after independence, for a system of provincial government (Ronald James May, 2003, p. 3).

\subsubsection{Decline in state capacity}

The declining capacity of the state to assert its authority within these provinces and especially the remote and rural parts of the country has undermined its legitimacy to enforce the rule of law; by extension it leads to weak governance at the local level. "The promise that wealth generated by mining would strengthen the state and increase its capacity to improve services across the nation was not fulfilled. The intervening years have ensured also that competing interests are manifest as political divisions that jeopardize sustainability" (Filer \& McIntyre, 2006, p. 228). The weak governance coupled with a lack of legitimacy perceived by the people 
has contributed to increased lawlessness and violent conflicts in parts of Southern Highlands and Hela provinces, and election violence both for local and national elections since 2002. The weak governance which is a major feature of the provinces has contributed to corrupt practice by public servants and politicians working in the provinces. As pointed out by Haley and May there are several development conundrums:

Good governance relies on public servants being in place and doing their jobs - police, magistrates, teachers and health workers are needed on the ground throughout the province. They need to be supported by a functioning administration. However at present there is negligible infrastructure in the western end of the province, so one of the first challenges is how to encourage public servants back into these areas (Haley \& May, 2007a, p. 17).

It was therefore difficult for the political leadership to bring bureaucratic institutions under its control and direction. The political leadership have also been preoccupied with attempting to consolidate their own political bases and manage their positions. Immediately after independence, the rivalry and competition between the technocrats (most of whom were expatriates) and the newly elected local politicians over the distribution of resources were a source of contention. This continued after the few remaining expatriates, mainly Australians, left.

\subsection{Politics}

PNG has had a continuous democracy for 55 years. It has been described as one of a few developing countries in the world with an unbroken democratic history (Lijphart, 1999; in Reilly, 2002). The democratic model adopted is the Westminster system, in operation since $1964^{20}$ when the colonial administration introduced the first national election (Woolford, 2013). By 1975 when PNG gained independence, there was already a well-established and functioning system, which was formalised into unicameral House of Parliament.

The political system at independence was however characterised by the absence or lack of a political party system, political institutions, political culture, and organized groups. There were

\footnotetext{
${ }^{20}$ In 1964, universal suffrage was granted allowing people to be nominated and elected into the first House of Assembly; the second general election was in 1968; self-government was granted in 1973, which paved the way for full independence in 1975. The first national election after independence was in 1977. Elections have been held every five years since.
} 
also demands for more autonomy versus the need for national unity. This was also a period of uncertainty by the different groups concerning the domination by particular groups. The electoral support is strongly based on "primordial affiliation" causing many candidates to contest elections, resulting in small winning margins. As pointed out by Axline:

There are neither ideological issues nor coherent programmes around which groups of voters might coalesce as an alternative to the voting behaviour. The promise that a candidate will deliver more to his people, which is an element of pleas for political support in all democratic systems, assumes a dominant role in PNG in the absence of well developed party-loyalty, ideological, or programmatic bases for political debate (1993, p. $35)$.

Despite these deficits, and although democracy as a system of government was a foreign concept, it has been generally accepted by the citizens as a way of securing political power and governing. The only concern is the process by which the people use the system to get into power. The basic and most important element of the democratic system is the acceptance of the election process in selecting political leaders - a procedural process of democracy where the "most powerful decision makers are selected through fair, honest, periodic elections in which candidates freely compete for votes in which virtually the entire adult population is eligible to vote" (Huntington, 1996, p. 6).

In PNG, there have been a lot of studies done that show that elections in most parts of the country there are either rigged or corrupt practices involved in getting candidates elected. Notwithstanding that, the people accept that this is the way leaders are selected in a democratic system - the challenge has been for candidates to use the system to get in. (Dorney, 2000; Reilly, 2008).

\subsubsection{Context of democracy in PNG}

Some of the tenets of democracy include: the separation of power, regular meetings of parliament, periodic elections, votes of no confidence, a free press, and citizen's rights to question the actions of the government of the day. These tenets should be inculcated among the citizens and institutionalized over time. In PNG, some of these fundamentals are challenged by the nature of the country. Eighty-five per cent of the population live in rural areas, which raises a number of fundamental issues, including the ability to comprehend the roles and 
responsibilities of elected officials, the separation of power, and the inner workings of the democratic processes of government.

The intensity of political competition reflects the weakness of both the political and administrative systems, but the logic of PNG politics also derives from the structure of the society and its economic base. The state can only deliver what the economic base provides, so the economy strongly influences politics and government programs. (Standish, 2007, p. 137).

\subsubsection{Democracy, reciprocity and loyalty}

Election is just one dimension of the democratic process, but is also the process most familiar to all the citizens in one form or another. Voting in PNG, especially in the rural parts of the country, is based on reciprocal relationships. Papua New Guinea's basic cultural unit “comprises ascriptive extended family networks or 'clans' which form the primary unit of political and social loyalty" (Hogbin, 1973, p. 23; in Reilly, 2008, p. 13). Elected officials are not viewed as law makers by the electorate but as deliverers of goods and services for their social networks.

Elections are highly competitive races where huge sums of money are spent by candidates and their supporters. Whole villages are organized along clan and family lines and are required to vote along clan lines. Although voting is done through secret ballots, the outcome is monitored through ballots cast at polling booths in each village. In other words a good candidate may not win if he or she is not endorsed by the 'tribe' (Ghai, 2000). There is also a high turn-over of elected leaders (Kaiulo, 1997) and so the person elected is expected to do a lot in terms of maximising the office for "personal and clan gain" in the first term of office. The distortion of democracy as practiced in PNG based on reciprocity and loyalty is aptly pointed as parochial by Ghai:

The whole parliamentary system is now lubricated by cash. Candidates unable to count on party organization or the loyalty of supporters to win elections, rely on monetary or other material incentives to win votes. Reciprocity and ethnic ties have become the basis of politics (Ghai, 1997, p. 325).

In discussing these electoral practices in the Pacific, Peter Larmour (2012) uses Marcel Mauss's anthropological explanation about social systems of systematic exchanges between collectives such as tribes, clans and families. Mauss sums up the obligations in a gift economy: 
- The obligation to give (you may not want to give but it is a cultural requirement);

- The obligation to accept (you may not like to accept but there are repercussions);

- The obligation to reciprocate (an acceptance requires repayment; in fact, gifts or acts of kindness are not hoarded but passed on). (E. P. Larmour, 2012, p. 123).

Graham Hassall reports that

Electoral candidates, when interacting with communities during campaign periods, faced traditional obligations to 'bear gifts' which were signs of hospitality rather than inducements for votes. ... In the Melanesian cultures of the South-West Pacific, the 'big man' was traditionally expected to not only possess wealth, but to distribute it for the benefit of all; this value system has transferred over to expectations of Members of Parliament and even senior public servants. (Hassall, 2017a, p. 10)

Leaders able to attract resources to their constituency were only doing what was expected, and the provenance of the resources was not a major concern. In PNG a leader cannot travel to an area (especially rural) or attend an event or a gathering without leaving behind a gift (or making a commitment to give something). For example if a member of parliament is invited to launch a sporting event, he or she will be required to make a financial donation. Herein lies the problem: the public does not care where the money comes from (either personal or from the state). Furthermore, when a leader addresses a problem (such as non-payment of royalties to landowners) and gives an assurance that the issue will be dealt with, the people reciprocate by accepting the leader's words (and abstain from civil disobedience). From the outside the political relationship is a patron-client style arrangement where state resources are being deployed with "varying degrees of subtlety and success in linking leadership aspirants with the community" (Standish, 2007, p. 140). Jurisdictions that allow MPs to administer constituency/electoral development funds promote this idea of the well-resourced leader.

\subsubsection{Party systems and coalitions}

The PNG party system is fluid with no clear ideological basis to differentiate between the parties in the country. The political parties become the vehicle which candidates use to campaign during national elections, and when it comes to the formation of governments after 
an election or during an attempted vote of no confidence in a government. A major feature of the PNG political parties is that they reflect the personalities of their leaders (Hegarty, 1983).

It can be said that political parties merely exist as parliamentary factions as it is difficult to distinguish their positions on a wide range of issues. The vote taken on issues by parties can easily be changed and so the general population does not know what each of the main parties stands for. One thing is for sure: all political parties in PNG love populist policies such as "free primary and secondary education", "promoting and supporting local industries" and "encouraging rural development", most of which cannot be easily explained in terms of funding, or through legislation or operationalized as public policy.

The large number and fragmented nature of political parties has also contributed to the instability of governments since 1975. Compounding is the fact that no single party has formed a government: every government since has been a coalition. Between 1977 and 2002, there have been five changes to government arising from votes of no confidence with one case being decided by the courts. The votes of no confidence have reduced the life span of PNG governments to an average 2.5 years and prevented governments from serving their full fiveyear terms except for 2002 when the Somare government served its full term and the O'Neill government which served a full term from 2012-2017. By law, a new government is protected during the first 18 months of their incumbency and the last 12 months before the next election. Prior to the introduction of the Integrity of Political Parties Bill in 2000, PNG's national government was often destabilised by frequent votes of no confidence and changes of government. Since the passage of that legislation, there has been more stability with fewer changes of government.

The changes in government, whether through a national election or a vote of no confidence has also meant changes in departmental heads, government policy, budget focus, and funding priorities, which means that sustaining a program/project has also suffered. The challenge for any prime minister of the day has been holding together the coalition partners by making them happy through agreeing to their various requests (funding pet projects, agreeing to appointments and supporting contracts for business associates). 


\subsubsection{Politics and corruption}

The push for democratic governments in developing countries as a necessary condition for developments, or at least receiving aid from western governments, is partly based on the anger against a corrupt or repressive regime as discussed above. However, democracy itself can create opportunities for corrupt practices such as in election campaigns (voter bribery), collusion with electoral officials to remove ballots or names from the common roll as is the case in PNG, and the exchange of favours to build coalitions in the formation of governments (E. P. Larmour, 2012).

Within politics there will have to be compromises made: groups do not get everything they want. Some groups are more powerful than others (E. P. Larmour, 2012, p. 136). The alternatives to political bargaining are coercion and secession of whole groups (ibid). In a democratic system transplanted into a country with weak institutions, a parochial political culture, and a people in transition from traditional settings to modernity, the result of bargaining and power struggles can be a recipe for corruption.

According to a 2012 report:

Nevertheless, corruption is present at the top echelons of government and bureaucracy, and it is the single biggest cause of the country's decline since independence. Huge sums of money have disappeared into the pockets of politicians and public servants or have been misspent by successive governments. There is very little political will to fight corruption as it permeates every layer of society, politics and bureaucracy. PNG is widely regarded by the international community as a "weak" state (Bertelsmann Stiftung, 2009).

Many people, including politicians and donor countries alike, have expressed concern over the widespread corruption and its effect on bureaucratic performance and development and a continued weakening of key institutions such as the Ombudsman (Hassall, 2017b). Given the cultural context of the country and the view that being elected into parliament or given a government job would assist one to meet and fulfil cultural obligations, ushered in an era of nepotism, bribery and general corrupt practices which were rampant in areas such as recruitment, awarding of government contracts, and embezzlement (it was generally small before it became pervasive). The important role of the bureaucracy in nation building and providing vital goods and services to very remote areas could not be performed. 
Former Prime Minister Sir Mekere Morauta once described the situation as "systemic and systematic" - systemic because it has invaded the whole process of policy making and decision making, and systematic because it is organized and often highly sophisticated. As Hassall describes it:

The auditor-general and the Permanent Parliamentary Committee on Public Accounts (PAC) have highlighted the extent of numerous government departments' noncompliance with their own rules and regulations for more than two decades, but with little impact on public sector behavior. Senior public servants whose inappropriate actions have been highlighted by the PAC have had their contracts renewed just weeks afterwards; improper use of funds continues to occur; vehicles purchased with public funds are not always placed on a government asset register; and vendors are sometimes paid in a manner that fails basic standards of documentation (Hassall, 2017b, p. 6).

The level of politicisation of the bureaucracy with unqualified and inexperienced personnel, which also extended to state-owned enterprises and statutory bodies, bred a culture of patronage and a general break down of the ethics that governed and characterised modern bureaucracies (Duncan \& Temu, 1995; Garnaut, 2000).

\subsubsection{Politics and accountability}

There have been nine general elections since independence. Some have argued that the smooth transfer of power reflects a "robust and viable democracy" but as pointed out by Standish:

Once a new government is formed political participation declines and the country's welldesigned accountability processes often lose effectiveness. Democracy means much more than the regular holding of free and fair elections. To be an effective mode of governance democracy also requires an executive which is responsible to the legislature, and representatives who are responsive to the electorate; ongoing participation by citizens is essential. (2007, pp. 135-136)

Standish goes on to point out that for a lot of Papua New Guineans "the system" is not delivering (ibid). Further, the fact that there is no proper accountability in the political system means that elected officials will remain unresponsive to their constituents. In Western democracies public opinion matters, but PNG governments appear immune and not swayed by public opinion (ibid). 
There is widespread anecdotal evidence indicating that poor accountability and transparency mechanisms both at the political and bureaucratic levels characterised most of the period between the 1990s to the early part of the 2000s and then again from the mid-2000s to the present time (Hassall, 2017b). This also meant that corruption, misuse of public funds, and general mismanagement flourished, forming the basis for the total disregard of laws (Biggs, 2007; Hassall, 2017b).

\subsubsection{Reason for persistence of democracy in PNG}

Politics in PNG is therefore characterised by political instability, a weak party system (where parties do not have any ideological differences), a political culture characterised by reciprocity and patronage, weak institutions (resulting in poor governance), a highly fragmented rural based and dominated communities whose interests are localized (do not care about what is happening nationally or globally) and who are mobilized during election times only for the purpose of voting. A rhetorical question that has been asked is why democracy has not delivered especially when the idea has been espoused by western countries and donor agencies. Is democracy a major impediment to economic development especially in newly independent and developing countries like PNG? This is a difficult question to answer but assists in putting the political context into perspective.

The following points have been used to explain why even in its dysfunctional state democracy continues to survive in PNG:

- There is no dominant social group (ethnic, religious, or class) that can come to power and control government or hold on to power (R J May, 2004; Reilly, 2008). Even if there was a military takeover it will not be able to exercise control over the whole country and the people will resist.

- The state-society relationship shows a weak state and a dominant society which is being held together by democratic principles, which include the acceptance of the transition and change of government, the rule of law and its application, the freedom of the press, and the independence of the courts (R J May, 2004).

- The courts have been independent and have ensured that the state does not abuse its powers and that society observes the rule of law. In the developing country context, the PNG courts have demonstrated an independence that has been fiercely protected. The courts have 
mediated and settled disputes and continue to be an arena for all parties to air their grievances.

The next section deals with the bureaucracy which is the main vehicle through which public goods and services are provided.

\subsubsection{The PNG Bureaucracy}

A vast majority of the electorates of the country measure the performance of their elected officials through the delivery and availability of services such as health, education, and improved transport and communication infrastructure. The functions of the modern state policy making and implementing, provision of goods and social services, creation of economic opportunities and the protection of its citizens and their property - are vested in the public service. It is not only concerned with the maintenance of law and order and the execution of public policies, but also with modernization, economic development, and the extension of social services. Though these functions are also performed in developed countries, they are of overwhelming importance in developing countries where some of these tasks are more comprehensive and cover nation-building (Haque, 1996). The bureaucracy is among the most important government institutions, without which the government cannot function. It is an institution with great power, influence, information, and expertise at its disposal.

It appears that while the Australian Colonial Administration built up a bureaucracy that was functioning as it should, the abrupt departure of highly skilled and experienced expatriate personnel meant that a lot of inexperienced, ill equipped, and unqualified personnel took on positions of responsibility. The important role of the bureaucracy in nation building and providing vital goods and services to very remote areas could not be performed. There has consistently been a decline in service delivery to the bulk of the rural people, a deteriorating infrastructure, an increase in corrupt practices, and a drop in work ethics and professionalism.

While the politicization of the bureaucracy is common in a lot of developing countries, the danger for countries like PNG is that it may be difficult to reform the bureaucracy once corrupt practices are deeply embedded, as those who benefit will resist reforms and try to maintain the status quo (Ruis \& van der Walle, 2003, p. 6). The situation is made worse when the state machinery is incapacitated and is too weak to deter corruption in countries like PNG (ibid.). 
Opportunistic mismanagement of resources because of poor oversight reduces the capacity of the state to perform its functions.

\subsubsection{Governance: traditional and modern}

The constitution of the country, while home grown, follows the liberal democratic tradition of affirming the basic God-given rights of the citizens and also sets out the checks and balances of the three arms of the state (Ghai, 2001). The Constitution in effect has provided the political, social, and economic parameters under which development has taken place in the country. As pointed out by Ghai:

The constitution has survived and with it the political and legal system. The Constitution provides the framework for national politics. Papua New Guinea is an open society, where most rights are protected. No-one can accuse the governments since independence of being tyrannical and no dictator has emerged to undermine the constitutional order. Elections have been conducted regularly and have been free and fair. Changes to governments have been conducted peacefully. To a significant degree, the rule of law has been maintained (2001, p. 53).

The country's policy and legislative frameworks covering the different sectors across the different levels of government are comprehensive and relatively sound, but the problem lies in enforcement, compliance and implementation.

Arguably, the failures of the administrative state in PNG reflect a more fundamental tension between state and society in PNG. A major challenge to good governance in PNG is that it is based on a "modern" system of values that conflicts with the values of traditional society. May has explained the dilemma PNG faces when advocating good governance using the work of Peter Ekeh, who distinguishes two public realms in post-colonial Africa: a primordial public realm governed by "primordial groupings, ties, and sentiments", and a colonially-derived “civic" public realm (Ekeh, 1975, p. 108; cited in R J May, 2004). Most African public servants belong to both these public realms:

On the one hand, they belong to a civic public from which they gain materially but to which they give grudgingly. On the other hand they belong to a primordial public from which they derive little or [no] material benefits but to which they are expected to give generously and 
to give materially ... their relationship to the primordial public is moral, while to the civic public is amoral. The dialectical tensions and confrontations between these two publics constitute the uniqueness of modern African politics ... The unwritten law of the dialectics is that it is legitimate to rob the civic public in order to strengthen the primordial public (Ekeh, 1975, p. 108).

The result of the incompatible traditional obligations within the legal bureaucratic system of governing has resulted in tribalism and corruption, according to Ekeh. The situation of newly independent African states described by Ekeh, has played out also in $\mathrm{PNG}^{21}$. According to a former finance secretary and former governor of the central bank, Mekere Morauta, “... the most corrosive and intractable problem we face now is corruption" (1996, quoted in R J May, 2004). Morauta further warned of "the institutionalisation of short-term ad hoc decision making and the catastrophic decline in the power, status, morale and productivity of the bureaucracy" (ibid).

\subsubsection{Public Sector Reform in PNG}

The World Bank in 1983 pointed out that the public sector was too big, over centralized, had "excessive proceduralism" and a demoralised staff, and was biased against staff from the provinces (G. Cochrane, 1986, p. 58; Turner \& Kavanamur, 2009, p. 12).

In the early 1990s the government embarked on economic and political reforms in Papua New Guinea, prompted by a liquidity crisis. As outlined by Kavanamur and Okole (2004) they include: reforms to the provincial government system (1997), private sector wage liberalization (1992), public sector reforms (1999), corporatization as a prelude to privatization (1990), investment deregulation (1990), trade policy reform (1990), tax and tariff reform (1999), political party and electoral reforms (2001), and financial sector reform (2001).

The World Bank and IMF were instrumental in ensuring that structural adjustment loans were given only when governments agreed to the terms and conditions they set. For instance, ideas

\footnotetext{
${ }^{21}$ In other respects there are fundamental differences between African tribal societies and traditional social groups in PNG. Biersack, writing about the Southern Highlands Ipili, affirmed that in PNG, social groupings are rarely bounded, static groups. "Even in those PNG societies which have patrilineal or matrilineal 'rules' of descent, actual groups are formed by other criteria and tend to be flexible in their boundaries and composition." (Biersack, 2012, p. 276). However, although PNG politics cannot thus be portrayed as a competition between tribes as it has been in, say, Nigeria or Kenya, PNG political leaders are still bound by a web of social obligations to their local communities.
} 
such as good governance were packaged with the loans referring to "open, transparent, accountable, equitable and responsive to peoples' needs" (P. Larmour, 1998)

\subsubsection{Why reforms fail}

Numerous reasons have been given as to why the reforms failed and most of the problems they intended to eradicate persist. These reforms were externally driven by foreign donor agencies, especially the IMF and World Bank, with little input from Papua New Guineans. Corkery (1995) argues that one of the main reasons for the failure of public sector reform is that models derived from developed countries mostly under the sponsorship of the IMF and World Bank are largely irrelevant because, within the more sophisticated institutional practices and procedures, any changes that have been introduced are supported by institutional safety nets which are not available in developing countries like PNG. He went on to argue that the private sector management practices imported in some countries have not always transplanted successfully because the parallel reform of monitoring and review procedures called for by the introduction of these practices is not taking place simultaneously.

Furthermore, blind imitation of western ideas and management practices is one of the reasons cited for failures of administrative reform efforts in the developing countries including PNG. In other words, the impetus for reform in these countries did not come from the host countries themselves but from external sources. No due attention was given to influences of social, political, cultural and religious factors of the society in which the reform was being carried out (Jreisat, 1988, p. 93).

Ruis and van der Walle (2003) say that middle income countries have the resources and drive to push political and economic reform programs when they are deemed necessary. Low income countries would find it difficult to do so since they are often preoccupied with other things that inhibit reform implementation. This point shows a truncated linkage between program design on the one hand and program implementation on the other. Central to this problem is a weak capacity of low-income countries to sustain reform continuity, and it is aptly explained this way:

Because of the combination of low administrative capacity and the absence or weakness of interest groups, the decision-making process in low-income states tends to be closed and non-participatory. Public decision-making is exclusive to a small cadre of public elites, at least within the domestic arena ... Relatively weak administrative capacity prevents low-income governments from fully carrying out their initial reform agenda 
... In the language of this literature, policy is characterised by extensive leakage, capture, unintended consequences and partial implementation (Ruis \& van der Walle, 2003, p. 4).

While the anecdotal evidence is overwhelming about the reasons why reforms have not had the desired effect, the following factors have been identified as recurring within the literature:

- The rapid and high turnover of governments, ministers, and departmental heads since independence, has prevented sustained commitment to major reform initiatives

- Wholesale changes forced by donors with little input from local bureaucrats and furthermore the lack of capacity to maintain and sustain reform programs.

- There was poor coordination between government agencies and lower levels of governments in the provinces. (R J May, 2009).

\subsection{A natural resource economy}

\subsubsection{Economic impacts}

PNG has a small, export-oriented economy dominated by primary production, with the sector comprising agriculture, forestry, fisheries, oil, gas, and mining. Exports are heavily reliant on primary products; minerals constitute roughly $75 \%$ of total exports, agriculture products $20 \%$, and forestry products 5\% (World Bank, 2019c). The agriculture sector includes subsistence agriculture which provides the livelihood for close to $85 \%$ of the population. The resource sector on the other hand, comprises oil, gas, and mining enclave projects which provide limited job and contract opportunities for locals. The resource sector instead provides an important source of revenue for the government (ADB, 2015, p. 1; GoPNG, 2010, p. 11).

The formal sector has been growing, but employs less than $15 \%$ of the working-age population (ADB, 2015, p. 1). According to the ADB about $88 \%$ of the population live in rural areas and depend on the subsistence sector of the economy for their livelihood (ibid). The agricultural potential is high across the country but a complex land tenure system, poor national transport infrastructure, and limited service delivery and credit facilities constrain agricultural production.

Large-scale mining in Papua New Guinea has underpinned the formal economy of the country since independence. The sector has also been the focus of intense high-profile conflicts over 
this period, most notably the civil war on Bougainville (Filer, 2006) and the international litigation over the environmental effects of the Ok Tedi mine (Banks \& Ballard, 1997).

Since independence, real economic growth has reflected prevailing international prices for minerals and petroleum products and to a lesser extent agriculture. In an economic boom the resulting increasing economic growth rates would be reflected in increased expenditures and likewise during a downturn in global economy there would be a low growth rate resulting in a contraction in the local economy. The net effect of highly volatile prices for these export commodities shows that growth rates have been fluctuating but with a consistent downward trend.

Auty and Warhurst (1993) point out that prior to independence (1973-74) and in the years 1979-82 and 1987-89 after independence, PNG managed the commodity booms very well, which they attribute to the slow withdrawal of Australian Aid, the successful renegotiation of the Bougainville copper mine, and the establishment of a mineral stabilization fund to smooth the flows of revenue.

The 1990s was a decade of high economic volatility. Government revenues suffered when Bougainville Copper Limited (BCL), the biggest producer of copper in the country, closed following civil unrest. However, oil discoveries in 1992 and an increase in revenue from other copper mines helped PNG to improve its economic record. But this performance was not sustained. Excessive government expenditure, public borrowing, and inflation resulted in the devaluation and eventual floating of the kina. Further macroeconomic mismanagement caused PNG's economic performance to deteriorate until the early 2000s.

\subsubsection{Role of the state}

There are differing views about the role of the state in the resource sector. Firstly, the state can be viewed as the custodian of public interest, which must regulate the resource industry and balance out the interests of all the parties including those of society. This would entail coming up with the best policies that will attract and maintain foreign investment in the resource industry and at the same time maximising the return to landowners and host communities, both with as little damage to the environment as possible. The state alone can guarantee the security of investment within the resource sector. (Lakau, 1997) 
Secondly, the state can be viewed as a developer and as such will take the lead in investing and developing resource projects. How the state chooses to participate will be dictated by the nature of the project (and its requirement in terms of equipment, skills and expertise), the required capital outlays, and the equity structure of the project. The ownership of naturally occurring resources is best entrusted to the state so that the people are the total beneficiaries and benefits are as fairly distributed as possible. (Lakau, 1997).

Thirdly, the state can play the dual role of a regulator and developer. This would require legislation and policies that balance out the role of the state in every stage of the project development process from negotiation to final production.

\subsubsection{The state, local communities, and land}

Throughout the world the intersecting interests of mining (petroleum) companies and indigenous peoples are woven into complex webs of social, political, and economic relations, which shape development opportunities and constraints for each group (Connell \& Howitt, 1991, p. 1). The role played by MNCs in developing countries is significant to the extent that they determine a country's development trajectory. PNG, like a lot of developing countries around the world, relies on foreign direct investment (FDI). However, the injection of capital and infrastructure into the country may benefit the national economy but may not necessarily benefit the local area where the investment is made. Related to this is the enclaved nature of the mining projects, which have limited forward and backward linkages to the rest of the economy. In effect the wider economy rarely benefits from a mining project because there is limited transfer of technology and expertise. Local employment typically increases during the construction phase, although skilled workers are often imported from outside. The rest of the economy does not participate in the provision of equipment and machinery as most is imported and there is very little down-stream processing.

In fact, there is a line of thinking that the exploitation of national resources has not been beneficial for host communities. There has been "increased marginalis[ation] and disempowerment of local indigenous peoples as a consequence of mining developments [which] has illustrated the difficulty of matching development outcomes to local aspirations" (ibid, pp. 1-2). As argued by Kuwimb: 
In the case of PNG, colonial mining and petroleum legal regimes, which were inherited by the neo-colonial PNG nation state upon political independence from Australia in 1975, extinguish traditional property rights in these resources and enabled the transfer (of) exclusive exploration and production titles to transnational corporations which consequently causes underdevelopment or the resource curse. The resource curse discourse, however, blames the victim in order to obfuscate the devastating effects of capitalist exploitation, unequal exchange, underdevelopment and environmental destruction, thus serving as an ideology protecting the 'free market' as well as public governance practices that protects these exclusive natural resources property regimes that perpetuate the effects of the so called resource curse (2010, p. 10).

The other line of thinking, that resource development is good for economic growth, has been supported by governments of developing countries. This same outlook has been embraced by developed countries like Australia and New Zealand regarding Aborigines and Maori (Connell \& Howitt, 1991, p. 3). In fact, local communities in PNG generally welcome the incursion of large-scale projects because of their expectations about the wealth they will generate. The challenges host communities face include securing "a future consistent with their changing goals, and visions. Mining (and other resources) is an ambivalent phenomenon presenting, on the one hand, opportunities for production of substantial wealth from traditional tribal lands, and on the other hand, threatening destruction of those lands and the social fabric woven from them" (ibid, p. 4).

Anthropological perspectives on the role of the state discussed later in this thesis (from scholars like Colin Filer, James Weiner, Glenn Banks, or Alex Golub) all emphasise two potentially conflicting themes: the fundamental incompatibility of, on the one hand, the state's need to fix and catalogue the identity of its citizens with, on the other, the multiple and shifting selfidentification of those citizens themselves; but the ongoing process of mutual adaptation of citizen and state actors with each other in their ongoing use of power in pursuit of interest.

Writers on Melanesia (e.g. Harris, 2007; or Morgan, 2005) talk about the resistance of traditional authority (big man, chiefly systems) to the hegemony of the national state, the ways in which traditional authority has "colonised" Parliamentary processes and thereby the national state, and the importance, referred to above, of other customary relationships like wantok in political and administrative relations (Bolger et al., 2005; White, 2007). 
At the centre of the state-local conflict is the question of land ownership and access rights. Any exploitation of natural resources requires conversion of land to the purposes of extraction. In the PNG LNG case, it emerges in the social mapping and landholder identification studies designed to determine land use and occupancy rights, which have been influenced by differing world views on how rights to land and natural wealth are created. PNG, like many other developing countries, is then confronted with the issue of conversion of land in customary ownership to freehold title or to forms of leasehold. This is important because a freehold title or leasehold provides the security of tenure needed for long term investments given the long gestation period before returns on investments are realised (ibid, p. 34).

PNG host communities and in particular landowners have had conflict with MNCs and the state over land use and land rights and the compensation associated with them. As in most instances around the world, MNCs in PNG have had very little 'historic connection' with the country and people - but have been supported by governments because of the capital, technology, and opportunities provided (ibid, p. 6).

The villager has experienced the transformation of being a citizen to a 'landowner' with increasing power that can be deployed in negotiations over resource projects. Colin Filer (1997) has documented the emergence of this powerful actor literally in the development process of the country. The balance of power and influence has tended to shift to the landowners away from the state, associated with the devolution of political power to the provinces. The provinces and host communities have been successful in increasing the benefits to the landowners during the resource boom of the 1990s (Ballard, 1997, p. 54).

An important factor in this shift, Ballard argues, has been a diminishing respect amongst local communities for the authority of the state. Other important events which undermined public respect included: the rebellion on Bougainville following the closure of the Panguna mine, which once and for all undermined the state's ability to contain violence and conflict and posed the biggest threat to the country's sovereignty; the Placer Share issue scandal, which greatly eroded public confidence in state actors; and the Mt Kare gold-rush where the state was unable to secure and protect the interests of the state and the developer in the face of landowner claims (ibid, p. 56).

Royalty agreements are a useful indicator of the state's capitulation to the demands by landowning communities: at the Porgera, Misima, and Kutubu projects, agreements yielding 
between $20 \%$ and $30 \%$ of the royalties were renegotiated. Porgera is credited by Glenn Banks with originating the concept of a development forum, eventually enshrined in the Oil and Gas Act 1998, which formalised the negotiations between state and landowner, and later between state, landowner, and developer, on the distribution of benefits from projects. Banks reports that:

Outcomes of development fora have ranged from a series of memoranda of agreement between the national Government, the provincial government and the local community at Porgera ... to a comprehensive integrated benefits package at Lihir that further included compensation and relocation agreements between the company and the community. (2003, p. 224).

Banks also observes that the Porgera negotiations introduced the idea of an equity share for local landowners. At both Porgera and Lihir, "local landowners have argued successfully for an equity stake in the mines at the respective development forum." (Ibid.) Banks asserts that "Papua New Guinea communities want to become involved as a shareholder in the mining operation that will be occurring on their land", which may give them "a sense of project ownership and control, albeit in a limited way", but also that there may be discontent if income doesn't flow from the shares, and that in practice a stake in the venture has been a weak incentive against disruption of project operations. (Ibid, p.231).

Currently, state sovereignty comes to the fore most obviously in Melanesian societies in the debate over resource ownership and competing claims founded upon relationship to land. A clear example identified in a UNDP report is that, although the state constitutionally owns subsoil wealth, "the handing back to landowners of a significant share of the State's royalties derived from mining and oil can be regarded as a de-facto form of recognition of local or shared 'ownership' of the resource" (UNDP, 2015, p. 76). The UNDP report recommends shifting to a formal shared model (although this may create greater uncertainty for developers).

A commentary by Richard Jackson identifies a basic challenge faced by the PNG government:

Does the government have the legal right, and capacity to enforce the exercise of that right, to possess its territorial minerals? Only if the answer is yes is it worth answering questions of optimal mode and size of government investment in mineral projects, planning optimal benefits, integrating mining projects into national budgets and infrastructural planning. 
Clearly if the government's right and ability to hold mineral resources is in doubt, then all these (and many other) issues are academic (Richard Jackson (Discussant) in Denoon et al. (1996), cited in Ballard (1997, p. 57)).

The failure to convert customary land to freehold title is a major source of contention and conflict which is discussed in more detail elsewhere in this thesis. It will however, suffice to point out here that communal ownership does not clearly define ownership over a period of many years, when ownership is passed on from a generation to the next and even then the ownership and rights are governed by complex arrangements. Typically, in traditional societies customary laws were strict. They were also enforceable because land owning groups were small, the costs of cooperation were low, and the probability of being caught for violation were high (ibid. pp. 36-37).

It is now obvious that the traditional land tenure system is not compatible with a capitalist system of organization especially with large multi-national corporations (MNC) who would like security over land leases to conduct their business operations. In other words, mining and petroleum projects require clearly defined ownership rights and user rights for clearly defined periods of time and legally enforceable by legal systems of the state.

The traditional land tenure system and its customary land title, on the other hand, is different: ownership and user rights are vested in households or clans; for various reasons, including increasing population, in-migration and changes in the value of land, these rights are continuously negotiated within the group. In PNG, anthropologists have pointed out that the complexities of Melanesian social organisation have multiplied these problems of reconciling law and custom many times compared to other, simpler, lineal descent systems. Colin Filer argues that even the vague concept of "custom" as embodied in PNG law is not something that existed before local encounters with Europeans and the state, but is in fact a specific construct for a specific purpose - relationships with the state and the other entities it creates, such as capitalist corporations:

Melanesian custom does not really exist in a form which would allow us to ask how it could or should be recognised in modern national law, because it was actually born out of the armpit of Australian colonial law ... In other words, custom needs here to be conceived as something which develops out of law, not something which develops into it. And this is 
simply one aspect of the wider form of "development" through which colonial capitalism develops into something else — whatever that might be. (Filer, 2012, p. 138).

As government and developer found in earlier projects (e.g. the Porgera and Lihir mining and the Kutubu and Hides oil and gas projects), a legal definition of land rights that local groups would regard as fair had to contend with the complex and dynamic local relationships between people and land in the project area and the strong incentives amongst these groups to access the expected project benefits. Most researchers who have studied social relations in these project areas argue that (1) these attempts at finally pinning down land ownership have more or less failed; (2) local groups have adopted adaptive strategies to game the legal framework to secure the biggest possible share of benefits for themselves; (3) these manoeuvres in themselves have created dissension amongst local groups and exacerbated hostile action directly against the projects ${ }^{22}$.

These complexities and their relationship to the legal framework for extractive industries are discussed in greater detail in Chapters 7 and 8 in the context particularly of major projects in the Southern Highlands where the gas fields of the PNG LNG project are located. ${ }^{23}$

\subsubsection{Management of the Economy}

There continue to be challenges that successive governments have not been able to decisively deal with. Firstly, "living within our means": governments since independence have not attempted to cut expenditure despite reforms pushed for by the donor community. There has been more focus in urban areas and very little investment in the agriculture sector where the bulk of the population live to either create new opportunities or maintain cash crop production levels. "The challenge for the government remains to convert higher expenditure into an improved standard of service delivery" (ADB, 2015, p. 2).

Secondly, the lack of capacity within the economic divisions of the public sector has hindered the government's ability to make important economic decisions. This includes collecting

\footnotetext{
22 These arguments are developed in research into the Porgera gold mine project in the late 1980s, brought together in Filer (2012). See particularly the chapters by Filer (2012), Bonnell (2012a; 2012b), and Biersack (2012).

${ }^{23}$ Weiner and Glaskin (2007) also includes chapters discussing how the complex and fluid social organisation of Southern Highlands language groups such as Foi, Huli and Enga (and subdivisions), which facilitate multiple membership of different groups for the purposes of access to land, not only defy the definitive final cataloguing of landowners envisaged by social mapping but also facilitate the adaptive strategies of these groups to gain access to project benefits. See Weiner (2007) and Golub (2007) in that volume.
} 
reliable and quality data. The ADB report says that "despite significant development partner and government capacity building efforts" reliable data is still lacking, which "impedes the government's ability to control expenditures, disburse the budget as approved, and provide essential services" (Ibid).

A consequence of these problems has been a persistent inability of governments to convert ambitious development planning objectives into real improvements in social and economic conditions.

\subsubsection{Fiscal performance}

A basic indicator of a government's performance is to look at the budget and assess its outcome - whether the budget is a deficit or a surplus. The budget is generally expressed as a percentage of GDP which in short reflects its significance to the economy. The PNG budget at this stage reflects a long-term trend showing deficit financing indicating a government's inability to manage its expenditure. There have also been several supplementary budgets that the governments since the 1990s have been resorting to, to address either any "windfall" or major shortfall in revenue. While increase in revenue indicates a growing economy and more money available, any corresponding increases in expenditure can have a negative impact. All deficit budgets must be financed and this will commit future streams of revenue to debt service. Debt repayments will reduce money available for priority areas.

On fiscal sustainability, a Public Expenditure Review and Rationalisation (PERR) ${ }^{24}$ paper suggested in 2003 that:

The root causes of PNG's fiscal malaise lie in poor governance in public finance management. Although most of PNG's budget systems are sound, and by some accounts even sophisticated, poor governance over the years has led to an erosion of budgetary discipline, weakening of accountability and proliferation of waste, leakage, irregularities and malpractices across the board ... tinkering with budget numbers and mandating ad-hoc expenditure cuts, as the Government has tried in the past, can hardly be expected to be effective in such a flawed system. (World Bank, 2003)

\footnotetext{
${ }^{24}$ The Public Expenditure Review and Rationalization (PERR) exercise was "a collaborative effort between the Government of Papua New Guinea (GoPNG) and a multi-donor team led and coordinated by the World Bank."
} 


\subsubsection{Budgets}

Since independence PNG has had a continued growth in public debt, which can be explained in part by the fact that the country is a small open economy highly dependent on primary commodities dictated by global pricing. The heavy dependence of the economy on a few resource based industries has made revenue volatility an issue of concern. On several occasions, the government has had to turn to the donor community for financial bailouts caused by poor fiscal management of the economy.

Since 1976 (one year after independence), deficit budgeting has been part of PNG's budgetary process (Chand, 2002). There are many explanations why PNG has had budget deficits except for 1995 and 1997 (where the World Bank demanded that budget deficits should be reduced to $1 \%$ of GDP as a precondition for the release of loans) (Chand, 2002). PNG also benefited from a commodity boom during this decade. The use of budget deficits is an important macroeconomic management tool that if planned properly can help smooth shortfalls in revenue collection. They are also useful if borrowed money is spent on projects and assets that add value to the economy. (Ibid.)

Deficit financing, fiscal indiscipline, huge recurrent spending, declining internal revenue and a growing public debt continue to plague the PNG economy. The cases of the various liquidity crises which characterised the 1990s and which has persisted until now can be traced to the deficit budgets and its direct relationship with the level of public debt. The debt level has triggered liquidity crises and it has worsened when governments have had problems funding debt roll-over with severe interest rate penalties (Chand, 2002, p. 6).

\subsubsection{Development Plans}

At independence PNG adopted an Eight Point Plan which was meant to guide the country's development. When reviewing the progress against the Eight Point Plan from 1975-2005, a National Summit on Development concluded that:

When we assess our development performance since 1975 against the "Eight Point Plan", it is obvious that we have failed miserably in every one of the eight aims. After three decades of political independence, our rural people still lack the basic services. (PNG IPA, 2008, p. 5) 
There has never been any shortage of plans since this first one. What has been lacking is the ability of various governments to implement them fully and effectively. Take for instance the MDGs (2000-2015) set by the UN for developing countries, which PNG did not achieve. There are also a number of on-going plans that were launched by the government, designed to "accelerate and re-energize the achievement of national development goals", including the "Vision 2050" (2010-2050), the Development Strategic Plan (DSP) (2010-2030) and a rolling Medium-Term Development Plan (MTDP) (2011-2015; 2016-2020).

The question that is being asked is: why are these plans not being fully implemented? Part of the explanation lies in the relationship of development planning to the budget process. Planning was short term, in line with the annual budget cycle. This created the tendency for development outcomes to be dictated by expenditure considerations and by revenue constraints.

The Medium-Term Development Strategy (MTDS) (1997-2002) was the country's first attempt to develop a five-year plan that was linked to the budget, where projects would be funded over a five-year cycle to ensure sustainability and completion. However, the annual budget remained an overriding factor as evidenced by the emphasis on expenditure priorities instead of on development policy priorities (GoPNG, 2010).

The PNGDSP 2010-2030 (GoPNG, 2010) is a developmental guide on how best to utilise scarce resources, thereby focussing development efforts on policy areas with the greatest potential. The 20-year development strategy sets long term goals and targets that will guide development planning and, importantly, will set the priorities for development expenditure. In so doing, it is an attempt to end the dominance of short term, annual budgets over the allocation of resources for longer-term development.

\subsection{Conclusion}

\subsubsection{Major effects of NRD in PNG}

For the past few decades, the PNG economy has been highly dependent on minerals and energy, and its government on resource revenues to finance its budget. Although this relative dependency has reduced in the last few years, it still has a profound effect on PNG's economic management and development, and its politics and governance. 
In the words of the World Bank, NRD in PNG has created a “... broad range of macroeconomic challenges":

These include relatively slow trend growth (particularly in the non-resource sector), commodity-price-induced volatility, procyclical fiscal expenditure combined with limited revenue mobilization, rising debt, a misaligned exchange rate, and a monetary policy framework with limited effectiveness. These are a consequence of the country's prevailing circumstances such as challenging economic geography, resource dependence, natural disaster vulnerability, limited data availability, and low public sector capacity, but they can also be attributed to macroeconomic policymaking that has not always been wellcoordinated, sufficiently risk-mitigating, adequately forward-looking, and wholly consistent with longer-term objectives for the economy. (World Bank, 2018, p. 57).

This dependence on the natural resource sector has also given rise to a number of characteristics of the resource curse.

(1) The Dutch disease has affected the economy through its relative price effects and the government's neglect of the agriculture and manufacturing sectors (there is no diversification policy) and a focus and reliance on the resource sector. "NR rents as a share of GDP have risen from below $30 \%$ in the 1980 s to $40 \%$ or above in some recent years..." (Avalos et al., 2015, p. 315). The manufacturing sector has in fact been in decline over the last 20 years (ibid.). The exchange rate has been affected differently where there has been a shortage of foreign currencies making it difficult for businesses to import goods.

(2) Price volatility has caused problems with the national budget projections, resulting in budget deficits. Further to the various budget deficits has been the rent seeking behaviour of the government and individuals and the distribution of rents.

(3) Most scholars agree about the weak governance that has flowed on to affect the unequal distribution of benefits from the exploitation of resources (ibid.); concerns about the abuse of power and politics of natural resource use (Banks, 2008); patronage behaviour (Teskey, 2013) and widespread and pervasive corruption (ADB, 2012; World Bank, 2018).

(4) A major issue for PNG has been the issues of land rights and sharing of resource rents with local communities which have been ongoing in most major minerals and petroleum projects 
and at times, as in Bougainville, have threatened the very sovereignty of the PNG state itself.

\subsubsection{Explanations for these effects}

\section{Economic characteristics of the sector}

Most writers agree that the economic characteristics of extractive industries are at the heart of many of the effects of NRD. Barma et al note that:

... significant distinctive factors of resource-dependent settings tend to shape political economy context and condition the overall development process in specific ways: in particular, the finite nature of hydrocarbons and minerals; the super-normal profits yielded by extraction of these resources and the state's sovereign right to some portion of those rents; the fact that commodity prices are extremely volatile and, from the perspective of most developing countries, are set exogenously; and the long timeframe of the extraction or production cycle along with the uniqueness of ownership structures in the resource sectors. (2012, p. 14).

Other characteristics are particularly important in PNG:

- The enclaved nature of most extractive industries means that the bulk of equipment and machinery and skilled personnel are brought in from abroad and the extracted commodities are not used in the country but exported. This means that the forward and backward linkages are never fully developed to connect to and benefit the rest of the economy. Most demand for local employment and services is during the construction phase - although they may contribute some technical know-how that can be used elsewhere in the economy - and tapers off rapidly in the operating phase.

- Ownership structure within the extractive industries in PNG is dictated by legislation with the PNG Government allowed to take up $30 \%$ equity in mining and $22.5 \%$ equity in petroleum ventures. The proportion of resource rents accruing to companies (mainly foreign) is because of their equity holdings in the project. A lot of developing countries like PNG rely heavily on capital, proprietary knowledge, and project management expertise of foreign companies for project development which leads to local claims (e.g. Kuwimb, 2010) that a disproportionate share of the benefits of extractive industries are flowing offshore. 


\section{Politics, governance and state capacity}

An extensive literature explores the relationship between NRD, NR rents, and governance. The argument runs both ways: weak governance and low state capacity enables poor management and corrupt use of resource revenues; and the existence of resource rents creates incentives that weaken political accountability and reduce transparency. Barma (2014) has traced these effects to the basic dynamics of the political system in which PNG would be classified as a clientelist rentier state in which rent generation is relatively low and rent distribution benefits client networks.

Explanations of the relationship in PNG emphasize:

- The basic characteristics of the PNG political system: the expectations of local electorates that the job of their MPs is to acquire and distribute benefits locally; the unstable and shifting coalitions in Parliament which leads to an incentive to ruling coalitions to acquire the rewards of office and distribute them to followers as quickly as possible; the incentives for political leaders to use state revenues and the windfall gains from NR rents to finance these patronage relationships which are the foundation of their political support.

- Low state capacity and limited reach of government services in the remote rural areas of PNG which cover about $85 \%$ of the country's population, leaving local services or infrastructure to be supplied by developers in project areas or non-governmental (frequently church-based) services, supplemented by distribution of state funds by local MPs to their followers.

In PNG, because extractive projects are typically in remote rural areas populated by people living in subsistence economies largely under the rule of local custom and beliefs, with a fundamentally different relationship to land and wealth from urban dwellers in the cash economy, this has a profound effect on local communities' relationship to the development (Banks, 2008; Filer \& McIntyre, 2006; Gilberthorpe \& Banks, 2011). An extended definition of "governance" is required to encompass the twin domains of the organised state on the one hand and, on the other, traditional society with its customs and beliefs which most of the people of PNG accept as the prime source of authority for their "rules of the game", in which "citizenship" is a remote concept compared with kastom derived from the affinity relationships of their village and wontok; and the contested boundaries between the two domains. 


\section{Chapter 5 Theoretical Framework}

\subsection{Introduction: purpose of the Chapter}

The purpose of this Chapter is to develop a framework for analysis of the Case, starting from the constructs and explanations in the existing scholarship on NRD in general and in PNG in particular, discussed in Chapters 3 and 4. The theoretical framework is the foundation on which the entire research is based. The literature review was the main basis used in the selection of the theoretical framework which was also guided by my experience within the oil and gas industry and intuition.

The Chapter discusses the political economy approach and the role of institutions; describes the value chain approach reduced to its two main elements of generation and distribution of NR rents; identifies the main actors and institutions in the PNG NRD literature; and concludes by summarising some of the principal influences from agents and institutions (and of agents and institutions on each other) in each of the two major phases of the value chain model, and the implications for analysis of the PNG LNG case.

\subsection{A political economy approach to modelling NR rents}

\subsubsection{Political and social salience of resource rents}

An economic rent is any income received in excess of a normal return in a freely operating market. A rent can arise because of monopoly control of a factor of production such as land or labour, or intellectual property (through a patent, for example); or from property rights in a natural resource such as minerals or energy; or state power to regulate any economic activity (leading either to lawful licensing of the activity or corrupt granting of concessions in return for payment). The defining characteristic of a natural resource rent is that it is the value of wealth that nature has bestowed upon us which we then combine with our own labour, investments, or knowledge.

Because a natural resource is given to us without our own efforts, this leads to specific perceptions. One is the perception that it is free wealth. Socially this leads to claims on the wealth based on right, such as occupancy of the land under which the resource lies, or as a sovereign entitlement. Politically its attractions are that it can be acquired at less political cost and risk than through taxation or other coercive use of state power: revenue from resource rents 
(1) requires less accountability of politicians to the public than revenue from taxation of income, goods and services etc; (2) is a politically inexpensive way of funding patron-client relationships. A further basic consequence is that claims upon shares of resource rents are built on ideas of distributive justice - what is fair or right - and when these claims conflict they must be settled by bargaining, compromise, or force. The institutions of politics, law and custom will play their part.

On issues of distribution of resource rents most writers are using multiple lenses: the economic characteristics of the sector: its production modes and costs and the characteristics of its markets; and the behaviour and incentives of groups (politicians, developers, locals) in influencing the sector, explained with reference to the institutions in which they are embedded. A political economy approach has particular relevance because of the issues of interests and power inherent in allocation of natural resource rents as noted above.

\subsubsection{Basis for political economy analysis}

Political economy: “... all the many activities of cooperation, conflict and negotiation involved in decisions about the use, production and distribution of resources." (Duncan, 2011; quoting Leftwich, 2008).

A political economy framework explains economic behaviour in terms of political, social, economic, and anthropological perspectives. The focus of the political economy involves actors in both the political and economic realms in a country and how they interact with each other over policy options and issues. It is important to differentiate between economics and political economy. Economics as a discipline is distinct from political economy when it draws on purely economic concepts such as markets, prices, and incomes to explain economic behaviour ("an actor's economic behaviour is rational and is aimed at maximizing benefits for himself'). It recognizes the effects of political action (for example, tariffs or taxes) or social conditions (such as ownership of wealth) but does not attempt to explain why they exist. Political economy on the other hand is concerned exactly with why political and social arrangements exist and their relationship to economic phenomena. As such it does not make claims of value-free objectivity and will inevitably discuss the values embedded in these arrangements. 
Types of regimes or political systems enter into political economy analysis to the extent that they determine why certain types of country settings (including historical, socio-economic and cultural contexts) yield certain outcomes (Nazneen Barma et al., 2012, p. 11). The political economy considerations also produce a "filter" through which resource-rich economies can be assessed to see whether they will use their wealth for growth (Collier \& Hoeffler, 2004, p. 639; see also Basedau \& Lay, 2009). Just as politics has rules for interactions between persons and institutions so does economics (market), wherever there is coordination or aggregation of individual interests, preferences, demands, or wants in social life.

Furthermore, the political economy framework: “...goes beyond describing the relationships between economic, political, social and cultural factors and moves towards identifying the incentives to which the stakeholders are responding and determining whether the incentives can be changed to generate different behaviour" (Duncan, 2011, p. 11).

In terms of Duncan's succinct description: political economy aims to properly understand certain political and economic outcomes through study of the underlying factors and incentives. This analysis includes looking at the constraints imposed by institutions, among which Duncan includes (ideally) well-defined and enforced property rights, impartial enforcement of contracts and law and order which are underlying enablers of economic performance (Duncan, 2011).

Ron Duncan and Charles Yala who are both economists have offered a lot of insights into bringing land into formal legal systems of registration. But continuing to offer economic solutions to what are in essence cultural problems fails to recognise, for example, the dynamic relationship between landowners and their land. In other words, the motivation of cultural actors and the institutions they represent cannot be squared off with either political or economic institutions to secure a certain outcome.

\subsubsection{The role of institutions}

"Institutions are the humanly devised constraints that structure human interaction. They are made up of formal constraints (rules, laws, constitutions), informal constraints (norms of behavior, conventions, and self-imposed codes of conduct), and their enforcement characteristics. Together they define the incentive structure of societies and specifically economies." (North, 1993). 
As noted above, economists and political scientists both write about institutions but tend to assume they are, or exist within, the formal institutions of the state. Within that, economists have focused on those values in formal institutions such as property rights and secure contracting, that support the efficient functioning of markets in setting prices and allocating resources. Political scientists tend to focus on the features of state institutions that support and constrain the use of state power. A lot of the writing by both is normative: how to use the framework of public law, regulation, organisation, and finance to better serve the objectives of development, including a just distribution of the benefits of resource exploitation.

From the literature review on PNG it will be evident that the specific context of PNG presents some challenges to the standard theoretical approach of economists and political scientists. The specific factors in PNG writing relating to institutions are:

- Prescriptive writing tends to assume that the correct mix of interventions within the formal framework can secure a just distribution of NR rents. In particular, writing on the value of "transparency" as an input into a just distribution gives little attention to how politicians consider themselves accountable for the distribution of NR rents, what they consider to be a just distribution, and what role better information about government would play in that accountability.

- Anthropologists in particular emphasize the importance of custom in locals' attitudes to property rights, related particularly to the centrality of land and its resources in belief systems.

- In a typology developed by Scott (see below), custom is largely normative or cognitive in origin and may be in tension with the formal institutions of the state.

- There is a mismatch of expectations at the interface between formal law and custom on critical matters such as land "ownership" (in quotes because of differences between written law and custom on what ownership entails) and the local distribution of NR rents.

- Customary processes of managing distributive issues may not solve the problem of a just distribution of NR rents: there is no agreement on what is just, and pressure on traditional authority systems to resolve differences between self- and clan interests on the one hand and definitions of "community" imposed by formal agreements and law on the other. 
- There is little writing on how and whether the two institutions of formal law and custom are adapting to each other and what the mechanisms are for that to occur.

- There is quite a lot of writing about the presence of corruption and patronage in PNG politics but little about the relative importance of customary obligation on the one hand and self-interest on the other in supporting these systems.

- There is not much writing specifically on how and at what stage of NR rent generation and distribution, NR rents are acquired for patronage or personal gain.

These features of PNG institutions lead to some conclusions for political economy modelling of NRD models - consideration of:

- The influences on NR rent generation and distribution of the formal institutions of the state, local custom and belief, and politicians' priorities;

- How politicians directly influence the generation and distribution of NR rents, both formally and informally;

- How politicians' priorities are shaped by both custom and formal law;

- What role custom and formal law have played in local distribution of NR rents.

In political economy, institutions help shape the role and motivations of agents in "cooperation, conflict and negotiation" leading to resource decisions. Institutions in general need to be understood in how they help maintain order and social systems. The neo-classical decisionmaking model suggests that the pursuit of purely rational self-interest by individuals produces stability and social order. The sociologists and anthropologists however point to structural forces that regulate individual behaviour. For PNG, a key question relates to the boundary between formal and traditional institutions and how they affect each other. It leads to questions like whether kastom is "plastic" in the face of the impact of resource extraction on local communities, where for example the architecture of corporations and property rights created under state law meets traditional local beliefs about the nature of land.

The answer to this is both a positive and a negative: March and Olsen (1989) argue that public institutions constitute a social reality, as they have emergent properties which structure and organize social systems and have a life of their own. This will make it difficult for a researcher to determine the outcome as originating from the institution or the individual's interest or 
preference. On the other hand, public institutions cannot be viewed as autonomous actors without looking at interests (individually or collectively). In short, an outcome is not only a function of an individual's interest but also the institution in which it is embedded.

The American sociologist W. Richard Scott notes that "institutions are transported by various carriers - cultures, structures and routines - and they operate at multiple levels of jurisdictions" (Scott, 2001, p. 33). Table 5:1 below shows what Scott refers to but clearly categorises the elements into both formal and informal constraints. The table shows that the regulative elements fall within the formal constraints that can be imposed from an organizational point of view while the normative element covers the informal constraints that would be imposed by social groups. The cognitive elements are developed from both the formal and informal constraints and become a part of the overall pattern of behaviour.

Table 5:1 Institutional Categories

\begin{tabular}{|l|l|l|l|}
\hline Theory Element & Regulative & Normative & Cognitive \\
\hline $\begin{array}{l}\text { Basis of } \\
\text { compliance }\end{array}$ & Experience & Social Obligation & Taken for granted \\
\hline Mechanisms & Coercive & Normative & Mimetic \\
\hline Logic & Instrumentality & Appropriateness & Orthodoxy \\
\hline Indicators & Rules, laws, sanctions & Certification, accreditation & Isomorphism \\
\hline $\begin{array}{l}\text { Basis of } \\
\text { legitimacy }\end{array}$ & Legally sanctioned & Morally governed & $\begin{array}{l}\text { Culturally or } \\
\text { conceptually } \\
\text { supported }\end{array}$ \\
\hline
\end{tabular}

Adapted from Scott (2001, p. 53)

Furthermore, and perhaps very important according to March and Olsen is that "institutions shape individual actors" (1989, p. 35). The new institutionalists put institutions at the heart of their analysis to avoid reducing politics to a by-product of non-political factors. March and Olsen reject the reductionist explanation of contextualizing an organizational phenomenon on social structures or individual actions. It is important to make the point that institutions and actors are mutually constitutive. Furthermore, they state that, at the point of decision, institutions are a given, but also that they evolve over time. Williamson (2000) attempted to include institutions into economic analysis by suggesting timescales for adaptation progressively lengthening from spot markets to time contracts to laws and regulations to underlying deep structures of belief and custom about social relations.

March and Olsen claim that the social systems can only function when participating actors are guided by rules, laws, and norms. In other words, institutions are constraints or enablers of action but (unless we believe that all action is socially constructed) not the only cause. If 
"institutions" explain everything then we cannot for example distinguish between law, custom, love for others, and self-interest. It also means that in order to understand the rationale of a person's action, one would have to look at the rules/norms of the social system. As pointed out by Scott, any institutional arrangement must "consider the processes by which structures, including schemes, rules, norms and routines, become established as authoritative guidelines for social behaviour" (Scott, 2001, p. 48).

PNG has a traditional system of institutions with values that fall under normative and cognitive categories of institutions as explained by Scott. An understanding of these categorised values will also help explain people's behaviour and may also explain why some communities are receptive to economic opportunities while others resist change to their own detriment. This is explained from a cultural perspective while Karl looks at economic and political incentives to explain productive or unproductive outcomes (Karl, 1997).

\subsubsection{Political economy analysis of the case}

The strengths, limitations, and risks of the case study as a subject for analysis are discussed in more detail in Chapter 6. For the purposes of developing the framework for analysis of the PNG LNG case, however, there are two basic phases identified here:

(1) Present the evidence relevant to the case: The choice has been made to present the evidence for the case in the form of a narrative, a sequence of events over time. This is not a necessary preliminary to case analysis in general but it is both a convenient form of organisation and justified because in this case, what went before (e.g. decisions on compensation for local landowners) has a strong influence on what happens after (e.g. determination of how local benefits will be distributed).

(2) Analyse the evidence in terms of the general model of political economy outlined in the previous sections. That is: identify from the narrative the arenas where choices are made affecting the distribution of rents and the institutions and actors in play when those decisions are made, together with the interests of those actors, their power to affect the decisions and the constraints on exercise of that power. 


\subsubsection{A narrative model of production and distribution}

As discussed, the basic purpose of a narrative model is to identify the major events in the Case that relate to the generation and distribution of revenues. The candidates are:

(1) Project investment covering construction and operation of the project and the associated flows of receipts and payments associated with its financing, costs, and revenues.

(2) Government management covering participation in the project, its regulation, and the public sector's revenue and expenses.

(3) Local response covering recognition of the project, experience of social and environmental impacts, group action and conflict resolution on these impacts and access to revenues, provision of labour and other services, and systems for acquisition of NR rents in cash or in kind.

\subsubsection{Project investment}

Figure 5:1: Oil Industry Production Model

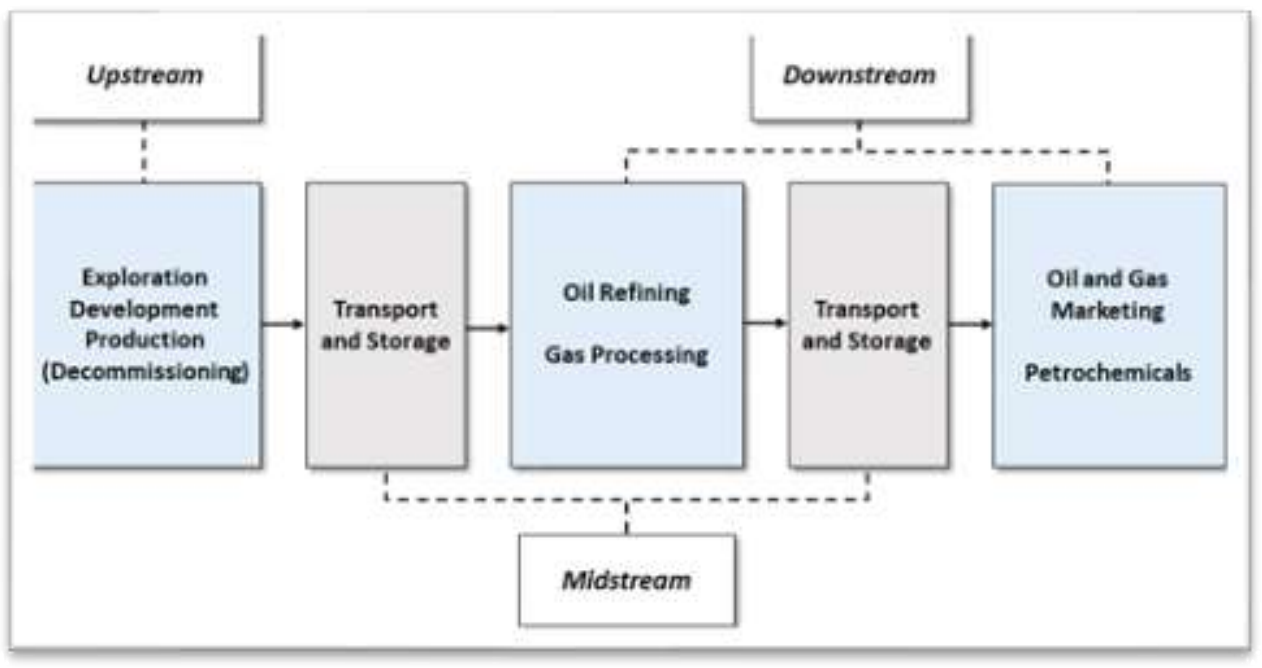

Adapted from Sigam \& Garcia (2012, p. 3)

There are three main stages of the oil and gas industry, illustrated in Figure 5:1 above: upstream, midstream, and downstream. Upstream activities commence with exploration and assessing the feasibility of exploitation and may take anywhere between 3-10 years. If the results of the exploration indicate its commercial viability the development is carried out. This stage would include: major infrastructure facilities such as "roads, the production wells, platforms, production installation, processing and metering equipment, etc." (Sigam \& Garcia, 2012, p. 3). This stage can take between 2-4 years depending on the "peculiarities" of the project. This stage could also amount to between $40 \%-50 \%$ of the total cost of the project (ibid: 
3-4). The production stage is the next stage "which comprises all the activities of commercial extraction of oil and gas from the deposit" (ibid., p. 4). The midstream phase provides the link between the supply side and demand side of the value chain, and includes the activities of storage and transportation of oil, natural gas, and processed products (ibid: 4). The downstream sector covers the refining and processing of hydrocarbons to selling to end users (ibid.).

An alternative approach focuses more on project financing and revenue generation. Gerritsen and MacIntyre identified three distinct phases of resource projects:

(1) Proving and establishing phase: This is the true risk capital phase where the company spends its own money to establish the feasibility of the project.

(2) Construction phase: This is a critical phase where finance is raised on capital markets for the construction.

(3) Operational phase: The focus for the company is revenue generation and the repayment of the loan capital to start realising the profit stream to be reinvested or distributed to the equity partners. (1991, pp. 38-39)

\subsubsection{Government management}

Analysis developed for World Bank publications (Naazneen Barma et al., 2010; Nazneen Barma, 2014; Nazneen Barma et al., 2012; Mayorga Alba, 2009) has been based on identifying the stages of natural resource projects and the policy responses required from the state at each stage.

Figure 5:2 Natural resources "value chain"

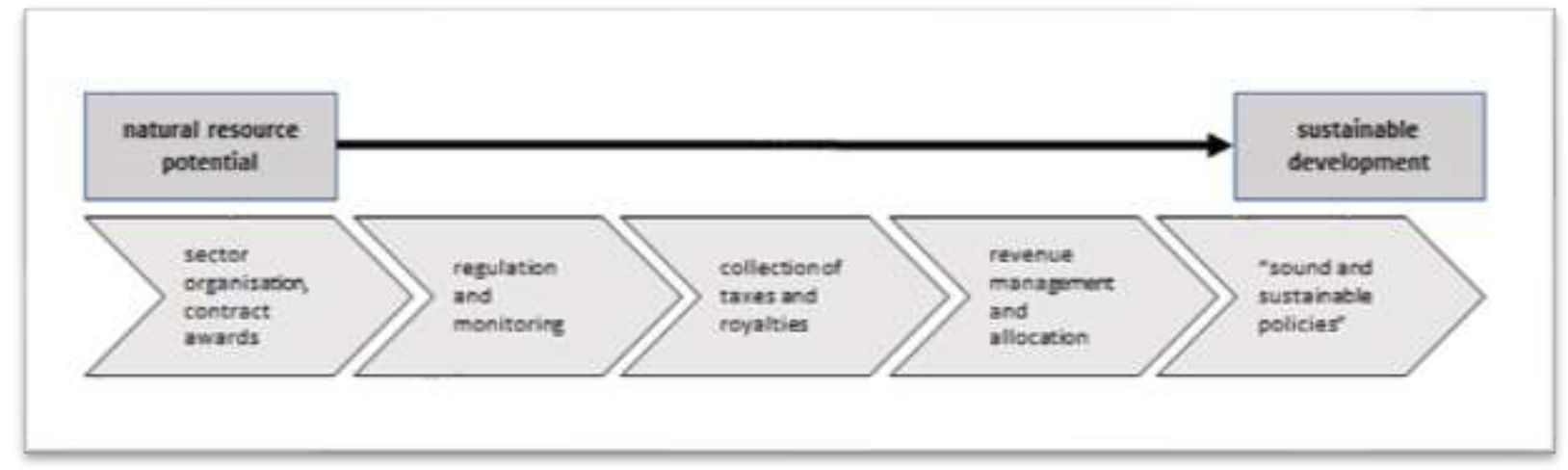

Adapted from Mayorga Alba (2009, p. 9) 
Mayorga-Alba's "value chain" 25 is a linked series of government interventions in the extractive industry aimed at optimising the industry contribution to "sustainable development policies and projects" (Mayorga Alba, 2009). The value chain (illustrated in Figure 5.2 above) has five major links:

(1) Award of contracts and licenses: A government's power to award mining rights or access to land is where it has maximum leverage within legal and institutional frameworks to determine taxes, royalties and other benefits flowing to the state and to other beneficiaries, and to stipulate conditions for mitigation of project environmental and social impacts. “Mining licenses usually establish the investor's obligation to carry out certain activities within a specified period of time (the 'minimum work commitment' or 'minimum expenditure requirements')." ... "In addition, specific time-bound procedures apply for the exploitation of commercial discoveries." (Mayorga Alba, 2009, p. 12)

(2) Regulation and monitoring: regulatory and monitoring regimes (by agencies ideally separated from production interests) to secure or enforce compliance. "Good practice encompasses enforcement of adequate environmental and social regulations as well as the establishment of an independent, competent authority charged with approving and monitoring environmental and social impact assessments and management plans and enforcing compliance".... "Accounting rules and procedures for EI operations and regular audits that meet international standards are also critical”. (Ibid. pp. 14-15)

(3) Collection of taxes and royalties: "Fiscal Regimes" - "accounting and reporting standards have been developed to deal with key financial accounting and reporting issues unique to the extractive industries" ... [it is] "essential to collect and verify data on the volumes produced, consumed, and exported, and on the prices actually realized by the seller" .. "Petroleum contracts and mining agreements usually contain special provisions to regulate inter-company transactions." (Ibid., p 17)

(4) Revenue management and allocation: "Decisions need to be made on how much revenue should be used for current and capital spending priorities and debt reduction, and how much

\footnotetext{
25 "Value chain" generally refers to a series of linked processes that add value to the final output or product.
} 
is to be set aside for revenue stabilization, expenditure smoothing, saving for future generations, or other specific needs.” (Ibid., p. 20)

(5) The objective of these four interventions is "implementation of sustainable development programs": "The actual use of the government revenue in sustainable projects, including capital or recurrent operating and maintenance expenditures, must take place within the framework of the national budget." (Ibid., p. 24)

Barma et al. drew on Mayorga-Alba in simplifying this model (Figure 5:3 below): "In essence, outcomes across the NRM value chain can be reduced to two core rent arenas: generating rents through extraction and taxation and distributing rents through spending and investment" (2012, p. 33). Barma et al. defined the actors who operate within each of these two "arenas". In the first: resource ministries, SOEs, private companies; in the second: sector agencies, public investment contractors, and beneficiaries.

Figure 5:3: Two core rent arenas

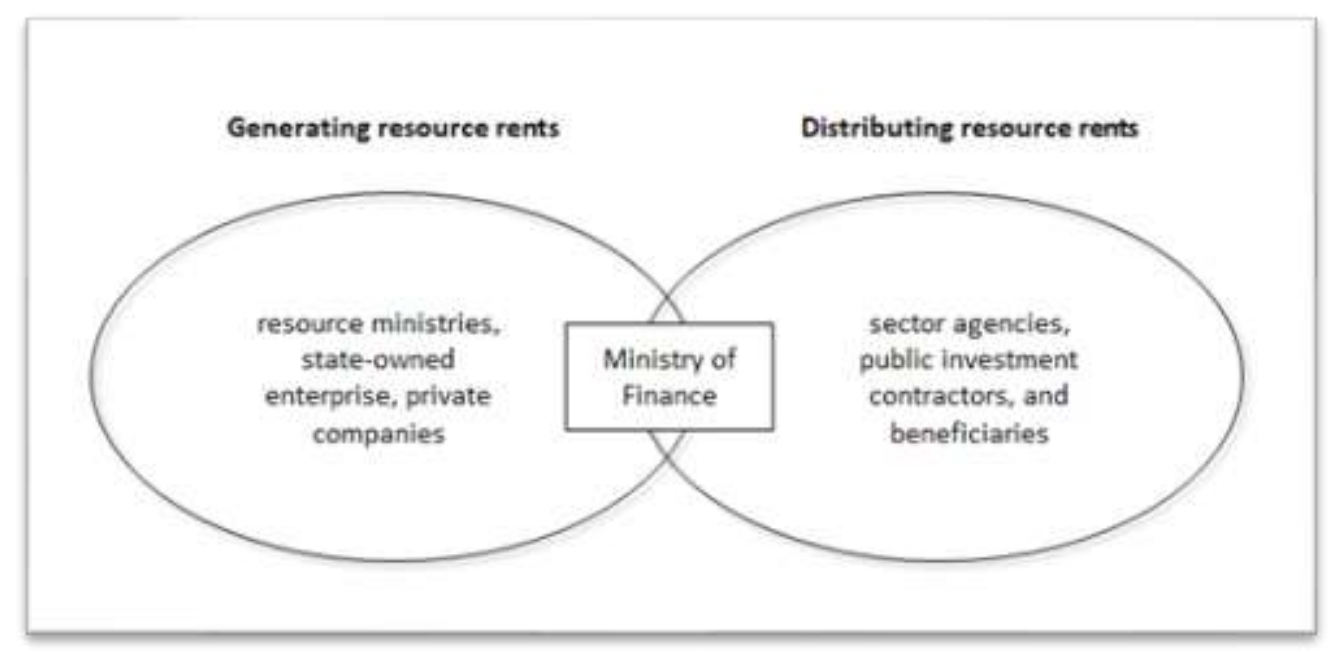

Adapted from Barma et al. (2012,

\subsubsection{Local response}

Communities in the footprint of the project will identify it, form expectations about its impact on them, and strategies of action in response. During the project their expectations will alter according to their experience. The elements of local community response will include:

- There is a recognition about the impact of the project and the various communities are very supportive of the project. 
- There is a recognition about the worth and value of their land and the accompanying tension over land and natural wealth which must be addressed.

- Negotiations over conditions of leases of land for development. The fact that land is communally owned means that a broader consensus must be reached. There are already discussion and formation of Incorporated Land Groups (ILGs) ${ }^{26}$ taking place.

- There is already organizing by communities to position themselves to receive seed capital among other project benefits.

- The high expectations are being tempered by the delay in the release of the various promised benefits and financial assistance.

\subsubsection{Summary Project Phases}

Table 5:2 Phases of Project-Related Processes

\begin{tabular}{|c|c|c|c|}
\hline Project Development & Project Finance & $\begin{array}{l}\text { Government } \\
\text { regulation, taxation } \\
\text { and participation }\end{array}$ & $\begin{array}{l}\text { Landowner } \\
\text { response and } \\
\text { participation }\end{array}$ \\
\hline $\begin{array}{l}\text { Exploration and } \\
\text { Feasibility }\end{array}$ & & Pre-production licensing & $\begin{array}{l}\text { Recognition of } \\
\text { project }\end{array}$ \\
\hline $\begin{array}{l}\text { Project formation } \\
\text { Developer agreement } \\
\text { on capitalisation, } \\
\text { equity, production and } \\
\text { revenue shares } \\
\text { Final engineering } \\
\text { design and construction } \\
\text { cost estimates } \\
\text { Marketing and supply } \\
\text { contracts }\end{array}$ & Equity Capital & $\begin{array}{l}\text { Production licensing } \\
\text { Agreement on } \\
\text { regulatory, royalty and } \\
\text { tax framework } \\
\text { Agreement on } \\
\text { stakeholder shares } \\
\text { State equity } \\
\text { participation } \\
\text { Planning and } \\
\text { government policy for } \\
\text { project impacts }\end{array}$ & $\begin{array}{l}\text { Status resolution } \\
\text { within social } \\
\text { groups } \\
\text { Self-definition and } \\
\text { representation to } \\
\text { government and } \\
\text { company } \\
\text { Negotiations on } \\
\text { compensation and } \\
\text { benefit shares }\end{array}$ \\
\hline Construction & $\begin{array}{l}\text { Borrowing } \\
\text { Capital outlays }\end{array}$ & $\begin{array}{l}\text { Regulation and } \\
\text { monitoring }\end{array}$ & $\begin{array}{l}\text { Response to project } \\
\text { presence }\end{array}$ \\
\hline Operation & $\begin{array}{l}\text { Operating Revenues } \\
\text { Loan Repayments } \\
\text { Dividends }\end{array}$ & $\begin{array}{l}\text { Collection of royalties, } \\
\text { taxation, dividends } \\
\text { Revenue management } \\
\text { and allocation } \\
\text { Review and revision of } \\
\text { economic, social and } \\
\text { fiscal impacts } \\
\text { Learning from project } \\
\text { impacts for future policy }\end{array}$ & $\begin{array}{l}\text { Organising for } \\
\text { benefits } \\
\text { Review of } \\
\text { expectations }\end{array}$ \\
\hline
\end{tabular}

\footnotetext{
${ }^{26}$ See Section 7.4.3 Landowners for discussion of ILGs as a vehicle for acquisition of benefits from a project.
} 
Based on the above, the narrative of the case has been roughly allocated to phases and activities in Table 5:2 above. The phasing is only approximate, and some activities may be initiated earlier or later than, or continued beyond, the period in which they are assumed to start. For example, the local responses of identifying who is entitled to benefits from the project is likely to be revisited and continue well beyond the initial rounds of local discussions.

\subsubsection{Elements of political economy analysis: actors, interests and institutions}

The phased narrative discussed in the previous sections will identify the arenas of activity where choices are made about the generation and distribution of revenues. The analytical step is to identify the influences on those choices of various actors with their interests and the institutions that empower and constrain them.

\subsubsection{Actors}

There are problems with constructing classes of actors as abstractions. Some of the considerations are:

- In a complex major petrochemicals project subject to state regulation and benefit-sharing and with significant local impacts, there are likely to be a multiplicity of actors with some influence, direct or indirect, on the ultimate destination of net revenues. In the various stages of the production model in Figure 5:1, the actors include the companies with equity in the project (multi-national corporations (MNCs) and national and local companies), government agencies and enterprises, local communities (landowners), international and local NGOs, financing/insurance and other service providers, storage/pipeline/shipping companies, trading companies/brokers, independent refineries, and independent marketers. Donors, IFIs and national governments may also have some influence.

- Abstracting, as this analysis has done, to simplified categories such as "developer", "government", and "landowner" reduces the complexity of the relationships within and between these various categories. The management of the development company, for example, is responsible ultimately to the board and shareholders, but must balance the competing claims of government and local communities. The government, as represented by its agencies and officials, is a multi-level organisation with different national and local 
priorities and interests, and is applying policies which are the result of political contest and compromise and subject to direct intervention by the politicians themselves. Local communities are in a constant process of defining and redefining their identity, relationship to the project, and competing claims for access to its benefits.

The point of a case is to bring out this richness and complexity of relationships that may be lost in a more reductionist analysis. So, while the following discussion, and the case itself, begin with the simple categories of "developer", "government", and "local community", much of it will be concerned with the complexities and interrelationships between them, and identifying additional actors who may be important influences in the generation and distribution of revenues.

\section{Developer}

The term "developers" stands in here for the corporate entities, together with their shareholders, governing boards, and management, and project financiers and bankers that have an equity stake in the development of the project. They may include state corporations but in the context of PNG are likely to be subsidiaries of transnational corporations. They are perhaps the most important stakeholder in terms of their power and influence in the developing country context.

Developers are presumed to be governed primarily by what Gerritsen and MacIntyre called the "capital logic" at the core of their hypothesis "... that the social, political and economic impacts of mining are principally about the distribution and redistribution of benefits. ... The "capital logic' of a mining project is moulded by its financial flows. The source of the money, the timing for repayment of loans, the need to make a profit, all force a particular negotiating outcome and timetable and as a consequence provide a characteristically 'legalistic' regime that encourages deferred dissatisfactions among local people”. (1991, pp. 36-37)

\section{Government: law, organisation, and politics}

Government is both the institution of the powers of the state and the actors who currently hold those powers. Government is formally organised into political governance (Cabinet and individual Ministers and MPs) and agency administration, although the distinction between politics and administration is never that clear-cut. For the purposes of analysis, the exercise of state power by government needs to be understood in terms of both the political interests of its actors as well as the formal laws and regulations by which state power is defined. 
As already stated in Chapter 4, the state is a creation of the colonial administration and continues to exhibit a lot of the characteristics of the colonial administration. In the case of PNG, it does not matter who comes to power - the state apparatus will shape and influence how they operate. Within the context of resource rich countries, governments "face mounting pressures to manage this resource wealth effectively, and to do so in a manner that meets the often high expectations of a combination of local, national, and international stakeholders." (Desai \& Jarvis, 2012, p. 2). This would require: "effective leadership; appropriate economic, financial, social, environmental and technical capacity; sufficient institutional strength and depth; and effective management of these expectations." (ibid). It is fair to state that the state at least in PNG has not been able to meet the expectations of all the categories of the stakeholders, since independence. While the PNG state machinery through the bureaucracy has survived governments, a lot of governments have also not sustained the reforms that were undertaken and strengthened important institutions to ensure proper governance was in place.

In the analysis, therefore, the tasks and capacities of the government agencies involved in the generation and distribution of rents are important. The PNG agencies involved are described in detail in the case analysis. Following Barma's typology in Figure 5:3, they include:

- Those which affect the generation of resource rents, including agencies holding the government's equity stake in the project: Kumul Petroleum Holdings Limited (KPHL), and the Mineral Resources Development Corporation (MRDC), which also has an equity holding in the project and is the designated company representing the landowners. Other agencies include the Internal Revenue Commission (IRC), collecting corporate and personal income taxes, the Central Bank, the Department of Petroleum and the Department of Treasury.

- Those affecting the distribution of resource rents, including: Department of National Planning and Monitoring responsible for tax credit schemes, Department of Commerce and Industry who are responsible for distributing seed capital to landowner companies, Department of Provincial Affairs and Lower Level Government responsible for distributing grants to local level governments (LLG), MRDC distributing royalties to landowner groups (including ILGs), community obligations and projects, contractors and landowner companies and beneficiaries. 


\section{Local community}

The term "local community" is shorthand in this case for people in the footprint of the project. In the case of PNG, where most in this footprint live in small rural villages with little direct influence of the formal world of government (gavman), it is assumed that their relationships with each other are mainly customary. As defined by the anthropologists (e.g. Filer, 2008; Gilberthorpe \& Banks, 2011), these relationships include kinship (by descent or marriage), wontok, or perhaps just proximity. But the anthropologists emphasize that these relationships are fluid and have a history to them. It would certainly include everybody claiming to have a spiritual or customary relationship to the land within the project footprint. This sub-group is frequently called "landowners", but they are not necessarily the same as the legal definition of landowners or project-affected people as formally defined in the legal framework for the project. Their interests are generally assumed to be defined by their culture and beliefs regarding the land and their status relating to it.

In the case of PNG, there is a dual economy: a subsistence economy supporting about $85 \%$ of the population and cash-based economy supporting the urban dwellers and those living and working on the plantations and enclave projects. Here the politics affects people differently: those living under the subsistence sector use it during elections to voice their concerns and demand for goods and services - but do not sustain their demands. Those who rely on the cash economy tend to use politics and its institutions more to influence economic outcomes.

The forms of leadership in PNG are either hereditary which is the chieftainship system or through the merit-based system commonly referred to as the big man model. The big man model is a form of patronage system where the leader is expected to provide for his people. As pointed out by Finney:

In traditional society a man became known as a big-man because of his deeds. Being a skilful warrior, a forceful orator, an expert in ritual, or a wealthy man and financier of wealth exchanges were the main accomplishments that brought an ambitious New Guinean renown and a political following. The system was open and fluid ... men become known as leaders because of their skills and their ability to use these to create ranks of followers. ... An especially strong and forceful man might achieve dominance over the others, but his influence, like that of lesser big-men, was always transitory (1973, p. 39). 
The modern political and bureaucratic systems provided the ultimate prize for a prospecting individual who wanted to become a leader and in most cases was supported by a father who was a big-man or by a clan. The gavman became the vehicle through which goods (cargos) could be accumulated and distributed to the tribe (Standish, 1994, p. 80). A manifested outcome of this (use of public office for personal or tribal gain) or where cronyism or corrupt practices become the norm (such as awarding of contracts to relatives) tends to be mutually reinforcing.

In the case of the extractive industry the form of patronage is played out when an individual is elected as the chairperson of the special purpose authority (SPA) or chairman of the ILG and the financial benefits are used to remain in power with little accountability and transparency.

In reviewing past resource projects, there appears to be a pattern confirming the people's attachment to their land. As pointed out in the case of the Bougainville Copper Mine:

Land is our life. Land is our physical life - food and sustenance. Land is our social life; it is marriage; it is status; it is security; it is politics; in fact, it is our only world. When you (the administration) take our land, you cut away the very heart of our existence. We have little or no experience of social survival detached from the land. For us to be completely landless is a nightmare which no dollar in the pocket or dollar in the bank will allay; we are a threatened people. (Dove et al., 1974, p. 182; cited in Connell, 1992)

\subsubsection{Some principal relationships and arenas in the sector}

The following discussion outlines some of the principal relationships identified in the literature review and then gives examples of some of the arenas where they might come together.

\section{Patron-client relationships}

The patron-client relationship is a major feature of a lot of developing countries and warrants some mention under the political component of the political economy framework. Operating at the micro-level of the political economy a patronage system provides the basis on which one can understand the dynamic relationships that exists within bureaucracies of developing countries. Patron-client relationships posit that the position one holds in the bureaucracy is dependent on one's followers or network in a complex set of dependent relationships. In other words, there are personal alliances within national institutions that are not easily observable but are elaborately disguised by the formal facades of modern institutions (Scott 1972, p. 92). In a resource rich country like PNG, those who are in power tend to use resource rents to stay 
in power by controlling the general population and suppressing any opposition to their rule. There has been little study done to understand the role of the patronage-client relationship in PNG but elements of it are at work and have been described by Duncan and Hassall (2011). Furthermore, corrupt practices abound when there are dysfunctional systems, weak institutions and when powerful groups and individuals break laws with impunity. The patron-client framework captures the network of relationships that are in most cases cultural in nature.

Duncan and Hassall outlined the main features of the patron-client model which include:

- There is an emphasis on targeted transfers to voter groups then the provision of public service.

- There is little interest by politicians in developing a reputation for policy making because of the difficulty of making credible promises.

- There is little interest by politicians in establishing secure property rights and impartial contract enforcements ... as doing so undermines the incumbent's ability to create rents and distribute targeted transfers.

- There is little interest in making the bureaucracy more efficient as this also undermines the politician's ability to deliver rents to their voters.

- There is little interest in establishing good controls over the expenditure of revenues from the exploitation of natural resources as again this undermines "rent seizure and rent distribution" (2011, pp. 266-267).

The ease by which revenue is collected from the resource sector, and when the citizenry is paying very low taxes, enables resource rich governments to avoid scrutiny and accountability. Spending priorities are formed and executed through a patronage network - where the patron allocates to targeted groups and the clientele in turn support the patron (Allen \& Hasnain, 2010).

\section{Corruption and development}

The corruption theme within the resource sector of PNG has been used to explain why host communities have failed to resolve land and royalty disputes, and non-payment of royalty benefits and non-prosecution of politicians and public servants misappropriating resources among other practices (Burton, 2017; Haley \& May, 2007b);. Further, the lack of development 
within the resource communities has been attributed to corruption, blamed on the lack of cooperation between politicians and public servants at the national and local levels and the general inability of the leaders to deal with lawlessness that has arisen as a result of the resource project (Haley \& May, 2007b, p. 13). There has also been a lack of accountability by provinces with the use of grants and royalties (ibid).

\section{Developer and state}

Gerritsen and MacIntyre suggest that governments are constrained by the "decision-making (sic) process engendered by the 'capitalist logic' of each mine's implementation timetable. ... (I)t is the imperatives of implementation, not economic greed or political ill-will, that make governments steamroller the villages" (Dove et al., 1974, p. 181). The capitalist logic as described by Gerritsen and MacIntyre stands in contrast to an earlier interpretation of the Bougainville copper mine events which states that:

The administration's actions gave a lie to its role as a protector of the people's rights and interests. It was all too clear that economic expediency was uppermost in its thinking. The welfare of the people was accorded mere token consideration (Dove et al., 1974, p. 181; cited in Gerritsen \& McIntyre, 1991, p. 37).

These writers suggest that Bougainville was a case of state capture. State capture commonly refers to the extent to which government policy making is unduly influenced by a narrow set of interest groups in the economy who provide private benefits to politicians (Hellman et al., 2000, p. 117). On account of the scale of malfeasance, state capture is a good fit for PNG. Companies have so successfully corrupted officials in the relevant ministries/departments with corrupt practices ranging from bribery to collusion and then sharing the spoils with politicians and senior public officials. But perhaps a worrying trend is where the public policy is being captured by powerful actors within the industry (such as in forestry, health - a few big pharmacy companies, fisheries, insurance, and the petroleum sector). The lack of capacity in a lot of the sectors to regulate and police has meant whole sectors have fallen victim to regulatory capture.

\section{Developer and landowner}

The relationship between developer and landowner is assumed to evolve during the development of the project, with three main phases: 
(1) Proving and establishing phase: The politics of this phase involves selling and convincing the villagers about the project. Unrealistic expectations of the various beneficiary groups are also created, and realistic fears are removed.

(2) Construction phase: There is a sense of urgency to operate within the time frame guided by the borrowed finance. The politics for this phase is to ensure cooperation between the government and company and minimise any negative views. There is an understanding by landowners about the potential winners and losers and the scale of environmental damage.

(3) Operational phase: The politics of this phase is characterised by distributional disputes: between local villagers themselves, between villagers and the company or government and between the different levels of government.

These three phases are important to note and understand as the developer's position will reflect the various phases of the project. The project is very sensitive to tax rates, exchange rates and interest rates especially during the construction and operational phases (Gerritsen \& McIntyre, 1991, pp. 39-40).

\section{Compensation}

In all the resource projects in PNG, an integral element of the resource agreements has been the compensation arrangements between the resource developers and the landowners. No compensation will ever adequately pay for the loss of land, environmental degradation, and to a significant extent the livelihood of the impacted people.

Connell (1992) goes on to point out that the landowners who had their land taken up by the BCL project from the mine pits to infrastructures (such as roads, bridges, power pylons and the township) were being paid different rates and on an ad hoc basis. In effect the compensation did not adequately cater for the different categories of claimants. Connell further points out that "... the structure of compensation payments became more complex than either the administration or BCL could ever have anticipated, and it was never able to respond adequately to landowners' concerns and demands" (1992, p. 38).

The underlying perception of compensation by villagers, not only in the North Solomons province but throughout the country, is that the extractive industry is very pervasive and harmful especially to the environment. As aptly pointed out by Jackson (1982): 
Most interested parties are going to get something from the Ok Tedi project. The one group over whom there remains serious doubts are the local people, that is, the people whose daily lives will be directly affected by the project. It is just possible that things could get worse for such local people, but that is difficult to credit for anyone who has seen conditions in Kiunga area over the past decade. But whilst material standards of life will almost certainly increase, there will certainly be a loss of traditional ways and values. The extent to which material standards improve will depend very much upon the willingness of the company, the provincial government and the national government in matters such as training, the allocation of land in the urban areas, the awarding of contracts and the provision of social infrastructure, to encourage local participation (1982, p. 178).

As is the case with all the projects in the country there is a demand by provincial governments and host communities for local people to be given preferences in employment and local business opportunities. The problem continues to be the low level of educated and skilled people from the neighbouring communities. It does not make commercial sense to employ unskilled workers and engage local companies in high tech industries.

\section{State and landowner}

The role of the state in development for the traditional and rural communities remains critical to maintain its authority and legitimacy. An understanding of the host communities of resource projects is important to analysing their relationship with the state and the developers and other communities within the province. The state may not have a visible presence in rural communities or pockets of urban settlements and may not comprehend themselves as citizens but will certainly identify themselves as part of sub-national or local groups (tribal or ethnic). The main underlying issue then is the limited presence and authority of the state in most of the communities affected by the project. To quote Ballard and Banks:

The material evidence of a state's presence has proved to be critical in Papua New Guinea, as elsewhere; a state that delivers services to the village, such as education, health, justice, security, and development, will usually find its claims to authority and legitimacy (and thus its claims to mineral ownership) respected, although not necessarily uncontested. Where state capacity to deliver these services is limited (through political or economic constraints), communities are likely to be more inclined to have less regard for the authority and claims of the state (Ballard \& Banks, 2003, p. 296). 
The boundary between traditional and civil society is therefore fluid (and contested). There is an important question of "incorporation" - the efforts of the state to bring traditional society into the institutions and under the control of the state - which in turn depends on the legitimacy of the state as perceived by the communities affected.

\subsubsection{Arenas and actors}

Mechanisms for generation of rents can be brought together with actors and their interests and institutions to define arenas for determining outcomes in terms of distribution. In terms of the Mayorga-Alba "value chain" some of these critical arenas are defined below.

- "Rights to extract the resource and to the land required for the project are secured": Actors may include the project developers, state agencies such as Ministries of Mines and Energy charged with negotiating resource licences, local landowners and other projectaffected people, social and environmental agencies charged with advising on impacts on project-affected people, Ministers and local Members of Parliament, and civil society and NGOs advocating on social and environmental impacts. Actors' capacity and power to influence negotiations of these rights is important. The relevant institutions may include state law on extractive industries, contracts and contract law, and landowner rights; CSR requirements of project developers (including membership of EITI for example); local peoples' customs and beliefs about land and the natural environment; and networks (formal or otherwise) of local and national political interests.

- "Finance is arranged to fund the required investment": Actors include project developers and their shareholders, commercial banks directly lending to the project entity or its owners, or financing the stakes to be held by the state or local interests, international aid agencies or multilateral financial organisations advising on or financing the state interest. Institutions would include loan agreements and their stipulations affecting project organisation; conditionality imposed on state borrowers by aid agencies and IFIs. Again, capacity of actors to negotiate is important.

- "The net revenues from the project entity begin to flow as dividends to shareholders, compensation for project-affected people, and royalties and tax for the state": Actors include the project entity, various beneficiary groups, national and local political interests, state "watchdog" organisations, media and NGOs. Important institutional elements are the 
formal regulations and agreements for reporting of payments by the project and receipts by beneficiary groups and the "recipient" state organisations (managing the public accounts or specific funds such as the Sovereign Wealth Fund (SWF) discussed later in this thesis), and the laws on public finance and taxation. The capacity of state agencies (Ministries of Finance, State Auditor), Parliament, and their local and international agents to monitor formal payments and receipts and to detect informal (probably illegal) transfers is important.

- "State expenditures adding to public investment or services may be affected by actual or expected revenues from the project." Key actors are Ministries of Finance in their accounting and budgeting roles, Ministers, local politicians and their influence networks, and watchdog organisations. Important institutions again include public finance and planning law and regulations and commitments on reporting plans and budgets. (NB - there is always a problem connecting changes in particular public expenditures to changes in specific revenue sources because of the "fungibility" problem in public budgeting, in which an increase in funds from one source such as resource royalties or foreign aid formally intended to be applied to a specific area of the public budget may result in a diversion of other funds to other public spending).

\subsection{Conclusion: implications for analysis of the PNG LNG case}

The approach to analysis outlined here is developed in Chapters 7-10, covering the specific actors, institutions and processes at the inception of the PNG LNG project, the narrative of its development and implementation, and an analysis of the roles of the main actors and institutions. Specific implications include:

- The definition of the time boundaries of the case: they should cover the major phases of project development as outlined in Table 5:2 above. The case in this sense is not "closed".

- The definition in Chapter 7 of:

o The pre-existing institutions shaping behaviour: since part of the study is how these institutions - formal and traditional - developed over the course of the project, a clear baseline is important. 
o The main groups of actors - developer, state and local communities - that are specific to the project and its footprint. Again, the definition of these groups may change over the course of the narrative - local groups particularly but also state agencies coming into the areas - but a baseline is important here too.

- As far as possible - although some of the relationships will emerge and evolve during the narrative - the link between the two at the outset: the institutions within which the actors and their power and interests are embedded.

- In the analysis, the actual actors are mapped into the categories proposed in the analysis model: there is some confidence from the literature review that the three main constructs can stand for the principal actors and their interests but the evidence may reveal that others were important, or that there are other groupings within these categories that have influence.

- Similarly, in the analysis, the principal motivations of the main actors will be drawn out as far as possible but it may be that as these are complex (e.g. the competing pressures on local leaders in regard to access to benefits and the ongoing contested relationship between the main actors) they do not fit simply into the scheme proposed in this Chapter.

- Finally, the literature review provided some propositions about the influences on revenue distribution from extractive industries in resource dependent economies. These propositions are shown in Table 5:3 below. A summary analysis in Chapter 11 relates the case study evidence to the propositions. 
Table 5:3 Propositions about impacts of resource dependence in PNG

1. Minerals and petroleum projects are largely enclaved: they have few linkages to other sectors of the economy and generate few longer-term employment opportunities; they thus contribute little directly to broader-based development.

2. Economic, financial and fiscal management have all been dominated by the requirement to respond to the effects of volatility of prices for exports of minerals and petroleum products.

3. The expectation of significant windfall revenue gains from new extractive industry projects will result in governments pre-committing those revenues to new public expenditure projects.

4. For short-term political reasons, government budgeting has tended to over-commit to new spending during the commodity booms and be forced in the downswings into cutbacks damaging to public services and investment or to rapid increases in broadly defined public debt.

5. Politics, both national and local, has been dominated by the struggle for resource rents, grievances about their distribution, and moral hazard from opportunities for corrupt access.

6. Local customary relationships have influenced the national politics of resource rent distribution and conversely have been put under pressure locally and fractured by contestation over project impacts and access to benefits.

7. International investors have exported a disproportionate share of the profits from their projects, have left behind significant negative environmental impacts, and have done little to ensure sustainable benefits for the local stakeholders.

8. Transparency: accountability for benefit sharing from major extractive industry projects will be improved by transparency about project agreements and planned and actual payments from the project to stakeholders. 


\section{Chapter 6 Methodology and Evidence Gathering}

This chapter details the methodology employed and how evidence was collected for this research. The chapter is divided into three parts: The first part gives the philosophical basis of undertaking the research, followed by how the evidence was collected. The last part details how the evidence was organized and presented in the case study.

\subsection{Research paradigms}

"Paradigms are universally recognized scientific achievements that for a time provide model problems and solutions to a community of practitioners" (Kuhn, 1970, p. viii; in Collis \& Hussey, 2009, p. 55).

The objective of the research is to form some useful theories about the specific events and context of the PNG LNG project. This section discusses the paradigms underpinning the methods and findings of this research that lead to the theories and concepts that the research employs. Within a paradigm, research draws on theory to produce a model or map of why the world is the way it is (Strauss, 1987; in Maxwell, 2013, p. 49). "A useful theory is one that tells an enlightening story about some phenomenon, one that gives you new insights and broadens your understanding of that phenomenon.” (Maxwell, 2013, p. 49)

Kuhn also described a paradigm as "the entire constellation of beliefs, values, techniques, and so on shared by the members of a given community" (1970, p. 175; in Maxwell, 2013, p. 42). At the most abstract and general level, examples of "such paradigms are philosophical positions such as positivism, constructivism, realism, pragmatism, and post modernism, each embodying very different ideas about reality (ontology) and how we can gain knowledge of it (epistemology)" (Maxwell, 2013, p. 42). At a more specific level, paradigms that are relevant to qualitative research include interpretivism, critical theory and phenomenology (ibid).

In line with Kuhn's definition, the research paradigm is relevant at three different levels:

(1) At the philosophical level, where the term is used to reflect basic beliefs about the world.

(2) At the social level, where the term is used to provide guidelines about how the researcher should conduct his or her endeavours. 
(3) At the technical level, where the term is used to specify the methods and techniques that ideally should be adopted when conducting research. (Collis \& Hussey, 2009, p. 58)

\subsubsection{Positivism and interpretivism: two main paradigms}

Table 6:1 outlines the assumptions of the two paradigms of positivism and interpretivism.

Table 6:1 Assumptions of the paradigms

\begin{tabular}{|l|l|l|}
\hline Philosophical assumptions & Positivism & Interpretivism \\
\hline $\begin{array}{l}\text { Ontological assumption (the } \\
\text { nature of reality }\end{array}$ & $\begin{array}{l}\text { Reality is objective and } \\
\text { singular, separate from the } \\
\text { researcher }\end{array}$ & $\begin{array}{l}\text { Reality is subjective and multiple } \\
\text { as seen by the participants }\end{array}$ \\
\hline $\begin{array}{l}\text { Epistemological assumption } \\
\text { (what constitutes valid } \\
\text { knowledge) }\end{array}$ & $\begin{array}{l}\text { Researcher is independent of } \\
\text { that being researched }\end{array}$ & $\begin{array}{l}\text { Researcher interacts with that } \\
\text { being researched }\end{array}$ \\
\hline $\begin{array}{l}\text { Axiological assumptions } \\
\text { (the role of values) }\end{array}$ & $\begin{array}{l}\text { Research is value free and } \\
\text { unbiased }\end{array}$ & $\begin{array}{l}\text { Researcher acknowledges that the } \\
\text { research is value-laden and biases } \\
\text { are present }\end{array}$ \\
\hline $\begin{array}{l}\text { Rhetorical assumption (the } \\
\text { language of research) }\end{array}$ & $\begin{array}{l}\text { Researcher writes in a formal } \\
\text { style and uses a passive voice, } \\
\text { accepted quantitative words, } \\
\text { and set definitions }\end{array}$ & $\begin{array}{l}\text { Researcher writes in an informal } \\
\text { style and uses personal voice, } \\
\text { accepted qualitative terms, and } \\
\text { limited definitions }\end{array}$ \\
\hline $\begin{array}{l}\text { Methodological assumption } \\
\text { the process of research) }\end{array}$ & $\begin{array}{l}\text { Process is deductive } \\
\text { Study of cause and effect with } \\
\text { a static design (categories are } \\
\text { isolated beforehand) } \\
\text { Research is context free } \\
\text { Generalizations lead to } \\
\text { prediction, explanation, and } \\
\text { understanding } \\
\text { Results are accurate and } \\
\text { reliable through validity and } \\
\text { reliability }\end{array}$ & $\begin{array}{l}\text { Process is inductive } \\
\text { study of shaping factors } \\
\text { simultaneously with an emerging } \\
\text { design (categories are identified } \\
\text { during the process) } \\
\text { Research is context bound } \\
\text { Patterns and/or theories are } \\
\text { developed for understanding } \\
\text { Findings are accurate and reliable } \\
\text { through verification }\end{array}$ \\
\hline
\end{tabular}

(Adapted from Creswell, 1994, 1998; Collis \& Hussey, 2009)

Positivism is underpinned by the belief that reality is independent of us and the goal is the discovery of theories based on empirical research (observation and experiment). Under positivism, logical reasoning must be precise: there must be objectivity and rigour when undertaking research, rather than subjectivity and an intuitive approach. Since positivists believe reality is independent of us, they assume that the act of investigating social reality has no effect on reality (Creswell, 1994).

Under positivism, "theories provide the basis of explanation, permit the anticipation of phenomena, predict their occurrence and therefore allow them to be controlled. Explanations consists of establishing causal relationships between variables by establishing causal laws and linking them to a deductive or integrated theory" (Collis \& Hussey, 2009, p. 56). 
Interpretivism as a paradigm emerged in response to criticism of positivism (Collis \& Hussey, 2009). Interpretivism is underpinned by the belief that social reality is not objective but highly subjective because it is shaped by our perceptions. The researcher interacts with the people being researched because it is impossible to separate what exists in the social world from what is in the researcher's mind (Creswell, 1994). Interpretivists, therefore, adopt a range of methods that "seek to describe, translate and otherwise come to terms with the meaning, not the frequency of certain more or less naturally occurring phenomena in the social world" (Van Maanen, 1983, p. 9; in Collis \& Hussey, 2009, p. 57).

\subsection{Linking the paradigm and methodology}

It is important to be guided by the chosen paradigm in selecting a methodology to be used in the research. A methodology is an approach undertaken by the research which covers a number of methods. Method refers to a technique for collecting and then analysing data (Collis \& Hussey, 2009, p. 73). In attempting to find a stronger rationale for the selection of methodology, knowing that a methodology will not comprehensively cover the phenomenon being investigated, a case study methodology was selected. While there are many methodologies under both paradigms, the following methodologies, discussed briefly below, fall under the interpretivism paradigm.

\subsubsection{Hermeneutics}

Hermeneutics is a methodology that focusses on the interpretation and explanation of text within the context of the underlying historical and social forces. This methodology will be advantageous for those seeking to give an historical account of what happened in the past and to link it to the present as an explanation to a current context. According to Lindlof, "( $\mathrm{t}$ )he method can be applied to any situation in which one wants to recover historical meaning" (1995, p. 31; in Collis \& Hussey, 2009, p. 79).

\subsubsection{Ethnography}

Ethnography is a methodology borrowed from the field of anthropology, which is the study of human society with their cultures and requires the researcher to immerse oneself in a community to observe and understand the pattern of human activity and behaviour (Boyle, 1994, p. 183). Fundamental to this approach is the idea that in order to interpret the social world in the same manner as those in the community, one is required to live within the community 
and be a participant observant to collect data of the group being studied (Boyle, 1994). While this methodology is perhaps a good approach for studying a community, it lacks the methods to undertake a public policy-based study.

\subsubsection{Grounded theory}

Grounded theory is a methodology which uses a systematic set of procedures to develop an inductive theory about a phenomenon. "The methodology does not depend on priori theories, but uses the data generated by the phenomena being studied to generate a theory" (Collis \& Hussey, 2009, p. 84). Aspects of the grounded theory were being used in the case study.

\subsubsection{Inductive Process}

Inductive research is typically associated with qualitative research. It involves exploration of a subject to find more information as less is known about it. This initially requires the collection of data, followed by analyses and theorisation or answering a question raised in the research. However, as stated above, in qualitative research, literature reviews are important to demonstrate familiarization with the subject and articulating the research issues, including prior propositions about field of study to be tested by the case.

A review of literature is important when investigating the distribution of and influences on financial benefits and the impact of transparency within the natural resource sector, because it is an expanding field of study with some strong propositions about resource dependence. This case study will explore any variable(s) of interest, and rely on multiple sources of evidence and prior development of theoretical propositions to guide data collection and analysis.

\subsubsection{Case Study}

A case study is a methodology that is used to investigate and research a single phenomenon in its natural context, using a variety or combination of methods to obtain in-depth knowledge (Collis \& Hussey, 2009). Case study research has become one of the most popular strategies of qualitative inquiry (Stake, 2000, p. 435). Yin (2009) is the well-known advocate of this methodology, although other proponents include Stake (2000, 2006) and Gillham (2000). 


\subsection{Use of case method in the research}

\subsubsection{Definition}

Yin defines case study as "an empirical inquiry that investigates a contemporary phenomenon within its real-life, especially when the boundaries between phenomenon and context are not clearly evident" (2009, p. 18). A case study is defined according to the purpose and focus of the research (Simons, 2009, p. 19). Case study method can use multiple frameworks if that will help answer the research questions comprehensively. Getting the context "right" is important. Eisenhardt refers to the focus on "understanding the dynamics present within single setting" $(1989$, p. 534) and hence the need for different frameworks, whose focus is to capture a certain context and then combine them in the write up.

\subsubsection{Types of case studies}

There are various categorisations of case studies. In summary, drawing on various writers (Collis \& Hussey, 2009, p. 82; Scapens, 1990; Stake, 2006; Yin, 1984, 2009), cases may be:

- Descriptive: to describe current practice.

- Exploratory: to gain in-depth knowledge and rich information.

- Illustrative: to illustrate new and possibly innovative practices.

- Experimental: to examine the difficulties in implementing new procedures and techniques.

- Explanatory: where existing theory is used to understand and explain what is happening.

- Comparative: examining and analysing how representative a case is by looking at similar cases, situations, and contexts; and identifying differences between cases.

These categories are not mutually exclusive. This research into the PNG LNG case aims to ask the "what" questions of descriptive and exploratory studies and the "why" and "how" questions of explanatory and comparative studies.

\subsubsection{The justification for the case method}

Case study enhances the research in that it focuses on first-hand information to gain in-depth and rich information from a case. Gummesson succinctly states that a case study allows an indepth and holistic understanding of multiple aspects of a phenomena and inter-relationships 
between different aspects (2000, pp. 86-87). This then provides the researcher with necessary and sufficient information to answer research questions or develop propositions. The conclusion therefore cannot be generalized and applied to other settings. In the context of this study, the distribution of benefits, together with the influences on, and the transparency of, the process of distribution will all be assessed.

\section{Case study as a research method}

Case study is a comprehensive research strategy or methodology that covers design, data collection techniques, and specific approaches to data analysis. Case study mainly uses three strategies in data collection: interviewing, observing, and document analysis. Clearly, the advantage in using the case study approach is the multiple strategies that can be used in order to examine a previously developed theory or to develop theories or propositions about a phenomenon after studying a social setting. The research involves interviews and document analysis to complement each other.

Secondly, case studies "[enable] the researcher to explore and gain a good understanding of complex (human, social, cultural, political and economic) situations within and across context" (Yin, 2009, p. 4). Thirdly, with case studies, public policies can be explained within the precise socio-political contexts, and the outcome of public policies can be explained in depth $(2009, \mathrm{p}$. 2). Finally, the researcher can maintain "holistic and meaningful characteristics of real-life events - life cycles, group behaviour, organizational and managerial process, change, performance and relations" (2009, p. 4).

\section{Advantages of case study method}

The case study method has several advantages which are briefly outlined below.

- The data generated is within its own context. For example, to study a community one would have to employ a strategy that collects data from within the community (Yin 2009). There is context given in the data which is different from an experiment that may be conducted in a laboratory using a limited set of variables.

- A case study would describe in detail the complexities of real-life situations that are not easily captured by other methods such as experiments or surveys. For example to explain crime in a developing country setting would require that all the variables including documenting the history, socioeconomic situation (looking at social indicators such as 
education, unemployment etc), level of development, the laws, ethnicity and family background among others compared to crime in a developed country setting. The case study method will explore and detail the complexities of crime better than another method.

- A case study approach can combine both qualitative and quantitative analyses of the data. In fact, a case study can focus only on quantitative evidence. There are strategies that can be combined to understand a complex phenomenon under investigation such as behaviours of poor people (Zainal, 2007).

The phenomenon being investigated is the distribution of financial benefits and the factors influencing the distribution, and how transparency has affected these processes. In the case of the PNG LNG project all the stakeholders who were involved in the negotiations which culminated in the signing of the various agreements are best understood and explained by using a case study. The other methods either do not have the explanatory power or are limited in time and scope. A central strength of the case study is that it can accommodate subjective and multiple realities of different participants (stakeholders). The author with previous (prior) experience can interpret the thinking of the different groups, representatives and players within the PNG LNG project.

\section{Disadvantages of case studies}

The main criticism of the case study is the lack of rigour where "too many times, the case study investigator has been sloppy, and has allowed equivocal evidence or biased views to influence the direction of the findings and conclusions" (Yin, 1984, p. 21; in Zainal, 2007, p. 5). The second criticism is that generalisations cannot be made (ibid): the theoretical basis can be generalised in a limited sense only. The third criticism is that the time required to undertake a case study is often long depending on the phenomenon being investigated. A case study, depending on the number of cases under investigation, produces a lot of documentation, a lot of description and analysis, and is voluminous (Yin, 1984). Moreover, the difficulty encountered also includes the ability to systematically organize data which can be tedious a process.

A major disadvantage of using the case study method in assessing the financial distribution, the factors influencing the distribution, and the transparency within the extractive industry is the challenge of getting the right people representing all the sectors and or categories of people 
into the study. The inability to generalize from the study is another disadvantage but at least lessons can still be detailed and noted for future projects.

\subsection{Approach employed in the field work}

Maxwell (2013) argues that a qualitative study method cannot simply be developed or borrowed and then implemented faithfully. There would be a need to construct and reconstruct the research design as the research is being conducted. As the author encountered new challenges in the field work a lot of adjustments were being made to accommodate new situations. For example, in the course undertaking the field work the author became a participant in a workshop (the EITI multi-stakeholder workshop).

\subsubsection{Maxwell's interactive model}

Maxwell calls his research design an interactive model, which has an interconnected structure. There are five components - each of which addresses a specific set of concerns:

(1) goals (the value of the study itself as an addition to knowledge);

(2) the conceptual framework employed (in this case, as explained in the previous chapter, a political economy lens but informed by other perspectives such as anthropology);

(3) the research questions, which are the purpose of the collection and analysis of evidence;

(4) the methods employed - in this research, a case method to provide a detailed analysis of the explanations for the phenomena under investigation, and the related forms of evidence collection and the questions asked of it; and

(5) validity - a test of whether the evidence collected reflects the underlying ontology of the situations being investigated.

Figure 6:1 below shows the model that has been used. It is important to note that the research question is at the centre of the model, the heart/hub of the design showing the connection between the components to it. The model shows that the research question is influenced and being influenced by the components. 
Figure 6:1: Maxwell's Interactive Model

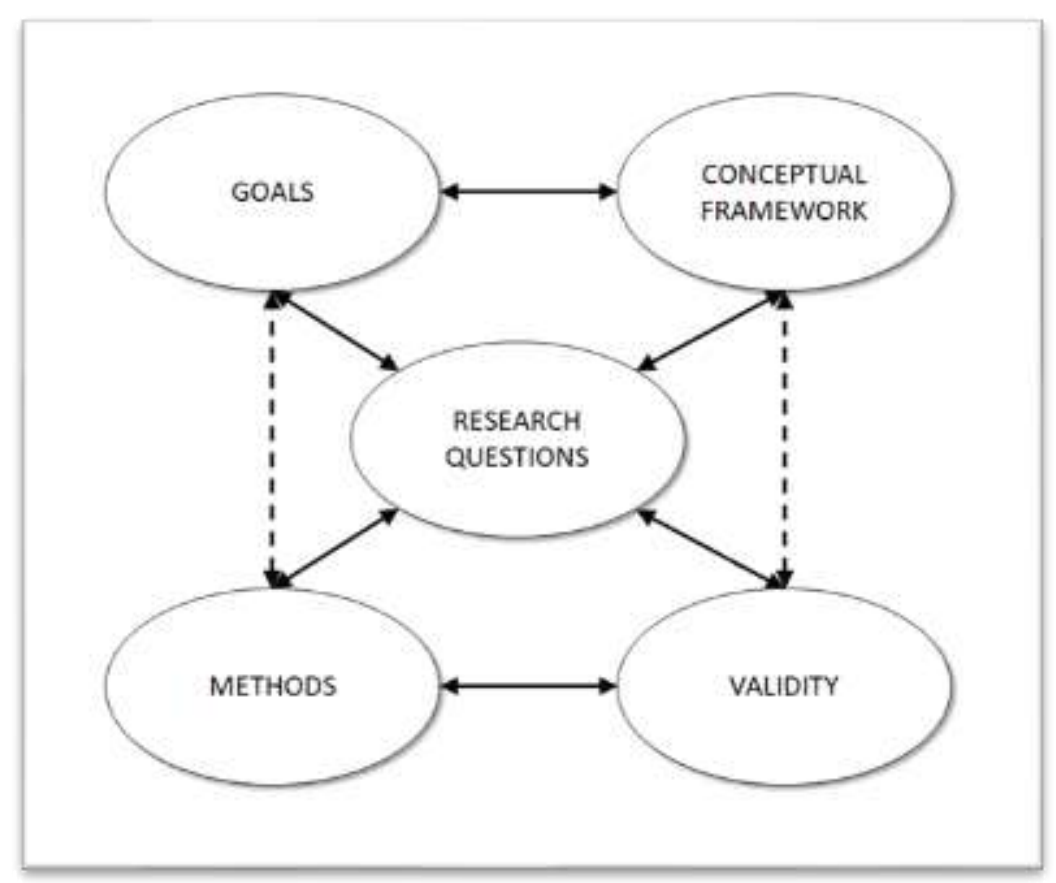

Adapted from Maxwell (2013, p. 5)

The interactive model just outlined above operates in an environment from which factors influence how the research was conducted as shown in Figure 6:2 below.

Maxwell's model illustrates the researcher's own understanding and construction of the social world (Maxwell, 2013, p. 42). The model clearly shows that the role of the researcher is influenced by his or her goals which are impacted by the perceived problems and respondents' concerns. The conceptual framework is naturally influenced by one's own experience or a prior theory which is being built on or being questioned. Even the methods are being influenced by the research settings and the paradigm that is being selected. The validity to a significant extent is being influenced by the methods selected and how the research question is being framed.

This is widely recognized both in science and in our everyday lives we recognize that what people perceive and believe is shaped by their assumptions and prior experiences as well as by the reality that they interact with. From this perspective, every theory, model, or conclusion including the model of qualitative research design presented here is necessarily a simplified and incomplete attempt to grasp something about a complex reality (Maxwell, 2013, p. 42) 


\section{Figure 6:2 Maxwell's interactive model in context}

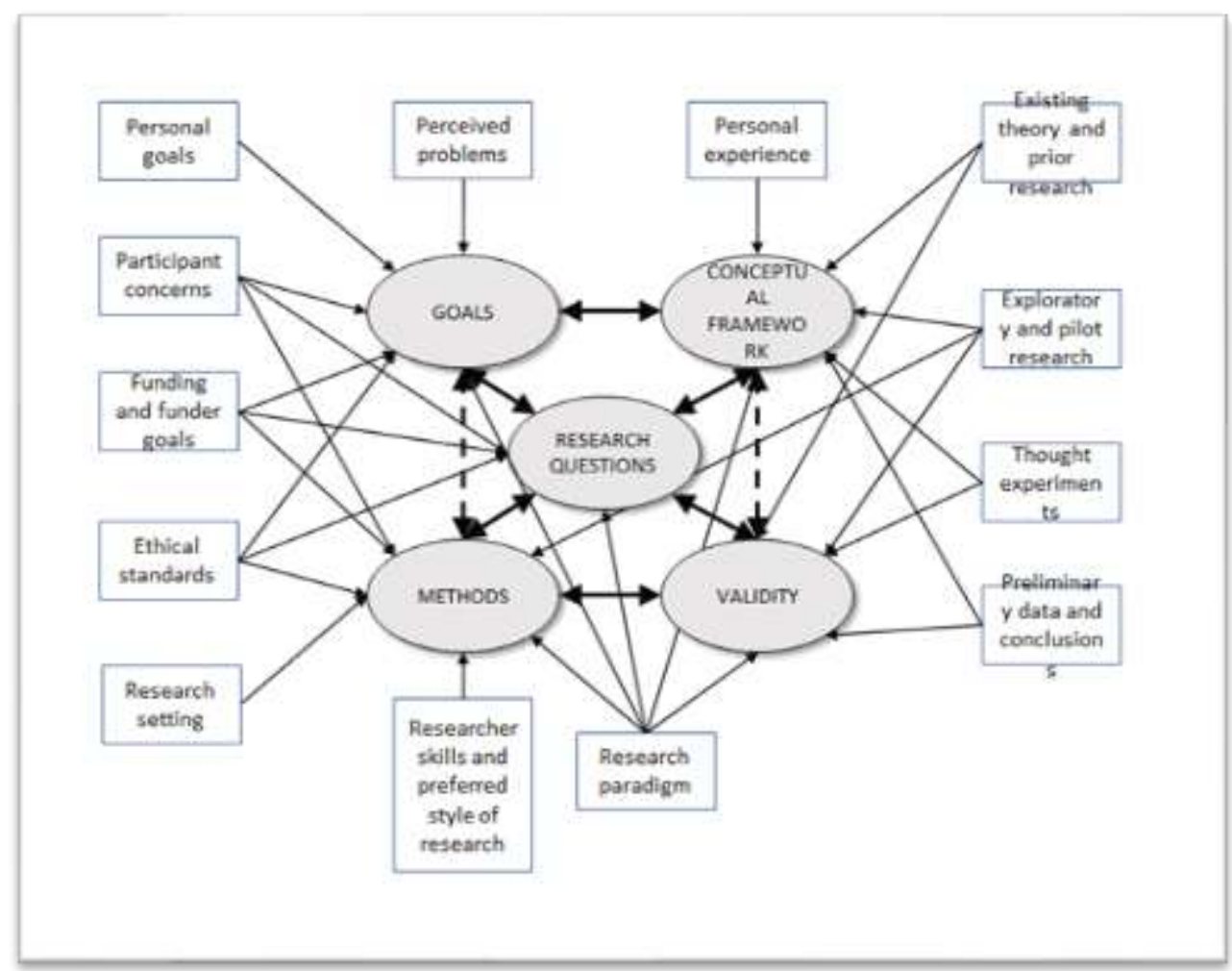

Adapted from Maxwell (2013, p. 6)

\subsubsection{Comparing quantitative and qualitative research}

Quantitative and qualitative research can be distinguished methodologically. In quantitative research the theory is largely causal and deductive while theory under qualitative research is non-causal and often inductive. The findings under quantitative research are assumed to be value-free and unbiased while under qualitative they are explicitly value laden and sources of bias should be identified. In terms of data generated, there are precise measurements under quantitative research while, in qualitative research, data are in the form of words from documents, observations, and transcripts. A major feature of quantitative research is that procedures are standardised, and replication is assumed, whereas in qualitative research research procedures vary and replication is rare.

Table 6:2 makes further methodological distinctions between qualitative and quantitative research. 
Table 6:2 Methodological Differences, Qualitative and Quantitative

\begin{tabular}{|l|l|l|}
\hline Dimension & Qualitative & Quantitative \\
\hline Analytic & Inductive & Deductive \\
\hline Basis for conclusion & $\begin{array}{l}\text { Evidence from naturally occurring } \\
\text { everyday experiences }\end{array}$ & Replicable numerical data \\
\hline $\begin{array}{l}\text { Cause-effect } \\
\text { explanation }\end{array}$ & $\begin{array}{l}\text { Idiographic; emergent, unfolding process } \\
\text { of interconnected actions }\end{array}$ & $\begin{array}{l}\text { Nomothetic; relations among } \\
\text { static variables }\end{array}$ \\
\hline Research design & $\begin{array}{l}\text { Emergent, improvisational; openness of } \\
\text { meaning }\end{array}$ & $\begin{array}{l}\text { Static design meanings, closed } \\
\text { before study begins }\end{array}$ \\
\hline $\begin{array}{l}\text { Types of research } \\
\text { questions }\end{array}$ & $\begin{array}{l}\text { Marginal or hard to study settings and } \\
\text { groups; ambiguous phenomena; open- } \\
\text { ended questions }\end{array}$ & $\begin{array}{l}\text { Specifiable, measurable } \\
\text { variables and relationship }\end{array}$ \\
\hline Goal of sampling & Explanatory power; variation and richness & Generalizability \\
\hline
\end{tabular}

(Adapted from Brower et al., 2000, p. 367; Creswell, 1994; Rubin \& Rubin, 1995; Schutt, 1999).

\subsubsection{Validity and Reliability}

Validity and reliability are means used in empirical research to provide assurance of the research design, process, analyses, and the conclusion reached. In qualitative research the researcher must validate findings. That means that the researcher will have to apply different strategies to ensure accuracy and credibility of findings. There are three points that Uwe Flick made about the validity of research which include procedural validity which outlines the relationship between the researched and researcher, including observing the emerging patterns and the link to generalisation. He also pointed out the need to maintain credibility which would require 'disclosing one's own blind spots' and to maintain dependability by ensuring quality management procedures (Flick, 2002, p. 228).

\subsection{Research Methods}

As this was a case study, qualitative research was undertaken in the field. This was a twopronged approach. The first part involved the collection of secondary data and visiting government, company, and NGO offices in Pt. Moresby. A number of key informants (former public servants) were also approached for any documents that they may have as a result of their involvement in the extractive industry. The case study method was employed and was guided by Yin in terms of format: layout and style especially the descriptive framework, coding and pattern matching (2009, pp. 40 \& 129).

Field work is perhaps especially challenging when attempting to elicit confidential information. In other words, even when a great research design is outlined on paper, it will still be a difficult task to collect reliable and accurate information (Creswell, 1998). 


\subsubsection{Data Collection}

The case study is part of qualitative research and interpretative inquiry purposely used to unveil social phenomena. The interpretative research paradigm adopts many different approaches in qualitative research for data collection. The qualitative data collection methods include narrative research, phenomenology, grounded theory, ethnography and case studies.

\section{Secondary sources}

The secondary data was collected first and formed the basis of answering the research questions. An extensive internet survey was also conducted of all the material covering various government documents (including ministerial statements, policy documents, plans, budget papers and archival documents); company documents (press releases, feasibility studies and annual reports); newspapers and reports from various stakeholders. Those that were not on the internet were collected from the respective offices. Among the materials collected were the various available PNG LNG agreements. The documentary analysis involved cross-checking with primary sources about the accuracy of some of the information (Maxwell, 2013). The core organizations that were consulted included: Treasury, Finance, Petroleum and Energy, Bank of PNG, National Petroleum Company, MRDC, ExxonMobil, Landowner groups, TI, EITI PNG.

\section{Primary sources}

The first primary source for the research is documentary evidence as shown in Table 6:3 below.

Several important documents could not be obtained. The CDOA, which is a key agreement governing the business operations of all the entities operating under the PNG Gas Agreement, has never been publicly available. It is referenced in other documents so some of its provisions could be determined indirectly. Only two of LBBSAs, between the PNG LNG landowners and the affected provincial governments, were available. LNG supply contracts, service contracts with the project, and most financing agreements were also unobtainable. There is a detailed discussion of the availability of documentary evidence in Chapter 10 of the thesis, as it was an important aspect of assessing the impact of transparency on the project. 
Table 6:3 Main documentary sources for the research

\begin{tabular}{|l|l|}
\hline Documentary sources & Description \\
\hline PNG LNG Gas Agreement & $\begin{array}{l}\text { This was the main agreement between all the equity holders and } \\
\text { the State. }\end{array}$ \\
\hline $\begin{array}{l}\text { Umbrella Benefit Sharing } \\
\text { Agreement (UBSA) }\end{array}$ & $\begin{array}{l}\text { This was the main agreement between the State and the } \\
\text { provincial and local level governments and the landowners. } \\
\text { A total of nine LBBSAs were signed between the State and the } \\
\text { Provincial and specific local level governments and landowners } \\
\text { Sharing Agreements } \\
\text { (LBBSAsing the Well Heads, the pipeline and plant sites. Two of } \\
\text { these agreements were discoverable online. }\end{array}$ \\
\hline $\begin{array}{l}\text { Coordinated Development } \\
\text { and Operating Agreement } \\
\text { (CDOA) }\end{array}$ & $\begin{array}{l}\text { This agreement was not discoverable but is referenced in other } \\
\text { documents. }\end{array}$ \\
\hline Parliamentary Hansard & $\begin{array}{l}\text { Covered many (but not all) of the Parliamentary sessions } \\
\text { (ranging from Question Time to Budget Debates) in the study } \\
\text { period. }\end{array}$ \\
\hline $\begin{array}{l}\text { Budgets, Budget Strategy } \\
\text { Papers and Economic and } \\
\text { Fiscal Updates 2007-2018 }\end{array}$ & $\begin{array}{l}\text { All budget documents (required by fiscal responsibility } \\
\text { legislation) published on the Treasury website. }\end{array}$ \\
\hline $\begin{array}{l}\text { Acts of Parliament (Oil and } \\
\text { Gas Act, SWF etc) }\end{array}$ & $\begin{array}{l}\text { Nearly all the Acts are available on-line and hard copies were } \\
\text { collected during the fieldwork. }\end{array}$ \\
\hline EITI reports & $\begin{array}{l}\text { The available annual EITI audits, particularly the three most } \\
\text { recent (2015-2017) were, given limitations on their completeness, } \\
\text { a source of information on payments made under the PNG LNG } \\
\text { agreements. }\end{array}$ \\
\hline
\end{tabular}

The second primary source was the interviews that were conducted with some of the informants from public and other organisations. A two-pronged strategy was employed:

(1) Contact was made with the various government departments/agencies, non-government organizations (NGOs) (which included Transparency International and the Council of Churches), the Chamber of Mines and Petroleum, Exxon Mobil, Total, Mineral Resources Development Company (MRDC), Kumul Petroleum Holdings Limited (KPHL) and the various landowner groups/individuals. During the initial contact a formal request was made for information relating to the PNG LNG project that would normally be available for public consumption and the names of individual officers who would be available for an interview so that a formal letter could be sent to the departmental/organizational head seeking clearance for an interview with them.

(2) After reviewing documents collected from the various government departments, questions for companies and organizations were framed to clarify, confirm or fill in information gaps. The actual interviews used both a structured and unstructured format depending on how the questions were being asked with the respondents allowed to freely speak. 
Several challenges were encountered in arranging and completing interviews, particularly with public organisations:

- There had been a high turnover of staff since 2009, so that those who were working or directly involved in the negotiations and signing of the agreements had either moved on to other government departments or resigned. Except for two government departments, all the key government departments and agencies had acting appointments. They included: National Planning and Monitoring (a female head was removed); Petroleum and Energy (the Secretary went for the national election); Commerce and Industry (acting appointment); Provincial Affairs (acting appointment); Justice (acting appointment); Conservation \& Environment Protection Authority (CEPA) (acting appointment); and Internal Revenue Commission (a female Commissioner removed).

- There were suspicions about anybody enquiring for information given the instability within the various departments as senior officers were vying for the top posts and were wary of inquisitive researchers. The officers that the researcher spoke to were young and had limited understanding about the PNG LNG project and could not explain in detail some of the aspects of the project as it relates to their departments/agencies. This was evident with the departments of Petroleum and Energy, Public Enterprise, National Planning \& Monitoring, and Treasury and Finance with most officers providing only documentary material. The limited questions posed to officers who were available to talk both formally and informally did not reveal much information that the researcher could use. The information sought would have to come from Secretary and Deputy Secretary level whom the researcher could not access despite making several attempts.

- Given the sensitivity of the information sought, a lot of government officers (both former and current) provided information privately and asked not to be named in the thesis. This was also the case with companies who referred the researcher to the companies' websites or provided additional documents. The researcher did receive some highly sensitive information, but this could not be used for legal and ethical reasons.

- The other option that was used was to approach former staff who were familiar with the PNG LNG Project for their views. While this was successful most of these key informants are consultants to the government and the various companies involved within the petroleum and mining sectors. 
Various government agencies such as the Central Bank, Internal Revenue Commission, and Investment Promotion Authority were very helpful with documentary material but could not provide specific responses to specific questions asked. The interviews conducted covered the secondary question of transparency. The questions regarding revenue distribution were very sensitive and government officers could not give interviews on record, even when it was pointed out that this was an academic exercise and the information would benefit the government.

On the other hand, landowner groups and individuals were more than happy to talk and provide documentary evidence and wanted to be quoted. This was the same with NGOs, churches and Transparency International who wanted more transparency and who were playing a more advocacy role for landowners and the general public. During the discussions that the researcher had with a varied range of landowners and NGOs a very disturbing picture emerged about the knowledge they had about the project. An initial assumption by the landowners was that they were owed hundreds of millions of dollars in financial benefits and felt that the government was siphoning it off. In short, while they understood the percentage that they were supposed to receive, they did not know the value or where the accruing monies were kept.

The researcher did conduct two focus group discussions with landowners of PDL 1 and PDL 7 but realised that the landowners had little understanding of the different categories of financial benefits and what they were owed.

The author also participated in a two-day workshop on the country's extractive industry organized by the EITI. It was a multi-stakeholder gathering that focussed on transparency but also on other aspects of the industry. The observations and participation are captured in Chapter 10. A major point noted at the workshop was the absence of the landowners and the lack of capacity in terms of resources (finance, expertise to collect and disseminate information).

The general difficulties in obtaining useful information from interviews relating to the research questions meant that the research relied to a greater extent than expected on documentary sources. Budget papers and parliamentary proceedings (Hansard) and the various agreements were therefore used in greater detail, particularly to illuminate the influences on the collection and distribution of revenues. The researcher was able to triangulate these sources to some extent with reference to other studies of the project and various newspaper, online, and social 
media commentaries, covering both the revenues and the positions of the various stakeholders including local communities.

\subsubsection{Data analysis}

Unlike in the past, data analysis has been made much easier with a lot of software that can assist in organizing huge data, including coding, aggregating, analysing and correlating. Although there is software available for qualitative data analysis, the data were manually constituted. Given the large amount of secondary data and information, it was a challenge deciding which information was important and necessary.

This was avoided where possible through cross-checking with secondary data, validation, reliability checks and triangulation. The data analysis for this research was guided by Yin (2009); Flick (2002) guided the cross-check with secondary data. The decision about the approach for analysis was based "on the character of the material (to be) obtained" (Flick, 2002, p. 166).

There were several levels at which the case study was approached. Firstly, the national level required that the research focussed on the key players such as the lead government agencies, developers, and the local landowners. Secondly, the focus was on the processes involved in securing the agreements to progress the project through the whole investment cycle from feasibility studies to production and thirdly, was to look at the influences on the distribution of the benefits and its transparency.

A case study data collection follows a formal plan, but the specific information that may become relevant to a case study is not readily predictable. As evidence is collected it must be reviewed continually against the settings. This will require a well trained and experienced investigator because of the continuous interaction between the theoretical issues being studied and the data being collected (Yin, 2003, p. 58).

\subsubsection{Experiential knowledge and position of the researcher}

\section{Role of experiential knowledge}

Traditionally, what one brings to the research from one's background and identity is being treated as bias which needs to be eliminated from the research. As pointed out by Maxwell, "separating your research from other aspects of your life cuts you off from a major source of insights, hypotheses, and validity checks" (2013, p. 45). Furthermore, Anselm Strauss refers to 
"experiential data" as the researcher's technical knowledge, research background and personal experiences. He argued that:

These experiential data should not be ignored because of the usual canons governing research (which regard personal experience and data as likely to bias the research), for these canons lead to the squashing of valuable experiential data. We say, "mine your experience, there is potential gold there!” (Strauss, 1987, p. 11; in Maxwell, 2013, p. 45).

\section{Position of the researcher}

The researcher is a lecturer at the University of Papua New Guinea who has been teaching courses within the field of social science and now more specifically in the field of public policy. He was able to make use of his experience in the sector under study for collection of evidence and its interpretation. The researcher has been involved with a number of consultancies for the Ok Tedi mine project and Porgera gold mine projects. His interest in the petroleum sector stems in part from his involvement in undertaking a series of consultancies with the Department of Petroleum and Energy who were reviewing a number of social and socio-economic impact studies of the PNG LNG project operated by Exxon Mobil. He was also engaged as a consultant by InterOil to do a number of preliminary social mapping and landowner identification studies for the Papua LNG project. He also assisted with the socio-economic assessment of the Papua LNG project and participated in awareness exercises along the Purari delta, placing him in a unique position to offer sights on challenges that companies and governments (at all levels) face when dealing with the expectations of landowners and host communities. Prior to undertaking this research, the researcher has had a good and close working relationship/network with people associated with the extractive industry, including landowners of both the PNG LNG and the Papua LNG projects.

\subsection{Thematic analysis}

The themes emerging from the research are developed by the researcher to allow the data to be reduced to key ideas. Marshall and Rossman define data analysis as the process of:

... bringing order, structure and interpretation to the mass of collected data ... It is the search for general statements about relationships among categories of data ... it is the search among data to identify content (Marshall \& Rossman, 1989, p. 45). 
A number of categories were used in the analysis of the data. Other categories emerged as the analysis proceeded. The author chose to rely on emergent or intuitive strategy (the intuition refers to the researcher's capacity to discern the important themes in the collected data). Figure 6:3 below summarises the thematic analysis outlined.

Figure 6:3: Data analysis

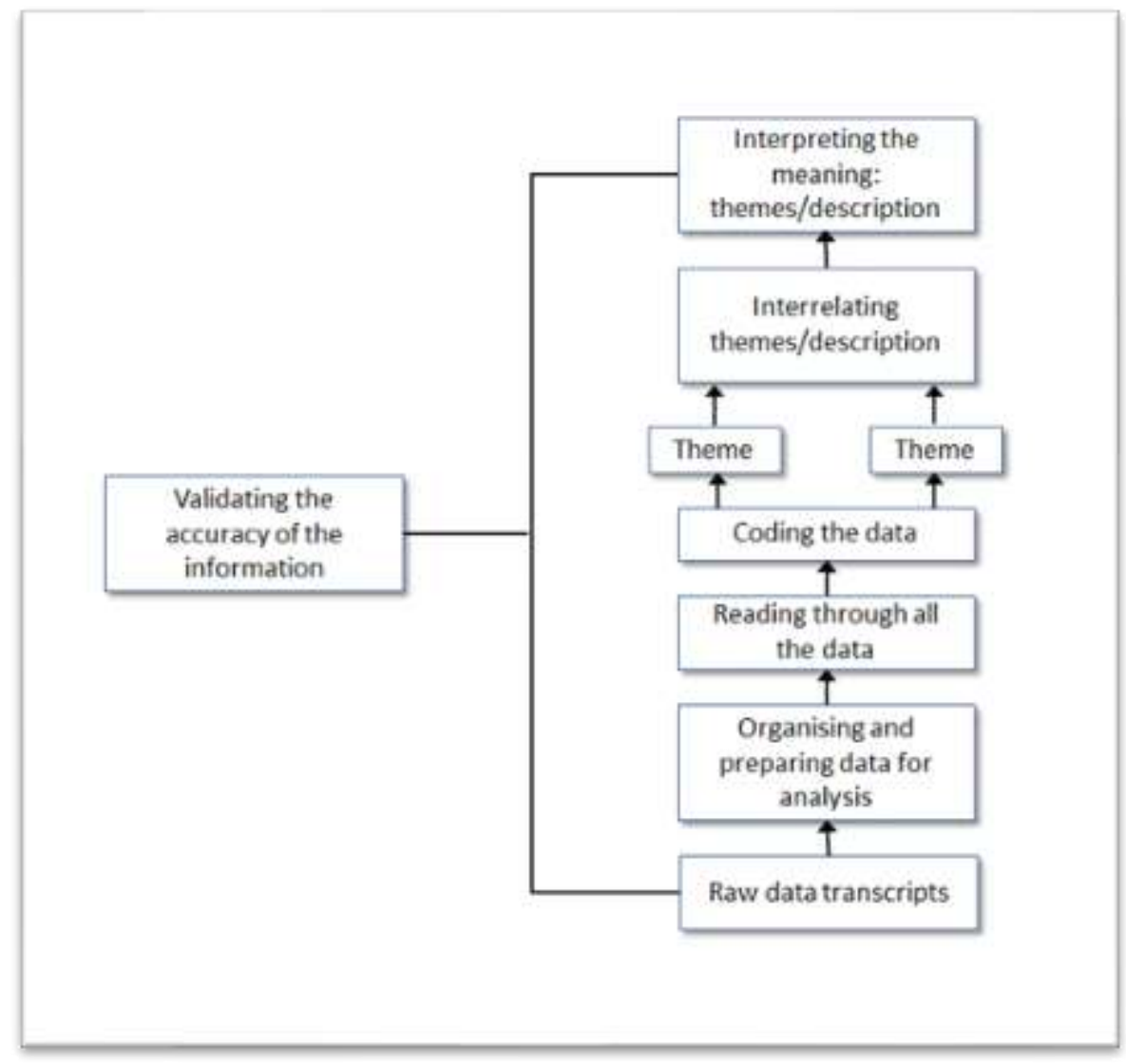

Adapted from Creswell (1994)

The thematic analysis can be divided up into six stages, which are discussed below.

\section{Organization of data}

The validity of the data and information is crucial and needs to be protected. As the research was being conducted the transcripts were being organized as there were different stakeholders of the PNG LNG project that were being interviewed. The data was organized according to the different stakeholders: government agencies, developers, landowners, and NGOs. The organization of the data covered both primary and secondary data and were classified under the main stakeholders. The emerging themes were also being identified at this stage. 


\section{Generating categories and/or themes}

This is the stage where recurring themes that respondents give are categorised. There were a number of themes that emerged and were categorised accordingly; for example: the nonpayment of royalties and compensation and payments being made to the wrong people. All themes were carefully labelled to be easily accessed when doing the write up. As suggested by Marshall and Rossman, categories should be internally consistent and externally divergent (Marshall \& Rossman, 1989, p. 5). The case study used this stage to prepare the write up, particularly as seen in Chapter 8 on benefit sharing, using the generated categories.

\section{Coding data}

The coding did not follow a systematic strategy but when writing up the thesis the documentary evidence was categorised under the various themes within the Case.

\section{Testing emergent understanding}

This was the stage where a better understanding of the data emerged and was placed in the context of the theory. Other theoretical frameworks and their variants also emerged and were added into the case study. As an example, a principal-agent framework helped explain the relationship between landowners in Incorporated Land Groups (ILGs) and their lawyers, where the power of attorney was given to lawyers to act on behalf of the landowners.

Using Marshall and Rossman (1989) the data was also being used to challenge some of the dominant thinking about the role of the state, in particular the notion that the state's role is to protect the rights of its citizens against MNCs.

\section{Search for alternative explanations}

This is the section where other explanations were investigated, including those from other disciplines. An issue of interest that emerged and which could be further explored is how the government agencies and their agents used psychological techniques to win across dissenting landowners. For instance, during the signing of the various agreements, the government told a number of landowners of the importance of the PNG LNG project and the need to put national interest ahead of their provincial and local interests.

\section{Write up of the case study}

Writing up the case study was a challenge on several fronts. Firstly, it was difficult to weigh up the influences of the different stakeholders and to identify their positions over certain issues 
such as land tenure systems, compensation, and royalty payments. The difficulty was using the law to apply to a cultural setting. Secondly, no single framework could sufficiently cover all the issues and so several were being used against the backdrop of the political economy approach.

\subsection{Conclusions}

In terms of the five components of Maxwell's model outlined above, the research method can be summarised as follows:

(1) Goals. This study is worth doing because there is a lot of interest in the PNG LNG project but with little research being done. The main issue remains the distribution of financial benefits and the influences on the revenue that resource projects generate. The author has been involved in the LNG sector over the last eight years and it is a personal goal to see research that will influence policy that will improve the extractive industry in terms of ensuring that the financial benefits are used to improve the livelihood of the project host communities and the country as a whole. There is also a lack of evidence-based policy to help decision makers. A personal goal is to see this study being used to inform their future decisions.

(2) Conceptual framework. There are several conceptual frameworks that have been used within the extractive industry but in different contexts. This research uses the political economy approach and focuses on the politics and economics of the resource sector. The NRD as a lens under the political economy approach is being used in the research. The unit of analysis is the institution. The behaviour of the various stakeholders is also examined in the study. As this is a case study, the value chain model is being used.

(3) Research questions. The research questions reflect the questions that ordinary villagers and generally citizens have been asking about influences on and uses of the financial benefits from the various projects as there seems to be little "development" taking place in the project sites and the country generally. The people do not know how the financial benefits of projects are being used, as most of the basic services such as health and education in rural areas are provided by the churches and most of the crumbling infrastructure is being financed by the donor community. Is it possible that a lot of the financial benefits are accruing offshore because of the equity arrangements? If so, why? Is this a case of how public policy and management works in the resource sector? The answers to these questions 
will help the people understand how the resource sector works and assist policy makers if there is evidence requiring legislative or public policy interventions.

(4) Methods. The case study method was used as the research questions required detailed responses from key informants. The companies and all the relevant government agencies are located in the capital of the country and a semi-structured and open-ended questionnaire were used in the interview that was conducted. Most of the key decision makers of the various landowner groups have moved and settled in the capital and so all the interviews were conducted in the capital. A focus group was also conducted for the landowners. Financial constraints prevented a visit to landowners at the well head project site (the source of the oil and gas). It was also difficult from the capital to track landowners along the $700 \mathrm{~km}$ pipeline. An important stakeholder group that was also consulted are the non-government organizations (NGOs), including Transparency International PNG (TIPNG), Churches, and Environmental (NGOs). The author also participated in an interactive EITI workshop over two days covering a range of issues within the extractive industry and gained a lot of insights of the players within the industry. The author while on the field trip attended a number of conferences and seminars on the extractive industry. Finally, many secondary sources such as annual reports, press releases, quarterly publications, government papers (such as budget papers, various government plans and reports), and agreements were used.

(5) Validity. In terms of the questions about the validity of the findings, the author also used secondary sources to cross check information - a process of triangulation. There were challenges to assumptions and so elements of bias were being minimised. 


\section{Chapter 7 The PNG LNG Project and its context}

\subsection{Introduction}

This Chapter is in three main parts. The first part covers some of the history leading up to the PNG LNG project, dealing particularly with the development of petroleum resources in the Southern Highlands. The second part provides a description of the PNG LNG project itself and the principal institutions and actors in the Case, covering particularly the legal framework in the mineral and petroleum sector, which is the formal basis for development and implementation of the project and management of its finances. The third part discusses the formation of the main project agreements themselves in the context of this legal and institutional framework.

\subsection{Project historical context}

\subsubsection{Background: Petroleum Policy}

Although there were petroleum and mining laws covering British Papua in 1888 and later Papua and New Guinea, when New Guinea came under British and Australian control after the First World War, there was no coherent petroleum policy guiding the role of government agencies, developers, and landowners until 1995. There was a mining policy prior to independence which guided the Bougainville Copper Mine and later various amended Acts of Parliament that affirmed the pre-independence mining policy. In the absence of specific oil and gas legislation and policy, the Mining Act was used to guide compensation, negotiation for development licenses, and other social and environmental issues that arose from time to time.

The discoveries of the Kutubu crude oil fields in 1986 and the Hides gas field in 1987 prompted the development of a specific oil and gas policy in 1995, leading to the Oil and Gas Act 1998. The fact that the policy was put in place ten years after the discoveries of oil and gas in the Southern Highlands Province reflected the reactive nature of the national government and implied that the exploration and interactions of the company with the national government and landowners were done on an ad hoc basis. The new Act however set out a comprehensive framework for licensing the development of petroleum fields, the share of revenues that would accrue to the state and landowners, machinery for defining eligible landowners, and agreeing on distribution of benefits. Amendments in 2004 and 2006 at the time of the development of the Queensland gas pipeline project specifically addressed the rules to be put in place for gas 
fields. Amendments to the Income Tax Act 1959 in 2000 introduced a specific Division on Mining, Petroleum and Gas Projects, defining a project basis of assessment and covering rules for allowable expenditure, depreciation, and offsets. Amendments in 2004 covered allowable exploration expenditure and additional capital expenditure. Concerning benefit sharing with landowners, a series of amendments to the Oil and Gas Act in 2006 covered social mapping and landowner identification, the principles for sharing benefits and equity interests with local landowners and subnational governments, and development forums and development agreements for settling these arrangements for specific projects. In short, by 2006, there was a comprehensive framework for establishing gas projects and managing the resource rents from them.

\subsubsection{Exploration and development before the project}

The granting to a group led by Chevron Niugini Limited (CNGL) of the first petroleum development licenses (PDLs) to Kutubu for crude oil export (PDL 2) and PDL 1 for the Hides natural gas field to produce and supply electricity for the Porgera gold mine in Enga Province was however done in the absence of this more detailed policy and legislation. This is important because it has been suggested as a possible cause of some of the problems facing the PNG LNG Project.

The Kutubu oil project is in the Southern Highlands province and was the country's only oil project with oil production facilities. The scale of operation was small compared to the bigger mining projects operating at the same time such as Ok Tedi, Porgera, and Lihir. The Kutubu project is highlighted briefly here is because some of the problems associated with the PNG LNG project in relation to lower level governments and landownership in part can be traced back to the Kutubu project. There was also an important project proposal for the piping of gas from the Kutubu and Gobe areas to Queensland which exemplified some of the problems that are currently persisting. This is further discussed in this Chapter.

\subsubsection{The national government arrangements for the Kutubu project}

Coordinating state institutional arrangements for managing the Kutubu project has been difficult: the government departments did not have the capacity; the provincial and lower level governments also did not have the capacity even though they hosted the project; the lead government agencies such as the Petroleum, Environment, Finance and National Planning operated in isolation on a lot of areas requiring coordinated and sustained effort. A whole of 
government approach was discussed and published in various government documents but in practice was absent not only in the resource sector but other sectors of the country.

Gai Pobe worked with Chevron for 13 years, Oil Search Limited ${ }^{27}$ for another four years and another eight years with Merrill Lynch and InterOil as Community Affairs Manager, and has held other executive roles within the extractive industry. He is currently an advisor to landowners and a consultant to the national government. His following comments confirmed the dependency of the state on the companies operating in the resource sector:

Gai Pobe: Chevron did everything for the state and on behalf of the government in terms of building infrastructure such as airstrip, roads and bridges, schools and aid posts, doing community awareness and funding various projects and programs. As the government liaison manager for the company and later as community affairs manager- I observed that the government did very little to enforce compliance. But Chevron went out of its way not only to comply (but did other things for the government, like offering advice to government officers).

\subsubsection{The socio-economic impact of the Kutubu project}

According to Gai Pobe, the Kutubu project has not had a similar social and environmental impact to those of mining projects around the country:

Chevron set the benchmark for companies operating in the oil and gas sector in the country. Chevron had a very good and positive relationship with the national, provincial and local level governments. Chevron Corporation introduced the "diversity" corporate policy/strategy and it was rolled out in over 100 countries including PNG. This policy means respecting the customs of communities and laws and policies of host countries. Chevron as a company is suited to operate in PNG because it respects the people and will not exploit the weaknesses of the government.

Gai Pobe also said that Chevron was focussed on ensuring that the host communities and neighbouring villages were not adversely affected environmentally from the project:

Chevron brought in the WWF and Conservation International (CI) to recommend environmental programs- these programs looked at animals (endangered species) and

\footnotetext{
${ }^{27}$ An oil and gas exploration company incorporated in PNG, with a 17.6\% PNG Government equity stake.
} 
flora and fauna. It was Chevron that started the CDI foundation (now maintained and continued by Oil Search) that identifies projects and supports livelihood programs for communities down to the Kumul terminal (where ships load up oil).

In terms of social mapping, Gai Pobe's view is that:

Chevron followed the law and incorporated Hela customs of clan ownership by stock clans and by physically surveying clan boundaries and incorporating land groups with the Registrar of Titles and formally gazetting in 2001 and assisted with opening of bank accounts and passed management responsibilities to MRDC.

Moran PDL 5 has 14 stock clans and share benefits with 24 sub-clans each with bank accounts that MRDC pay money directly into. There has been no Moran land disputes since gazettal of clans in 2001 and they have one Parliament- Homa People Association lead by one Chairman not being disputed ... since his election and I see him being in the role until the depletion of oil and gas.

Gai Pobe says that he has not seen another company either in the mining or petroleum sector (operating in PNG) that has as good a corporate social responsibility track record as Chevron. Chevron was practising transparency even before TI was talking about it. They left behind great work ethics in terms of honesty, discipline, and hard work.

\subsubsection{The Queensland pipeline proposal ${ }^{28}$}

In the mid-1990s, Chevron, the operator of the Kutubu project, decided to investigate a 3800 $\mathrm{km}$ pipeline to North Queensland, based on its gas fields in the Southern Highlands Province. "Throughout the late 1990s, Chevron negotiated gas sales agreements, pursued PNG Government approval and worked on route selection." By April 2001 "ExxonMobil had taken over from Chevron as project managers and recommenced gas sales negotiations in the middle of the year." The project was supported by the PNG government but lost momentum in 2004 . However, conditional gas sales contracts were still being signed in late 2004 and the project partners moved to the Front End Engineering and Design (FEED) stage. By late 2005 BHP Billiton withdrew from the conditional gas purchase. The pipeline costs "reportedly blew out

\footnotetext{
${ }^{28}$ Information mostly from The Australian Pipeliner (2006).
} 
by almost $\$ 1.5$ billion, prompting AGL [Australian energy distributor and project partner] to review its role and the pipeline's route".

By late 2006 / early 2007 the partners had announced that they had abandoned the project (PNGReport, 2007). The proposed gas pipeline was a major project that the PNG government wanted to see get off the ground and it was a big disappointment when it was abandoned at the FEED stage.

\subsection{The PNG LNG Project}

\subsubsection{Initiation}

At the same time the proposed pipeline to Queensland was abandoned, gas licensees in the Hides, Angore, and Juha fields were signing an initial Cost-Sharing Agreement (CSA) to develop an LNG project. In announcing its participation, Oil Search said that the CSA was effective until 30 March 2008 and that it was "anticipated that CSA participants [would] be in a position to decide whether to progress to the Front End Engineering and Design (FEED) phase of an LNG project prior to the end of the CSA term." (Botten, 2007).

Also at the same time, a proposal for another LNG project (the Liquefied Niugini Gas Ltd LNG project) was being investigated, to draw on the Elk/Antelope fields to the southeast of the fields for the PNG LNG project. The project did not proceed in 2007, but was revived from 2016 as the Papua LNG Project. (The Australian Pipeliner, 2016).

The PNG government approved the PNG LNG Project in 2009; construction of the various facilities commenced in March 2010. The total cost of the project was US\$19 billion. It is projected that over its 30-year life span it will produce over nine trillion cubic feet of gas, which will be exported mainly to the Asian market. The PNG LNG project was the single "largest capital investment and most complex engineering, construction and production venture undertaken in the country's history, ensuring intense scrutiny of its performance and impact by both supporters and critics" (Nelson \& Valikai, 2014, p. 4).

\subsubsection{Production components}

The PNG LNG project has three main production components ${ }^{29}$, shown in Figure 7:1 below:

\footnotetext{
${ }^{29}$ Information from PNG LNG website (ExxonMobil, 2019: 'Our operations').
} 
(1) Gas conditioning plant: The Hides Gas Conditioning Plant, located outside the township of Hides in Hela Province, processes natural gas from eight wells. The raw gas is dewatered and separated into condensate (a form of light oil) and gas, and sent to the pipeline. Condensate goes via its own pipeline to the Kutubu Central Processing Facility and then to export from the Kumul terminal.

(2) Gas Pipeline: the conditioned gas is transported via a $700 \mathrm{~km}$ pipeline to the LNG plant near Port Moresby: the first "onshore" section of $290 \mathrm{~km}$ from the Hides plant to the Omati River is overland and buried underground. The remaining $407 \mathrm{~km}$ "offshore" section extends from the Omati River to the LNG Plant.

(3) LNG Plant: the plant is located $20 \mathrm{~km}$ northwest of Port Moresby and includes two LNG processing trains to liquefy the gas, two LNG storage tanks, and a marine loading terminal. The liquefaction plant was designed to process 6.3 million tonnes per annum (mtpa) of LNG.

Figure 7:1: Pipeline route and project sites

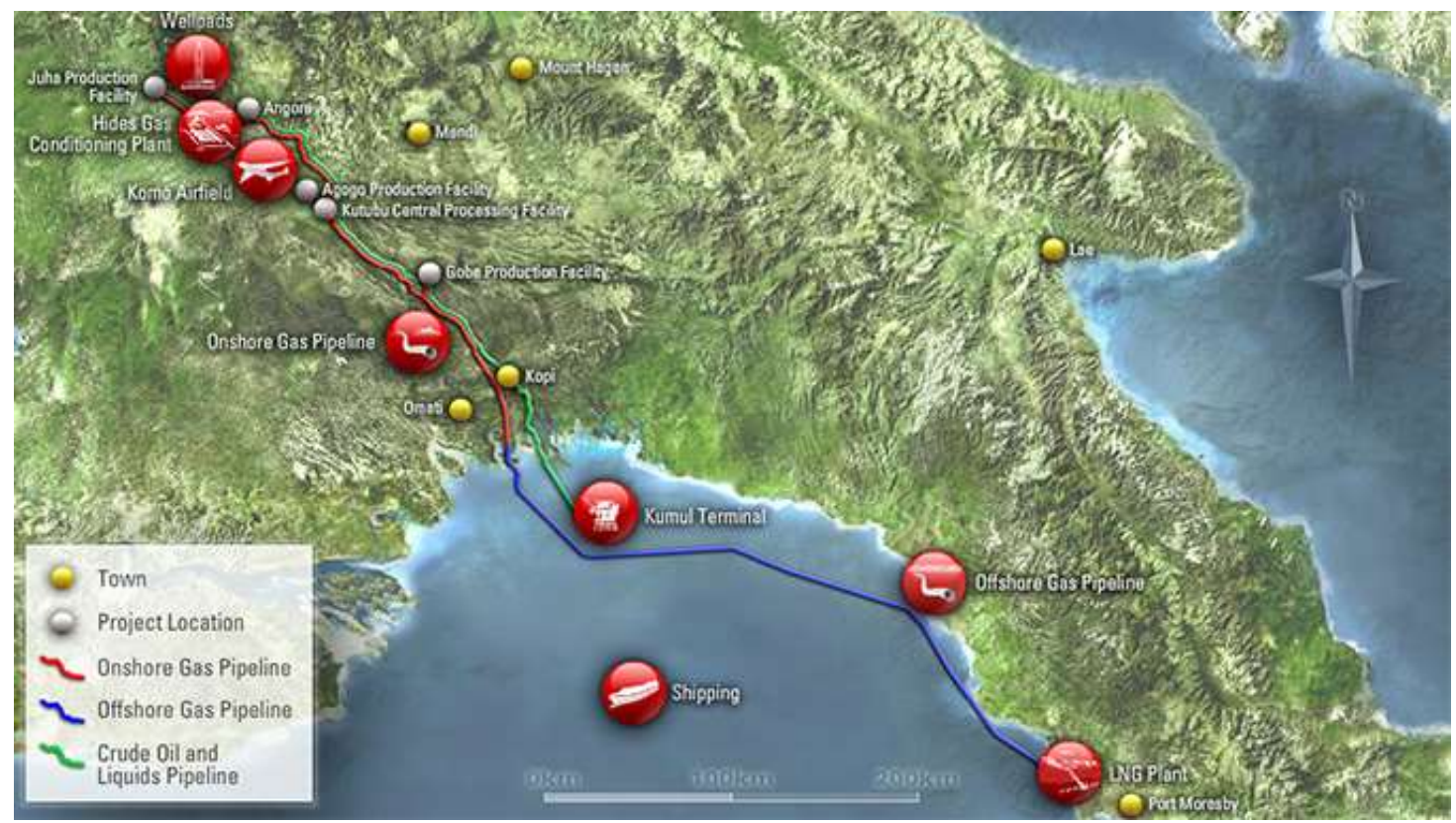

(ExxonMobil, 2019: 'Project overview')

The PNG LNG project greatly benefited from the extensive work undertaken previously for the abandoned Queensland pipeline project. The Primary Gas Fields are close to the existing oil operations commonly referred to as the Kutubu Pipeline System. The PNG LNG project pipeline was constructed along the existing crude oil pipeline corridor which was already surveyed. 


\subsection{Main actors}

The criterion for inclusion in the analysis is "players" who have, or could have, an influence on the generation and distribution of revenues. As is the case with a lot of mining and resource projects in the country, the three main actors are the state, developer, and landowners. It will be shown what levers the main identified actors can potentially pull to influence revenue distribution - particularly payments to the state and landowners and how they are managed. There are other stakeholders who are very influential at different phases of the project and they will be discussed accordingly.

\subsubsection{Project Companies}

The legal basis for the project is discussed in more detail later in this Chapter. In brief summary: the parent companies of the various licence holders agreed on an unincorporated joint venture to develop the project. There were 16 licence holders, and the shares of their parent companies in the venture reflected their initial aggregated interests in these licences. These interests at the time of this agreement are shown in Table 7:1 below.

Table 7:1 PNG LNG Project Joint Venture Initial Interests

\begin{tabular}{|l|l|c|}
\hline Parent & Description & $\begin{array}{c}\text { Initial } \\
\text { Interest }\end{array}$ \\
\hline ExxonMobil Corporation & US multinational oil and gas corporation & $41.5 \%$ \\
\hline Oil Search Limited & $\begin{array}{l}\text { Oil and gas exploration company incorporated in } \\
\text { PNG. PNG Government equity share 17.6\% (2008) }\end{array}$ & $34.0 \%$ \\
\hline Santos Limited & $\begin{array}{l}\text { Australian listed public company - exploration, } \\
\text { development, production, transportation and } \\
\text { marketing of hydrocarbons }\end{array}$ & $17.7 \%$ \\
\hline $\begin{array}{l}\text { Australia Gas Light (AGL) } \\
\text { Energy Ltd }\end{array}$ & $\begin{array}{l}\text { Australian listed public company - electricity and } \\
\text { gas generation and distribution }\end{array}$ & $3.6 \%$ \\
\hline \multirow{2}{*}{ JX Nippon Oil \& Energy } & $\begin{array}{l}\text { Japanese company, member of Mitsubishi Group: } \\
\text { "exploration, importation, and refining of crude oil; } \\
\text { the manufacture and sale of petroleum products, } \\
\text { including fuels and lubricants; and other energy- } \\
\text { related activities" }\end{array}$ & $1.8 \%$ \\
\hline \multirow{2}{*}{ Government of PNG } & $\begin{array}{l}\text { Mineral Resources Development Corporation } \\
\text { (MRDC) on behalf of landowners }\end{array}$ & $1.2 \%$ \\
\cline { 2 - 3 } & Petromin (on behalf of Kutubu landowners) & $0.2 \%$ \\
\hline
\end{tabular}

Adapted from ExxonMobil (2019, 'Co-Venturers')

The GoPNG is entitled by law to take up to $22.5 \%$ in any oil and gas project in the country. This is understood and acknowledged by all companies doing exploration work in the country. In the case of the PNG LNG Project, the Government decided to purchase a $19.6 \%$ interest 
from the existing license-holders, causing a change in equity holdings of each of the participants in the project.

This is a brief summary of a more complex commercial structure and relationship amongst the Project Companies. The main points to note here are that:

- The companies signing the Gas Agreement were also licensees who were involved with the Kutubu oil project and who will now be contributing gas to the project. While the companies are incorporated in PNG, except for the GoPNG entities, their parent and beneficial owners are foreign.

- After the signing and the acquisition by the State of its equity interests there were changes to the equity structure. In 2014 the GoPNG restructured its petroleum and gas investment into a new holding company called Kumul Petroleum Holdings Ltd.

- The Companies agreed that since ExxonMobil had the largest equity interest in the project, its subsidiary Esso Highlands Limited (EHL) would be the project operator responsible for the development and operation of the project facilities. EHL will also represent the Project's interests in dealings with contractors, government agencies, landowners, and other stakeholders.

- The GoPNG, while having an equity holding in the project, is also regulating and taxing the Project Companies and holds an equity stake in the project itself, directly and in trust for landowners.

\subsubsection{State agencies}

The State represents the national government, provincial, and local level governments, and relevant agencies. Again, the principle is any actor who may have an influence on generation and distribution of revenues.

The government agencies involved in the LNG project included: Treasury (Chair). National Planning, Lands, Attorney General, Public Enterprise - these departments constituted the Ministerial Economic Committee, made up of their Ministers and departmental heads which reported directly to the NEC. 
The key department that drove the Project was the Public Enterprise Department. Its Minister up to 2011 was Arthur Somare, the son of the Prime Minister. He had a very good relationship with William Duma, Minister for Petroleum.

The DPE, Department of Lands and Physical Planning (DLPP), Department of Environment and Conservation and Attorney General - while playing their respective roles were dictated by NEC decisions as the Project was given special and high priority treatment. The MEC played a pivotal role in fast tracking the project to the development forum phase. A lot of policies, regulations, and key legislative amendments were quickly facilitated under this arrangement.

Many State entities are directly important in revenue collection. In the case of PNG, the Treasury Department is central. It provides oversight of the IRC, and houses both the National Economic and Fiscal Commission (NEFC), responsible for calculating the distribution of grants to provinces, and the Secretariat for the EITI, the watchdog of the extractive industry. While the IRC is the main agency responsible for collecting and managing taxes paid to the national government, it only gives technical and legislative advice and makes exemptions. It must be noted that it is Parliament that makes tax laws which the IRC must enforce from time to time.

It has been observed that the Department of Petroleum and Energy (DPE) has a very bureaucratic structure and there has been very little reform within the department. The DPE continues to record licenses manually and, with limited technical capacity of its own staff, continues to rely on consultants to do the work within the department.

It is also at this stage that the national government realised the lack of capacity in coordinating and facilitating all the necessary legislative, regulatory and policy and fiscal requirements to bring the project to the final investment decision (FID). While this is not a specific provisiona FID triggers a whole process that requires key departments to monitor, regulate and ensure compliance with the terms of the development license.

Figure 7:2 below shows the coordinating arrangements set in place between the key departments and ministries, centred on a state coordination body - the GPCC - to ensure that all the legislative and regulatory requirements were met. 
Figure 7:2: PNG LNG Project:- State Coordination Mechanism

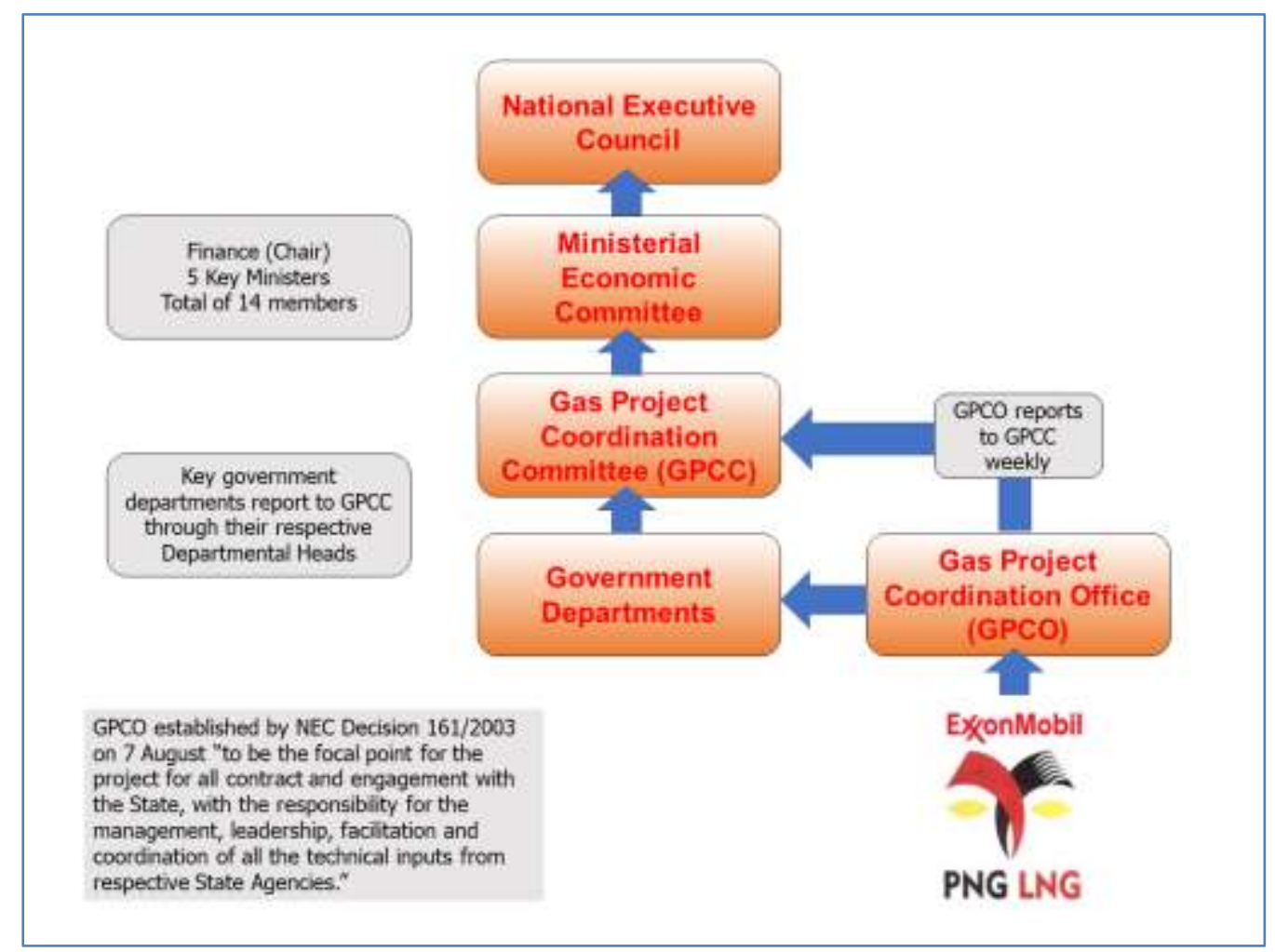

Adapted from Department of Public Enterprise (2014)

\subsubsection{Landowners}

The landowners have managed to assert themselves in the forefront of the national discussions on their role in the extractive industries. They have been recognized as victims of powerful interest groups, at least in the case of PNG. The fact that landowners own the land makes them an influential voice in the distribution of benefits. The Oil and Gas Act 1998 stipulates that ILGs are the preferred agents for receiving benefits. In March 2009, the following two Acts were passed: Land Groups Incorporation (Amendment) Act 2009 and Land Registration (Customary Land) (Amendment) Act 2009.

These two Acts were part of a reform to empower customary landowners to access their customary land for economic development and ensure participation by all members of the clan. The Land Groups Incorporation Act 1974 was designed to give "legal recognition of the corporate status of certain customary and similar groups" (Land Groups Incorporation Act, 1974).The ILG is a corporate vehicle that can be used - while at the same time maintaining a lot more transparency and accountability through the inbuilt management system where people are appointed to a committee and regular meetings held (GoPNG, 2009a, pp. 5-6). 
An important point to note is that the ILG prevents a person from being in multiple ILGs (ibid., p.6). Landowner Associations are expected to represent landowner groups in the negotiation of agreements on benefit sharing and other matters, including at Development Forums.

Compensation for landowners is a constitutional principle ${ }^{30}$. It has been a source of contention, tension, and conflict. Many landowners do not understand that the state can compulsorily acquire land for development purposes. At times compensation demands can be very high. There have been many lawsuits both within PNG and abroad by law firms representing landowners. An example is the suit brought by the Lower Ok Tedi and Fly river people of Western Province against BHP Minerals Ltd., BHP Billiton, OTML, and the State of PNG, in the Victorian Supreme Court (Australia) ${ }^{31}$ (Kirsch, 1997).

\section{Incorporated Land Groups and Customary Ownership}

The provisions of the Land Groups Incorporation Act 1974 allow for ILGs to be formed and registered, "recognize the corporate nature of customary groups", and "allow them to hold, manage and deal with land in their customary names" (Land Groups Incorporation Act, 1974:Introduction). The primary test for membership of an ILG is that the members are bound together by "relevant custom". Individuals may belong to more than one ILG. The sole purpose of ILGs is to give customary land a legal status. ILGs can "acquire, hold and dispose of customary land and rights in or in respect of customary land, in the manner (if any) and to the extent (if any) allowed by custom." (Ibid. S 13(2)(a)).

Since the passage of the Act in 1974, there have been many ILGs formed to take advantage of resource projects with their generation of claims for compensation and other benefits. Based on 2005 records, there were over 500 ILGs in the PIA at the time of inception of the PNG LNG Project (Goldman, 2009:Table 2.11, p. 219 ff.), and possibly 700-800 ILGs in total.

While there are alternatives to ILGs in the Oil and Gas Act for vesting benefits ${ }^{32}$, Goldman states that "For the petroleum industry, the Oil and Gas Act appears to imply that ILGs should

\footnotetext{
${ }^{30}$ The PNG Constitution s. 53 (2) requires "just compensation on just terms", and directs the state to make payments to property owners and landowners for any loss or damage suffered in the course of development, where the state has exercised its powers of compulsory acquisition of land.

${ }^{31}$ Slater and Gordon, a law firm took up a "class action" lawsuit against BHP in 1994 on behalf of the affected landowners of Ok Tedi Mine, for \$A2 billion for environmental damages.

${ }^{32}$ S. 169(2)(b) of the OGA provides that the Minister shall determine "the incorporated land groups or ... any other persons or entities who shall represent and receive the benefit on behalf of the grantees of the benefit." (Oil and Gas Act, 1998).
} 
be seen as the default system for benefit distribution in the absence of some other agreed upon system." (Ibid., p. 213). Forming and validating ILGs is one of the most complex tasks of benefit distribution under the OGA. The complexity arises from two reasons: (1) the strong incentive on local communities to incorporate as ILGs in order to register an interest in the benefits they assume will flow from resource projects; (2) the extraordinary complexity and diversity of PNG cultures and of their beliefs and practices regarding rights in land.

With respect to the Kutubu project and his research into the Foi, Weiner argued that the LGIA and ILGs were based on the "ethnographically indefensible" principle that ILGs can be formed from pre-existing stable customary land-holding units (called here "clans") when in fact there are no such units: Foi groups with interests and claims on land were "unstable, porous, nomadic, centripetal and fluid" (Weiner, 2007, p. 2). The Foi themselves saw ILGs simply as necessary mechanisms for the receipt of petroleum benefits. ILG membership, decisionmaking, and allocation of benefits were political and contestable: “... the ILG is simply seen by the Foi as a strategic device whose purpose is primarily political-economic rather than one of customary land management per se.” (Ibid, p. 5).

The Fasu people who host the Kutubu project are peaceful and semi-nomadic who have embraced the project but whose social world is also threatened not so much with environmental impact but the economic impact. Gilberthorpe, an anthropologist who did her research on the Fasu people, points out that: "Villages retain a traditional structure, subsistence lifestyle, and principles of socio-political exchange- while there is an underground pipeline and isolated production facilities" (2007, p. 2). The Fasu:

... loosely organize themselves around a patricore defined by biological ties between a father and his productively mature sons within a kinship grouping known as Kepo. Landholding was defined by paternal biological ties and social and cultural processes linking individual males to land through the transference of sago palms, ongoing segmentation and fusion within groups, and perception of male and female substance (ibid).

The Fasu received a lot of royalties which were distributed through the ILG systems (Gilberthorpe, 2007, p. 2). The imposition of this "judicial construct of corporate landholding groups" had the effect of changing membership of the kinship groups (kepo) by restricting others from joining who would normally join through other relationships (such as adoption). The Fasu people also used the cash benefits to attain status through various transactions that 
involved exchanges and gifting. The Kutubu project unwittingly transformed the people within the vicinity and the neighbouring districts in how they viewed resource projects. Using the work of Strathern and Stewart (1998), Gilberthorpe showed how "development values force indigenous customary land tenure principles to adapt in order to justify their use of, and rights to land" (Gilberthorpe, 2007, p. 4). While the colonial administration and plantation companies were gradual and evolutionary with the culture and land tenure system of the people, the mining and petroleum companies were very transformative.

Filer, Golub and others have reached similar conclusions about other Highlands social groups such as Ipili, Huli and Enga ${ }^{33}$.The 2008 Social Impact Assessment for the PNG LNG project (SIA) (Goldman, 2009) identified approximately 34,000 34 people in 117 communities in the Project Impact Area (PIA). The PIA covers "the people and places likely to be immediately and directly and/or indirectly impacted by the PNG LNG Project intervention and its associated benefit streams" (2009, p. 1). The SIA identified eight broad "linguo-cultural groups" within these communities and many sub-groups (2009, pp. 14-15). Two cultural groups "associated" with the project (not confined to those estimated to be in the PIA) dominate these numbers Huli $(130,000)$ and Kewa $(50,000)$, but there are many smaller groups and sub-groups. Goldman comments:

The numerical preponderance of Huli (who inhabit the catchments of Hides, Komo and Moran) within and outside the PIA has directly impinged on the strategies adopted by other groups in their various land benefit negotiations. It has contributed to a tendency by the numerically disadvantaged groups to adopt the litigation strategies, genealogical models, and principles of land tenureship of the numerically dominant Huli culture in an effort to compete with them. (2009, p. 145)

Custom with respect to land ownership and use varies widely but claims on land are almost always based on identification as members of a cultural group. Goldman describes the "culturally ideal" mode as "patrilineal (or agnatic) descent" when "people are born into, or

\footnotetext{
${ }^{33}$ Weiner and Glaskin observe that "The Ipili do not even have a word for 'clan'. Rather, like the word ruru for the Kewa of the Southern Highlands Province, the Ipili term yame refers to any group of people, at any level of organisation, who coalesce for any reason, and thus can refer, among other things, to a cognatic grouping at any level of inclusiveness." (Weiner \& Glaskin, 2007, p. 9)

${ }^{34}$ In nearly all the ExxonMobil publications 60,000 is the number of people stated as affected or impacted by the project. Nelson and Valikai give this estimate (2014, p. 5). The pipeline along the coast to the plant site covers about 20,000 people just by looking at the National Statistical information covering the LLGs.
} 
become members of, named groups commonly called clans by virtue of their capacity to demonstrate an unbroken line of descent to founding ancestors through successive generations of male links." (2009, p. 60)

In most agnatic societies people may thus also become members of groups by virtue of residence or long-term contributions to that group's affairs. This typically happens where, for example, a man moves to his mother's land and then has children who continue to work those gardens their father was given. (Ibid.)

In addition, "cognatic" kinship through one's mother or sister may also impose "important obligations of care, of land giving and exchange" (Ibid.).

Other complications include how land is "used". Hunters like Febi or Kubo may live in one place but regularly "return to traditional land to hunt, garden and work sago". (Ibid). In Huli culture, on essence, there is a high tolerance of multi-residence within the society such that members and segments of any one named clan are invariably spread across huge distances in Huli territory. The picture that emerges of any given piece of land tract is one composed of a mosaic of garden plots and forest areas the owners and users of which may or may not be resident, and who invariably trace descent to a wide variety of clans. (Ibid.)

Because of a multitude of reasons - warfare, severe flood or drought in gardens, better access to hunting areas, personal preferences — individuals often moved out of their natal clan territories to take up residence on a permanent or temporary basis with other relatives or friends. In other words, people were free to move out of their clan lands and stay elsewhere without necessarily losing any of their rights to land in their 'home' clan territory. (Ibid.)

The corollary to this land ideology is that Huli will and can justify their claims to be members of multiple licence areas on the basis of their believed history and oral accounts. Whilst this is not problematic to Huli, it is to a Government agency such as DPE faced with competing land ideologies of multiple ethnic groups who refuse to endorse the land claims of others for fear of depleting their own share of the benefit cake. Moreover, because of the multiple-parish residence practices of Huli there will be some $30 \%$ of project landowners in these catchments who will, legitimately in their eyes and in the O\&GA law, claim membership to multiple-licence areas for their benefit share. (Ibid.) 
Goldman concludes that "On the one hand operators could rightly indicate that despite all problems the ILG system 'has worked' in the sense that the 'benefits have flowed' to some project landowners. On the other hand, there has been systemic and persistent factionalising of ILGs presenting problems of further registration, monitoring and validation, and delayed payments." (2009). ... "The consensus is that groups have been opportunistically massaging their oral histories and manipulating the resource operator's lands personnel to maximise their financial shares." (Ibid)

\section{Landowner Companies}

Landowner Companies (LANCOs) are "incorporated under the PNG Companies Act, [to] give expression to local business aspirations and provide an avenue for direct and indirect employment and income generating activities. They have been formed to undertake business ventures." (Goldman, 2009, p. 212). LANCOs are commonly formed to bid for local construction projects related to the principal resource project. The landowner companies in the Kutubu project were the major beneficiaries from the standpoint of community benefits. The landowner companies either as stand-alone or joint venture have been part and parcel of the development and success stories of the resource projects.

Under the PNG LNG arrangements, participation by landowner companies was an integral part of the project. The UBSA contains a general reference to the engagement of landowner companies. The landowner companies would come under the National Content Plan of the project.

\section{Landowner Associations}

Goldman notes that Landowner Associations (LAs)

... are incorporated, under the Associations Incorporation Act, to collectively represent local landowners that may also have formed themselves into ILGs or Agencies within a PPL, PRL or PDL. Whereas ILGs function to distribute royalties and equity dividends, a Landowner Association is supposedly vested with authority to represent landowners in negotiations that may affect their social and economic welfare. Although LAs are not formally recognised by or alluded to in the Oil and Gas Act, they are often mandated by MOA/MOUs as for example in the Moran PDL 5 Development Agreement. (2009, p. 212) 
LAs have played an important political role in gaining access to resource project benefits. They are seen as "a vehicle used by political leaders to promote further ILG claims as a means of boosting their support base, power and control over LANCOs." (Goldman, 2009, p. 223). "The practice of dealing directly with Landowner Associations has tended to alienate grass roots understanding of, and support for, project and licence area agreements." (Ibid.). "The longitudinal SIA data from the IPA suggest that dissatisfaction with ILGs-LAs and LANCOs - is averaging more than 64\%. This should be a cause for anxiety to these organisations and responsible government agencies." (Goldman, 2009, p. 216)

The Parties to the UBSA acknowledge the undertakings under the Agreement in relation to participation by LANCOs in providing services to the LNG Project, namely:

- they must be financially and technically capable of the work they propose to perform;

- they must be able to provide their services competitively with international service providers on quality and price; and

- in accordance with the LNG Project operator business development plan, existing local companies must pre-qualify as to skills and business abilities to be able to provide their services to the LNG Project. (Pipeline License Benefit Sharing Agreement 2009: p35)

Under the PNG LNG arrangements participation by landowner companies is an integral part of the project. The UBSA says that "... [LANCOs] provide a mechanism for local entrepreneurs and businesses to compete for direct and indirect employment opportunities and for income generating activities associated with resource development project" (Nelson and Valikai 2013: 17).

\subsubsection{Other actors}

\section{Lenders}

The lenders were a "public-private Lender Group consisting of ExxonMobil, six public sector export credit agencies, and 17 commercial banks from Australia, China, Italy, Japan, Norway, the United Kingdom and the United States ... providing project finance" (Nelson \& Valikai, 2014, p. 16). This was one of the biggest project financing in the energy sector costing US\$15.7 billion (ibid). Conditions in the financing agreements had important effects, discussed later, on revenue distribution and borrower liabilities: the project partners had to provide completion guarantees and loan servicing had first call on revenues from the project. 


\section{International Development Agencies}

The International Financial Institutions (IFIs - IMF, World Bank, and ADB), UN agencies such as UNDP, and country donors, mainly the Australian government, have had a considerable influence on GoPNG policy relating to the project, particularly on management of its revenues.

The World Bank and the IMF have played a very important role in the development of the country since the early 1970 s and have continued to do so now. In most of their loans to the country since independence, both the World Bank and IMF have attached conditions. The most notable was the condition in which the World Bank released the structural adjustment program (SAP) in 1999, with stringent conditions on the use of mineral revenues (World Bank, 1999).

The SAP loan also, in effect, put an end to the Mineral Resources Stabilization Fund (MRSF). The World Bank contended that the government was abusing the MRSF and using it to finance unsustainable levels of public expenditure (World Bank, 1999). The World Bank also encouraged the government to undertake a major review of the fiscal regime in the mining and petroleum sectors, with the view of encouraging private sector investment and limiting the role of the government in the extractive industry (Daniel et al., 2000). It is worth noting that this was part of the Washington Consensus which guided the Bank's policy - encouraging private sector investment within the industry by reducing tax rates comparable to other developing countries (Ibid). The World Bank further encouraged the GoPNG to include a "sustainable development policy" in the planning framework that covered the provinces with resource projects. This was further followed by a second institutional strengthening project in 2007, funded by the World Bank (Hancock, 2010).

Government budgets refer to IMF reviews and advice on revenue management particularly in the development of the SWF. Other international agency reports, such as the 2014 UNDP Human Development Report (UNDP, 2015) and the World Bank's Systematic Country Diagnostic (World Bank, 2018) have addressed resource policy issues. Both of these reports advocated operationalizing the SWF, a stronger fiscal management regime, supporting the EITI, and reviewing taxation of resource extraction projects.

PNG remains the biggest recipient of Australia's foreign aid, which "accounts for 70 per cent of Papua New Guinea's total Official Development Assistance (ODA), which equates to around eight per cent of Papua New Guinea's national budget” (DFAT, 2018, p. 4). Australian development assistance for the 2017-18 year was A \$541 million, with \$472 million delivered 
bilaterally. The ADB delivers nine per cent of PNG's total ODA and the World Bank four percent (ibid).

The Australian government continues to view PNG as a very important neighbour not only because of the historical relationships (a colonial power and the relationship established during the Second World War) but also because of the geo-politics and economic potential of the country. Australia's official view is that it is in its interest that PNG remains a stable and viable democracy and to this end Australia supports governance and human development programs. On the economic side, PNG remains an important market for Australian products and the country also has a large Australian investment that needs to be protected.

The Joint Understanding between PNG and Australia on further cooperation on the PNG LNG Project which was signed between Hon Simon Crean of Australia and Arthur Somare in 2009 called for "a robust framework for effective and transparent governance of LNG Project revenue in place well in advance of the flow of revenue to PNG" and among other assistance "provide advice to PNG on the structure and operation (of funds) to assist PNG develop a Fund to manage effectively the PNG Government's future petroleum (oil and gas) revenues" (GoPNG \& Government of Australia, 2009).

\section{Contractors}

The PNG LNG project has "appointed eight engineering, procurement and construction contractors, all of which are either large national or multinational companies or joint ventures from seven different countries" (Nelson \& Valikai, 2014, p. 17). These companies have many years of operational experience and local companies contracted by them or individuals working for them will greatly benefit from the them through "shared learning" (ibid).

\section{Consumers}

LNG from the project is sold to buyers mostly in China, Taiwan and Japan ${ }^{35}$. PNG LNG plant is supplying "gas to four major LNG customers in Asia: China Petroleum and Chemical Corporation (Sinopec), The Tokyo Electric Power Company Inc, Osaka Gas Company

\footnotetext{
35 The World LNG Report gives the following figures for PNG exports of LNG in 2017 (MTPA): China 1.96, Japan 3.94, South Korea 0.06, Taiwan 1.74, Total 7.70. (International Gas Union, 2018, p. 16, Table 3.2). According to Nelson and Valikai, the four major customers are China Petroleum and Chemical Corporation (Sinopec), The Tokyo Electric Power Company Inc, Osaka Gas Company Limited, and the Chinese Petroleum Company from Taiwan (Nelson \& Valikai, 2014, p. 17)
} 
Limited, and the Chinese Petroleum Company from Taiwan" (Nelson \& Valikai, 2014, p. 17). The commercial details of these sales are not available.

The 2019 Budget was the first to give any information about how LNG prices are determined ${ }^{36}$. It reported that "The natural gas market is globally segmented" and "the current pricing of Papua New Guinea's LNG exports is based on norms observed in the Asian LNG market and involves long term contracts linked to the price of oil" (Abel, 2019, p. 222). ${ }^{37}$ The Budget said that supply contracts in the market were typically for 15-20 years and contract prices typically varied with an average of Japan crude oil import prices (called Japan Crude Cocktail (JCC)), which in turn was highly correlated with Brent Crude oil prices, lagged by about five months ${ }^{38}$.

\subsection{Legal and fiscal framework: overview}

This section provides an overview of the principal legislation governing the generation and distribution of revenues in oil and gas projects. PNG law affects the finances of oil and gas project companies in the following ways:

- Compensation of landowners under the Mining Act;

- Taxation of project companies under the Income Tax Act 1959;

- Royalties and development levies due under the Oil and Gas Act 1998;

- State equity participation in projects;

- Benefit sharing arrangements.

\subsubsection{Sector regulation}

The petroleum industry in PNG is regulated under three principal statutes: the Oil and Gas Act 1998 (OGA), the Environment Act, and the Mining Act. The OGA defines petroleum licenses and makes provision for benefits to landowners and provincial and local level governments arising from the production of oil and gas. The Environment Act regulates many of the biophysical and social conditions and impacts arising from any resource development. The Mining Act covers various compensation and grievance processes.

\footnotetext{
36 "Box 1: The Relationship between Crude Oil and Liquefied Natural Gas (LNG) prices" (Abel, 2019, p. 30).

${ }^{37}$ At least one spot shipment has been reported: (Jaganathan, 2018).

${ }^{38}$ LNG prices are very highly correlated with 5 month lagged oil prices implying that LNG contract prices are indeed indexed on crude oil prices. Price information for LNG (Japan CIF imports) and OIL (Brent crude index, lagged 5 months) obtained from a commodity price database published by the World Bank (World Bank, 2019).
} 


\section{State ownership of minerals and petroleum}

When PNG gained independence in 1975, much of the legislation covering the various sectors was either adopted or inherited by the new State. The PNG Constitution under section 248 affirms that the new PNG nation-state simply inherited the mineral and petroleum property rights of the colonial government upon independence (PNG Constitution, 1975). The colonial legislation dealing with mining and petroleum products was retained as part of the laws of PNG (Kuwimb, 2010). The Mining Ordinance 1911 (Papua) removed the rights of customary landowners in petroleum by deeming all petroleum to have always been the property of the Crown (ibid). The provision was enacted in the new petroleum legislation in 1976. This legislation provided in section 5 (1) that: "all petroleum and helium at or below the surface of any land is, and shall be deemed at all times to have been, the property of the state". This provision was carried over into the Oil and Gas Act 1988 section 6 (1).

\section{Mining Act 1992}

The main legislation in PNG that regulates minerals activities today is the Mining Act 1992 and the Mining Safety Act (Chapter 195A). Section 5(1) of the Mining Act grants the State "all minerals existing on, in, or below the surface of any land in PNG'. The Mining Act governs some aspects of other extractive industries, including oil and gas.

While the Mining Act provides the overarching legal framework, the operations of any resource projects from operation/production through to closure and the distribution of benefits including resolving grievances are contained in project specific understandings, agreements and contracts. Developers of resource projects generally enter into an agreement with the State of PNG in addition to obtaining a resource development licence or mining tenement. This typically involves a broad consultation process with all affected parties. The details of contracts and licences are confidential and not publicly available. The State has the right, but not the obligation, to acquire up to $30 \%$ of a participating interest in a designated mining project.

\section{Oil and Gas Act 1998}

By 1998, a new Oil and Gas Act was passed by Parliament and formed the basis for all the new oil and gas projects (Oil and Gas Act, 1998). The Act is administered by the Department of Petroleum and Energy. The Act provides for: 
- The Minister to grant licences for exclusive rights for companies to prospect for petroleum (including natural gas) ${ }^{39}$, secure fields for future development, and develop (extract and sell) in the licence area (Ibid. S. 59).

- A requirement for licensees "to pay compensation ... to the lawful owners and rightful occupiers of, and any persons interested in, any private land in relation to their several interests, in respect of the entry on or occupation of the land" (Oil and Gas Act, 1998:S.118(1)).

- Royalties of $2 \%$ of well-head value of petroleum produced (s. 159(1)) to benefit "project area landowners, the affected Local-level Governments and the affected Provincial Governments of a petroleum project" (s 168(1))

- A development levy of $2 \%$ of well-head value payable to "affected Provincial or Locallevel Governments" (s. 160)

- A $30 \%$ rate of tax on assessable income from projects (Sch. 4.4)

- The right of the government to acquire, for a consideration, up to $22.5 \%$ participating interest in a project, for itself or on behalf of landowners and Local-level Governments (s 165)

- Benefits for project area landowners to be held in trust (s 176)

- A Gas Agreement between the government and licensees covering the government's equity interest and "any other matters", including how the Oil and Gas Act or other Acts will apply to the project (s 184)

- A process, triggered by an application to develop a field for production, to define the affected landowners and subnational governments, and enter into a development agreement (s.50) with them on how project benefits will be shared and what other conditions will apply to the project.

\footnotetext{
39 The definition of "petroleum" includes "any naturally occurring hydrocarbons, whether in a gaseous, liquid, or solid state".

${ }^{40}$ Where both a Royalty and a Development Levy has been paid, the royalty paid "shall be deemed to be income tax paid" (s. 159(4)(b))
} 
The Department of Petroleum and Energy issues licenses based on the development status of each field. The first license issued is normally a petroleum prospecting license (PPL). A petroleum retention license (PRL) permits the retention of rights to discoveries that are not currently commercially viable. The license is retained by the holder for a maximum period of 15 years. During this period, the licence can be upgraded to a petroleum development license (PDL) when it has been determined that there is commercial viability to proceed to the development phase of the discovery. From September 1995 until the present time a total of eight PDLs have been issued, five for crude oil exports and three (Hides, Angore, and Juha) for $\mathrm{LNG}$ and condensate export. ${ }^{41}$

The applications for licences to develop gas fields, particularly the Hides field, were a relatively new development. The practice of exploration companies in the mid-1980s and 1990s had been to look for oil and to abandon or cap any gas discoveries. It would be another 30 years, until 2017, before a specific PNG Natural Gas Policy was developed.

The process of applying for and granting a PDL triggers other processes:

- Applicants are required to prepare "a full-scale social mapping study and landowner identification study of customary land owners" in the licence area and other areas that may be affected by the development (Ibid. S. 47) and a "socio-economic impact study as part of the environmental plan required under the Environmental Planning Act 1978". "A petroleum development licence will not be granted until PNG Conservation and Environment Protection Authority (CEPA) grants environmental approval. CEPA is the government agency responsible for administering the Environment Act 2000.” (Ernst \& Young, 2017b, p. 97).

- Before granting a licence, the Minister has to convene a Development Forum of the applicant, project area landowners, and central, provincial, and local government representatives (Ibid. S. 48). As part of that process, the DPE prepares a proposal "for the equitable sharing of the equity benefit and the royalty benefit amongst project area landowners" (Ibid. S. 49). The definition of these benefits and the principles for sharing them out amongst project landowners are discussed below.

\footnotetext{
${ }^{41}$ DPE Briefing notes provided to the researcher by DPE.
} 
- " $[T]$ he the State and the project area landowners, the affected Local level-Governments and affected Provincial Governments may enter into a co-ordinated development agreement" (Ibid. S. 50A). The development agreement may include an agreement on sharing out of the equity and royalty benefits and other grants out of the public budget, (Ibid. SS 170173). Total benefits granted in this way may not "exceed $20 \%$ of the total net benefit to the State from that petroleum project as determined in a cost-benefit analysis" (Ibid. S. 174).

- Sub-national governments and landowners are free to acquire additional participating interests in the project from the PDL holders on commercial terms (Ibid. S 175).

- All benefits are held in trust by a subsidiary of the state Mineral Resources Development Company (MRDC) (Ibid. S. 176). In the case of landowners, "unless otherwise agreed between the State and the grantees of the benefit or prescribed by law, the beneficiaries of the trust shall be incorporated land groups [ILGs] on behalf of the grantees" (Ibid.).

\section{Environment Act}

The Environment Act requires an Environmental Impact Assessment (EIA) to be undertaken by any resource project, followed by a public review process. The EIA is a two-step process: the submission of an Environmental Inception Report (EIR) followed by the submission of an Environmental Impact Statement (EIS). The Department of Environment and Conservation (DEC) has specific guidelines for the conduct of EIA and preparation for EIS and Social Impact Assessments. All projects must also take into account relevant industry practice policies (Nelson \& Valikai, 2014).

Other general legislation and regulations and policies that must be observed include: Fauna (Protection and Control) Act 1996, Oil and Gas Regulation 2002, and Industrial Safety, Health and Welfare Act 1961. In their case study on the project, Nelson and Valikai also note "The case study illustrates the mutually reinforcing approaches the PNG LNG Project has taken in adapting internal corporate policies, standards, and risk management systems to local context and culture, while also applying and complying with external principles and standards, such as the IFC [International Finance Corporation] Performance Standards that have become integral to most large-scale project finance agreements, in addition to host country regulations." The IFC environmental guideline is the de facto standard for financial institutions regarding the assessment of major development projects around the world. (Nelson \& Valikai, 2014, p. 6). 


\subsubsection{Fiscal framework}

This section discusses the law and policy governing management and distribution of revenues from the project.

\section{Taxation of gas projects}

Applicable tax law: General tax law applies to companies operating in the extractive industries, but there are specific applicable sections of the Income Tax Act 1959 as well in Division 10 Mining, Petroleum and Designated Gas Projects. Two subdivisions relate specifically to gas projects: Subdivision A: General provisions applicable to mining, petroleum and designated gas projects and Subdivision D: Specific provisions applicable to designated gas projects. The PNG LNG project is a "designated gas project" under the Act. The general rate of income taxation for gas projects is $30 \%$, for both resident and non-resident companies.

Project basis of assessment: Project revenues and expenses for extractive industries are ringfenced for the purposes of taxation: “ ... effectively taxing each project like a separate taxpayer. This means that revenue, expenses and losses from each project are effectively quarantined from each other, with any expense attributable to more than one project apportioned to the projects on a reasonable basis." (Ernst \& Young, 2017b, p. 52). The ring-fencing of expenses does not apply to some exploration expenditure and expenses of discontinued projects, which can be pooled for deductions, subject to a cap. However, tax losses for resource projects can be carried forward indefinitely.

Accelerated depreciation: Deductions from taxable income for depreciation of capital assets is normally calculated on a straight-line method based on the Commissioner's determination of effective life of the asset. However, eligible companies (which would include oil and gas projects) can elect to use a diminishing value method. If they do, depreciation can be accelerated to 1.5 times that available on the ordinary effective life. They can also deduct an extra $20 \%$ of capital value in the initial year of income. (Internal Revenue Commission, 2018, p. 4) and Income Tax Act (Income Tax Act, 1959. Sections 73-78 and 155F.) Accelerated depreciation has considerable tax advantages for large capital-intensive projects and has been often cited as a reason for the delayed revenues from the PNG LNG project.

Infrastructure Tax Credit: In addition, "[c]ompanies can claim expenditure on prescribed infrastructure projects as a credit against tax payable. The credit amount is generally limited to the lesser of $0.75 \%$ of assessable income or tax payable each year." (Ernst \& Young, 2017b, p. 
53). The Infrastructure Tax Credits (ITC) scheme is "a public/private partnership model to promote the development of infrastructure in areas where mining and petroleum resource projects or agricultural companies are operating." (Ibid.)

Fiscal Stability: A Fiscal Stability Agreement between developers and the government provides for an additional $2 \%$ rate on income from the project until the "foundation volume" is delivered. As noted below, an Agreement is in force for the PNG LNG Project

Stamp Duty: The transfer of petroleum licenses is subject to stamp duty under the Stamp Duty Act. Concessional rates apply to transfers between affiliates for the purpose of restructuring the ownership of gas project licenses or for redeterminations under the CDOA.

Additional Profits Tax: The Income Tax Act also provided for an Additional Profits Tax (“APT") if the returns for a particular project exceeded a "reasonable return threshold" of $15 \%$. "The purpose of APT was to provide a progressive tax instrument to tax economic rents of highly profitable resource projects." "Additional profits tax (APT) [now] applies only to designated gas projects (APT for mining and petroleum projects was abolished from 6 June 2002).” (Ernst \& Young, 2017b, p. 53) It does not apply to the PNG LNG project.

Crediting of royalties and development levies against company tax liability: The revenue from royalties and development levies on the Project was already reduced by calculating them as a percentage of wellhead value after all downstream costs, rather than the gross value of the gas exported. Their value was further reduced by the government's agreement that they should be offset against taxable income, rather than a deduction for expenses.

\section{Public financial management}

The Public Finances (Management) Act 1995 (PFMA) (Public Finances (Management) Act, 1995) sets the basic architecture of accountability for "public moneys", covering all money received "on behalf of the State" at both national and sub-national levels, to be paid into the Public Account. At a national level the Public Account consists of a Consolidated Revenue Account for receipts and payments generally governed by Parliamentary appropriation (ss 13 and 14); and a Trust Fund comprising Trust Accounts "established as directed by the Minister or prescribed by any other law" covering moneys held in trust or "the proceeds of commercial or trading activities carried on by any arm, agents or instrumentality of the State" (s. 15). 
The Act provides for a National Budget for each fiscal year, prepared by the National Executive Council and submitted to Parliament. (s 22). The Budget must contain specific estimates of revenue from "designated mining enterprises" and "designated petroleum enterprises" to be reported in Volume I of the Budget (s34B). Revenue from mining and petroleum up to $10 \%$ in excess of estimate must be applied to debt reduction unless otherwise appropriated by Parliament. (s 34C).

Borrowing must be authorised by Act of Parliament and is subject to a limit set by the Central Banking Act 2000. Debt servicing is a permanent appropriation. The Minister may guarantee borrowings and authorise loans. The Act sets reporting requirements and standards for all public bodies (s. 63). The Public Accounts Committee of Parliament is to review accounts of the Public Account and (on its own motion - s.87) of public bodies. The Audit Act (Audit Act, 1989) mandates the Auditor-General to audit and report annually to Parliament on public accounts and transactions relating to public moneys and property (s. 3(1)). Audit powers cover all arms of National and Provincial Governments and all public bodies except KPHL. The Auditor-General nevertheless reported on an audit of KPHL and subsidiaries for 2016, made under the Companies Act, and reported mid-2018 that a 2017 audit was "in progress").

The Fiscal Responsibility Act (Fiscal Responsibility Act, 2006) requires fiscal policy to be set in a "sustainable medium term framework" having regard to a Medium Term Fiscal Strategy (MTFS) and a Medium Term Development Strategy. There have been three MTFSs: for 20022007, 2008-2012, and the current 2018-2022. The Act establishes an annual fiscal reporting framework: a Budget Strategy Paper, to be published at least three months before the presentation of the Budget (typically in November/December before the start of the budget year, a Mid-year Economic and Fiscal Outlook ${ }^{42}$, and a Final Budget Outcome.

The Public Money Management Regularisation Act 2017 (Public Money Management Regularisation Act, 2017), passed in December 2017, is a significant modification of the rules set by the Public Finances (Management) Act 1995 for management of public money through the Consolidated Revenue Fund. After a three-year transition, with some exceptions, "public and statutory bodies shall receive public money solely by appropriations made by or under the

\footnotetext{
${ }^{42}$ In July/August each year. The PNG fiscal year is a calendar year.
} 
National Budget" (s14(1))". The exceptions however include the Kumul companies, including KPHL (s. (3)(2)).

\section{The EITI Framework}

The EITI is a multi-stakeholder initiative that focusses on transparency as an approach and as a tool that can be used to eradicate corrupt practices. It has membership across the world. The EITI is made up of various groups including the governments, mining and petroleum companies, civil society groups including the media, and international organizations (including the donors). ExxonMobil has been a member of the global EITI since 2002. Since the inception of the PNG LNG project it has pushed for PNG to become a full member (Nelson \& Valikai, 2014, p. 29).

The EITI is the only framework that "voluntarily" facilitates revenue management transparency by the government and its financial arrangements with resource companies. Companies operating within participating countries are required to publish what you pay (PWYP). Second, government officials must record the revenues they receive and entrust an independent auditor/administrator to compare extractive sales and revenues (Avalos et al., 2015, p. 357).

Governments must create a multi-stakeholder group which includes civil society representatives. This multi-stakeholder group is tasked to evaluate the information provided by the companies and government and reviewed by an independent evaluation (Aaronson, 2011, p. 51$)^{43}$. Finally, an outside organization checks and validate the reports, part of the validation "evaluates EITI implementation in consultation with stakeholders" (Ibid).

Discussions on an EITI for PNG started in 2006 in the context of the PNG Gas Project ${ }^{44}$. The Asian Development Bank sought government implementation of the EITI as a condition of its financing of the project. The government initiated a scoping study, and, in April 2011, the NEC agreed to set up a working group to come up with a detailed workplan for its introduction in PNG. In 2013 the NEC agreed to apply for membership of the EITI and to establish a MultiStakeholder Group and a Secretariat. The EITI International Board accepted PNG as a

\footnotetext{
${ }^{43}$ Citing "EITI (Extractive Industries Transparency Initiative). 2010. Business Guide.” (See also EITI, 2013).

${ }^{44}$ Information on the history of EITI in PNG obtained from a Treasury background paper (GoPNG, 2014b) and the PNG EITI website (EITI PNG, 2019). Information on the history of EITI in PNG obtained from a Treasury background paper (GoPNG, 2014b) and the PNG EITI website (EITI PNG, 2019). Information on the history of EITI in PNG obtained from a Treasury background paper (GoPNG, 2014b) and the PNG EITI website (EITI PNG, 2019).
} 
"candidate country" in 2014. Since then, PNG has been submitting a process of "validation": independent audits to assess its progress towards meeting the requirements of the EITI Standard.

In the meantime, the PNG EITI has commissioned five reports on annual extractive industry transactions with the government, for 2013-2017. The international accountancy firm Ernst \& Young has prepared each report. The last three of these reports contain information on the operating phase of the PNG LNG project. The research draws on these reports for discussion of project financial flows during the operating phase.

The EITI audits draw on information provided by both companies and government entities with transactions in extractive industries. The quality and comprehensiveness of this information has improved over the five years of the audits, but there are still significant gaps. The last validation report, in April 2018, drew on Ernst \& Young's 2016 annual report only (the 2017 report was not available when the validation team was doing its work). However, the scorecard produced by the validation highlighted areas which are still problematic, particularly in the quality of reporting by government organisations on the payments received, and confused and inadequate accounting for payments by these organisations to subnational governments and landowners. These problems are discussed later in this Chapter.

\section{Entities for management of revenues}

The government manages the revenues it receives from resource projects as follows ${ }^{45}$ :

- Taxation: to the Internal Revenue Commission (Consolidated Revenue Account);

- Royalties and development levies: to a trust account within the Trust Fund (the trustee is a subsidiary of the Mineral Resources Development Company (MRDC);

- Income from equity participation: to a state company; at the time of the Gas Agreement, this was Petromin but in 2015 following the reorganisation of all the GoPNG's equity interests, it is now Kumul Petroleum Holdings $\operatorname{Ltd}^{46}$.

\footnotetext{
45 The main points about this is that the rules for getting money out of these accounts are different for each of these entities and the Trust Fund entities have been used as borrowing vehicles.

${ }^{46}$ The dividends meet the definition of "public money" so technically the KPHL account is an account within the Trust Fund (see the PFMA).
} 


\section{Kumul Trust Holdings}

The state decided to consolidate all the main state-owned enterprises and then to use it as collateral to secure funding to finance its equity in the project.

In 2015, changes were made to PNG SOEs to coordinate the National Government's participation in commercial activities. All the state's companies with petroleum interests were aggregated under Kumul Petroleum Holdings Ltd (KPHL). The Independent Public Business Corporation of PNG was renamed Kumul Consolidated Holdings Limited $(\mathrm{KCH})$ and restructured under a new Act of Parliament. $\mathrm{KCH}$ remains the trustee of the General Business Trust (GBT). The State remains the beneficiary of the GBT (Kumul Consolidated Holdings, 2017).

Figure 7:3 below shows the state's assets that have been consolidated under the Kumul Trust Holdings. The bulk of the state's assets and investments in the petroleum and the mining industry are held by Kumul Mining Holdings limited (looks after state equity in mining projects) and Kumul Petroleum Holdings Limited (KPHL) (looks after state equity in petroleum projects) and the Kumul Consolidated Holdings Limited (KCHL) which looks after all the other state owned enterprises (SOE), share holdings and the state's investments.

KPHL has gone through number of restructurings and name changes since its establishment in 2008. In June 2015 the Kumul Petroleum Holdings Ltd Authorization Act 2015 made KPHL the state nominee for all investments in the oil and gas sectors (Kumul Petroleum Holdings Ltd, 2019). KPHL is represented on the PNG LNG project's sales and marketing committees. 
Figure 7:3: Kumul Petroleum Holdings Ltd Interests

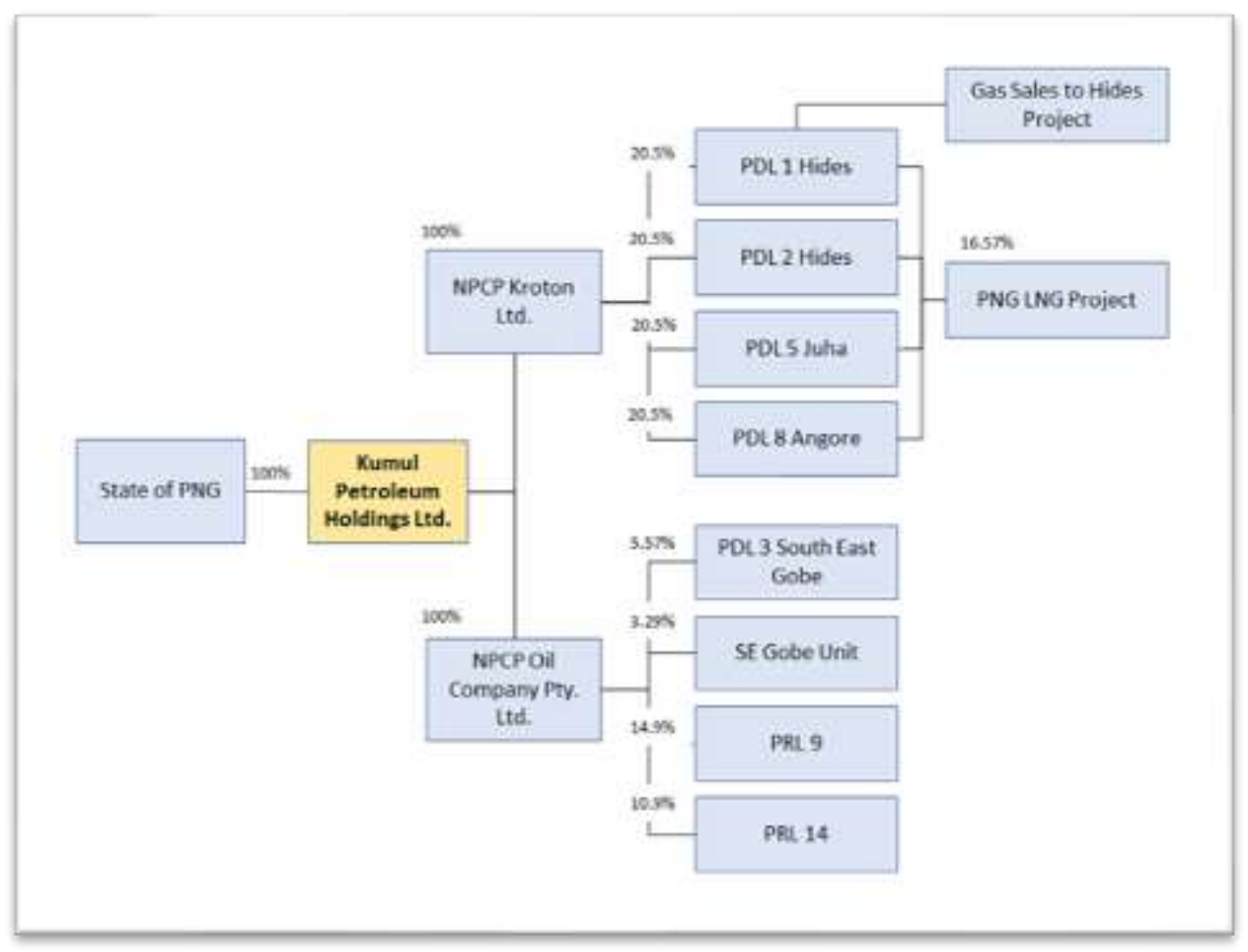

Adapted from Ernst \& Young (2017a, p. 119, Figure 50)

\section{Mineral Resources Development Company}

The Mineral Resources Development Company Ltd (MRDC) is a 100\% state owned enterprise through an Act of Parliament. It is directly under the Prime Minister's Office. The Prime Minister is the single shareholder on behalf of the people of MRDC.

MRDC acts as a trustee shareholder for beneficiary landowners and provincial governments. Its other roles are:

(1) Acquiring, financing and managing equity interest in mining and petroleum projects for and on behalf of the State, landowners and provincial governments in the most costeffective way;

(2) Payment of royalty and equity to petroleum project landowners;

(3) Holding and managing landowner and/or provincial government interest in mining and petroleum projects;

(4) Developing community infrastructure and assisting with providing basic service to project area landowners. 
The MRDC has three mechanisms by which it holds or manages interests on behalf of the government of PNG.

(1) Management of landowner/provincial government interest in resource projects, as trustee, under a management agreement.

(2) Direct equity in resource projects.

(3) Subsidiary companies that hold equity in trust for landowners. The boards of these companies are chaired by landowners.

The MRDC plays a very important role as it is the only legislated company that operates on behalf of landowners and provincial governments.

The MRDC which is the fund manager of the petroleum and mining equities of landowners believes the distribution and percentages given to the landowners and provincial governments is insufficient when distributing the shares to the many groups. The $2 \%$ was not enough and there was a need to relook at the benefits for the provincial governments and landowners. In the mining projects, landowner equity was about $5 \%$ and another $25 \%$ for the state, a total of $30 \%$. In the petroleum projects it is $2 \%$ for landowners and up to $20 \%$ option for the state.

The MRDC Managing Director said a benchmark was set in the Kutubu oil project, the first petroleum project when it was given $6.75 \%$ where the landowners were given $4.05 \%$ equity and the provincial government $2.7 \%$ but that was never followed in subsequent projects. In the petroleum projects like Moran, Gobe and Hides, the provincial government missed out. He called for a new formula to be worked out to cater for the different beneficiary groups. He also pointed out that landowner identification was a major problem and should be addressed as more than K450 million are still parked in trust accounts awaiting proper landowner identification before payments can be made.

Once the Royalty distribution had been agreed to, section 176 of the Oil and Gas Act dictates that $40 \%$ of the final distribution will be cash, $30 \%$ will be placed in Future Generations Trust, and the remaining $30 \%$ kept in Community Investments Trust ${ }^{47}$.

\footnotetext{
${ }^{47}$ Report given to researcher from MRDC $2^{\text {nd }}$ Petroleum and Energy Summit, March $19^{\text {th }} 2018$.
} 
Mr Imbi Tagune is a very senior executive of the MRDC and has served in various capacities including as acting managing director over the years. In the interview conducted with him, he highlighted the important role that MRDC plays within the extractive industry:

\section{Describe the role MRDC plays in the extractive industry.}

As you know the state owns all the minerals and petroleum by, law but the state does not own the land. The land is owned by the people. Our role is to ensure that landowners (papa ground) again under the law are paid what is rightfully theirs. We are devoted to ensuring that the landowners - no matter how remote or inaccessible they are, must be paid their benefits.

Furthermore, MRDC supports communities and groups from project areas in providing assets such as ambulances, generators for schools, financing construction of buildings for community use. Given the lack of development in a lot of the areas - we step in from time to time to assist these community groups (include churches). ... You have to remember that we are a management company managing landowner monies .... But when we see a big need in a community - we move in quickly to assist.

2. Could you briefly discuss how you make the payments to landowners and how do you know that monies paid are distributed fairly to the intended beneficiaries

As I said our priority apart from managing the landowner monies is also to ensure that the cash component of the royalties and other financial benefits are quickly paid to the landowners. The true landowners. We pay those landowners who have bank accounts directly into their bank accounts and those that do not have bank accounts we physically travel to the villages and make public payments to the landowner leaders (Headman)... how they distribute the monies is their prerogative. I am the one that travels to these villages. I just want to see that our people are not deprived of their rightful benefits.

... with the PNG LNG case, it is a very big issue. MRDC must get it right (in terms of identifying the real and true landowners) before payments can be made. After landowner identification (which is the vetting process) we will be assisting in the election of office bearers and the opening of bank account for the groups for monies to paid directly into.

\section{What about monitoring of the monies paid to the landowners}

Unfortunately, we do not monitor what they use their monies on. As I said paying them their rightful financial dues is very important for me. Other things such as monitoring is secondary. 


\subsection{The Main Project Agreements}

This section discusses the development and content of the main project agreements and how they influenced the generation and distribution of revenue from the project.

Table 7:2 below shows the main agreements that govern the relationship between the various parties and purpose of those agreements.

Table 7:2 PNG LNG Project: Main Agreements

\begin{tabular}{|c|c|c|c|}
\hline Agreement & Parties & Signed & Purpose \\
\hline $\begin{array}{l}\text { PNG LNG } \\
\text { Coordinated } \\
\text { Development and } \\
\text { Operating } \\
\text { Agreement } \\
\text { (CDOA) } \\
\end{array}$ & PNG LNG Project Companies & 2008 & $\begin{array}{l}\text { Provides the commercial } \\
\text { framework for the PNG LNG } \\
\text { Project }\end{array}$ \\
\hline $\begin{array}{l}\text { PNG LNG } \\
\text { Agreement or Gas } \\
\text { Agreement }\end{array}$ & $\begin{array}{l}\text { Esso Highland (subsidiary of } \\
\text { ExxonMobil), other PNG } \\
\text { LNG Project Companies and } \\
\text { the State }\end{array}$ & 2008 & $\begin{array}{l}\text { Establishes the fiscal regime and } \\
\text { legal framework by which the } \\
\text { PNG LNG project is to be } \\
\text { regulated throughout its lifetime } \\
\text { and sets the terms and mechanism } \\
\text { for State equity participation in the } \\
\text { project }\end{array}$ \\
\hline $\begin{array}{l}\text { Fiscal Stability } \\
\text { Agreement }\end{array}$ & $\begin{array}{l}\text { PNG LNG Project Companies } \\
\text { and the State }\end{array}$ & 2009 & $\begin{array}{l}\text { Locks in aspects of the fiscal } \\
\text { regime (taxes, duties, fees) in } \\
\text { order to provide the Project } \\
\text { Companies with long-term } \\
\text { certainty regarding their } \\
\text { investment }\end{array}$ \\
\hline $\begin{array}{l}\text { Umbrella Benefit } \\
\text { Sharing } \\
\text { Agreement } \\
\text { (UBSA) }\end{array}$ & $\begin{array}{l}\text { State, provincial and local } \\
\text { level governments and } \\
\text { landowner groups impacted by } \\
\text { the project }\end{array}$ & 2009 & $\begin{array}{l}\text { Outlines how the state's project } \\
\text { revenue streams will be shared } \\
\text { with project area landowners, local } \\
\text { level governments and provincial } \\
\text { governments. }\end{array}$ \\
\hline $\begin{array}{l}\text { Licence Based } \\
\text { Benefits Sharing } \\
\text { Agreement } \\
\text { (LBBSA) }\end{array}$ & $\begin{array}{l}\text { For each PDL: state, } \\
\text { provincial and local level } \\
\text { governments and landowner } \\
\text { groups impacted by the project }\end{array}$ & 2009 & $\begin{array}{l}\text { Outlines the distribution of } \\
\text { benefits, including those received } \\
\text { by the state under the Oil and Gas } \\
\text { Act, to the various governments } \\
\text { and landowners for each PDL. }\end{array}$ \\
\hline
\end{tabular}

Adapted from Ernst \& Young (2017b, p. 104)

\subsubsection{Coordinated Development and Operating Agreement (CDOA)}

The CDOA fulfils a requirement of the Oil and Gas Act (s. 123A) that "where there is more than one holder of a licence, the holders shall, as soon as reasonably practicable after the date of grant of the licence, provide to the Director a copy of an agreement between holders, relating to designation of operator and the conduct of operations in relation to that licence." The participating licence holders signed a CDOA for the PNG LNG project in March 2018. 
The CDOA is the key agreement that gives all the participants in the PNG LNG Gas Agreement their legal mandates. The CDOA has never been made public and its description or analysis here of its provisions are based on secondary sources. The CDOA (named in the Gas Agreement as the agreement of 13 March 2008 by the Project Companies) is referenced in the Gas Agreement and in the UBSA.

\section{Project structure}

The CDOA creates an unincorporated joint venture among the Project Participants. This is described in the EITI Report for 2015:

The project partners have jointly under relevant agreements agreed to develop the project as an integrated LNG project. The decision to integrate the interest has been recorded under the PNGLNG Coordinated Development and Operating Agreement (CDOA) executed on the 13 March 2008. Under the CDOA, the parties have agreed that it will govern their relationship as the owners of the Project and the conduct of operations to design, execution, operation and abandonment will be governed by it. The CDOA further defines each participant's interest in the Project consistent with their licences interest and provides the manner of calculating their interest. The Project required a legal entity to be created which [sic] each participating interest holders holding shares in it. (Deloitte, 2015, p. 122)

As recorded in the Gas Agreement: "The licensees have agreed ... to aggregate their natural gas reserves and to sell those reserves into international markets after compression and liquefaction, with costs and revenues shared between the licensees on the terms agreed ...". (GoPNG, 2008, p. 12). The parties to the CDOA also include the holders of the Oil Field Licenses: the CDOA imposes contractual obligations on these parties to deliver Associated Gas to the Project. Table 7:3 lists the licensed gas fields and Figure 7:5 below shows the interests in the licences for each field.

Figure 7:4 below portrays the legal structure of the PNG LNG Project. At its centre is PNG LNG Global Company LLC (GloCo), the venture's financing and marketing company. Each of the PNG LNG participants owns the company in proportion to their PNG LNG share. GloCo has been established and incorporated under the laws of the Commonwealth of the Bahamas. Its activities include borrowing and on-lending to the participants of the project and the purchase and re-sale of the project liquids (LNG and LPGs). GloCo receives direct payments 
for PNG LNG Project LNG and liquids sales. Sales proceeds are returned to participants in accordance with financing documents (net of financing and operating costs).

Figure 7:4: Legal structure of the PNG LNG Project

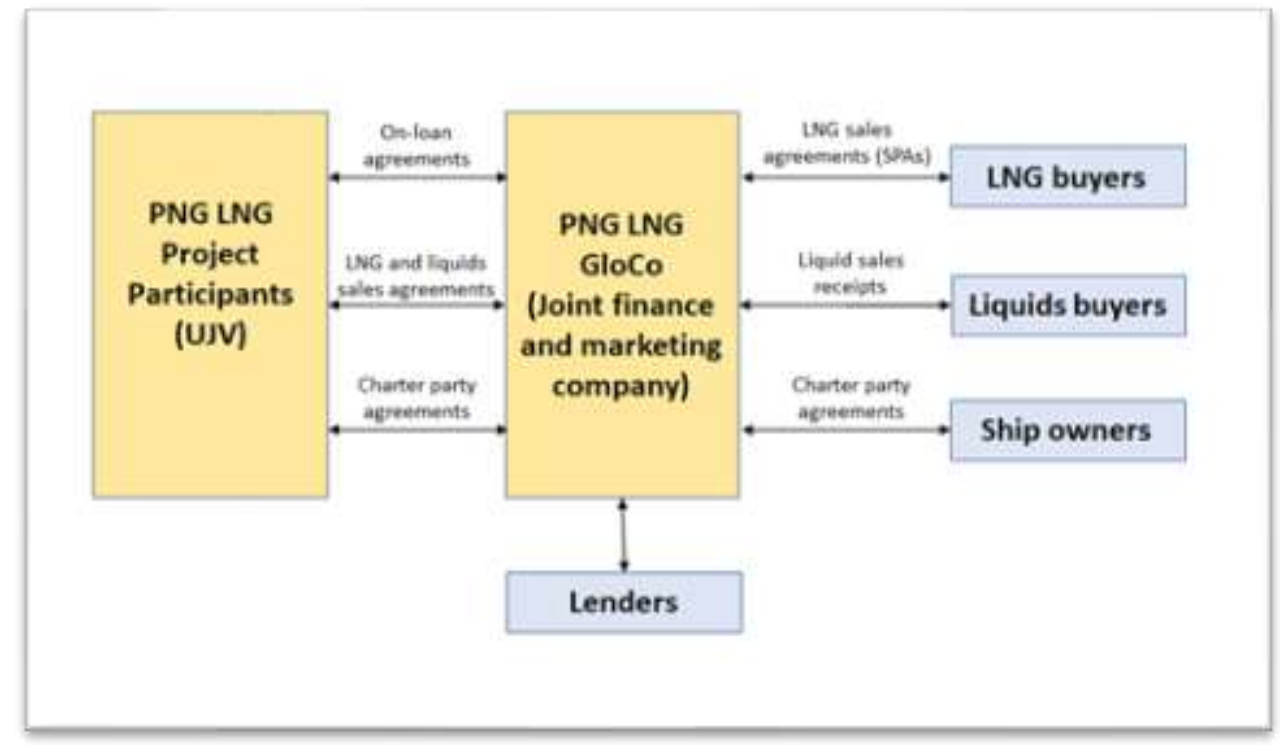

Adapted from Somare (2017) ${ }^{48}$

GloCo is a shell company which has no staff. It is operated on behalf of the project partners by the designated project operator. As required by the Oil and Gas Act, the CDOA designates the operator of the project, currently Esso Highlands Limited, an Exxon Mobil subsidiary. (GoPNG, 2008, p. 27). The operator is effectively responsible to the joint venture partners for all management decisions relating to the development and operation of the project.

The CDOA also contains provisions relating to corporate governance, preparation of work programs and budgets, making of cash calls and allocation of costs for shared facilities and Associated Gas production.

The CDOA distinguishes between the holders of Primary Gas Field Licences (these are the new licences for the PNG LNG project and holders of Associated Gas Field Licences (these are the licences for companies operating under the Kutubu project most of whom extracted the oil and capped the gas). Figure 7:5 below shows the two types of gas fields: the licensed holding Primary Gas Fields (shaded blue), which account for $80 \%$ of total gas to be piped out, and the

\footnotetext{
${ }^{48}$ Slide from a Power Point presentation at the University of PNG Law Faculty. The researcher has been advised that the organisation chart is probably from the CDOA. When he lost the 2012 elections, Arthur Somare, son of the former Prime Minister Michael Somare, formed Resource Logistic Solutions (PNG) Ltd., providing consultancy advice to the Government and other companies.
} 
associated gas fields (shaded yellow), which are part of the Kutubu oil projects (also covering Gobe and Moran) and account for the balance of $20 \%$ of all the gas being supplied to the PNG LNG project. The Kutubu oil project extracted the oil only and left the gas behind which is now being piped out to the Gas Facilities using the oil pipeline infrastructure.

Oil Search Limited (OSL) took over from Chevron Niugini as operator of Kutubu oil project in 1992. The oil fields were therefore under the old arrangements prior to the passage of the 1998 Petroleum Act but the abandoned gas reserves are now covered by the new Oil and Gas Act as they are being commercially extracted. The new oil finds are also covered under the new Oil and Gas Act.

Figure 7-5 below actually shows the geological makeup of the various PDLs on the map. Each PRL or PDL has through a complex unitization process been converted into project interests in the project agreements.

Figure 7:5: Primary and Associated Gas Fields

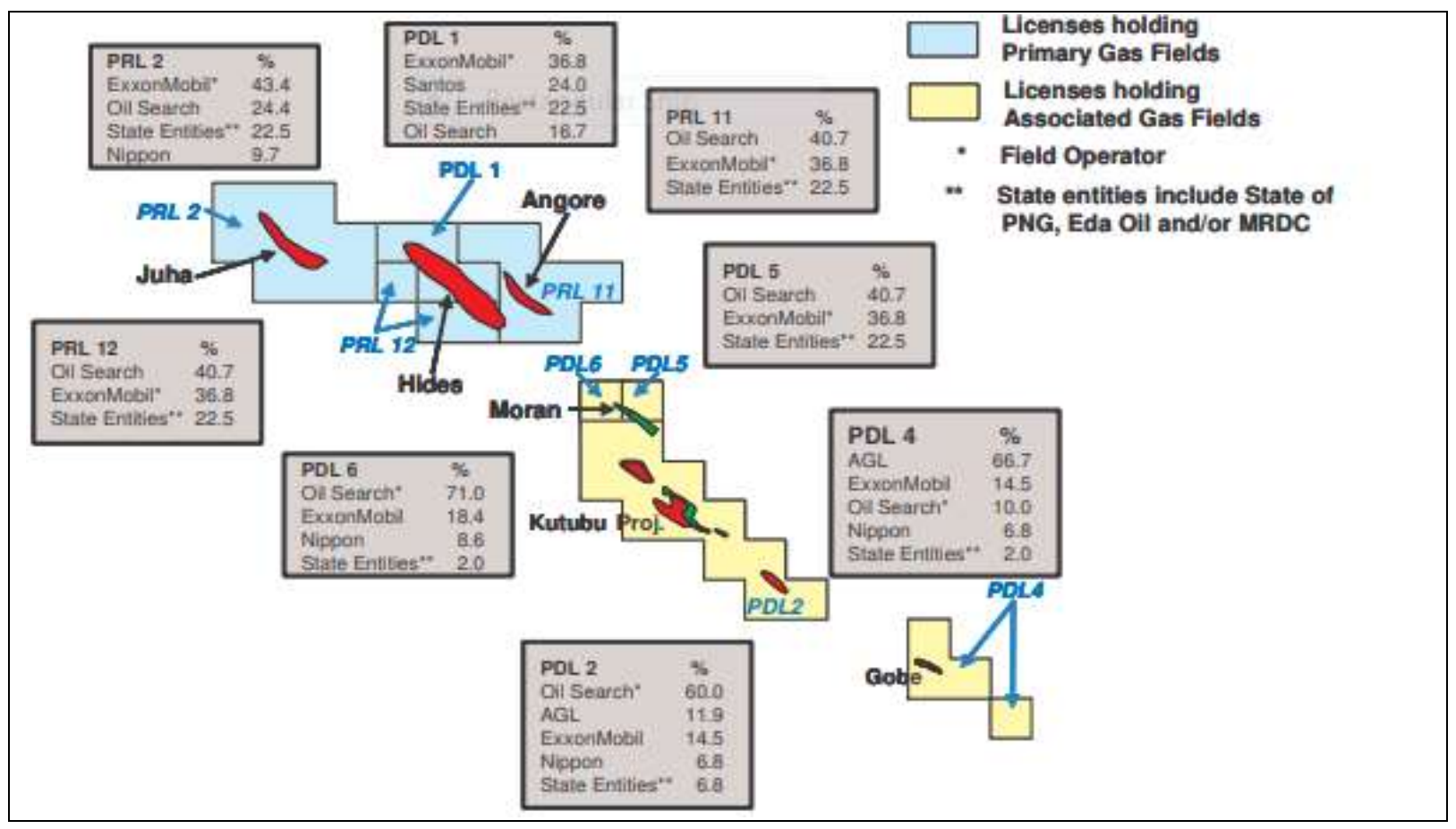

$\left(\right.$ Somare, 2017) ${ }^{49}$

There is a distinct difference and important point to be made: some of the holders of the Associated Gas Field Licenses are not participants in the project but are parties to the CDOA and have agreed to give their share of the Associated Gas to the project. The participants'

\footnotetext{
${ }^{49}$ Power Point presentation at the University of PNG Law Faculty
} 
interests are reflected in the direct interests they hold in the gas fields licenses as well as what their affiliates hold in the Associated Gas Fields. Table 7:3 shows the status of the various licences.

Table 7:3 Licensed Gas Fields

\begin{tabular}{|c|c|c|c|c|}
\hline License & Field Covered & Date Granted & $\begin{array}{l}\text { Initial Term } \\
\text { (years) }\end{array}$ & $\begin{array}{l}\text { Renewal Terms } \\
\text { (years) }\end{array}$ \\
\hline PDL 1 & $\begin{array}{l}\text { Part of Hides and Angore } \\
\text { Field }\end{array}$ & $28 / 09 / 1990$ & 25 years & 20 \\
\hline PRL 2 & Juha Field & $13 / 04 / 2000$ & $\begin{array}{l}5 \text { (extended to } \\
10)\end{array}$ & $\begin{array}{l}\text { Convert into PDL } \\
\text { with initial term } \\
\text { of } 25 \text { years }\end{array}$ \\
\hline PRL 11 & $\begin{array}{l}\text { Part of Angore and Hides } \\
\text { Field }\end{array}$ & $21 / 03 / 2003$ & $\begin{array}{l}5 \text { (extended to } \\
10)\end{array}$ & $\begin{array}{l}\text { Convert into PDL } \\
\text { with initial term } \\
\text { of } 25 \text { years }\end{array}$ \\
\hline PRL 12 & Part of Hides Field & $21 / 03 / 2003$ & $\begin{array}{l}5 \text { (extended to } \\
10)\end{array}$ & $\begin{array}{l}\text { Convert into PDL } \\
\text { with initial term } \\
\text { of } 25 \text { years }\end{array}$ \\
\hline PDL 2 & $\begin{array}{l}\text { Kutubu Complex Field, } \\
\text { southeast Hedinia Field and } \\
\text { Agogo Field }\end{array}$ & $10 / 12 / 1990$ & 25 years & 20 years \\
\hline PDL 4 & $\begin{array}{l}\text { Gobe Main Field and Gobe } \\
2 \text { X Field }\end{array}$ & $24 / 12 / 1996$ & 25 years & 20 years \\
\hline PDL 5 & Part of Moran Field & $18 / 02 / 2001$ & 25 years & 20 years \\
\hline PDL 6 & Part of Moran Field & $30 / 04 / 2008$ & 25 years & 20 years \\
\hline
\end{tabular}

DPE 2010/2011 ${ }^{50}$

\section{Project financing}

The CDOA provided that the venture partners would meet $30 \%$ of the project's financing requirements by a cash contribution and the remaining $70 \%$ would be financed by a long-term loan.

Figure 7:6 below shows the overall project financing structure. The financing was developed to take into account the structure of the unincorporated joint venture and the financing structures customarily adopted in LNG project financings. This structure provides a mechanism for the equity holders to deal with Participant defaults among themselves in a way that minimizes potential impacts on the Project. The debt finance was via an offshore joint borrowing through GloCo that allowed for the pledge in full of Project revenues and all rights under the LNG Sale and Purchase Agreements (SPAs), Liquids Sales Agreements, a customary offshore secured account structure, and the pledge of the physical assets of the Project. Since

\footnotetext{
${ }^{50}$ Department of Petroleum and Energy 2010/2011 "inventory notes" collected in the field.
} 
the Project also includes the underlying Gas Field Licenses: all the Participants' Gas Field License interests was also be part of the collateral pledge (DPE Notes ${ }^{51}$ ).

The government was however unable to participate on the same basis as the private sector venturers. It could not pledge its interests in the project as collateral because of the limitations imposed on the State's ability to grant security interests under the World Bank and other financing negative pledge ${ }^{52}$ obligations. The arrangements made for the state to assume a share of the financing liability are discussed below.

Figure 7:6: PNG LNG Project Financing Structure ${ }^{53}$

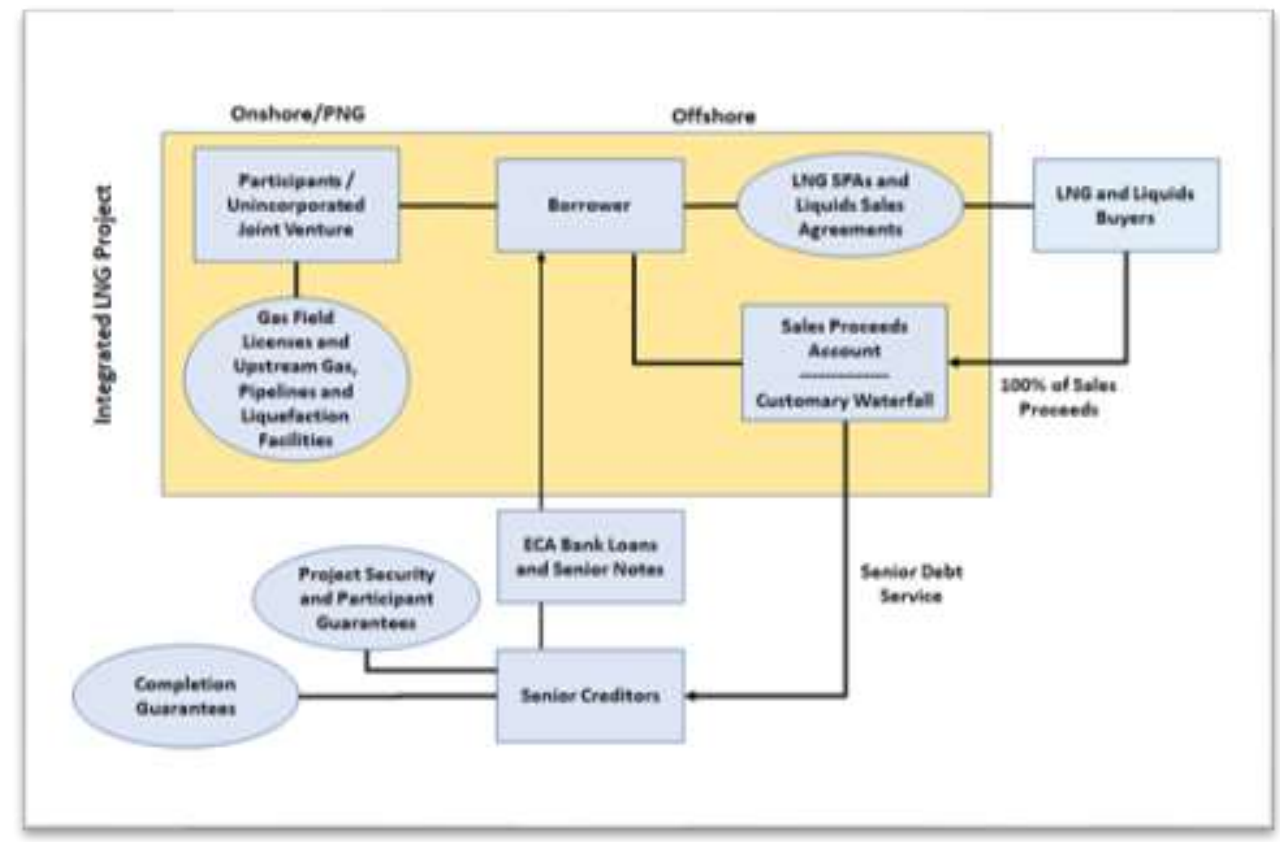

Adapted from DPE notes (2018).

\subsubsection{Gas Agreement}

As discussed in sections 7.3.4 and 7.3.5 the abandonment of the Queensland gas pipeline project allowed the government to aggressively pursue the PNG LNG project when it became clear that such a project was a commercially viable proposition. The Primary Gas Field and

\footnotetext{
${ }^{51}$ A collection of notes provided from the DPE office. Their provenance cannot be sourced or verified.

${ }^{52}$ A negative pledge clause in a loan agreement prevents the borrower from pledging any assets if it would jeopardise the lender's security for the loan.

${ }^{53} \mathrm{SPA}=$ Sale and Purchase Agreement. ECA = Export Credit Agencies. The "Customary Waterfall" probably refers to the prioritisation of allocation of sales proceeds from LNG and liquids buyers to service debt and then be distributed to the various beneficiaries including the local groups with shares in the project. In project finance a "cash waterfall" is the project cashflow statement rearranged to show the order of priority ("seniority") of receipt of cash proceeds from the project. (Corality, 2019)
} 
Associated Gas Field License holders entered into a Gas Agreement with the Government, dated 22 May 2008, in relation to the Project. All relevant legal, fiscal, and commercial provisions necessary for the development and operation of the project are covered by the Gas Agreement.

This section outlines the events leading up to the Gas Agreement and the main provisions of the Agreement affecting revenue flows:

\section{Events leading up to the Agreement}

The 2008 Budget reported that "two proposals for Liquefied Natural Gas (LNG) projects were submitted to the Government. They are the Liquefied Niugini Gas Ltd LNG project and PNG LNG project." (Pruaitch, 2007, p. 92).

“The Liquefied Niugini Gas Ltd project is led by InterOil Ltd, Merrill Lynch and Global Pacific LNG. They have tabled a draft project agreement with the State and negotiations are progressing on fiscal terms and technical terms, especially on some of the concessions that they are seeking. The project involves building an LNG plant and a pipeline from the plant to the feed gas at Elk wells. This project is expected to cost around US\$6 billion. InterOil Ltd will develop the upstream Elk wells separately. InterOil is now in the process of proving up its reserves and having them certified.” (Ibid.)

"The second LNG project is led by ExxonMobil with its co-venturers; Oil Search, AGL, Santos, Nippon Oil and MRDC. This project is based on the gas reserves from the previous PNG Gas Pipeline to Australia project plus a number of new wells. They have tabled a draft term sheet for negotiation with the State. The negotiation is continuing and is expected to be completed by the end of 2007. The project is expected to cost around US\$10 billion, which includes the cost of building the LNG plant, the pipeline from the gas fields to the plant and the development of the gas fields.” (Ibid., p. 93)

"Both projects are working towards a 2011 first LNG shipment, as per the Prime Minister's announcement on the floor of Parliament. The Government has some options and rights to take up equity in both LNG projects." (Ibid.)

The Budget also reported that "The Joint Ventures are currently working on a Cooperative Development and Operating Agreement that will define the relationship of the different 
partners in relation to the LNG project for its full economic life. This agreement is scheduled to be signed before the end of 2007." (Ibid p 121).

\section{Main points from the Gas Agreement}

From the viewpoint of the government and landholders, the Gas Agreement is a critical step in the determination of how revenues will be distributed since it sets out formally the basis for project revenues to accrue to them through taxation, royalties and levies, and equity shares. It also sets out the GoPNG's obligations, including the cost of acquisition (through its assignees) of equity interests in the project. The government also attested that it could raise the finance to fund the State's $22.5 \%$ equity. Other main points from the Agreement:

- The State guarantees to "grant or procure" the Project "such leases, licences, easements or other exclusive or nonexclusive rights of entry on to Land as may be necessary or desirable for all or any of the purposes of the LNG Project" (Ibid p 38) and "Upon request from the LNG Project Companies, the State shall exercise all powers, authorities and discretions available to it under the Land Act and any other applicable legislation to procure the grant of a lease from customary landowners in respect of all or any part of the LNG Project Area (or areas expected to become part of the LNG Project Area)" (Ibid p 39)

- Licensees shall offer $22.5 \%$ of their interest to the State. (Ibid p.44) (why only $19.6 \%$ was taken up is a question to be dealt with in the subsequent discussion). The State assigns its interests to "State Assignees". Through its Assignees, the State pays for its share of the cost of assets of the venture in each license area (s. 10.4 p 47). The State attested that it could finance up to $30 \%$ of the project cost.

- The income tax regime for the project is set out in full, covering

- allowable deductions of operating and capital costs and financing costs,

○ the basic income tax rate of $30 \%$ and the application of Additional Profits Tax,

○ exemption of the project from dividend or interest withholding tax,

○ depreciation rules (including provisions for "accelerated depreciation"),

- special additional deductibility if after ten years of production, the profit rate exceeds specific threshold rates, 
- A Fiscal Stability Agreement (annexed to the Gas Agreement), carving out the project from any future adverse changes in tax or other law for a period, in return for an additional $2 \%$ on the base income tax rate.

- The government agreed to the specific changes to the Income Tax Act required to give effect to these provisions, scheduled to the Agreement.

- Definition of royalties and development levies and their calculation based on well-head value (see below).

- The government agrees that it "must procure" that funds are appropriated and paid out of the Consolidated Fund to the extent necessary to meet its obligations under the Agreement.

The definition of "well-head value", which is applicable to the PNG LNG project, is revenues minus operating costs. According to the World Bank "This definition means that in times of low prices the well-head value could be negative, in other words the revenues are less than the costs even if large operating profits are being made.". Furthermore, according to the Bank, "It would appear that for PNG LNG negative royalties and development levies are being accrued which will be used to write-off any future positive royalty payment obligations in much the same way corporate income tax losses can be carried forward." (World Bank, 2018, pp. 6667). The World Bank argues further that

... royalties that factor in project costs are the most complex for government authorities to administer. This is particularly the case where the resource extractor is foreign-owned, and a significant proportion of costs are incurred overseas (e.g. imports of foreign machinery, foreign technicians and engineers, management overheads, shipping costs, etc.). This is due to the well-known risks of transfer pricing, when the owning corporation purchases these items from itself (this is known as the problem of 'arms-length pricing'). ... A segmented project can, for example, levy royalties on the upstream gas production operations, and treat the lower risk downstream pipeline, liquefaction and shipping operations the same as any other industrial activity (so no royalties, only income taxes). (World Bank, 2018, p. 68)

\section{Fiscal Stability Agreement}

Under the Resource Contracts Fiscal Stabilisation Act 2000, developers of mining, petroleum and designated gas projects can enter into a Fiscal Stability Agreement (FSA) with the government. In the agreement, the government guarantees for a period not to change the rates 
at which "applicable taxes, duties, fees and other fiscal imposts" will be charged and "the manner in which liability in respect thereof will be calculated" (Resource Contracts Fiscal Stabilization Act, 2000:S. 2). In return the developer pays a special additional rate of tax. In the case of designated gas projects, the guarantee is for "the period of time necessary to produce a volume or quantity of resource as defined in the relevant Gas Agreement to be foundation volume or quantity for that long-term resource based project" (Ibid. S 5).

The PNG LNG project venturers are the only resource company so far to have opted for this provision. The Fiscal Stability Agreement (FSA) for the project is scheduled to the Gas Agreement. The FSA provides for the venturers to pay a $2 \%$ premium on the base income tax rate of $30 \%$ "in exchange for receiving fiscal stability for a period equal to the financing period or 20 years, whichever is shorter" (Ernst \& Young, 2017a, p. 52) . In fact this premium was “waived off”. (Abel, 2019, pp. 125-126).

\subsubsection{Government financing ${ }^{55}$}

When the Gas Agreement was signed in May 2008 the total project cost was estimated at US\$11bn. However, upon completion of the FEED this cost was pushed out to US\$15bn, with a total cash contribution required from the venturers of $30 \%$ or US $\$ 4.5 \mathrm{bn}$.

The Government's share of this cash contribution was of the order of US $\$ 1.1 \mathrm{bn}$. To finance its share of this required cash contribution it had to borrow offshore. In March 2009 the government arranged financing through the Independent Public Business Corporation (IPBC) in the form of a five-year US $\$ 1.1 \mathrm{bn}$ exchangeable bond ${ }^{56}$ issued to the International Petroleum Investment Corporation (IPIC), wholly owned by the Emirate of Abu Dhabi (Botten, 2009). The agreement included a provision for all or part of the repayment of principal on the loan to be settled at maturity by transfer to IPIC of the government's $17.6 \%$ equity stake in Oil Search Limited. Coincidentally, the government would give up an indirect interest in the PNG LNG licences through its equity stake in Oil Search, amounting to about $5.2 \%$.

\footnotetext{
${ }^{54}$ According to the EITI Scoping Study this $2 \%$ premium does not in fact apply - was waived for the PNG LNG project.

55 The discussion of the IPIC financing deal draws on Kramer (2019).

56 "Exchangeable bond (or XB) is a type of hybrid security consisting of a straight bond and an embedded option to exchange the bond for the stock of a company other than the issuer (usually a subsidiary or company in which the issuer owns a stake) at some future date and under prescribed conditions." (Wikipedia, 2019)
} 
What portion of the principal the government had to settle by this transfer depended on the Oil Search share price at the time. The share transfer would just match the repayment required if this "strike price" was AUD8.55. If the price was less than the strike price, the government would have to pay the different in cash. If it was greater, then the government would only have to surrender the portion of its shares necessary to repay principal. At maturity in 2014, after a dispute between IPBC and IPIC about the applicable basis for the strike price, a court ruled that it was AUD8.19, and IPBC was ordered to pay the difference in cash of AUD103.3m, plus penalties and costs.

At the time, the O'Neill government sought to buy back the shares from IPIC, who refused. Also in March 2014, however, the government approached Oil Search, who were seeking to finance a purchase of an interest in the Elk/Antelope project in the Gulf, and negotiated a placement of a $10 \%$ share issue. The government purchase, made through Petromin, was financed in turn by a AUD\$1.2bn loan from UBS AG (Australia Branch). (GoPNG, 2014c; Oil Search Ltd, 2014)

In the case of PNG, the government still must repay loans it took to finance its equity before whatever is left can be remitted to Kumul Petroleum Holdings Limited (KPHL). KPHL then decides how much it will pay as dividends to the government.

\subsection{Conclusions: the PNG LNG main project agreements and their legal and institutional framework}

By the time the development partners led by ExxonMobil had presented their proposals for the PNG LNG project to the government in 2008 , there was already a comprehensive legislative and regulatory framework in place for both oil and gas projects, developed largely in response to the perceived requirements first of the Kutubu Oil Field and then the abortive Queensland Pipeline Project.

The main agreements for the project were all offspring of this framework. In summary:

- The CDOA had its statutory basis in s. 123A of the Oil and Gas Act 1998 (inserted 2006) that the licence holders "shall [make] an agreement between holders, relating to designation of operator and the conduct of operations in relation to that licence."

- The Gas Agreement stems from s.184 of the Act (inserted 2006) providing for agreement between licence holders and the government on definition of a gas project, state equity 
interest in a project and its assignment to MRDC, "any other matters" (covering in effect all questions of state regulation and fiscal matters that affect the project).

- Division 10 of the Income Tax Act 1959 on Mining, Petroleum and Gas Projects, introduced in 2000 with further amendments in 2004, covered the project basis of assessment, deductibility of capital expenditure, interest, allowable exploration expenditure, allowable capital expenditure, depreciation rules, and offsets against tax liability for approved infrastructure expenditure. Subdivision D covered "designated gas projects". Amendments in 2004 further addressed allowable exploration expenditure and additional capital expenditure, Tax arrangements specifically for the project were confirmed in the Gas Agreement and the government and project developers also signed up to a Fiscal Stability Agreement, provided for in the Resource Contracts Fiscal Stabilisation Act 2000, for a period guarantee by government of no change in these arrangements, in return for an additional $2 \%$ on the company tax rate paid by the project (later waived).

- As regards identification of landowners and benefit sharing, section 47 of the Oil and Gas Act (inserted 2006) covered social mapping and landowner identification studies at prospecting and development licence stages, sharing of benefits with local level and provincial governments, provision of grants and other benefits by the government to project landowners, the ability for LLGs and landowners to acquire additional equity interests, and trust arrangements for landowner equity benefits through the MRDC. An amendment also inserted in 2006 established the requirement for the Development Forum of landowners and government where these arrangements were to be agreed in a Development Agreement.

These processes defined by these legislative provisions fit well with the narrative and normative models of resource rent decision making (Barma, Mayorga Alba) developed in Chapter 5. In Mayorga-Alba's terms, the two main Acts - Oil and Gas and Income Tax between them define processes for award of contracts and licenses, regulation and monitoring, and collection of taxes and royalties. The Fiscal Responsibility Act is a framework for budgetary decision-making on, and accountability for, revenue use. In the Barma framework, there are processes in the legislation for giving legal identity to the main actors in the two arenas of generation and distribution - state agencies, SOEs, private companies; and sector agencies, contractors, and beneficiaries. The legislation also clearly identifies how the principal 
interests in natural resources and rents will be specified and reconciled - particularly property rights of both landowners and project developers, and shares in resource rents flowing from the development. The main questions to be answered in the next two chapters are how these processes actually played out in the development of the PNG LNG case in terms of identification of landowners and land rights and agreements on benefit shares; and how flows of resource rents, expected and actual, were taken into account in government planning and budgeting. 


\section{Chapter 8 Benefit Sharing}

\subsection{Introduction: Benefit Sharing Agreements - development and implementation}

The outcome of the OGA process was the Development Agreement specified in s. 50 of the Act, now universally known as the Umbrella Benefit Sharing Agreement (UBSA), and the associated License Based Benefit Sharing Agreements (LBBSAs) for each license area of the project. This Chapter discusses the process for developing the Agreements and the problems encountered, and the consequent landowner discontent with the outcomes, particularly in terms of social relations and land rights in the traditional societies of the Southern Highlands.

\subsubsection{Social Mapping and Landholder Identification}

Under the Petroleum Act which existed prior to 1998, OSL in its capacity as the operator of the Oil Project commissioned, completed, and submitted comprehensive SMLI studies for the oil fields (Gobe, Kutubu, and Moran) and the oil project facilities prior to 1992 as a precondition for its application to the director for the granting of petroleum (oil) development licenses (PDLs) for the above oil fields prior to 1992.

Subsequently, landownership for these oil fields including clan hierarchy, membership, and leadership were relatively clear when ExxonMobil dealt with the conversion of the oil fields to associated gas fields in relation to the PNG LNG Project in 2009.

Between 2008 and 2009, ExxonMobil, in its capacity as operator of the Project, commissioned, completed, and submitted comprehensive social mapping and landowner identification studies (SMLIs) covering all planned infrastructure for the Project. These included the primary gas fields (Juha, Hides, PDL 1, Hides 4 (PRL 11), Angore), the conditioning plant, the entire gas pipeline, and processing plant. The SMLIs were a precondition for the operator's application, pursuant to the OGA, to the department of Petroleum and Energy for petroleum development licenses, made in 2009. The SMLIs were prepared by anthropologists. While mapping the main ethnic and language groups in the licence areas they did not identify individual landowners eligible for compensation or project benefits. 


\subsubsection{The Development Forum ${ }^{57}$}

The Department of Petroleum and Energy chose a two stage consultation and awareness program: firstly, awareness of the concept of the Development Forum and Benefit Sharing Agreement, and secondly, the policy rationale based on which the benefits would be shared among members of the Beneficiary Group.

The DPE undertook a major awareness exercise between November 2008 and February 2009 which covered 52 villages in all four provinces including Southern Highlands (and Hela split from Southern Highlands in 2011), Gulf, Central, and Western Provinces. Representatives from other government departments and ExxonMobil and Oil Search also participated in the awareness program. An estimated 4,500 local people from the impacted villages participated in the awareness meetings. A big part of the awareness involved explaining the impact of the project covering: socio-economic changes; environmental impact; and the financial benefits.

The DPE published a schedule shown in Table 8:1 below of tasks and milestones leading to the negotiation and signing of the BSA. The schedule was clearly very tight and needed whole of government support including the MCES in order to succeed. (DPE notes collected from DPE office. See also Nelson \& Valikai (2014)).

Table 8:1 Development Forum Process

\begin{tabular}{|c|l|l|}
\hline Phase & Activity & Date \\
\hline 1 & Awareness development forum and BSA & Nov 2008 to Feb 2009 \\
\hline 2 & Minister's invitation & 17 April 2009 \\
\cline { 2 - 3 } & Transportation of participants & 18-19 April 2009 \\
\cline { 2 - 3 } & Development Forum (BSA negotiation) & 20 April to 8 May 2009 \\
\cline { 2 - 3 } & UBSA signing & 8 May 2009 \\
\hline 3 & License Based Benefit Sharing Agreement & FID (8 December 2009) \\
\hline
\end{tabular}

\section{Source: DPE notes (2018).}

\section{Development forum representation}

The Minister for Petroleum \& Energy, using his powers under the Oil and Gas Act, selected the representatives of the various beneficiary groups to participate at the Development Forum. The selection and finalization of the representatives were done with the guidance of the SMLI report and through the meetings conducted during the awareness exercise. The landowner representatives came from the PDL, LNG pipeline, and the LNG plant areas. Representatives

\footnotetext{
${ }^{57}$ This section draws extensively on briefing notes supplied to the researcher by DPE.
} 
were also selected from women and youth and church groups. The Minister also invited the governors of the four provincial governments and all the impacted local level governments (DPE notes).

\section{Issues encountered in the awareness exercise}

The issues encountered in the project footprint areas included:

- The need for a national content plan that detailed the benefits the people would be getting such as employment/training; business spin-offs and contracts. The specificities of the national content plan were not available to be explained to the people.

- Settlement and payment of all outstanding oil MOA under Chevron and now Oil Search which were not being fulfilled for the wellhead impact areas since 1991: landowners wanted to know when these commitments would be settled. The MOA were broad commitments made nearly 20 years earlier but the landowners still remembered.

- The State also noted that ExxonMobil had only started rolling out its Local Business Development Plan as part of the National Content Plan in the first week of March 2009.

\section{The venue for the benefit sharing arrangement}

The decision made by the National Executive Council for moving landowners and provincial and local level government officials away from the project site to a different province was to prevent unnecessary people from attending who were trying to take advantage of the uncertainty about the real landowners and who were looking for business opportunities. There were also a number of landowners who were dissatisfied with the landowner identification process and who wanted to stop the Development Forum from proceeding.

The venue was Kokopo, the administrative capital of East New Britain Province, an island province accessible only by sea and air. On the $23^{\text {rd }}$ April 2009, about 2,000 landowners (recognized by DPE) from the affected PNG LNG project areas were flown to Kokopo. Another 800 so called "landowners" based in Port Moresby managed to get a court order granting them the right to attend the Kokopo Development Forum. The influx of additional landowners caused a blowout of the budget with additional accommodation, meals, return airfares and allowances, from K15.3 million (about NZ\$ 7million) to K24.3 million (about NZ\$ 12 million) (DPE notes). 
The key players who attended the Development Forum included:

- The Managing Director (ExxonMobil PNG) who made it very clear to the participants at the gathering that the project partners had spent US\$400 million to get the project to Early Works stage which was a risk that was being taken before it knew the cost of the project to get it to production. The cost of the project was being assessed in the front end engineering and design (FEED) stage which would be completed towards the end of 2009. There were two important points that he made: firstly, there was a small window of opportunity in 2013/2014 where the project would have the opportunity of a stake of the LNG market; and secondly, "the PNG LNG project has the capability to transform PNG as a nation, including the (lives of the) 60,000 landowners represented at the ... forum" (DPE notes). In effect the Managing Director was telling the landowners and the government that this was an opportunity that would not become available in the near future if there was delay in signing the agreement as governed by the capitalist logic elaborated by Gerritsen and McIntyre in Chapter 5 .

- The Governor of Southern Highlands Province, Anderson Agiru, was perhaps the most important individual without whom the signing of the UBSA would not have been possible. The Governor recognized the importance of the project for the country and also the impacted provinces and wanted to see meaningful development including infrastructural development, employment, and participation by locals in business opportunities. He also wanted to see past commitments made by the government to Kutubu impacted communities honored (DPE notes).

- The State was represented by the various government ministers and included: the Minister for Treasury; Minister for Petroleum and Energy; Minister for Public Enterprises; Minister for Education (the local member impacted by the project). The State position was dictated by a number of NEC decisions and the Oil and Gas Act as it relates to the benefit sharing agreement forum. The state's position was to sign the agreement with the landowners and provincial governments and to show the investors that the landowners and sub-national governments were supportive of the project. In the process the state made a lot of commitments to accommodate the landowners demand. There was also an emotional plea by the State Team for the landowners to put the country's interest ahead of their own demands for more benefits including equity. 
- The landowners were represented by the different groupings but essentially the chairmen of each of the ILGs and executives of the various landowner companies and associations. The most vocal landowners were those who were previously under the Kutubu oil project which was managed and operated by Chevron and later by Oil Search (DPE notes). In a lot of the oil wells the oil was extracted and the gas plugged off. Now that the gas was being extracted, the same landowners renewed their demands for all the outstanding commitments made by the state ${ }^{58}$.

- Leading up to the Development Forum, oil landowners and GTE landowners were vocal about the need for the State to resolve all outstanding MOAs commitments before agreeing to sign a new Benefit Sharing Agreement. The landowners were mindful that a new BSA could effectively undermine State commitments under the oil-based MOAs. The Hides Gas to Electricity (GTE) and the Oil Projects were integral to the success of the Development Forum and for the commencement of the PNG LNG project.

The discussion and negotiations that ensued revolved around increased equity and other benefits for the landowners and the need for a new Hela Province. The next section captures some aspects of the negotiations.

\section{Presentations by beneficiary groups}

Many participants spoke of the LNG Project as a "prophetic project" with spiritual connotations for the people of Hela (DPE notes). The LNG Project was viewed as a gift from God which was meant to benefit the people and shared with the rest of the world.

The forum allowed for individual beneficiary groups to do their presentations. Nearly all the presentations called for additional equity and other benefits (mainly infrastructures) to be locked into the agreements before signing could be done. The presentations ran for two days from the $06^{\text {th }}$ May 2009 to the $07^{\text {th }}$ May 2009 (DPE notes). After the presentations, discussions and negotiations continued for about another two weeks.

Governor Agiru delivered the official response of the Southern Highlands Province and the landowners of his province to the National Government. He placed an offer on the table to

\footnotetext{
${ }^{58}$ According to Filer, the problems are familiar and this adds to the evidence that at least some landowners affected by the PNG LNG Forum were (a) not fairly represented at the Forum or (b) mistrustful of the undertakings given by the company and government. (Filer, 2019).
} 
purchase additional equity from the State's 19.4\% stake on behalf of landowners. He also urged the signing of a MoA that would roll out a K600 million infrastructure plan for the project areas, including 11 road projects, a wharf at Kikori and a new Hela City (DPE Notes).

The participants also wanted to know why the state ended up with only $19.4 \%$ equity instead of the $22.5 \%$ it was entitled to as specified in the Oil and Gas Act.

\section{The government's response}

The Secretary for the Department of Petroleum and Energy, Rendle Rimua, gave an undertaking that the government would look into and address the issue of outstanding MoA commitments under the Kutubu project agreement, prior to the conclusion of the Development Forum. However, the landowners continued to be skeptical of the government's undertakings given that a lot of projects were not fulfilled and serious allegations of misappropriations leveled against the department ${ }^{59}$ and government generally.

The Director of the Gas Coordination Office ${ }^{60}$, Daire Vele, used the forum to explain why the state held only $19.4 \%$ in the PNG LNG Project. Origin Minerals (a state owned entity and vehicle used by the state) took up $15.75 \%$ of the original $22.5 \%$ the state was entitled to. The government and landowners held the balance of $6.75 \%$ interest in the Kutubu oil fields. Origin Minerals was publicly floated in 1996 (DPE Notes). Origin ${ }^{61}$ eventually merged with Oil Search and the government obtained a 17.6\% stake in Oil Search in exchange for its interests. It should be noted that the Kutubu deal was concluded prior to the current Oil and Gas Act of 1998. Government equity in Gobe and Moran had also been watered down with $2 \%$ equity held by landowners and 20.5\% sold to Origin Minerals. The landowner stake in Moran (PDL 5) was sold to Eda Oil, a subsidiary of Petromin (DPE notes)

\footnotetext{
${ }^{59}$ Chapter 10 provides highlights of the Public Account Committee's report on the management of DPE which is very revealing (see chapter 10.6 .2 of the thesis).

${ }^{60}$ The Gas Office is a standalone office but comes under the Prime Minister's Department.

${ }^{61}$ Previous governments have made mistakes in the past with their decision making. Such mistakes include the selling of all our shares to Origin Minerals. Origin Minerals now owns 100 percent of all our shares. During early 2002 Origin Minerals was merged into Oil Search, thus reducing our shares of 100 percent down to 15 percent." (Hansard 8 May 2014). This was in response to a question from Camillus Dangima (Kerowagi) about why the government hadn't taken up its full $22.5 \%$ entitlement in the PNG LNG project.
} 
The Southern Highlands Provincial Government and the Hides landowners continued to ask for more benefits. In particular, the Southern Highlands Province Government wanted a greater share of the $4.22 \%$ additional equity.

A Ministerial Team met with Governor Agiru to discuss his concerns. The meeting reached agreement on the National Government's terms of a $4.22 \%$ equity share, at a value of US\$240 million for each $1 \%$ interest. The meeting also agreed on certain impact projects for the Southern Highlands Province (DPE Notes). The Landowners and Provincial Governments could acquire an additional PNG LNG Project equity of $4.22 \%$, through a $25.75 \%$ shareholding in Kroton No. 2 Limited, at a cost of US\$240 million per 1 per cent of equity. The offer was open until 30 June 2016 . The offer of $4.22 \%$ would decrease IPBC's interest to $12.17 \%$ from $16.39 \%$. If fully taken up, the additional purchase would bring Landowners' and Provincial Governments' total equity to $7 \%$. This was the National Government's final offer on Project equity. A $7 \%$ share was close to the $10 \%$ equity demanded by the Landowners and Provincial Governments (DPE Notes).

The Hides (PDL 1) landowners who are the major contributor of gas to the LNG Project had several meetings with the State Team and agreed on their share of the Kroton equity among other issues. The other major Landowner Group, Kutubu, also had meetings with the State Team and agreed to their share of Kroton Equity. The Gobe and Moran, and the Kutubu Group agreed with the State Team that their share of CDOA equity would be financed with their own funds. They also accepted their share of the $4.22 \%$ equity as offered by the State (DPE Notes).

The Southern Highlands Provincial Governor and all the major Landowner Groups accepted the State's final offer on equity shares and other provisions for incorporation into the final UBSA.

\section{Signing of the UBSA}

The important event of the Development Forum was the signing of the UBSA without which there would be no project. The signing began with Moran, Angore, LNG plant, and Pipeline landowners as well as respective Presidents of the impacted Local Level Governments signing the agreement. The Hides Group (PDL 1 and PRL 4 or PDL 7) was the last to sign the UBSA in Kokopo who constituted the important landowner groups.

A few of the leaders were unwilling to sign but this was not expected to impact negatively on the LNG Project activities in Hides. The signing continued well past midnight and resumed the 
next day (24 May 2009) (DPE Notes). Some Beneficiary Groups continued to hold out from signing in Kokopo. They included:

- The Gobe Main (PDL 4) Landowner Group did not sign because they did not want PDL 3 (South East Gobe) to be included in the LNG Project. Their objection related to the dispute over the sharing percentage of benefits from the Oil Project in Gobe between PDL 4 and PDL 3.

- The Juha Landowner Group of Western Province did not sign because their Governor, Bob Danya, was not present, and also because they did not want the Huli landowners to claim benefits in Juha (PDL 9) which was geographically on the border between the two provinces. The Juha Landowner Group from the Western Province eventually signed in Port Moresby, together with the President of the Nomad Local Level Government.

- The Governor of Gulf Province did not sign at the signing of the UBSA as he felt that his province would not adequately benefit. He eventually signed in late July 2009 along with Mark Maipakai (MP). Mark Maipakai is the member for Kikori in the Gulf Province where the Kumul Terminal is located (where the loading of oil from the Kutubu project takes place). (DPE Notes)

\subsubsection{Content of the UBSA}

The benefits in the UBSA that emerged from the Forum were all derived from provisions in the Oil and Gas Act. They had the following major elements:

(1) As described above, up to $7 \%$ equity in the overall project $-2.78 \%$ "CDOA equity" arising from existing landowner interests in licenses and available without cost; and a further 4.22\% "Kroton Equity" which landowners and SNGs could purchase from the State's share;

(2) A royalty of $2 \%$ calculated on well-head value of gas produced;

(3) A development levy of a further $2 \%$ calculated on the same basis;

(4) Infrastructure Development Grants of PGK 1.2bn "for infrastructure development and maintenance in the affected Provinces", allocated over ten years from the "go" decision for the project; 
(5) Business Development Grants of PGK 120m "to assist landowner companies in business development activities".

The UBSA lists and explains all the financial benefits and the percentage of the different categories of entitlement of each of the parties to the Agreement. The major components of the benefits consist of royalty and development levy (both calculated at $2 \%$ of the well-head value, as defined in the Gas Agreement), and equity distributions.

The Umbrella Benefit Sharing Agreement required agreement only down to the licence level. As required by the process in the OGA, it was planned to hold subsequent Development Forums for each licence area to endorse the UBSA and resolve the sharing of benefits between the affected landowners, Provincial Governments and Local Level Governments in each area. The resultant LBBSAs would be annexed to the UBSA.

Once the Royalty distribution was agreed, section 176 of the Oil and Gas Act dictated that $40 \%$ of the final distribution will be cash, $30 \%$ will be placed in Future Generations Trust, and the remaining 30\% kept in Community Investments Trust.

\subsubsection{Licence Based Benefits Sharing Agreements (LBBSAs)}

Following the process defined by the Oil and Gas Act required execution of LBBSAs, subsidiary Benefits Sharing Agreements for each of the licence areas in the overall project, to be completed by the National Government and Provincial and District Governments, and landowners in the licence area. The LBBSAs are supposed to define how the various benefits agreed in the UBSA will be shared amongst the parties in the licence area that they cover.

The LBBSAs for the PNG LNG project have not been made public. Two of them are however available on the Internet: for the Hides PDL1 area (GoPNG et al., 2009b) and the Angore PRL11 area (GoPNG et al., 2009a), two of the three Primary Gas Fields defined by the CDOA in the Hela region. Both agreements appear to have been signed in December 2009. Comments in this section are based on their content, recognizing that they may not be representative of other completed LBBSAs.

The two LBSSAs reviewed are broadly similar in what they cover including:

- Basis for selection of attendees at the Forums to discuss and agree on the LBBSA provisions; 
- Attestation by the landowners attending that they did in fact represent the landowners of the licence area;

- Ratification of the terms of the UBSA on principles for overall sharing of equity interests, royalties and development levies and other benefits;

- A formula for allocation of these benefits to subnational governments and to landowner sub-groups - "clans/tribes/villages" within the licence area as identified by the SMLI (with specific provision in the case of the Angore LBBSA for further negotiation amongst landowners on the detail of the shares, for a period, after which the Minister would decide).

- Landowner agreement to unimpeded access to land required by the project and assistance in "controlling any obstructive elements inside and outside their communities or provinces who might attempt to hinder development or production and, where necessary, assist in the removal of any obstructions or blockades or assemblies formed to obstruct or blockade project equipment or facilities".

- Acknowledging that generally benefits will be distributed to Incorporated Land Groups and that the State will "establish an inter-agency task force to be known as the PNG LNG Land Group Incorporation and Clan Vetting Task Force comprising officers from the Departments of Petroleum \& Energy and Lands \& Physical Planning" to "identify, coordinate and facilitate incorporation of land groups for each affected clan or sub-clan identified within the licence area in accordance with the Land Groups Incorporation Act 1974". The process was to be completed by 2010 .

However, two principal issues relating to the LBBSA process sowed the seeds of future problems.

The first is that the attendees at the local Development Forums to agree on the LBBSAs were in fact selected by agreement with DPE officials at local village meetings. These attendees then declared themselves to be representative of all landowners in the license area. The researchers for McIlraith (2012) in the Hela region asked people about the Development Forum process. They reported:

While it is a challenge to include in some manner everyone in the landowner agreement process, the hurried preliminary selection process left many people feeling left out of the landowner agreements. ... There were numerous accounts of the confused and 
haphazard nature of the Development Forums. ... A number of people interviewed further suggested that many fraudulently attended the BSA negotiations as landowners in the hopes of capturing associated benefits. ... [The] overwhelming majority ${ }^{62}$ of people sampled considered the benefit sharing negotiations unfair and non-transparent. (McIlraith, 2012, p. 43)

Their comments apply to both the UBSA Forum and the LBBSA Forums in the region. Given the land tenure system of the country and the cultural context, it would always be difficult to get all the landowners covering hundreds of miles together to agree on project benefits. However, the discontent with the method of selection for the Forums was a harbinger of future landowner discontent.

Secondly, the LBBSAs ${ }^{63}$ were effectively written on the implicit understanding that the SMLI had not resolved all questions of benefit eligibility within the license areas and the actual detailed allocation of benefits and the mechanism for it had not yet been settled. The Clan Vetting process to establish ILGs left plenty of room for further argument.

\subsection{State-landowner relations following the benefit-sharing agreements}

In the decade following the signing of UBSA and LBBSAs, several issues have played out in the political economy of PNG. The major issues have been with: slowness of clan vetting, disputes about the legitimacy of claims going back to the representativeness of the Development Forums, major discontent with the delays in releasing benefits, and the lack of transparency in the management of funds held in trust for landowners. These issues have contributed to landowner discontent and mistrust of government, and occasional outbreaks of violent direct action.

\subsubsection{Clan vetting}

In launching clan vetting, the government specifically acknowledged that the requirements of the SMLI process - to produce an agreed list of landholder beneficiaries - had not been met. The Minister for Energy in 2013 noted that at the time of the UBSA the DPE had a "basic

\footnotetext{
$6284 \%$ of the researchers' sample.

${ }^{63}$ Although the benefit sharing issues involved quite complex social processes with no guarantee of clear resolution, there was no possibility that an inability to resolve them would in any way delay the timetable for financing and construction.
} 
report that showed who landowners were" but acknowledged that "for some reason some genuine landowners were left out" and that the department would now "conduct house to house surveys and head counts" in project sites. He maintained that the government would not release any money until all landowners had been properly identified. (William Duma, Hansard, 22/5/2013).

\section{The process}

The Hides and Angore LBBSAs studied stipulated completion of the clan vetting process in 2010. In fact, vetting in the Hela region did not begin until 2011, employing a contractor, Heritage Consultants Ltd, who were expected to complete the work during 2011 (McIlraith, 2012, p. 44). In a statement on progress with the project, the Minister of Energy told Parliament in 2013 that "This work was undertaken by the contractor but was mostly delayed and jeopardized by State administration and politics and local issues especially in the Hela region." (William Duma, Hansard, 12/9/13).

At the same time the Minister said that the DPE had restarted clan vetting in early 2013 "to meet project schedule of first gas delivery in 2014”. (Hansard 12 September 2013). Despite this assurance, vetting was to drag on for several more years, without producing a definitive list of beneficiaries in any project area. In August 2016 the Prime Minister announced that he had set a 2016 deadline for distributions to start:

I have directed the Minister for Petroleum and Energy and his Department that within 30 days after this Parliament rises, they must complete the clan vetting exercise. After 30 days we will then start distributing out the funds that is rightfully due to the landowners, provincial governments and all the stakeholders that we have committed to. (Peter O'Neill, Hansard, 17/8/2016).

In fact, DPE was only able to begin reporting completion of landholder identification in 2018, and then only in some areas. In May 2018, the new Minister for Petroleum and Energy ${ }^{64}$ announced completion for eight areas covering about $400 \mathrm{~km}$ of pipeline, and that further project areas would follow "soon". (O\&G Links, 2018). The MRDC Chairman followed with a statement that the segments where vetting had been completed "are the ones we are going to proceed with their preparations of opening up their account, appointment of their board and

\footnotetext{
${ }^{64}$ Dr Fabian Pok, Minister in the coalition government following the 2017 election.
} 
then start making payments" (Post Courier, 2018) but that "for upstream landowners they were different because there's no clan vetting or identification of landowners as yet" (Ibid).

\section{Reasons for delay}

At the time of writing, it appears that the clan vetting exercise and landholder identification may have finally reached completion. But an exercise which was targeted to be completed in 2010, in fact continued over the following nearly nine years. Various reasons have been advanced for this delay.

Management of the process: One is poor management. In his 2013 statement, the Minister of Energy blamed lack of capacity in the DPE, which “... has lost a lot of people to the industry and this is still continuing. The consequence of this is that the Department is understaffed as there is a lack of motivation and drive." (William Duma, Hansard, 12/9/13). Others have cited a reluctance of DPE officials to appear on the ground in project areas. The risky security situation in the Southern Highlands may have contributed ${ }^{65}$. But the inherent difficulty of the exercise has also played its part, both in terms of the law and social relations among the landowners themselves.

Legal issues: In a Devpolicy blog, Sam Koim and Steven Howes (Koim \& Howes, 2016) cite two legal issues which they say have played their part: the requirements of registering an ILG and the legal challenges to the clan vetting process itself.

On ILG registration, Koim and Howes observed that

... the requirements to register an ILG were tightened up in the 2009 Land Group Incorporation and Land Registration Acts. For example, to register an ILG you now need a complete membership list, and birth certificates for all members. That is a much higher bar for registration, and it is unclear how it will be met. (The SMLIS studies don't have the

\footnotetext{
${ }^{65}$ The group of independent researchers in Hela noted the "... practical challenges of undertaking field research in the Hela region. In particular, access to local communities is limited and there are ever-present security risks in the Hela region. These factors limited freedom of choice and movement. This eventually led to an altered research programme and reduction in the sample size." (McIlraith 2012:17). The officials and contractors charged with the clan vetting exercise would have faced the same difficulties and risks.
} 
names of individuals, and many of them will lack birth certificates.) The new rules came into force in 2012, meaning that they apply now. (Ibid.) ${ }^{66}$

In addition, the entire clan vetting process has come under legal challenge in the courts. As Koim and Howes reported in 2016:

... the CVP is also stalled, because the Courts have ruled that it is "without statutory foundation and null and void". The Courts also issued an order restraining DPE "from conducting any clan vetting exercise or landowner identification process". (Ibid.)

Both orders are mentioned in a 21 July 2016 Court Order, which refers to earlier Court Orders along these lines (cited in ibid., p. 4). Alternative dispute resolution (ADR), a voluntary dispute mechanism to resolve land disputes, had not progressed as at 2016 because of funding constraints (ibid., pp. 4-5).

Social issues: Finally, delays in completing clan vetting can be attributed to social relations among the landowners themselves. The tensions generated at the interface between kastom and the state when resource benefits are at stake have been discussed in earlier sections of this thesis. Landholder identification has in particular been made more complex by disputes within local communities about entitlements. As an example, in the 2013 Parliamentary debate cited above, the Minister of Energy argued that landowner identification had to contend with customary relationships which among other things would produce claims from people outside the licence areas:

Landowners who come from the PDL areas want to share their benefits with landowners who are outside the PDL areas, and the Government recognizes that. In some cases it is an internal matter for those landowners from within the PDL areas and the landowners from outside who are accommodated by the PDL landowners. Mr Speaker, it is not a relatively easy task, it is an ongoing process. (William Duma, Hansard, 6/2/13).

Access to business development grants was another source of conflict. McIlraith reported that “There are frequent charges of 'outsiders' fraudulently registering local LANCOs, depriving

\footnotetext{
${ }^{66}$ A new Schedule inserted by the 2009 amendment to the Land Groups Incorporation Act requires an application for incorporation to include, among other things, “...2. A true and complete list of its members including the qualification of each listed member. 3. Where a member is under a disability, the name and qualification of his guardian. 4. The original or in its absence a certified copy of the birth certificate of each person who claims membership of the group ..." (Land Groups Incorporation (Amendment) Act, 2009).
} 
legitimate local landowners of LNGP business as well as complaints about the structure of many LANCOs, operating for the benefit of those in leadership positions and not the community." (McIlraith, 2012, p. 10) In Hela, an interviewee said "Now the LNG project is owned by big men, only 50 or 60 big shots who can speak English and get the payments, not legitimate landowners who live in poor areas.” (HuffPost, 2013).

Commandeering of benefits from resource projects by local power figures was not a new concern. The 2010 Budget had said:

There continues to be a concern that benefits such as MOAs for infrastructure projects and royalties are being misused by the leaders/chairmen of the Landowner Associations and that members are losing out on benefits such as health, education and transport services. A similar situation exists for the Special Support Grants which are allocated to Provincial Governments where mining projects are located. The State has also been accused by the landowners and Provincial Governments of impacted areas for not honouring its commitment in terms of funding projects identified in the relevant MOAs. (Pruaitch, 2009, p. 133)

Highlands MPs repeatedly complained about the misuse of landowner benefits held in trust and their diversion to "paper landowners" descending on Port Moresby:

Yes, many millions of kina has been paid, it has been paid to individuals, to fund their gambling habits, extravagant lifestyles such as chasing after women with very lower moral standards. ... You have no right of discretion under those agreements to spend money at your leisure, paying money to individuals is not the State discharging it obligations under these agreements. (Anderson Agiru (Hela) - Hela Governor, Hansard, 14/5/13)

McIlraith reported that in Hela

Many people contended that the gas was in the Hela region, yet those who sought to control or regulate its exploitation were in Port Moresby. People flew to Port Moresby to collect sums of money and argue their case, only to lose all their money and return nothing to the people. Many felt greater effort should be made to move such [LNG project] related activities into Hela. (2012, p. 60)

Wera Mori (Member of Chuave) pointed out that if the genuine landowners were not properly identified then he likened it to a "time bomb". The landholder identification process had to be 
completed "... to avoid people living in settlements in Port Moresby to claim to be landowners when the genuine landowners are left in the project site - some have ventured into Port Moresby only to be dealt with by [our] Security Forces." (Wera Mori (Chuave), Hansard, 22/5/2013). In the same debate, Philip Undialu (Koroba-Lake Kondiago in Hela Province) said that

... over the years, MOUs have become free money for landowners on the street or paper landowners, or whatever they call it. I would like to see us put a stop to that. ... Let's put a stop if we are using the funds in Port Moresby as discretional grants. (Philip Undialu, Hansard, 12/9/13).

Contests between landowner groups for access to benefits led both to the legal challenges noted above and to competition to create ILGs and Landcos to obtain a slice of the benefits. There is little evidence of communities being able to agree on benefit sharing amongst themselves, using customary means of collective decision-making. This could be for a variety of reasons.

First, the claims that had to be reconciled could span several communities, which would increase the difficulty of resolution. Despite William Duma's reference quoted above to landowners wanting "to share their benefits with landowners who are outside the PDL areas", it seems likely that outside claims would not always be welcomed.

Second, McIlraith's group speculated that "With the advent of significant resource development windfalls, traditional mechanisms for customary trade and exchange of items simply cannot meet demands for equality" and in this context "people in the Highlands now seem less able to regulate conflict, perhaps in part because of a growing disregard for traditional norms and values as well as a lack of mechanisms for dispute resolution by the younger generation.” (McIlraith, 2012, p. 22).

Third, there is a sense that local communities were being forced into a legal process from which they felt alienated. Thus, as earlier noted from McIlraith's report, while those attending the UBSAs and LBBSAs attested that they represented their communities of landowners, many left behind did not agree, which delegitimised the agreements in their eyes. (Ibid., p. 43).

\subsubsection{Landowner discontent and direct action}

From the time of the signing of the UBSA and LBBSAs, local discontent with the benefit sharing process increased steadily. Some of this, as discussed above, was with the perceived illegitimacy of the process itself and a widespread suspicion that the benefits were going to 
"big men" and "paper landholders". But increasingly it was due to the continuing delay in release of the moneys held in trust in the form of payments to landholder groups. From 2011 there were repeated complaints in Parliament and elsewhere, particularly from Hela MPs, that the royalty, development levy, and dividend benefits promised in the UBSA were not flowing ${ }^{67}$. A moral question was raised by some landowners: if it is right and correct to commit hundreds of millions of Kina to infrastructure development in the Capital City including the payment of APEC Haus (partly paid through the tax credit scheme) for the APEC Meeting and to turn around and tell the landowners to follow the rule of law and process if they have issues with benefit payments.

The government's position throughout was that the clan vetting exercise needed to be completed for all landowners before any could be paid. But discontent grew and from 2011 onwards, there were sporadic incidents of landowner direct action against the project.

A thousand people shut down work at the Hides 4 wellhead and the LNG conditioning plant site at Para village in the Hela region in January 2011 (HuffPost, 2013). The next month, landowner groups led a protest in the capital demanding payments of business development grants, taking three Petroleum and Energy Department officers hostage. National Planning Secretary Joseph Lelang also made accusations of political interference in the allocation of the grants. After several petitions, fraud allegations, and demonstrations, the then Deputy Prime Minister Sam Abal declared that some government departments involved in administering business development grants would be "cut off from having a direct involvement with landowner payments." (HuffPost, 2013)

In his Ministerial Statement in September 2013, the Minister of Energy acknowledged that while security [for the project] had been good during the 2012 National Elections, "the frequency of security incidents has since increased, particularly along the onshore pipeline section of the project ..." and that "the project is concerned that it is frequently used by our

\footnotetext{
${ }^{67}$ For some while around this time, government officials had been visiting villages and making cash payments. The amounts were relatively small and in most cases once they were distributed within the clans became negligible. The amounts that an individual would receive ranged from K50 (about NZ\$20) to about K200 (NZ\$90). Most of these monies are used on the same day they received. The Hela research in 2011 reported that "Cash 'windfalls' are quickly spent and there is little evidence of improved saving habits." (McIlraith, 2012, p. 10)
} 
landowners to leverage a response from our National Government". (William Duma, Hansard, $12 / 9 / 13)$

Between late 2015 and late 2017, there were several violent incidents involving local groups, directed at the project. There was a clash between armed locals and PNG Defence Force soldiers at Komo in December 2015, in which two soldiers were killed, resulting in the withdrawal of PNGDF personnel from Komo. In August 2016, there were reports that landowners had shut down all PNG LNG project sites, including the Hides to Porgera power plant (denied by ExxonMobil, who said its facilities were still operating) and that the government had sent officials to negotiate. (Business Advantage PNG, 2016). A further report said that negotiations with the Hides PDL1 landowners had not achieved a positive result. (ABC News, 2017a). In February 2017 there were reports of local villagers blocking access to the LNG plant in Port Moresby. Again in November 2017 armed landowners in the Papua New Guinea highlands said they had blocked access to gas wells because of an ongoing dispute with the Government over the payment of royalties. (ABC News, 2017b).

Although the operators denied any interference with actual plant operations, the security situation in Hela was causing them concern. In August 2016, ExxonMobil "urged a quick resolution to a dispute between the government of Papua New Guinea and disgruntled landowners, following a protest at its $\$ 19$ billion PNG LNG project over royalty disagreements" (Reuters, 2016) and in November 2017 reported that it had withdrawn all nonessential staff from the Hides Gas Conditioning Plant and was "continuing to monitor ongoing tension in the Highlands (Hides, Angore, Komo) areas" (ABC News, 2017b). In May 2018, at the Oil Search AGM, the Chairman said that "community discontent and violence around Oil Search's PNG LNG project, is because of the Papua New Guinea government's failure to distribute LNG royalties" and "clearly it's the lack of distribution [of funds], not the lack of payment, that is the cause of it." (The Sydney Morning Herald, 2018).

There was more violence and destruction of equipment. On 22 June 2018, ExxonMobil "confirmed that there were [sic] further vandalism at the Angore well pad A in Hela yesterday. Earlier in the week, armed landowners from the Angore PDL 8 dug up sections of the road and blocked access to protest the delayed benefit payments" (The National, 2018, 21 June). The vandals reportedly "set fire to equipment and machines owned by a landowner company" (ibid). 
All of this unrest was taking place in the context of a general deterioration in the security situation in the Southern Highlands. In June 2018, following destruction of buildings and commercial aircraft in the provincial capital Mendi ${ }^{68}$, the O'Neill government suspended the provincial government and declared a state of emergency (Radio New Zealand, 2018b). The Australian Jubilee Research Centre suggested that "With the introduction of the PNG LNG project, and the subsequent increase in landowner frustration, the build-up of arms has accelerated to the point where it is often speculated that the landowners are in possession of more firepower than the entire PNGDF, which is known to be severely under-resourced." (Main \& Fletcher, 2018, p. 28).

Based on its own research in Hela, the Jubilee Centre reported that there were two further sources of local discontent. The first was the failure to deliver promised infrastructure projects: "The co-author of this report spent seven months conducting research in Hela Province and was able to witness first hand the complete absence of the vast majority of promised infrastructure projects, and the failure to implement functioning versions of those projects that had been attempted." (Main \& Fletcher, 2018, p. 17).

There were also rumours that the big February 2018 earthquake was somehow connected to the project. According to the Jubilee Centre:

Almost immediately, people across Papua New Guinean society and global activists, began to question the cause of the earthquake and possible links with ExxonMobil's operations. This view is largely driven by substantive evidence of gas operations causing earthquakes in other parts of the world. ... ExxonMobil has never released its internal reporting into the disaster, and the Huli population continues to blame the company for the deaths that resulted. (Main \& Fletcher, 2018, p. 26).

\subsubsection{The Kroton Equity}

The Kroton Equity as defined in the UBSA (see section 8.1.3) provided for the purchase by SNGs and landowners of the $4.22 \%$ of project equity held in trust by KPHL. From early 2013 , Hela MPs and the Provincial Governor began to lobby for a "free carry" of their share of this

\footnotetext{
${ }^{68}$ A "mob armed with high powered weapons" destroyed an Air Niugini Dash 8 aircraft and "went [on] to burn down the governor's residence, the local courthouse and other buildings in Mendi town". The action was apparently in protest against alleged corruption in the governor's election win in 2017. (Radio New Zealand, 2018a).
} 
equity, meaning that the government should transfer it to them free of charge. The mechanism for this purchase would be (in total) by acquiring $25.75 \%$ of the Kroton No. 2 Company, a Kumul subsidiary, which had a $16.57 \%$ interest in the project. The estimated transfer price was of the order of PGK3.34bn or about US\$1.1bn. The Provincial Governments argued that this would be too much for the landowners to contribute.

The issue came to head in 2016. The offer of sale was due to expire in June but the government extended it to the end of the year. In August, several MPs returned to the argument that the Government should give the Provincial Governments and landowners the $4.7 \%$ equity interest it was holding for them. The Hela MPs leveraged their argument by reference to the ongoing discontent in the region. In Parliament Philip Undialu, acting Hela governor, referred to “... a shut-down and threats imposed by the landowners in Hides in particular, some of these threats have been propagated by political interest." (Philip Undialu, Korobe-Lake Kobiago, Hansard, 17/8/2016).

Prime Minister O'Neill stuck to the government position on purchase but argued that with a drop in the price of oil a lower price could be negotiated and that when a new Mining Act, shortly to be considered by Parliament, was introduced "there will be a review that the freecarry for the landowners and the provincial governments will be addressed'. (Peter O'Neill, Hansard, 18/8/2016). In September the NEC endorsed an offer by KPHL, which (according to KPHL) was of "no-recourse" vendor finance for the purchase "providing very low interest rates at low oil prices" (Kumul Petroleum Holdings Ltd, 2016). Four Provincial Governments and a number of landowner groups in fact signed an application to acquire the equity. It appears that in the end the applicants did not proceed with the purchase. A further report in March 2017 was that a "collective of Hela province landowners from the ExxonMobil-led LNG project have reportedly raised USD230 million to pay government for 4.27 percent equity in the project" (Pacific Islands Report, 2017) but this too apparently came to nothing. At time of writing the Kroton Equity remains with KPHL.

\subsection{Conclusions on benefit sharing}

Over the years since 2009, the factors discussed in this narrative have reinforced each other. The clan vetting process dragged on and, despite the growing discontent, the government repeatedly asserted that it would not release payments to any eligible landowners until all had been vetted and the ILGs formed. There was widespread suspicion of the illegitimacy of some 
claims. The court action by some governments and landowners challenging the vetting process helped delay matters further and increased landowner frustration. The general simmering mistrust of the BSA process and of the government and the occasional outbreaks of violence, increased the difficulties, in Hela particularly, of completing the vetting.

There was continuing discontent amongst landowners with delays in receipt of payments promised in the benefit sharing agreements. The discontent was strongest in Hela Province where landowners almost universally mistrusted the benefit sharing process and its results. The Governor and local MPs repeatedly attacked the government for delays in benefit distribution. There was suspicion that the money for payments, supposedly held in the MRDC trust fund, was not actually there.

There was widespread belief that many of the people positioning themselves to receive benefits were doing so illegitimately or ensuring that they kept benefits for themselves at the expense of the legitimate claimants. There were accusations that "paper landowners" migrating to Port Moresby, were falsely representing themselves as genuine claimants and receiving handouts of cash; and that those landowners who controlled the ILGs would keep a lion's share of the money for themselves and their families. Relatedly, the business development grants were also seen as a source of corruption: the landowner companies set up to receive them were frequently accused of being paper companies, with the grants being spent on personal consumption rather than the development of genuine businesses. There were ongoing attempts of new people often from outside licence areas to insert themselves into the claimant process by forming new Landcos or ILGs.

All this was exacerbated by a clan vetting process that was late to start, went on for nearly a decade with only some segments of the project completed, and in any event lacked legitimacy in eyes of many landowners, leading to legal challenges. Discontent boiled over frequently in periodic outbreaks of direct action against project facilities, sometimes resulting in destruction of property. The direct action most often occurred in Hela in the region of the Hides and Angore fields and the project facilities there. The Southern Highlands and Hela province were subject to ongoing inter-clan violence anyway, quite apart from action against the project.

There were approaches to the government to relitigate the BSAs, particularly in terms of the purchase of the Kroton Equity. The Hela Governor and local MPs made several approaches to the government to make the Kroton Equity available as "free carry", and raised it as an issue 
in Parliament. Although the Prime Minister said he was willing to negotiate, and the offer period for purchase was extended, in the end the national government held firm on the purchase terms, the Provincial Governments were unable to raise the money, and the Kroton shares remained in national government hands.

Matters were not helped by the lack of transparency in the government's accounting for the dividends, royalties, and development levies it received from the project. In the most recent three years of EITI reporting (2015-2017), MRDC has disclosed receipts totalling PGK1.18bn (the lion's share of which is share of sales receipts) but payments of only PGK28.3m. The MRDC does not publish accounts and there are no audits available ${ }^{69}$. This opacity gave rise to continuing accusations that the money was not there. In Parliament, Don Polye accused the government of not being able to make pay-outs because it had pledged the money as security for the UBS loan. The PM attempted to allay suspicions by quoting some figures for balances held. Officials were even despatched to Hela to show the numbers to local landowners. About that time one Hela landowner said he had been shown a cheque but then it was taken away again.

A root cause, as several authors have pointed out (Filer, 2019; Koim \& Howes, 2016; McIlraith, 2012), was the enormous difficulty for the state in compiling a complete list of legitimate and undisputed beneficiaries. The SMLIs which were supposed to underpin the Development Forums for the UBSA and LBBSAs did not achieve this result. The Forums proceeded anyway. The benefit division was agreed for major ethnic groups, but it was left to the clan vetting process and the resultant formation of further ILGs, to establish the definitive list of beneficiaries.

Late in the process the PM conceded that the failure to define the legitimate claimants before agreeing on benefit sharing was a fundamental flaw in the process and that many of the disputes around PNG LNG stemmed from the way the government and Exxon proceeded with the project without first resolving landowner claims. "It should have been done before, it wasn't only for Exxon and the partners but even the government at the time did not do the proper clan

69 As at November 2019, Googling produced a single web page for MRDC (https://www.mrdc.com.pg/rlinks/index.htm) but there were no active links from the page to further information about the company. 
vetting, proper identification of the land owners - they allowed this project to go on without that" (Reuters, 2019).

By late 2009, however, it was too late. When the BSA process started with the UBSA, the Gas Agreement had been signed, the PNG LNG project was a done deal in the government's mind, and the necessary engineering and financing arrangements were well underway. The Forums and the Agreements were simply necessary legal steps in a process that would not be halted. There was no realistic prospect that the project would be held up until landowners could agree on their role and share of the benefits.

Filer and other anthropologists leave little comfort that, given the complexity of customary land rights in the project footprint, this would ever be possible. Any permanent "settlement", whether or not informed by a better SMLI and clan vetting, would be an impossibility. According to Anoser, "It is obvious that the conversion of customary ownership into a legal instrument would in the long run encounter problems of representation, accountability, power relationship and transfer of rights" (2013, p. 38). Gilberthorpe and Banks argued that "... the landowner model has its foundations in traditional conceptualizations, a fact that has facilitated its implementation. However, the rigidity of the ILG model does not complement the characteristically fluid nature of traditional organizational features" (2011, p. 6). On the other hand, if the state owns the resources and the state distributes the benefits, the state has to be able to "see" its citizens to make payments. While it is true that the ILG does not fit into the various traditional organizational structures for the distribution of financial benefits, the developer and the state must have a vehicle to make payments. 


\section{Chapter 9 The project and government fiscal planning and budgeting}

\subsection{Introduction: emergence of the PNG LNG project in fiscal planning}

This section of the Case looks at the government fiscal and financial policy during construction and operating phases of the project. The discussion and analysis begin by looking at the various influences, issues and events that have an impact on revenue distribution during the construction and operating phases of the project.

At the time of the 2007 Budget in late 2006, the government was still envisaging that the AGL project to pipe gas to Queensland would go ahead. The 2007 Budget allocated K100m to the government's equity stake in the AGL project, in addition to the K400m allocated in 2005 (Namaliu, 2006, p. 25). By early 2007, Oil Search had formally abandoned the AGL project. However, more or less at the same time the CSA was signed to study a possible LNG project drawing on the same fields. As recorded earlier, however, by late 2007, the Minister of Finance was able to record in the 2008 Budget that both the Liquefied Niugini Gas Ltd LNG project ${ }^{70}$ and PNG LNG project were on the table for negotiation.

The abandonment of the AGL project had a significant impact on government expectations. The Budget Strategy Paper for 2007 noted that "PNG has been subjected to changes in major economic anticipated stimuli with the cancellation of the gas pipeline project." (Namaliu, 2007, p. 9). In the longer term the government was looking for new sources of production to replace oil production from the depleting Kutubu oil fields, forecast to peak in 2007 and start declining rapidly from then. The government was therefore looking at the extraction of the huge quantities of gas as a new source of revenue to replace this loss. The development of gas reserves for LNG was a welcome prospect.

Table 9:1 PNG Oil Exports: Actual and Projected

\begin{tabular}{|l|c|c|c|c|c|c|c|c|c|c|}
\hline Year & $\begin{array}{c}2003 \\
\text { Actual }\end{array}$ & $\begin{array}{c}2004 \\
\text { Actual }\end{array}$ & $\begin{array}{c}2005 \\
\text { Actual }\end{array}$ & $\begin{array}{c}2006 \\
\text { Actual }\end{array}$ & $\begin{array}{c}2007 \\
\text { Proj. }\end{array}$ & $\begin{array}{c}2008 \\
\text { Proj. }\end{array}$ & $\begin{array}{c}2009 \\
\text { Proj. }\end{array}$ & $\begin{array}{c}2010 \\
\text { Proj. }\end{array}$ & $\begin{array}{c}2011 \\
\text { Proj. }\end{array}$ & $\begin{array}{c}2012 \\
\text { Proj. }\end{array}$ \\
\hline Million barrels & 15 & 12.6 & 13.3 & 14.4 & 14.8 & 13.4 & 11.3 & 9.5 & 7.9 & 6.9 \\
\hline
\end{tabular}

$$
\text { (Pruaitch, 2007, p. 167. Table 4) }
$$

By the time of the 2009 Budget, delivered in late 2008, the government had concluded the Gas Agreement with the project licensees and, although the UBSA and LBSAs remained to be

\footnotetext{
${ }^{70}$ Which as recorded did not proceed at this stage.
} 
settled with the landowners, the project was committed and the government was including its effects in its fiscal planning. The 2009 Budget contained a section on "The Potential Economic Impact of the LNG Project on the PNG Economy" (Pruaitch, 2008, p. 135). The Budget analysis drew on a study by an Australian-based consultancy (ACIL Tasman, 2008) but the Treasury also varied its assumptions to make its own forecasts.

\subsection{The ACIL study}

The ACIL study was commissioned by ExxonMobil, who used it to make the case on behalf of the licensees for government approval of the project. In the absence of any government studies of the project, it was the sole source of analysis of project costs and benefits at the time and had a strong influence on the Government's decisions. The Treasury supplied its own estimates, but they relied substantially on the ACIL study.

The ACIL study forecast both the direct returns to the PNG economy and government and, using an equilibrium econometric model, the indirect returns. The study estimated direct payments to the government in three cases, a "Study Case" and High and Low cases. The principal differences between the Cases were oil price assumptions and equivalent LNG prices $^{71}$, shown in Table 9:2.

Table 9:2 ACIL report: Oil and LNG price assumptions

\begin{tabular}{|l|c|c|}
\hline Case & Oil (US\$/bbl) & $\begin{array}{c}\text { LNG } \\
\text { (US\$/mmbtu) }\end{array}$ \\
\hline Study & 65 & 9.35 \\
\hline Low & 36 & 5.50 \\
\hline High & 100 & 11.50 \\
\hline
\end{tabular}

(ACIL Tasman, 2008, p. 16)

The direct payments to the government covered taxes under the Income Tax Act, other revenues (principally the development levy and gas royalty under the Oil and Gas Act, and returns to a GoPNG equity investment in the project, assumed to be $19 \%$ of total equity. The ACIL forecasts of total cash payments to GoPNG and their sources are shown below.

\footnotetext{
${ }^{71}$ Historically, LNG prices in the Japanese reference market have tracked indicator oil prices very closely, with a slight lag.
} 
Table 9:3 ACIL forecast: Total net cash payments to GoPNG, ACIL forecast, 2008-2042

\begin{tabular}{|l|c|c|}
\hline Case & $\begin{array}{l}\text { PGKbn } \\
\mathbf{( 2 0 0 7 )}^{\text {72 }}\end{array}$ & US\$bn $^{\text {73 }}$ \\
\hline Study & 116 & 32 \\
\hline Low & 58 & 16 \\
\hline High & 155 & 43 \\
\hline
\end{tabular}

Data from ACIL Tasman (2008, p. 17, Figure 9)

Table 9:4 ACIL forecast: net cash payments to government, 2008-2032 ${ }^{74}$

\begin{tabular}{|l|c|}
\hline Revenue & $\begin{array}{c}\text { Percentage } \\
\text { shares }\end{array}$ \\
\hline Company Tax & $58 \%$ \\
\hline Development Levy & $5 \%$ \\
\hline Gas Royalty & $4 \%$ \\
\hline Other & $1 \%$ \\
\hline Total Revenue & $\mathbf{6 8 \%}$ \\
\hline Net cash returns to equity & $32 \%$ \\
\hline Total net returns & $\mathbf{1 0 0 \%}$ \\
\hline
\end{tabular}

Data from ACIL Tasman (2008, p. 16, Figure 8)

Thus $90 \%$ of returns over this period were forecast to come from two items: company tax and dividends from the government's equity share.

Figure 9:1: ACIL Forecast of total net revenue plus dividends

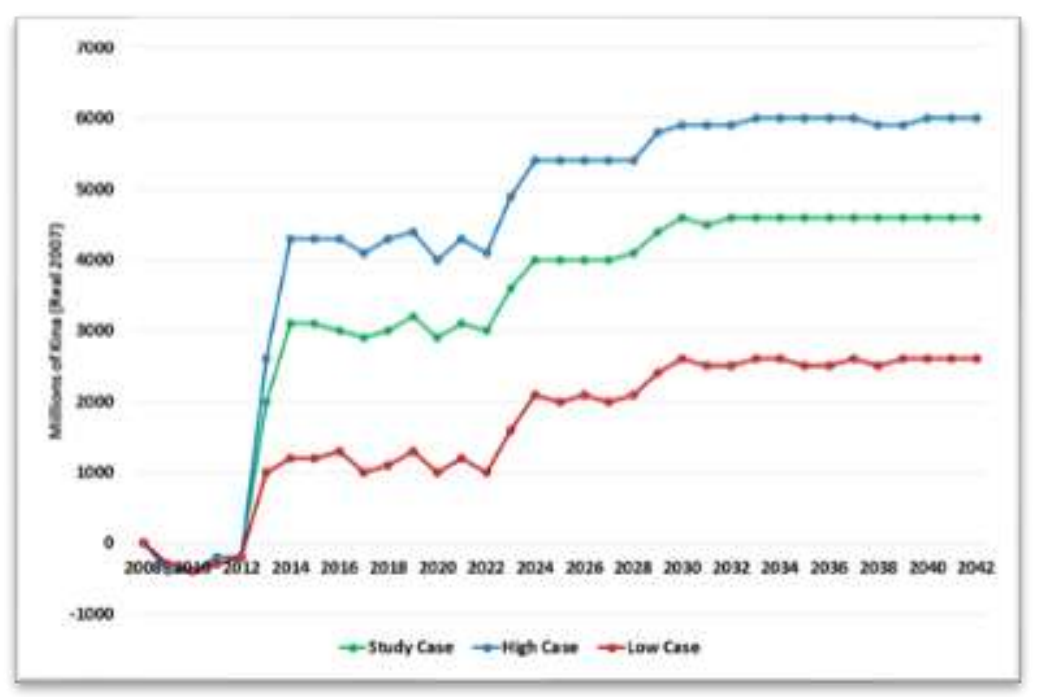

Data from ACIL Tasman (2008, p. 17, Figure 9)

\footnotetext{
72 All forecasts were made at "real" prices in kina applying in 2007. Variation in prices of new assets and recurrent cost items in subsequent years would affect nominal reported prices. For a comparison of this forecast with other forecasts made on different price assumptions, price deflators would have to be applied.

${ }^{73}$ At assumed exchange rate of US $\$ 1.00=$ PGK3.6

${ }^{74}$ Not the entire project lifespan to 2042 , but some elements of returns were estimated only up to this date.
} 
The forecast profile of these returns was a result of several assumptions in the ACIL study:

- Total annual output value of the project: during a peak production period, the project was assumed to operate at nameplate capacity of 6.3 million tonnes per annum but, allowing for "production ramp-up, plateau production level and reserves depletion over time" average annual production would be 5.4 mtpa over project operating life from 2014-2042. From 2024, there would be some addition to revenues from production of LPG.

- Tax, development and levy payments were broadly at two rates. From 2014-2022 annual payments from the project were expected to be about PGK2.0bn a year. During this period, the project partners were able to reduce their liability for corporate income tax by allowances for accelerated depreciation and interest on project debt. These allowances were assumed to expire in 2022. From 2023-2042 corporate income tax was assumed to be about PGK3.0bn a year.

- Gross cash flow from dividends for the government's assumed $19 \%$ equity share was assumed to be about PGK1.6bn a year from 2014-2042. Net cash flow to the government from its equity interest would be negative in the first few years as the government met some of its required payments for its equity share from its general cash reserves. The balance was assumed to be financed by a ten-year table loan. Outgoings servicing this debt (plus some smaller further equity calls) would reduce net cash flow by about PGK500m a year until the loan was paid off in 2028 .

- As Figure 9:1 shows, the ACIL annual revenue forecasts were "levelized", showing only average revenues for the three periods of (a) substantial tax write-offs and reduced dividends to meet debt charges; (b) full production revenues with higher company tax and dividend payments; and (c) the period when these returns would be supplemented by LPG production. The report adds the proviso that "In practice there will be some variation in revenue year-on-year as a result of differences in the operating regime of the project and changing commodity prices.” (ACIL Tasman, 2008, p. 11). Figure 9:1 thus gives a misleading portrayal of the actual profile of revenues. There is no evidence that Ministers or their advisors misunderstood that the full use by the project of available tax write-offs would result in a quite different actual profile of revenues in the early years of the project. However, at the time of the ACIL report it was not clear exactly what the impact of the project tax regime would be on this profile. 


\subsubsection{The Treasury forecast}

The Treasury's own forecasts drew on the economic analysis in the ACIL study. Two figures in the 2009 Budget clearly portray government expectations that the project would have a massive impact on the PNG economy, both in the construction and the operating phases. Figure 9:2 shows the effect of the LNG project in filling the gap left by declining oil production and Figure 9:3 the forecast direct economic impact. The Budget concluded that the direct impact during the construction phase would be "relatively small ... because most of the expenditure will take place offshore, or will be paid to expatriate labour, who are assumed to spend only 10 per cent of their income within PNG" (Pruaitch, 2008, p. 136). The major economic impact was expected to be from the production phase: once production began "the direct impact on GDP will be very large" adding an average 15-20\% to GDP over the peak production phase. Annual gross value added was expected to average about PGK 5bn over the project life. (2008, p. 137).

Figure 9:2: Budget 2009 forecast oil and gas production

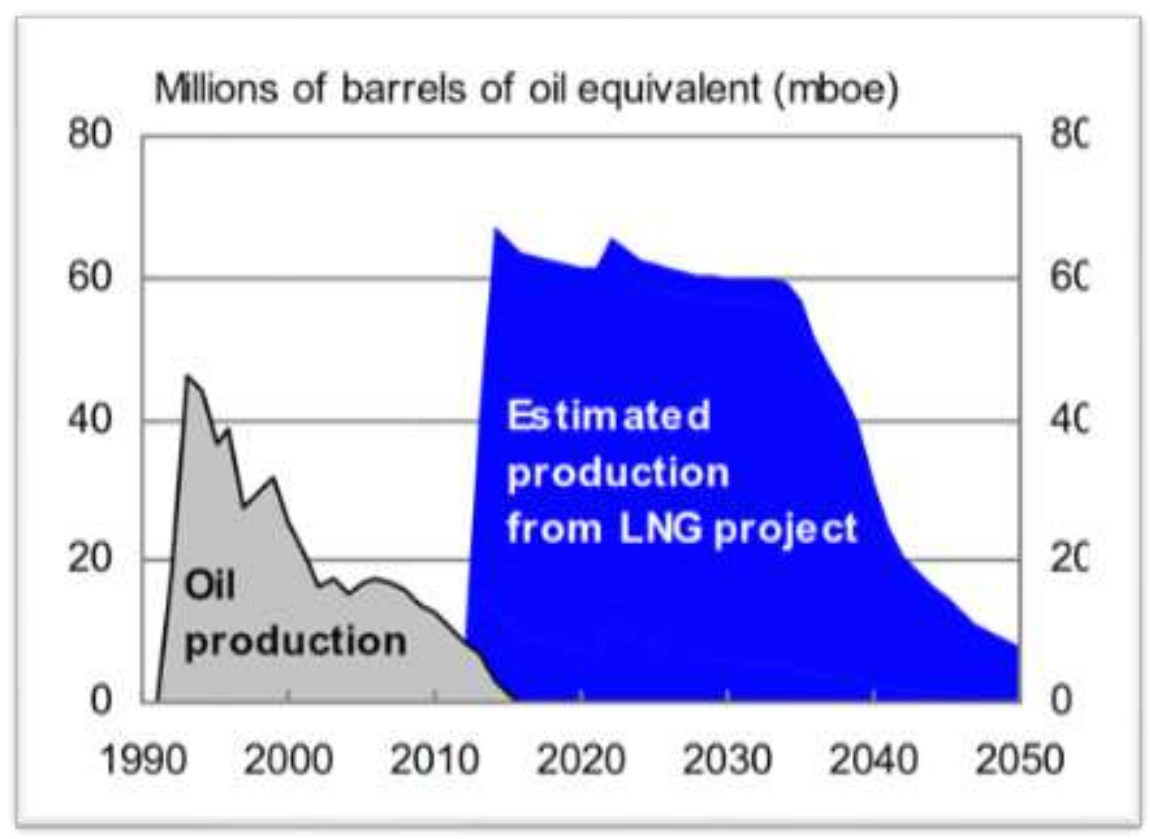

(Pruaitch, 2008, p. 136, Figure 17) 
Figure 9:3: Budget 2009 forecast total direct activity from LNG project

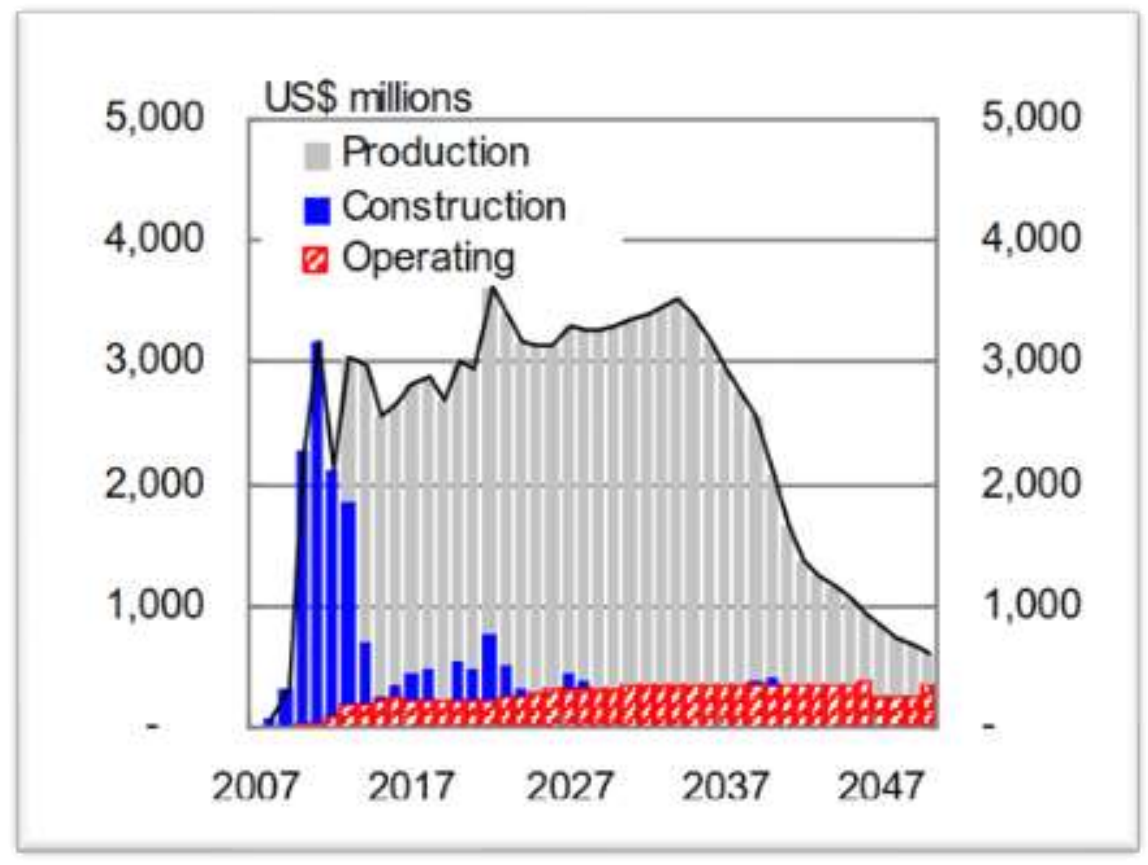

(Pruaitch, 2008, p. 136, Figure 16)

Once net income outflows from the project were taken into account, however, the Budget forecast that the effect on gross national income would be much less. "This is because most of the gross operating surplus will be repatriated offshore, in the form of dividends or interest repayments on debt."

Once the income outflows are accounted for, the direct economic impact of the LNG project on the domestic economy is estimated to average around $\mathrm{K} 2$ billion per year over the life of the project. ... This will include tax payments, which make up the bulk of the impact, dividend payments to the State, royalty and Development levy payments to landowners and Provinces, as well as income earned by local employees and contractors. (Pruaitch, 2008, pp. 138-139)

There is no specific forecast in the Budget of total revenues accruing to the government and landowners or of their profile. The Budget noted that, over the first decade of production, the direct revenue impact would be depressed by capital write-downs allowed for tax and interest expense. "Once full company tax and dividend flows begin to be received, the direct impact is expected to increase, to around $\mathrm{K} 3 \frac{1}{2} 2$ billion per year, before declining in line with lower production levels towards the end of the project's life." (Pruaitch, 2008, p. 139). This estimate compares with the ACIL Study Case forecast of maximum annual payments of revenue and 
dividends to the government of about K4.5bn, reached around 2029. The source of difference is not clear.

By late 2008, when the Budget was tabled in Parliament, the LNG project was a virtual certainty. The GoPNG had signed the Gas Agreement with ExxonMobil and had obtained financing for its equity share; the UBSA was signed in Kokopo in May 2009; sale and purchase agreements were being negotiated with prospective buyers; and the venture partners were expected to take a final decision to go ahead with the project by the end of the year. The Budget made specific provision for the government's financial commitments for the project.

\subsection{The evolution of budget expectations and policy}

\subsubsection{Budget -the debate on "Dutch disease"}

The 2010 Budget was prepared in the context of a sharp fall in commodity prices affecting mineral and petroleum revenues. The government was wrestling with how to contain public spending in the face of this cutback in revenues.

However, the government was starting to build its expectations regarding development and economic management around the project. In the construction phase, "economic activity is anticipated to be significantly higher than previously projected, due to the direct and indirect impact of the LNG project's construction, although this is expected to be partially offset by declining oil production due to the maturation of existing oil fields" (Pruaitch, 2009, p. 136). Construction was expected to add 3\% to GDP in 2010.

A final major issue was how to manage the impacts of large new flows of income from resource projects. Chapter 10 of the Budget on "Long-Term Fiscal Issues" was devoted to a discussion of government's fiscal strategy for managing strongly fluctuating minerals revenues, in the light of the economy's continued dependence on extractive industries (Pruaitch, 2009, p. 159). The Budget foreshadowed a review of the rule in the current Medium-Term Fiscal Strategy of basing recurrent (ongoing) expenditure on "normal" mineral revenues, defined as 4\% of GDP. The government's current principle was to sequester "windfall revenues" in trust accounts, but they had "limitations" related to "scale and efficiency": onshore accounts held by commercial banks created problems for the Bank of PNG in mopping up excess liquidity and "allocation of funds to trust for specific purposes limits the capacity of the Government to later use those funds to fund priority investments that later emerge". (2009, p. 159) 
The Budget did address the issue of "Dutch Disease", specifically in those terms:

The LNG project is expected to increase GDP in PNG very substantially and LNG exports are expected to become PNG's largest source of export revenue by a large margin. These increases would make PNG highly susceptible to Dutch Disease. (Pruaitch, 2009, p. 168)

It claimed however that the exchange rate and relative price effects of commodity booms were largely unavoidable: "Following the discovery of natural resources, it is generally not possible to avoid an overall contraction of other trade-exposed industries." (Pruaitch, 2009, p. 166). However, "while it is not possible to avoid Dutch Disease, there are policy options to minimise its effects, primarily through the creation of a sovereign wealth fund." (Ibid.).

According to Osborne the idea of establishing a SWF "to manage the PNG LNG Project revenues and dividends" had been discussed at an Australia-PNG Ministerial forum in October 2009. Osborne says "SWF establishment was seen as a condition for directing Australian support towards the PNG Government's role in developing the LNG project; support which was viewed as critical to getting the project past the point of Final Investment Decision (FID) stage." (Osborne, 2014, p. 9). The IMF also had an influence. In its 2010 Article IV consultations with the government, the IMF reported that there was

.. considerable discussion of a Sovereign Wealth Fund (SWF) to augment the macro framework to help manage resource revenue. With the LNG projects expected to eventually deliver a large increase in public revenue, the authorities were interested in the advantages of establishing an SWF. Staff provided an assessment of what type of SWF would best address their needs ... Staff agreed to work closely with a joint Treasury/BPNG working group tasked with preparing an SWF proposal for the National Executive Council by end-June 2010. (IMF, 2010, p. 14)

The Budget discussion of a SWF cites IMF references and draws on IMF views on the policy and governance requirements for establishing a fund.

The 2010 Budget reached no firm conclusions on the establishment of a Fund. However, in March 2010 in Parliament Prime Minister Sir Michael Somare announced the government's intention to establish three SWFs. (Osborne, 2014, p. 9). The NEC commissioned a working group led by Treasury and the BPNG "to consider alternative arrangements to help manage the 
significant revenues arising from this project to be used for PNG's development needs whilst promoting macroeconomic stability". (O'Neill, 2010, p. 163). The Department of Public Enterprises was separately commissioned to examine "options relating to the management of dividends arising from the Government's equity stake in the PNG LNG project”. (Ibid.)

The Working Group received a wide range of technical submissions and had extensive support with analysis and policy design from the IMF, World Bank and the Australian Government. (Ibid, p. 166). It delivered its final report in October 2010.

\subsubsection{Budget - how to manage the LNG revenue "bonanza"}

By the end of 2010, the projected expenditure on construction of the LNG project was having significant effects on government expectations about economic activity. The Budget reports likely growth of $7.1 \%$ in 2010 and forecasts growth at about $8 \%$ in 2011 "largely driven by the expected ramp up in PNG LNG construction activity and stronger mining and agricultural production in 2011." (O’Neill, 2010, p. 16). The Budget reported that high level of investment activity was running into capacity constraints and inflation was accelerating, with a forecast to over $8 \%$ in 2011.

The Budget reported the PNG Treasury's own "indicative estimates" of government and landowner revenue from the project, which were considerably more optimistic than those in the 2009 Budget. The Treasury estimated a total of about US $\$ 31$ bn over the project operating life (2016-2040). This estimate was “... 64 per cent higher than the 2009 Budget estimate of US\$19 billion over the same period, largely due to higher price assumptions compared to the earlier analysis" (Ibid, p.162). The Treasury's assumptions were more optimistic than their own 2009 forecasts (based on the ACIL Study Case) in several respects. They assumed higher LNG prices and a larger share of earnings going to dividends, including to the government and landowners, who were assumed to take up their full equity entitlement of 4.1\%. (Ibid, p. 161). Revenues to government were forecast to rise "rapidly" over the first ten years of production: tax revenues would rise once the developers had exhausted their deductions for accelerated depreciation, and dividends once project debt had been repaid.

The total forecast government net receipts over the 32 years were approximately the same as the ACIL Study Case forecast. The main difference was in the profile, as the following figure shows, comparing the Budget assumption of a slower build-up of revenues with the ACIL case, which "levelised" the returns in earlier years. 
Figure 9:4: 2011 Budget - Forecast government revenue plus dividends from PNG LNG project (m Kina)

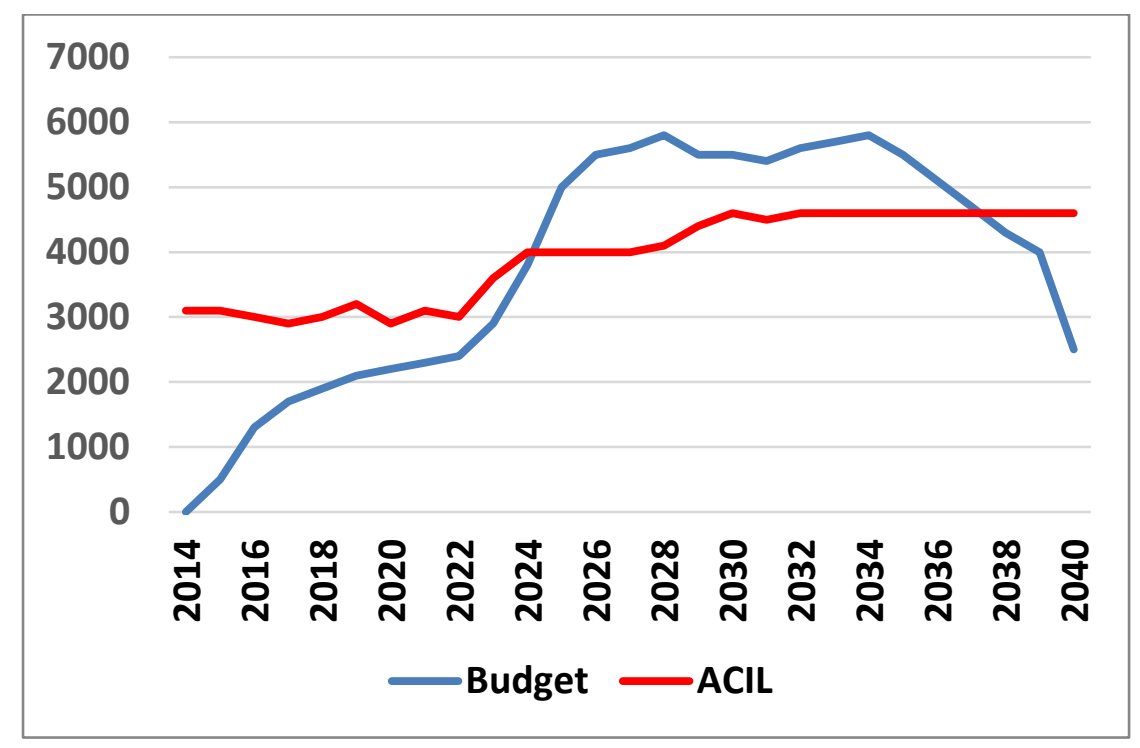

(Data from ACIL Tasman, 2008; O’Neill, 2010, p. 161)

The 2011 Budget confirmed the establishment of

... a consolidated pool of offshore funds with three coordinated and integrated Funds:

1. A Stabilization Fund (Stabilization SWF) established from LNG tax revenue and other mineral and petroleum revenue, 2. Future (Savings) Fund established from LNG tax revenue and other mineral and petroleum revenue, and 3. An Infrastructure Fund (Infrastructure SWF) established from LNG dividends. (O’Neill, 2010, p. 168)

The Budget promised that future Budgets would report each year on progress with setting up the funds.

As to what growth in LNG revenues the economy could absorb, as foreshadowed in the 2010 Budget, the Working Group had recommended that the MTFS 4\% rule should be revised to accommodate LNG revenues. The technical arguments on the specific rules for operation of the SWFs turned on this figure. There were two potentially conflicting arguments. On the one hand, expectations were rising rapidly about what could be done with this apparent huge increment to government revenue. There was domestic pressure to mobilise a greater share for pressing investment requirements. The Budget acknowledges that "[s]ome other domestic stakeholders argue that development needs in PNG are such that all funds should be brought onshore and spent immediately" (2010, p. 166). But the Budget text continues that this was "a radical and dangerous view that would be very likely to result in severe economic instability and losses for the majority of the population." (Ibid.). Officially at least, the government 
acknowledged the "resource curse" argument that strongly cycling mineral revenues could jeopardise both economic and fiscal stability. The Budget concluded:

... the IMF/World Bank modeling [sic] suggested that additional Government spending arising from LNG revenues could grow sustainably in accordance with growth in nonmineral GDP. This equates to an increase in Government investment spending of up to about 6.0 per cent per annum over the medium term. The Working Group considers this recommendation by the IMF/World Bank to be conservative. ... The Working Group recommends a balanced approach that will allow for a substantial lift in development spending while maintaining macroeconomic stability. (O’Neill, 2010, p. 16)

It is worth noting that in identifying risks to the construction phase of the project the Budget reported "... [a] slight delay in the construction work ... affected to some extent by landowner issues delaying progress at different stages during the year. However, the commencement of LNG production in 2014 is not expected to be affected." (O'Neill, 2010, p. 32). There is no further mention of the "landowner issues" but the Budget commits extra budget to the Police to provide security in project areas. The Budget did commit K650m to fund UBSA commitments and local roading projects.

In March 2011, in his annual Monetary Policy Statement (Bakani, 2011), the Governor of the Central Bank explicitly addressed the Dutch Disease risks presented by the project, defining them as "an economic condition where a resource boom leads to an appreciation of the real exchange rate, which in turn depresses outputs in the traditional tradable sector" $(2011$, p. 4). The statement noted that, to help manage the liquidity effects of increased resource revenues, the Government had agreed to open all new trust accounts with the BPNG. The statement went on to recommend that

Prior to the establishment of the SWF, the Government should refrain from appropriating windfall mineral tax revenues and allow the Bank to manage them in an offshore bank account. The Bank already has experience and expertise from managing the nation's foreign exchange reserves and therefore can manage this offshore account. (Bakani, 2011, p. 6).

In June 2011, Prime Minister Somare resigned due to ill health, triggering a political crisis and a change of government in August of that year, with Peter O'Neill becoming Prime Minister and his coalition partner Don Polye Treasurer. 
The new government approved the SWF policy in October 2011 substantially in the form that had been recommended by the Working Group but with one significant change: the Future Fund was dropped and the Infrastructure Fund was renamed the Development Fund. The government introduced an Organic Law to create the SWF into Parliament in December 2011 and it was certified in March 2012 (Organic Law on Sovereign Wealth Fund, 2012) ${ }^{75}$.

\subsubsection{Budget - when to capitalise the revenues?}

The 2012 Budget (Polye, 2011b) was delivered in late 2011 by Don Polye, the new Treasurer, in the context of continued strong growth in the economy. Growth in 2011 was forecast at $8.9 \%$ and strong growth was expected to continue in 2012, again largely driven by the construction of the PNG LNG project.

The Budget included a re-estimation of project receipts over the project life of K49.5bn in nominal terms and K27.6bn in real terms (assuming 4.5\% annual inflation). The profile of nominal receipts was significantly lower than the 2011 Budget forecast and seemed to assume a somewhat slower rise in revenues, a much lower peak value of production, and an earlier depletion of reserves.

Figure 9:5: 2012 and 2011 Budgets - Forecast government revenue plus dividends from PNG LNG project (m Kina)

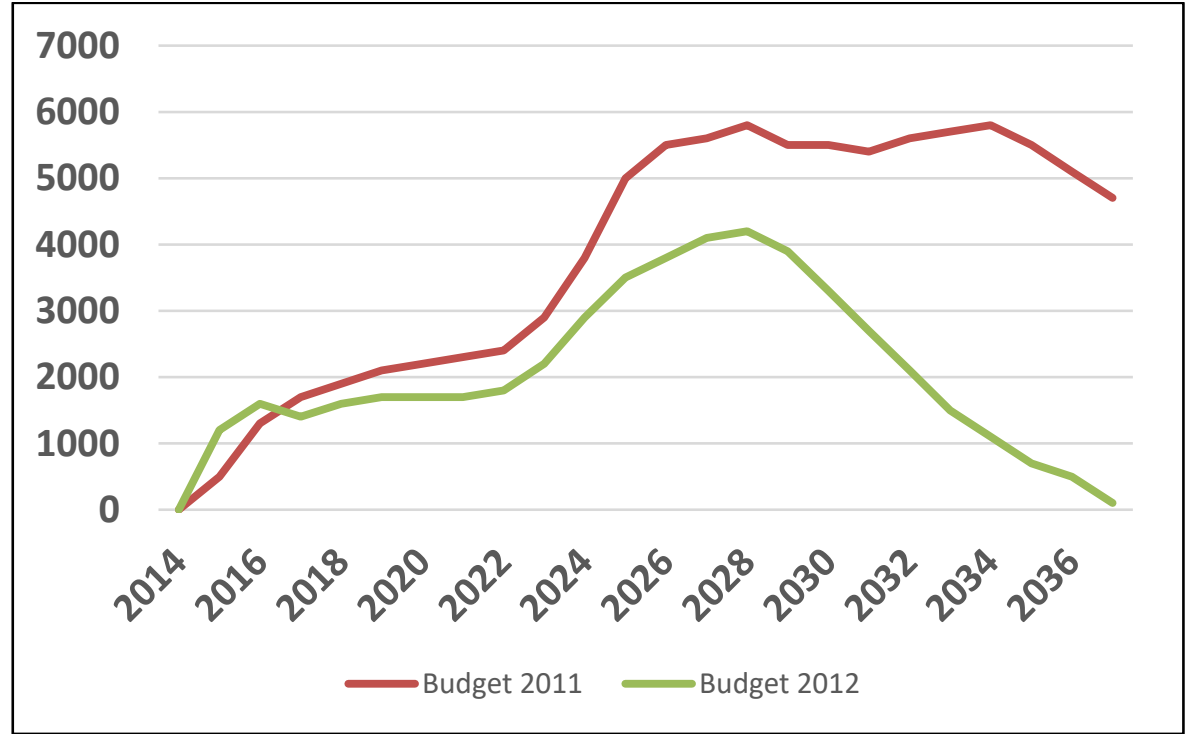

(Data from O’Neill, 2010, p. 162; Polye, 2011b, p. 175)

\footnotetext{
${ }^{75}$ After it is enacted by Parliament, a law comes into operation on the date, usually a few weeks later, when it is certified by the Speaker. (PNG Constitution, 1975, p. 47. Section 110.) The law's title includes its year of enactment. (In some cases certification may be in the following calendar year).
} 
Major announcements in the Budget included a revised MTFS for the period 2013-2017, designed to align with the planned SWF, to be published in late 2012. (Polye, 2011b, p. 21). The Budget foreshadowed the passage of the SWF Law in the first quarter of 2012. However, the government's intention set out in the pre-Budget Strategy Paper was to use all "additional mineral revenue" above the $4 \%$ rule to "pre-fund public investment expenditure" in line with the PNG Development Strategic Plan (2010-2030) (Polye, 2011a, p. 6). The Budget itself proposed:

...[a] guaranteed minimum level of payments [from the proposed SWF] made through the budget for activities such as priority national infrastructure as well as (over the next ten years) recapitalising public enterprises. This guaranteed level of funding will be based on the expected dividend returns from the Government's equity stake in the PNG LNG project (Polye, 2011b, p. 118)

The commitment to use all LNG revenues above the $4 \%$ line for investment would be in breach of the MTFS rule that $30 \%$ should go to reduction of public debt. The Budget argued that this was justified because “... government debt (which is below 30\% of GDP, excluding contingent liabilities) is now at a more sustainable level." (Polye, 2011b, p. 5).

The government was incurring significant liabilities to finance its commitment to the project. A PGK 900m domestic debt issue through a state vehicle (the Independent Public Business Corporation) would fund the state's 19.2\% share of the project (including allowance for cost overruns) and there would be a contingent liability for the state's share of the completion guarantee during the construction phase.

In his Budget Speech, the Treasurer said:

Mr. Speaker, it is important that our expectations are realistic. Even when we look ahead to beyond 2015 when PNG LNG revenue start flowing, we see that there will not be as much money as many people think. PNG LNG revenues will be important, but they will simply replace mineral revenue from projects which are winding down or becoming less profitable. Money does not grow on trees, and for all of its importance, the PNG LNG project is not a magic saviour to the PNG economy. The challenge will remain on spending our Government revenues well. We must use what we have well and honestly, as we do not have money to waste or be stolen through corruption. (Polye, 2011b, p. 24) 
Figure 9:6, a chart prepared by the Treasury, illustrated the Treasurer's contention.

Figure 9:6: LNG contribution to the economy*

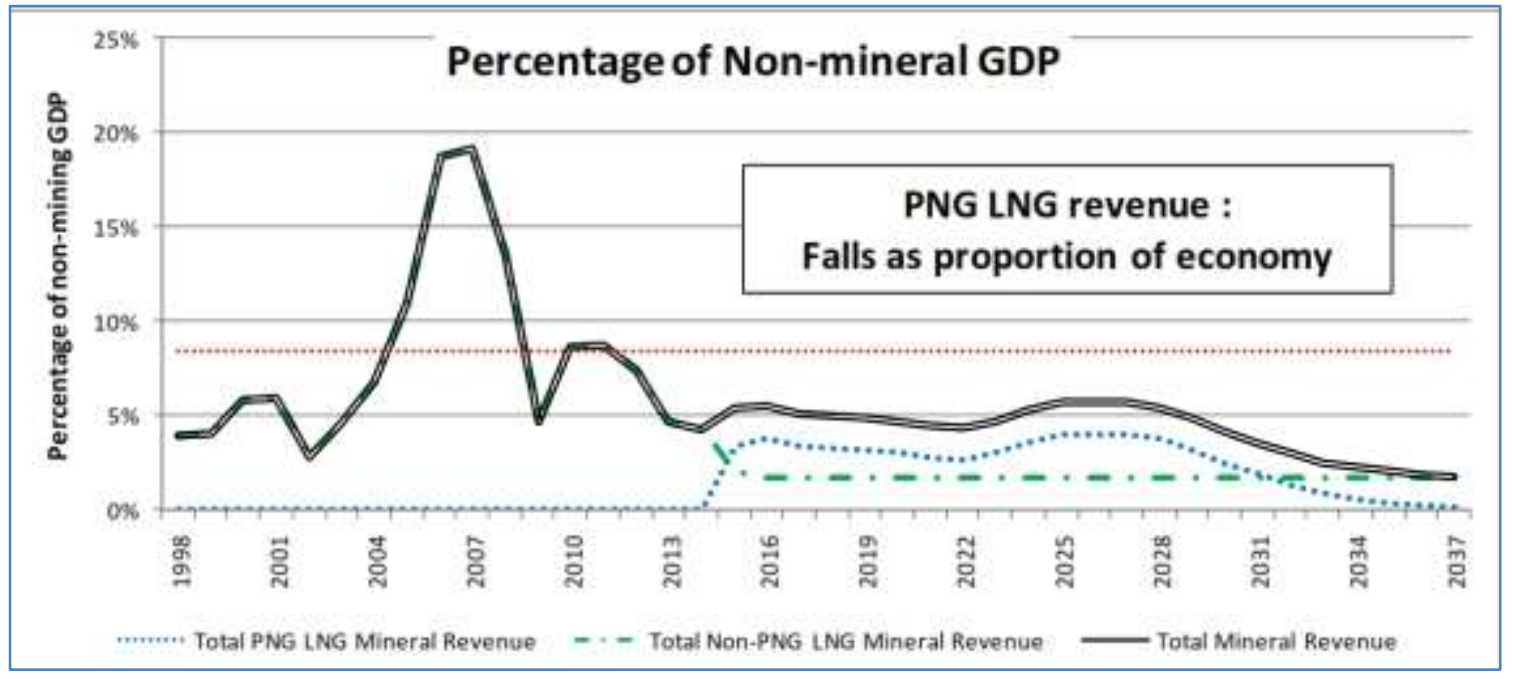

(Polye, 2011b, p. 175) ${ }^{76}$

Other statements reflected the pressure on the government to be seen to be using the LNG revenues for its development objectives, if necessary before they started arriving. Speaking in Parliament, the Minister for Education, spoke strongly for the Government to borrow money outside of the budget if necessary and then to systematically invest in Health, Education and infrastructure now rather than in the future:

Let me post this question, do we wait 10 years to harness the LNG revenue and reeducate an adult 20 years down the line or harness that revenue today and educate that child now? What is the logical question? I am making this statement from the perspective of many criticisms that will come in relation to why get K6 billion loan or K2 billion additional outside of the Budget. Mr Speaker, if you find an optimum space and optimum figure to advance that revenue that we have down the line, get it and start to invest systematically today in the Health, Education and infrastructure sectors. That is the work of a responsible government seeing the need into the future by advancing secured revenue we have today. Mr James Marape, Tari Pori. (PNG Parliament, 2019, 25 October 2012).

\footnotetext{
${ }^{76}$ Red line in figure: long-run mineral/non-mineral ratio 1998-2012
} 


\subsubsection{Sovereign Wealth Fund Mark I}

A Chapter in the Budget set out the provisions of the draft law on the SWF, gazetted a month earlier (Polye, 2011b, p. 169 ff.). The Budget set out the "key design elements" in the Law including:

- The two Funds: a Stabilisation Fund to "manage the impact of fluctuating mineral and petroleum revenues on the PNG Economy and on the Budget"; and a Development Fund "to provide a definite and ongoing funding source for the provision of development in key economic and social priorities in accordance with the development plans as determined by the Government, from time to time".

- A Board with a majority of PNG citizens charged with managing the two funds and supported by

○ an Administrative Secretariat "sensibly located in the Bank of PNG drawing on its existing experience and expertise";

$\circ$ a Policy Secretariat in the Treasury to advise the government on budgetary and fiscal policy matters relating to the Fund operations;

○ an Office of SWF under the PM with "a high-level oversight role on SWF matters" to "ensure that broad resource allocation targets under the PNG Vision 2050 are achieved; and that specific development initiatives ... are realised by the implementing line agencies and provinces".

- A policy of predominantly offshore investment of the two Funds: the policy "better protects the PNG economy from the volatility of revenue flows" and "provides the prospect of higher returns back to the people of PNG".

- Rules for receipts and payments:

- All minerals revenues from taxes and dividends to be paid into the Stabilisation Fund;

- Annual withdrawals from the Stabilisation Fund to be appropriated in the annual Budget and to be limited to "the 15-year long-term moving average of mining and petroleum revenues as a share of non-mineral revenue"; 
- Annual allocations from the Budget to the Development Fund "no less than the guaranteed minimum annual allocation as determined by an Act of Parliament based on the expected average PNG LNG Dividends" together with the Fund's investment earnings and any additional amounts allocated in the Budget;

○ Withdrawals from the Development Fund "to support the development plans of Government in accordance with an Act of Parliament".

- Accountability arrangements including:

- Annual public reporting by the Board on the operations of the Funds with the Auditor-General empowered to audit the Funds' financial statements;

○ An "Independent Probity Auditor" to audit the Board's investments "including the engagement of investment managers", the "application of deposit and withdrawal rules" and the "operation of the Development Fund".

O "Given the importance of openness and transparency, it is proposed that all information on activities by the PNG SWF Board, including its investments, be freely available through its website."

Figure 9:7 below is the illustration in the Budget of how the SWF would operate. The figure describes the revenue sources as "volatile": the Budget estimated that in 2012 the Stabilisation Fund would have received about K1380m, dropping to K340m in 2016. PNG LNG was expected to generate $750 \mathrm{~m}$ taxes and $560 \mathrm{~m}$ dividends in 2016 . The withdrawal rule would permit K1500m to be allocated to the Budget in 2012. Based on estimated dividend flow in 2011, minimum payments to the Development Fund would be K280m in 2012. When PNG LNG came on stream, "the level of guaranteed minimum funding could be equivalent to the estimated flow of PNG LNG project dividends (about K560.0 million per annum in nominal terms)." (Polye, 2011b, p. 178). 


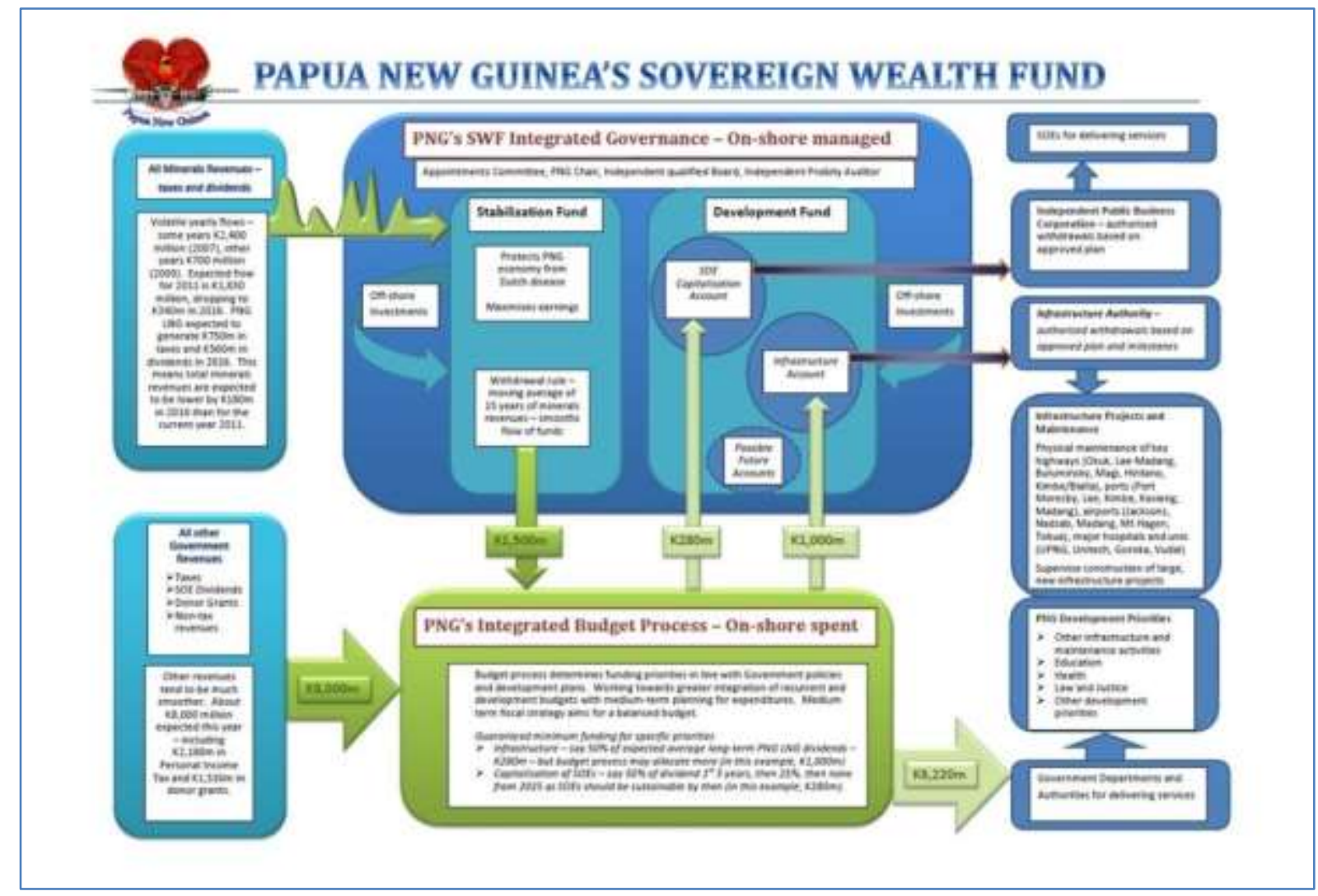

(Polye, 2011b, p. 180, Fig. 39)

Osborne (2014, p. 13) simulated the effects of the SWF rules to show what the fund would have received if it had been in place in 1998. He concluded that in 2011 fund balances would have exceeded K10bn. With these rules from the 2012 Law in operation, and assuming similar long-term trends in commodity prices and (importantly) the assumed shares accruing to the state from PNG LNG and other extractive projects, the SWF had at least the potential to contribute significantly to the desired objective of macro-economic stabilisation.

\subsubsection{Budget - revenue optimism and a shift to deficit budgeting}

Don Polye's second Budget in 2013 followed an upwards revision of 2012 growth forecasts in the 2012 MYEFO, largely due to increased activity across the economy driven by the "overwhelming demand generated by the PNG LNG project" (Polye, 2012, p. 7). Despite the note of caution in the 2012 Budget, the Budget was strongly expansionary. While revenue was forecast to increase by only $3.2 \%$, total spending was forecast to increase by $23.4 \%$, resulting in a projected budget deficit of K2.6bn or about 7\% of forecast GDP in 2013.

The Budget continued to forecast sharp increases in revenue when the LNG dividends started flowing from 2015. However, the Budget also noted the decline in total government revenue 
as a share of GDP, falling from a forecast $31 \%$ of GDP in 2012 to $27 \%$ projected in 2017 . A large part of this fall was due to the "significant" fall in the share of resources revenue in GDP, from $37 \%$ in 2011 to about $20 \%$ in 2017.

The Budget attributed some of this reduction to concessions made for specific resource projects through project agreements. The concessions were often "difficult to cost, but in many cases they have the effect of depriving the Government of significant amounts of revenue." (Ibid., p. 178). Specifically: "The PNG LNG project concessions were based on a first mover basis for this particular industry and should not be used as a benchmark for future projects." (Ibid.). This is the first public sign that the government was reassessing the cash it would receive from the PNG LNG project over its life.

The year 2013 marked a turning point in government budgets. From 2006 to 2012, expenditure had more or less tracked revenue, with successive budgets responding to cycles in resource revenue and economic activity generally by adjusting expenditure plans accordingly. From 2013 to 2018, budgets were generally deficit budgets.

Figure 9:8: Emergence of deficit budgets from 2013

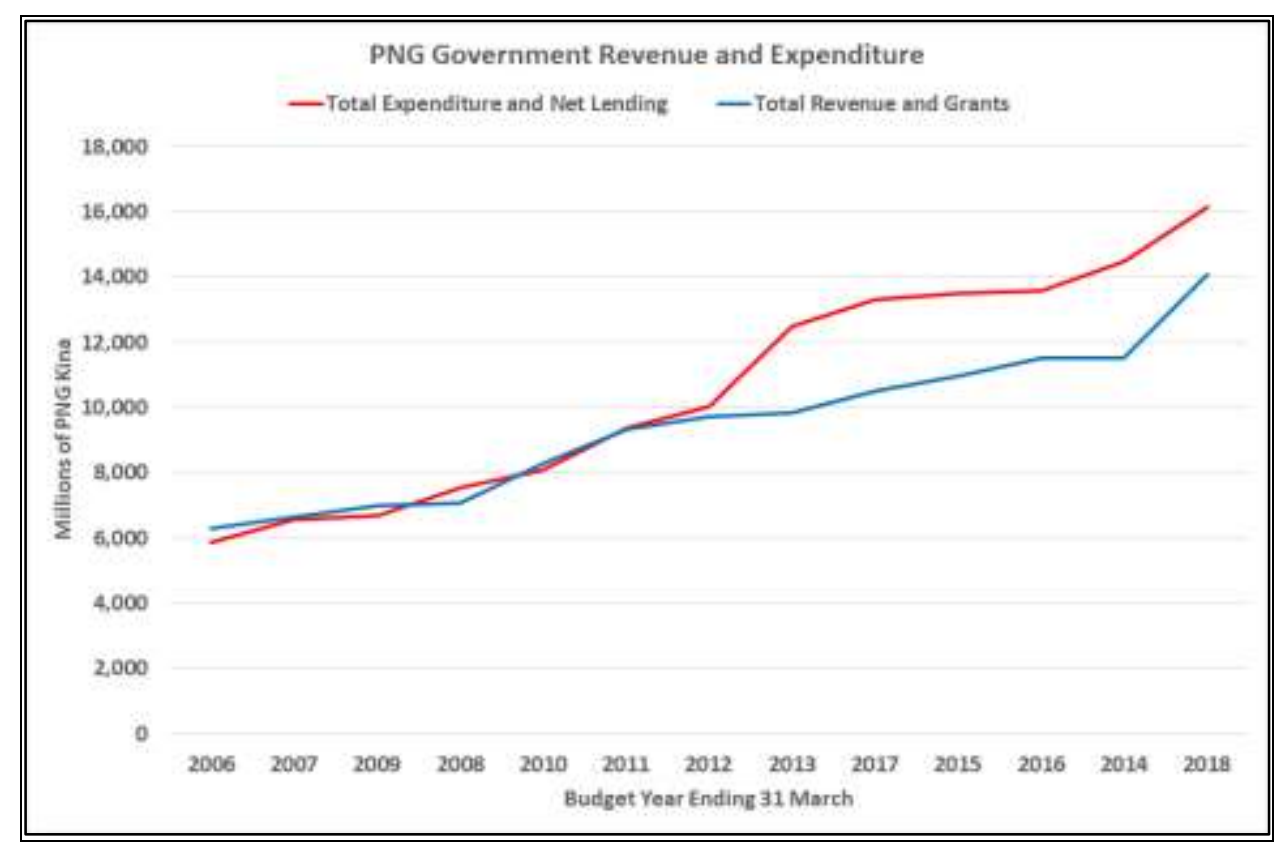

Data from PNG Budgets, 2006-2018

On the $12^{\text {th }}$ September 2013 Mr Philip Undialu (MP Koroba-Lake Kopiago) made an important observation in Parliament about the projected benefits as outlined in the ACIL Report: 
The problem that I see here is that when the PNGLNG Project when it came was that the State only depended on the ACIL/Tasman Report. The National Economic Fiscal Commission had never put in an effort. Maybe they tried to do their best but it was us who then suppressed their efforts to come about. We never had a good State team, environment team, lawyers and petroleum engineers at that time. Therefore, the ACIL/Tasman was a consultant company engaged by the project developers to do a feasibility study which unbeknown to a lot of people was relied heavily upon by the State in its decisions and especially in a number of budgets (PNG Parliament, 2019, 12 September 2013).

\subsubsection{Treasury downplays the Sovereign Wealth effect}

The Treasury wanted to see the SWF come into operation. In the 2013 Budget a whole Chapter was devoted to the SWF, which reported that an Implementation Plan was in place aimed at the Fund becoming operational in mid-2013. (Polye, 2012, p. 193). The Chapter also reported some modelling that showed, under the 15-year rule and with current assumptions about LNG prices and revenues, there would be "no net accumulations in the Stabilisation Fund until 2024”. (Ibid. 190).

Figure 9:9: Sovereign Wealth Fund: Treasury forecast of accumulations

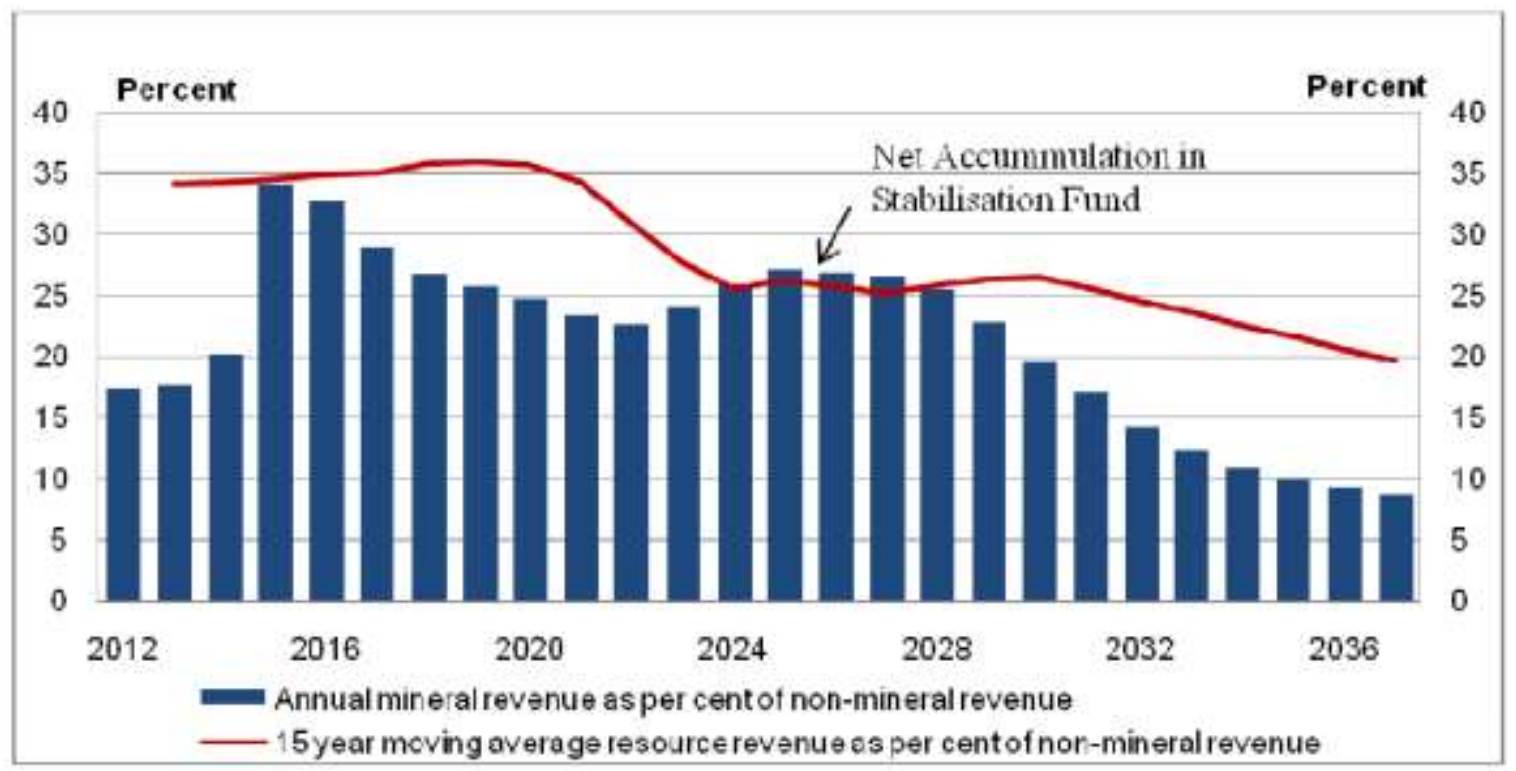

Source: Department of Treasury

(Polye, 2012, p. 190, Figure 48)

However, during 2013 the rules of the Fund were under review. In November 2013, while introducing the 2014 Budget the Treasurer announced that the government: 
... has undertaken a review of the Organic Law to ensure proper constitutional processes are followed. The Government is considering modifying the design of the PNG SWF to provide a greater focus on intergenerational equity consistent with our Constitutional obligations. In considering this, the Ministerial Committee on Economic Sector (MCES) has agreed to have a Savings Fund to replace the Development Fund. ... The next phase of work is to finalize the Organic Law and re-introducing it in the Parliament in 2014. (PNG Parliament, 2019. 19 November 2013)

\subsubsection{Budget - ongoing optimism}

There was an ongoing optimism about the overall growth in the economy and in government revenue, financing a significant increase in expenditure on public investment and social priorities. All these were reflected in the 2014 Budget. Deficit financing continued. Total revenue and grants were forecast to increase by $21 \%$; and total expenditure and net lending by $13.6 \%$. The Budget deficit was forecast at 2.4 bn kina - 5.9\% of GDP.

The Government expected the PNG LNG project to make a significant contribution to government revenues, scheduled to start operations in 2014 but the Budget returned to the problem of reductions in revenue from significant tax concessions to new projects, including PNG LNG:

Mineral revenue is expected to increase after the PNG LNG project production begins in 2014. However, revenue on mining and petroleum is falling as a per cent of mining GDP due to generous tax concessions, including to the PNG LNG project (due to its special status as a pioneer project) and a number of other mines, including Ramu Nickel with tax concessions and exemptions that are not in line with standard tax law. (Polye, 2013, p. 48)

\subsubsection{The Kumul entity}

The Government was deeply concerned about the reduced dividend payments coming from state enterprises with equity interests in resource development projects. The NEC decided to consolidate government holdings into a new entity, Kumul Holdings, to replace the existing General Business Trust incorporated under the Independent Public Business Corporation. "The greatest source of dividends to the Kumul Consolidated entity will come from the State's equity 
in the PNG LNG project and the Ok Tedi mine, both of which did not pay dividends to the GBT.” (Polye, 2013, p. 120)

This was to be Don Polye's last budget as Treasurer for the O'Neill coalition government. The Prime Minister dismissed him from Cabinet in March 2014, for causing "instability in the Government" (L. Cochrane, 2014). Mr Polye left the government coalition and became an opposition member, but the other members of his party, which he led, stayed with the government, giving it a "comfortable majority" (Ibid).

\subsubsection{Budget - further expansionary fiscal policy}

The 2015 Budget (Pruaitch, 2014) was also expansionary, projecting a further substantial increase in government expenditure on the back of a forecast faster rise in revenue. While it is not clear why the Government made a big forecast in its 2015 projections, a major influence was early production and shipment of the LNG in May of 2014. Total revenue and grants were forecast to rise by $9.9 \%$ and total expenditure and net lending by $7.3 \%$. The fiscal expansion was based on a relaxation of the MTFS rules, breaching the new (2013-2017) debt/GDP target of $35 \%$ (cf $30 \%$ ) slightly.

The Budget explicitly acknowledged that future growth was "closely linked to the developments of the LNG project." The project was in part filling up a hole left by declining petroleum production. Official forecasts showed that LNG output, forecast to increase to 300Tbtu in 2015 and a maximum 330 in 2016-19. Over the same period to 2019, production of oil plus condensate was expected to decline from $20 \mathrm{~m}$ barrels to $13 \mathrm{~m}$ barrels. (Ibid, p.26).

There is no doubt that expectations of tax and other income from the project had a big influence on economic and revenue forecasts. The project had started operations in late 2014, about a quarter earlier than predicted. The forecast first full year of production was expected to make a big contribution to total revenue. Of the total forecast increase of about K1.4bn in 2015, about 1.1bn kina was in mining and petroleum taxes, of which a large part would have been the forecast full-year increment in LNG taxes, and "other" non-tax revenue including forecast LNG dividends.

In his Budget Speech in November 2014 the Treasurer also foreshadowed the re-introduction of an Organic Law on the SWF "revised since its passage by Parliament in February 2012 to 
account for further refinements and technical issues of the Constitutional Law process" (PNG Parliament, 2019. 18 November 2014).

\subsubsection{Budget - end of the commodity cycle and its effect on revenues}

The 2016 Budget showed a significant change in tone from the jubilant forecasts of 2015 . The Budget reported a weakening in the global economy and sharp drop in commodity prices (including oil) affecting PNG exports. The 2015 Budget forecast an oil price of US\$90. By October 2015, the actual price had fallen to under US\$50. Figure 9:10 below reflects the fall in oil prices.

Figure 9:10 - Oil and Gas Price Downturn, 2015-16

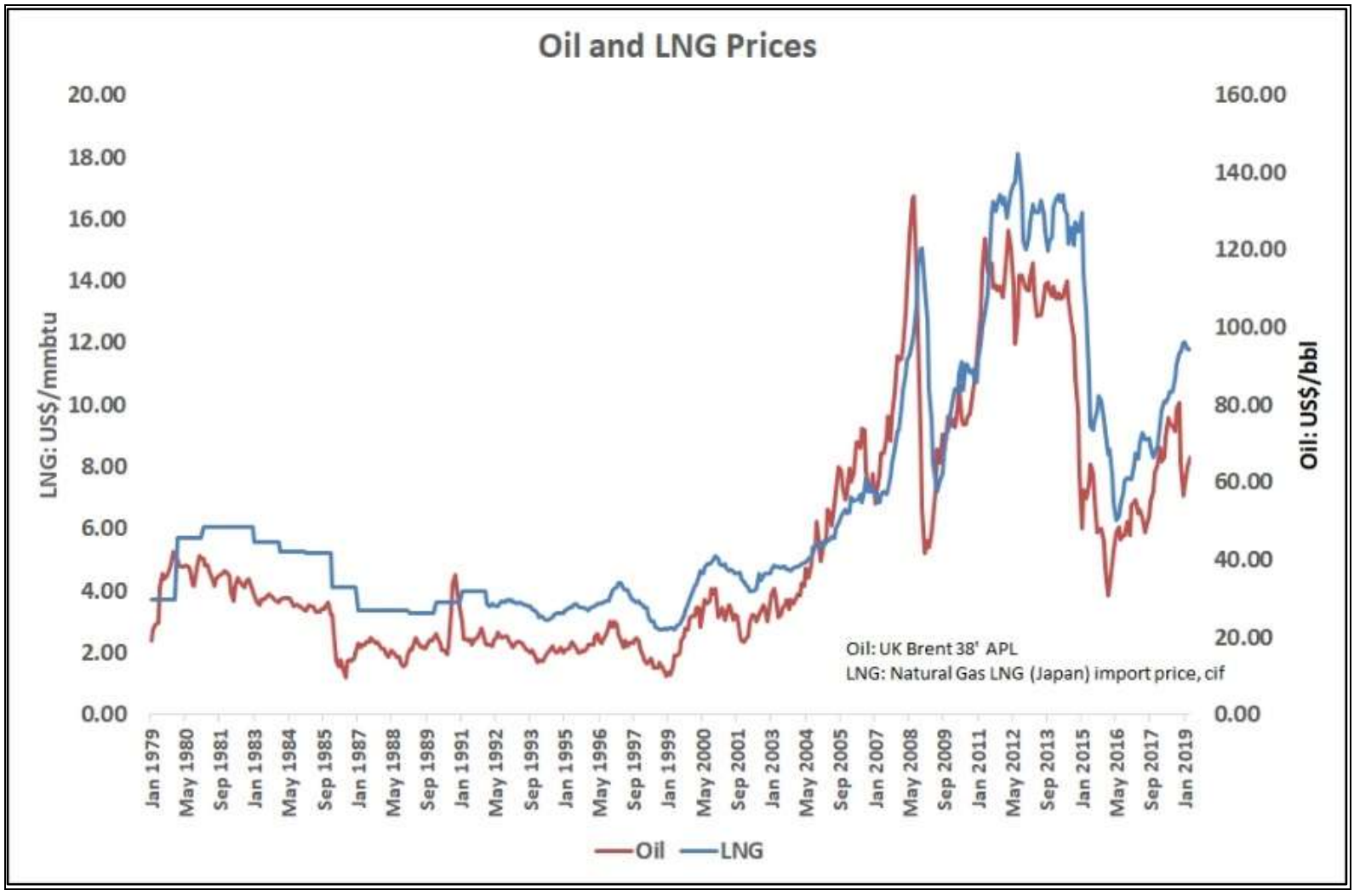

Data from World Bank (2019b)

Budget expenditure and revenue forecasts were revised as a result. The reduced revenue forecasts in large measure reflected sharply reduced estimates of Mining and Petroleum Tax and Dividends. The forecast outturn for MPT in 2015 was now K300m compared with K1,769 billion in the 2015 Budget. The 2015 Budget forecast K698.5m for Mining, Petroleum and Gas Dividends. The figure for the 2016 Budget is zero. The government attributed these reductions to the $50 \%$ reduction in oil and gas prices compared with forecast. 
Revenue was thus forecast to be virtually static compared with the revised 2015 forecast outturn and forecast expenditure was reduced. The Budget was still in deficit, however. The deficit (on an IMF "Net Borrowing" basis ${ }^{77}$ ) was forecast at $3.8 \%$ of GDP compared with an estimated $4.9 \%$ in 2015. In the medium term 2016-2018 the projections were for deficits slightly exceeding the modified MTFS Debt/GDP target of 35\%. A return to surplus was forecast for 2020.

Table 9:5 2015 and 2016 Budget forecasts (PGK m)

\begin{tabular}{|l|c|c|c|}
\hline & $\begin{array}{c}\mathbf{2 0 1 6} \\
\text { Budget }\end{array}$ & $\begin{array}{c}\mathbf{2 0 1 5} \text { Budget } \\
\text { (revised) }\end{array}$ & $\begin{array}{c}\text { Percent } \\
\text { change }\end{array}$ \\
\hline Revenue & $12,650.1$ & $12,637.9$ & $0.2 \%$ \\
\hline Expenditure & $14,762.6$ & $15,129.7$ & $2.4 \%$ \\
\hline Net borrowing & $\begin{array}{c}-2,112.5 \\
(3.8 \% \text { GDP) }\end{array}$ & $\begin{array}{c}-2,419.8 \\
(4.9 \% \text { GDP })\end{array}$ & \\
\hline
\end{tabular}

(Pruaitch, 2015)

\subsubsection{Sovereign Wealth Fund Mark II}

The Government introduced the revised version of the SWF law in February 2015 and, after some further revisions ${ }^{78}$, a new law was certified in January 2016. (Organic Law on Sovereign Wealth Fund 2015, 2016). It went beyond the "further refinements and technical issues" referred to by the Treasurer in his 2014 Budget Speech. Although the basic objectives and governance of the Fund remained largely unchanged, the revisions included substantial changes in the Funds and their operating rules. The Development Fund was replaced by a Savings Fund, and there were new rules for deposits and withdrawals for both Funds (Annex p. 258).

The main potential revenue sources for the Fund would be mining and petroleum taxes and dividends from the newly established Kumul Holdings, consolidating all the state's equity interests. The legislation for the new Kumul Holdings structure for the State's resource

\footnotetext{
${ }^{77}$ From 2015 Budget revenue, expenditure and balances were reported on an IMF GFS basis so are not strictly comparable with previous years.

${ }^{78}$ According to Hansard, the Organic Law on Sovereign Wealth Fund Bill 2012 had its first reading on 17 February and second reading debate on 18 February 2015. The debate indicates that the amended Bill included the new Savings Fund and made some changes to the deposit and withdrawal rules, but the exact content isn't clear. In Hansard of 5 June 2015 in the debate on the Kumul legislation Ben Micah said that "further work" needed to be done "to align the revenue flow from the Kumul companies to the Sovereign Wealth Fund and Treasury for budgetary support to the government." So, it seems that the Bill underwent further revision before it emerged as the new Sovereign Law in 2015. The third reading of the law was on 30 July 2015, when it was entitled Organic Law on Sovereign Wealth Fund 2014.
} 
company equity was in place and the Kumul entities were expected to pay dividends directly to the SWF after deduction of $30 \%$ of profits for operating costs.

In 2014, Osborne (2014) had concluded that the deposit and withdrawal rules in the 2012 version of the SWF Law had the potential to sequester significant balances in the Funds. Predicting the impact of the 2015 rules changes on balances involves too many assumptions to be useful.

The Treasury was predicting that the payment of a part of Kumul dividends into the Savings Fund would allow accumulation of balances in the years to 2020. However, the Treasury did not expect the rules to be a constraint on withdrawals from the Stabilisation Fund. The forecasts for oil and gas revenues in the 2016 Budget were based on oil prices rising somewhat from US\$52 in 2015 to US\$70 in 2020. Minerals prices were forecast to be static or declining. On this basis, the Budget forecast receipts, payments, and balances for the two Funds as shown in Table 9:6 below.

Table 9:6 Budget 2016: Projected Sovereign Wealth Fund Transactions (m Kina)

\begin{tabular}{|l|l|l|l|l|l|l|}
\hline & $\mathbf{2 0 1 6}$ & $\mathbf{2 0 1 7}$ & $\mathbf{2 0 1 8}$ & $\mathbf{2 0 1 9}$ & $\mathbf{2 0 2 0}$ \\
\hline Stabilisation Fund & 129.9 & 120.5 & 102.0 & 366.9 & 344.2 \\
\hline Mining and Petroleum Taxes & 249.0 & 229.5 & 346.5 & 351.0 & 208.5 \\
\hline Mining Petroleum and Gas Dividends & 379.2 & 350.3 & 448.8 & 718.4 & 552.9 \\
\hline Total revenue & 379.2 & 350.3 & 448.8 & 718.4 & 552.9 \\
\hline Transfer to Budget & 0 & 0 & 0 & 0 & 0 \\
\hline Accumulated Balance & 0.1 & 3.0 & 5.7 & 9.9 & 14.2 \\
\hline Savings Fund & 83.0 & 76.5 & 115.5 & 117.0 & 69.5 \\
\hline Interest & 83.1 & 79.5 & 121.2 & 126.9 & 83.7 \\
\hline Mining Petroleum and Gas Dividends & 0.0 & 0.8 & 1.6 & 2.8 & 4.1 \\
\hline Total revenue & 83.0 & 161.7 & 281.2 & 405.3 & 485.0 \\
\hline Expenses
\end{tabular}

(Pruaitch, 2014, pp. 133-134, Tables 14 and 15.)

\subsubsection{Budget - continuing downward revenue expectations}

As described above there was a marked downward revision in revenue expectations - from tax receipts from oil and gas and dividends from KPHL - as compared against the 2016 Budget. The reduction in forecast MPT is attributed mainly to "weak low oil and copper prices" plus some interruption in mining operations (Pruaitch, 2017, p. 16). The oil price had fallen to a low of $\$ 26$ in early 2016. Similarly, a projected K549m in dividends was revised down to K300m, again attributed due to low prices. (Ibid.). 
In fact, all three Budgets from 2014-2016 significantly overestimated revenue, as shown in Table 9:7 below.

The 2017 Budget was delivered in advance of the general election in mid-2017 and included a defensive reaction to criticism following the widening deficit in 2016.

Over the years, critics have argued that we are not doing enough in the face of the reduced revenue outlook. This is disappointing as I can rest assure the people of PNG that the O'Neill/Dion Government has and will continue to monitor events and respond deliberately and responsibly to maintain the growth momentum and protect and provide opportunities for our people and our businesses. ... For the first time in the history of PNG, the current Government has wound back on increased spending on the eve of elections. ... However, key policy priorities and programs will still be maintained to ensure goods and service delivery to the people of PNG are not compromised. (Pruaitch, 2017, pp. 3-5)

Table 9:7 Budget forecasts and outcomes 2014-2016

\begin{tabular}{|l|c|c|c|c|c|}
\hline Totals & $\begin{array}{c}\text { Budget } \\
\text { Year }\end{array}$ & $\begin{array}{l}\text { Budget } \\
\text { Forecast }\end{array}$ & Outcome & Variance & $\begin{array}{l}\text { Variance } \\
(\mathbf{\%})\end{array}$ \\
\hline Revenue and Grants & 2014 & $12,688.5$ & $11,497.6$ & $-1,190.9$ & $-9 \%$ \\
\hline Expenditure and Net Lending & 2014 & $15,041.5$ & $14,489.8$ & -551.7 & $-4 \%$ \\
\hline Budget Balance & 2014 & 0 & -63.7 & -63.7 & \\
\hline Revenue and Grants & 2015 & $13,927.4$ & $10,963.5$ & $-2,963.9$ & $-21 \%$ \\
\hline Expenditure and Net Lending & 2015 & $16,199.1$ & $13,496.1$ & $-2,703.0$ & $-17 \%$ \\
\hline Budget Balance & 2015 & $-2,271.7$ & $-2,532.6$ & -260.9 & \\
\hline Revenue and Grants & 2016 & $12,650.1$ & $10,485.5$ & $-2,164.6$ & $-17 \%$ \\
\hline Expenditure and Net Lending & 2016 & $14,762.6$ & $13,572.4$ & $-1,190.2$ & $-8 \%$ \\
\hline Budget Balance & 2016 & $-2,112.5$ & $-3,086.9$ & -974.4 & \\
\hline
\end{tabular}

Data from PNG Budgets 2014-2016

The Budget forecast continued deficits in the medium term with a return to balance pushed out to 2021 .

\subsubsection{Budget: the collapse in revenues and its causes}

The 2018 Budget followed a general election and a change of coalition partners. The outturn for the 2017 Budget was fairly close to forecast with only minor variances in the overall balance, revenue and expenditure. Revenues from MPT in 2017 were projected to be marginally down on 2016 actuals - K89.5 m compared with projected K92 m. Royalties and management tax were also down somewhat: K31.9m compared with K44.3m. 
The result was a continued and substantial deficit. The Budget painted the situation in stark terms:

Total government revenue has collapsed as a share of the GDP from 20 per cent in 2012 to 13.4 per cent in 2016 and is expected to decline further to below 13 per cent by end2017. This has resulted in larger than anticipated budget deficits and delayed the projected return to a balanced budget.(Abel, 2017, p. 3)

The Budget identified the commodity price cycle as a major cause:

In recent years the PNG economy has endured a series of economic shocks following the rapid growth brought about by the commodity boom and the construction of the PNG LNG project. Commodity prices have fallen and remain relatively low and the severe drought in 2015 added to the difficulties. (Ibid.)

Failure to get spending under control was also identified: ambitious investment spending and the perennial struggle to contain the public sector wage bill were contributing factors. But ongoing shortfalls in revenue compared with earlier medium-term forecasts, particularly from mining and petroleum, were cited as a significant factor.

An important observation made is that falls in commodity prices were not the main cause of these failed expectations. The PNG all commodity price index fell during 2014 and 2015, rose sharply in 2016, and fell again in 2017. However, the prices of some key extractive industry commodities rose during 2017. Copper prices rose sharply during 2016 and held relatively firm in 2017. Gold was trading around US\$1300 an ounce in both years. After reaching a low in early 2016, the oil price firmed to around US\$50 a barrel during 2016 and 2017.

The Budget acknowledged that some of the revenue shortfalls were the result of the application in practice of the taxation and royalties regime for mining and petroleum. A prominent issue was the resource companies' use of deductibility to reduce tax liability.

Overall, key mines continue to claim Infrastructure Tax Credits, as well as exemptions, accelerated depreciation allowances and debt amortisation to foreign shareholders which have adversely affected collections in recent times. The Large Taxpayer Office (LTO) will review compliance of large mineral resource companies and the number of concessions will be reviewed as part of the medium term revenue strategy reforms. (Abel, 2017, p. 51) 
Tax policy measures also included:

- Making royalties tax-deductible rather than offsets against tax liabilities.

- Taxing parent companies for dividends paid by PNG-resident resource companies

However, these measures would not affect the LNG project's tax treatment because of the Fiscal Stability Agreement with the project. There was a specific amendment in the Income Tax Act for a "carve-out" of the project from any amendments to the Act affecting its liabilities. (Ibid., p. 71)

A further factor was the low dividend payments from SOEs and holding companies. The new Medium-Term Revenue Strategy aimed to:

... lift non-tax revenue collections substantially by amending the respective legislation of public bodies to improve the pass-through of collections and dividends into the Consolidated Revenue Fund (CRF), transfer unutilized trust fund balances to the CRF, and enhance the performance of state bodies to sustain higher collections and dividends. (Ibid., p. 60)

The 2018 Budget projected that resource revenues would more than double compared with the 2016 actuals:

- "Mining Petroleum and Gas Dividends": 500m (300.5m)

- "Dividends from Statutory Authorities": 626m (228.4m)

- "Dividends from State Owned Enterprises": 225m (0.0m)

(2017, p. 55, Table 17.)

It is important to note that a large part of this increase appears to be due to expected improvements in the state's share of resource revenues rather than any projected lift in commodity prices.

After being announced in the 2016 Budget to come into effect in mid-2016, the SWF was still not operational: 
The SWF Board of PNG is expected to be in place by early 2018 even though it is expected to play a limited role in the area of investment of funds in the initial stages. (Ibid., p. 119)

\subsubsection{Perspective from KPHL}

In the middle of 2016 ( $24^{\text {th }}$ June 2016), given the roller coaster ride of the commodity markets, the managing director of KPHL gave a wide ranging interview where he outlined the benefits from the PNG LNG and the reasons PNG was not getting the full value of benefits:

The three reasons that he put forward were: taxes, debt servicing (the project was funded by 70 per cent project finance debt and 30 per cent equity from partners), and accelerated depreciation which the State allowed for the developers. He said:

In the PNG LNG project, a 30 Per cent tax has been agreed to in the Gas Agreement. The tax revenue is supposed to be paid to the IRC. And again, that is as per the Tax Act. The joint venture partners in the project do their own tax assessment because the PNG LNG is an unincorporated entity and pay tax to the IRC. So far, all joint venture partners have paid. But because of the low price last year and this year, the tax revenue to the State from the project had been very minimal to none. This would improve as the price recovers. The other factor is that the project was funded on a 70 per cent project finance debt 30 per cent equity from partners. Hence the project financiers take priority in the revenue distribution before others. Apart from the price and debt repayment affecting the tax revenue to state, the other reason is that in the Gas Agreement negotiations, the state allowed for "accelerated depreciation". It means that when the joint venture partner assess their tax positions, they also depreciate the project assets at a higher rate than normal, hence less tax to the Government (The National, 2016, 24 June).

He went on to point out the reason why KPHL has a Singapore account to which dividend payments are made and payments received from each shipment:

KPHL is a joint venture partner in the project and our revenue from the project is distributed to us after deductions for royalty, development levy, project debt repayments, project capital expenditure and operational expenditure deductions and tax to the Government. This is the same for all project partners. Each joint venture partner 
has their nominated account where the distributions are paid to. But for KPHL, our nominated account is in Singapore. The reason is that KPHL is an oil and gas company that transacts in US dollar which has cash calls in USD. And to pay for our commitments not only in PNG LNG project but other assets operated by Oil Search and others, we need to have a USD account and ability to pay in the currency of trade in the business we are in at the moment (ibid).

The PNG-based operations are funded in Kina and also dividend payment to the State. Hence we would bring in USD into the country. And we have done this since 2014. The question of how much revenue we earn per shipment is not an easy question to answer because every shipment is different and there are various variables mainly because the LNG sales contract are different types with different buyers. Some are delivery ex-ship (DES), some are freight on board (FOB) and they fetch different prices. The volumes we sell on the spot market also fetches different prices depending on what the world price market is on the day of the trade (ibid).

\subsubsection{April 2018: The Jubilee Report - challenging the forecasts of the PNG LNG economic and financial effects}

A report published by the Jubilee Australia Research Centre in April 2018 (Flanagan \& Fletcher, 2018) sought to compare the economic and fiscal predictions in the ACIL Tasman report with actual results. The report examined both the predicted direct impacts of the project on government revenue and the economy-wide effects, the latter using an economic model developed by the ACIL Tasman authors ${ }^{79}$. The Jubilee report compared the predicted direct net fiscal impacts with their own estimates, based mainly on the EITI reports for 2014 to 2016. They concluded that the actual revenue flows to government were significantly lower than the original ACIL Tasman forecasts. Only part of the difference could be attributed to lower LNG prices, which were above the ACIL Tasman "High" estimate in 2014 and then between the "Low" and "Study Case" estimates for 2015-2017 (2018, p. 19). The difference here could be explained by a significant escalation in project capital costs, offset by higher production due to

\footnotetext{
79 The modelling compared the re-estimated effects of the PNG LNG project with an assumed economic track if the project had not proceeded. The baseline assumption that, in the absence of the project the economy would have continued to grow at the average rate from 2005-2009, has been criticised (McGillivray, 2018), with a rejoinder by Flanagan (Flanagan, 2018). However this is not relevant to the estimates of direct government revenue discussed here.
} 
an improvement in nameplate capacity but: "The primary phenomenon that the EITI data reveal is the extraordinarily low payments in company tax." (Ibid., p. 21). The authors predicted that, if the lower revenue payments continued "the revised estimates are that PNG LNG will not start to contribute net revenue to the budget until 2024, building to around K1.5 billion per year from 2031.” (Ibid. p. 25).

In a speech in Brisbane in May 2018, Prime Minister O’Neill responded that the report was "utter nonsense" and "fake news" $"$. He was quoted as saying:

It is quite common, and well known, that the predicted and quoted revenue stream that was going to go to the project and the country was based on prices that were US\$110 per barrel. No one could have foreseen that the price of oil would collapse to \$US27 per barrel, and nobody expects the project to make money at those low prices. (PostCourier, 2018).

\subsubsection{December 2018: the EITI report for 2017}

The Ernst \& Young EITI audit, published in December 2018 showed total payments in respect of the PNG LNG project of K520m. The main elements were as follows, compared with the previous two years:

Table 9:8 EITI: Payments to government and landowners from PNG LNG project (PGK)

\begin{tabular}{|l|l|l|l|}
\hline & \multicolumn{1}{|c|}{$\mathbf{2 0 1 5}$} & \multicolumn{1}{c|}{$\mathbf{2 0 1 6}$} & \multicolumn{1}{c|}{$\mathbf{2 0 1 7}$} \\
\hline Company tax & $98,307,209$ & $40,845,470$ & $3,196,905$ \\
\hline Employees withholding tax (“Group tax") & $263,147,552$ & $226,375,138$ & $120,098,841$ \\
\hline Development Levy & $90,763,062$ & $69,689,630$ & $7,746,881$ \\
\hline Royalties & $94,171,985$ & $37,089,116$ & $77,610,525$ \\
\hline Dividends (ex Kumul Petroleum Holdings) & $86,400,000$ & $100,000,000$ & $300,000,000^{81}$ \\
\hline Other ${ }^{82}$ & $73,078,107$ & $48,012,418$ & $11,466,212$ \\
\hline Total & $\mathbf{7 0 5 , 8 6 7 , 9 1 5}$ & $\mathbf{5 2 2 , 0 1 1 , 7 7 2}$ & $\mathbf{5 2 0 , 1 1 9 , 3 6 4}$ \\
\hline
\end{tabular}

Sources: Various ${ }^{83}$

\footnotetext{
${ }^{80}$ (Post-Courier, 2018). According to the report, the Prime Minister did not name the report, but it is generally assumed that it was the Jubilee Australia report, published a month earlier.

${ }^{81}$ Figure reported by Treasury as received. KPH did not report in the EITI format.

82 "Various withholding taxes" reported as "received".

832015 \& 2016: analysis in Flanagan and Fletcher 2018:23, Table 2 of EITI Reports of Direct Revenue Flows from the PNG LNG Project; 2017: summary analysis from Ernst \& Young 2018 of reported payments.
} 
Exxon Mobil reported that due to an improvement in trading conditions it was able to make further payments of company tax and levy and royalties towards the end of 2017. These payments were too late to be recorded in the 2017 EITI report. However, the total payments made by the project for all three years were substantially below forecasts made at the time of the 2013 Budget. A significant feature was the very low level of company tax payments, expected to be the biggest single source of government revenue.

Table 9:9 below compares the ACIL Tasman forecast of revenues with the forecast made in the 2013 Budget and the actual revenue reported by EITI for 2015-2017. Actual oil prices in the three years were above the "low" case in ACIL Tasman, but revenues were about half the forecast for that case. Furthermore, based on 2013 Budget forecasts, the estimated public share of total project output value (using ACIL median "study case" estimates of value) would be around $17-20 \%$ in the first three years of full production, rising to $35-40 \%$ starting around 2023. By comparison, the EITI audits for 2015-2017 compared with estimated value of exports from the project shows a public share of about $7 \%$ falling to $5 \%$.

Table 9:9 Average annual early project revenues for government: forecast and actual (2015-

2017)

\begin{tabular}{|c|c|c|c|c|c|c|c|}
\hline $\begin{array}{l}\text { ACIL } \\
\text { Tasman } \\
\text { Case }\end{array}$ & $\begin{array}{c}\text { ACIL } \\
\text { Assumed } \\
\text { Oil Price } \\
\text { (US\$/bbl) }\end{array}$ & $\begin{array}{c}\text { ACIL } \\
\text { Forecast } \\
\text { Average } \\
\text { Annual } \\
\text { Revenue } \\
\text { Phase } 1 \\
\text { (PGKm) }\end{array}$ & $\begin{array}{c}\text { ACIL } \\
\text { Forecast } \\
\text { Average } \\
\text { Annual } \\
\text { Revenue } \\
\text { Phase } 2 \\
\text { (PGKm) }\end{array}$ & $\begin{array}{c}\text { Budget } \\
2013 \\
\text { Average } \\
\text { First Full } \\
3 \text { Years } \\
\text { (2015- } \\
2017)\end{array}$ & $\begin{array}{c}\text { Budget } \\
2013 \\
\text { Average } \\
\text { Oil Price } \\
\text { Assumed } \\
(2015- \\
2017)\end{array}$ & $\begin{array}{c}\text { EITI } \\
\text { Actual } \\
\text { Average } \\
\text { Revenue } \\
(2015- \\
2017)\end{array}$ & $\begin{array}{l}\text { Actual Oil } \\
\text { Price } \\
\text { Average } \\
2015- \\
2017\end{array}$ \\
\hline Low & 36 & 1190 & 2421 & 1900 & 100 & 583 & 48 \\
\hline Study & 65 & 3090 & 4432 & & & & \\
\hline High & 100 & 4300 & 5805 & & & & \\
\hline
\end{tabular}

(Data from ACIL Tasman, 2008; Ernst \& Young, 2018; Polye, 2012)

\subsubsection{Budget: continuing concern about revenue sources}

The Budget in late 2018 (Abel, 2019) was able to report a significant improvement in revenues, exceeding the forecast by $\mathrm{K} 1.3 \mathrm{bn}$ or $11 \%$, but also an ongoing struggle to manage expenditure $-\mathrm{K} 1.4 \mathrm{bn}$ or $10 \%$ ahead of forecast.

The Budget reflected political concerns about the low or negative rates of return from SOEs and the limited payments from KHL and KPHL to the Consolidated Fund. It repeated the risk identified in 2018: 
Failure of Statutory Agencies to pass through the collection of fees and charges in line with the Government's 25 Point Plan for a 90/10 ratio and failure of State Owned Enterprises to pay the appropriate levels of dividends to [Consolidated Revenue Fund]. (2019, p. 244).

The Budget showed a significant increase in revenues from Kumul Petroleum Holdings representing a greatly increased dividend return from the PNG LNG project. This increase was attributed mainly to higher LNG prices and restored production volumes following the interruption to operations in 2018 due to the February 2018 earthquake ${ }^{84}$.

In 2018, the State has received K250.0 million as dividends to date which excludes the K50.0 million paid earlier in 2018 to the SHP as part of the earthquake relief efforts. The receipt of substantial dividends from Exxon expected in December 2018 due to higher gas prices has lifted projected receipts from KPHL to K700.0 million for 2018 and a further K800.0 million in dividends is programmed in the 2019 Budget which reflects the budget assumptions for oil and gas prices and the elevated expected production volumes in 2019. (Abel, 2019, p. 21)

The limited revenues from the PNG LNG project in its early years of production (see the information on estimated revenue profiles below) may have been one of the reasons why the government was reviewing its policies for new petroleum and gas projects. The Budget refers to negotiations of Gas Agreement(s) for new LNG projects and foreshadows changes to the Mining and Petroleum Acts covering among other things state participation in projects, benefits for landowners and subnational governments, and a more standardised tax regime for new projects.

On the proposed petroleum and gas projects, the Government established the State Negotiating Team in mid-2018 to facilitate the Gas Agreement which sets out the administrative, technical, regulatory and fiscal arrangements for the new LNG projects. Term sheets have been submitted and significant progress has been made with agreement expected to be reached over coming months with the project proponents.

\footnotetext{
${ }^{84}$ Oil and gas production was significantly affected by earthquake damage to PNG LNG project plant including the Hides Gas Conditioning Plant although production was partly recovered for the year by operation above nameplate capacity.
} 
In 2019, the Government will embark on a number of policy and legislative changes including amendments to the Mining Act 1992 and the Petroleum Act 1998, a policy guiding state participation in resource projects and third party access in the oil and gas sector, a policy to guide the distribution and management of benefits to landowners and subnational governments, and the introduction of a policy on domestic market obligations for gas and petroleum products.

Whilst the Government embarks on the policy and legislative changes, it also recognises the need to strengthen its concessional fiscal regime. In this respect, the Government will focus on a major reform towards getting a standardised fiscal regime that is globally competitive and that provides appropriate returns from resource extraction at minimal cost and acceptable risk levels. (2019, p. 214)

By 2019, however, the official forecasts had pushed out the expected rise in revenues from the PNG LNG project even further: "The Government expects receipts from the PNG LNG Project to increase beginning in 2021 and accelerate significantly from 2025 onwards." (Abel, 2019, p. 82, fn 15.) The Budget included an updated forecast of PNG LNG revenues through to 2040.

Figure 9:11: Budget 2019 Forecast of Revenue from PNG LNG Project (US\$m)

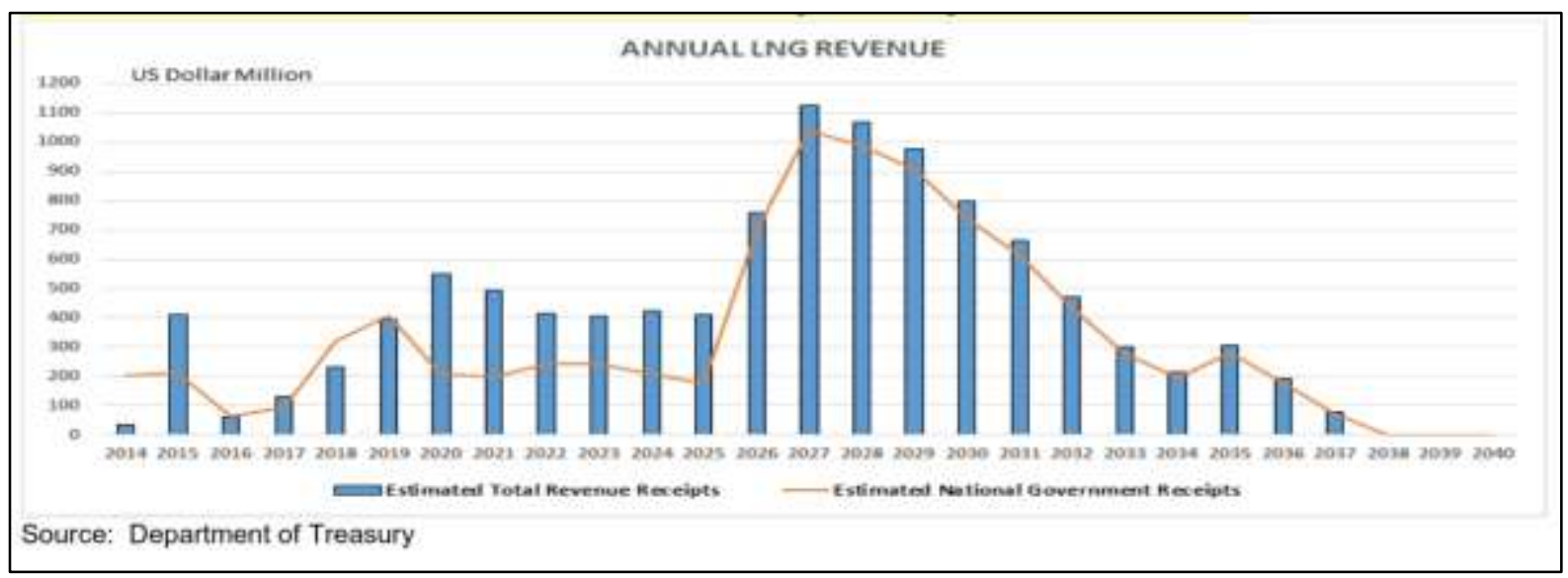

(Abel, 2019, p. 82, Chart 31.)

A footnote to the Chart explains:

PNG has yet to be able to fully benefit in terms of foreign exchange inflows as (i) most of the revenue from the PNG LNG Project has been held in offshore accounts for the servicing of project finance debt, (ii) the Government's tax receipts in the near term remain reduced due to amortization of the PNG LNG Project's loans, which is expected 
to end in 2025 and (iii) high (accelerated) depreciation expenses, which are expected to fall off substantially after 2025. (Abel, 2019, p. 82, footnote 15.)

The net result was a further substantial reduction in forecast revenues from the project. Total revenues over the whole life of the project to 2040 were forecast as US\$11bn, compared with US\$22bn forecast in the 2012 Budget, a 50\% reduction.

\subsection{Summary: the effects on budgetary and fiscal policy of expectations about the PNG LNG project}

When it was formulating its 2007 Budget, the government was still expecting that the original Queensland pipeline project would provide a means of replacing declining oil production with gas production as a source of economic activity and government revenue. The abandonment of the project in early 2007 looked like forcing a major change in these expectations. However, by late 2007, licence holders had made two proposals for using gas to produce LNG, which came as a welcome prospect. The government and the licence holders moved very quickly to settle the terms under which the project would be developed. By late 2008, the government had settled the Gas Agreement with the ExxonMobil group and had the UBSA in place defining the terms for benefit sharing with landowners and Provincial Governments. Much of the subsequent evolution of the project can be traced back to the way in which these agreements were negotiated and their content.

The government's initial expectations of the project were that, given its size and contribution to national output and government revenues, it would be nothing less than transformative of the PNG economy. These expectations were based on a single economic and financial evaluation for the project, the ACIL Tasman study commissioned by ExxonMobil. The Treasury's own forecasts of the economic and financial impacts of the project were substantially based on the analysis in the ACIL Tasman report. They portrayed the economic impact of the project as more than replacing declining oil production and having a very large impact on GNP, particularly during the production phase. The Treasury recognised that much of the gross value added by the project would flow offshore in the form of dividends and debt repayments, and that tax concessions granted the project in the early years would substantially reduce returns, but nevertheless forecast that the domestic benefit would average around K2bn a year, mostly in the form of revenues for the government and landowners. By 2011, the Treasury had made even more optimistic estimates of LNG prices and dividend flows. 
The government was starting to build its expectations regarding development and economic management around the project towards the end of 2009. It had revised its forecasts of the economic impact of the construction phase substantially upwards. The size of the project had become a central factor in medium-term economic and fiscal planning. The "Dutch Disease" phenomenon and how to manage the impact of large windfall flows of resource revenues were explicitly discussed. In March 2010, apparently influenced by both the Australian government and the IMF, the government announced its intention to establish a Sovereign Wealth Fund to manage the economic and financial impact of large inflows of revenue from resource projects, but specifically to help manage the expected windfalls from the PNG LNG project. The government introduced a draft SWF law at the end of 2011, and it passed Parliament in early 2012. If long-term revenue trends continued, the Fund's operational rules would generate significant balances.

The government was under conflicting pressures at this point: on the one hand to commit to more ambitious expenditure plans, particularly for pressing investment requirements, on the basis of forecast LNG revenues; on the other not to fall prey to the "resource curse" of accelerating spending to match the expected upwards cycle in revenues. But IMF/World Bank modelling seemed to support a "sustainable" significant medium-term increase in the rate of Government investment spending. The Treasurer was downplaying expectations that the project would be "a magic saviour to the PNG economy" but other statements reflected the pressure on the government to be seen to be using the LNG revenues for its development objectives, if necessary before they started arriving. In fact, the 2012 Budget Strategy was to use all additional mineral revenue above the threshold 4\% of GDP to "pre-fund public investment expenditure" which the Budget said would be "based on expected dividend returns" from the government's PNG LNG equity.

In 2012 the government was in fact riding a boom in which the project construction was the major driver. The 2013 Budget was the first of several to be strongly expansionary and where deficits increased markedly. The Budgets of 2014-2016 were also for further substantial rises in government spending on the back of forecast increases in revenue, a large part of which was put down to the project coming on stream in 2015. The government also relaxed its debt target. All three Budgets from 2014-2016 significantly overestimated revenue.

The events of 2016 saw a major turn-round in expectations, driven by a sudden drop in the oil (and LNG) price to a low of \$26 in early 2016. The budget outcome for 2016 was markedly 
worse than forecast. It was becoming evident that not all the fall in resource revenues could be attributed to falling commodity prices. The 2017 Budget acknowledged also that some part of the failure to achieve forecasts was the result of the application in practice of the taxation and royalties regime for mining and petroleum. The analysis in the Jubilee Report and this research support the conclusion that actual oil prices in the three years could not explain all of the shortfall. The EITI audits showed that government revenues from the PNG LNG project in 2015-2017 were considerably less than forecast in 2013. The 2018 Jubilee Report used the EITI findings to challenge the forecasts of the direct revenue impact of the project.

The 2019 Budget foreshadowed changes in the taxation and local benefits regimes for new extractive industry projects. Revenues from the project were now not forecast to increase until 2020 with a further substantial lift predicted in 2025. The new SWF law of 2015 was forecast to lead to some accumulation of dividends in a Savings Fund, but in the next few years no constraint on drawings from the Stabilisation Fund. The Budget attributed the delayed revenues to servicing project-related debt and the effects of the accelerated depreciation provisions. 


\section{Chapter 10 Transparency and its effects}

\subsection{Introduction: Availability of information and its effects}

As discussed in earlier parts, transparency is twinned with accountability of the executive. Accountability implies not only that the state gives a full account of its activities to its citizens but is responsive to them: first that the requirement to be transparent constrains the state to act lawfully and secondly that it enables the public scrutiny and debate of its plans and actions that is at the core of a democratic process.

The aim of this research was to discover how revenues from the PNG LNG project were generated and distributed, and the influences on those processes. So, the research was also a practical experiment in discovering information that would support these findings. While the research has drawn on some interviews, in practice most of the evidence on the principal research question is drawn from publicly available information and accounts of how it was used in public debate. This evidence gathering has in itself identified both the strengths and the gaps in public transparency and accountability in PNG affecting this case.

\subsection{Official information}

Several key documents, listed in this thesis, were important for understanding the stages in the development of the project: the CDOA, Gas Agreement, UBSA, and the LBBSAs. None were obtainable from official sources. Some were obtainable unofficially online. The CDOA, although referenced in other official documents, was not discoverable from any source.

The PNG Fiscal Responsibility Act 2006 prescribes the fiscal documents to be prepared in each fiscal year, including the Budget, Mid-Year Economic Outlook, Budget Strategy Paper, and Final Budget Outcome. All of them are available on the Treasury website for all the years of this study. The information in these documents about government revenues and expenditures, together with the underlying assumptions made in forecasts, provided a great deal of the source material, particularly for understanding the way that expectations about the project affected fiscal planning and decision-making.

The Public Finances (Management) Act 1995 (s. 63) requires the PNG Public Accounts ("reports and financial statements of public bodies") to be tabled in Parliament. They are not discoverable online. Both the PNG Auditor-General and the Public Accounts committee have 
chastised public bodies for failing to meet the requirements of the Act with timely financial information.

Financial reports and balance sheets of two state organisations which receive the majority of non-tax payments from the project - the Mineral Resources Development Company (MRDC) and the Kumul Petroleum Holding Company (KPHL) - are not discoverable online. The MRDC website is not functioning. The research relied on the EITI reports (see below) for much of the data on revenue flows to and from these organisations. Other information found its way into the public domain, particularly for politically salient issues like the UBS loan and Oil Search share purchase (and subsequent sale), managed off-budget through KPHL ${ }^{85}$.

The PNG Parliament has published records of its proceedings ("Hansard") online for most sessions from August 2012 to March 2017. Inexplicably, publication then ceased. The Parliamentary debates that are on record are a rich source of information about political issues relating to the project and frequently reveal information not available elsewhere.

The website of the Pacific Islands Legal Information Institute (PACLII) is a comprehensive database of all the relevant PNG legislation and is referenced by the Parliamentary website. This too was an invaluable source for information about the legal framework surrounding the project.

There has never been a full published official economic and financial analysis of the project. The initial analysis was commissioned by ExxonMobil. The research discovered the report on a Timor-Leste website (https://www.laohamutuk.org/). Statements in the Budgets indicate that in early years the government relied substantially on the ACIL Tasman analysis. However, later Budgets included forecasts, periodically revised, of project revenues.

\footnotetext{
${ }^{85}$ See for example the references in the EITI 2017 Report to the UBS / Oil Search transactions discussed elsewhere in this thesis: (2018, p. 110 and footnote 239.)
} 


\subsection{EITI}

For information on flows of revenues from the project to the state, the research could draw on detailed audits and evaluation by the PNG EITI in its annual reports and its validation reviews (which review PNG's progress towards achieving full implementation of the EITI Standard) ${ }^{86}$. The annual EITI audits have now produced revenue flows for resource projects including PNG LNG for 2015, 2016, and 2017; their results are summarised elsewhere in this report. The audits have had the more or less complete cooperation of the PNG LNG project operator ${ }^{87}$ and the other companies, which met most of the EITI standards for publication of information. The major exceptions recorded by the 2017 EITI audit on the corporate side were information on the profitability of the project companies and on the project sales revenues. In collecting evidence on management of revenues within the state, however, the EITI investigators, and this research, found some significant gaps in the official published information.

The EITI audit for 2017 recorded the same problems as this research found with information from KPHL and MRDC. KPHL did not report dividend flows from state equity holdings. The EITI investigators estimated its share of sales from its percentage interest in the project and income reported by other project companies. (Ernst \& Young, 2018, pp. 141-142). Although MRDC does not publish audited accounts, it did supply data on its receipts and payments, including some payments to SNGs (although not to landholders: the government was withholding payments until the clan vetting exercise was completed).

However, there was a wider concern with the validity of the data on sub-national payments. The report welcomed a "scoping study" on these payments and commented "We understand that the scope of PNG's sub-national revenue payments are complex and subject to volatility and this process will be a complex, but ultimately very valuable exercise to improve trust and transparency for this element of the extractive industry." (Ernst \& Young, 2018, p. 149). The 2018 Validation, based on the 2016 audit, graded this as unsatisfactory and noted that

\footnotetext{
${ }^{86}$ Note that the government has ostensibly given its support and responded to recommendations. E.g. National Executive Council. 2017. NEC Information Paper on PNGEITI Second Country Report \& Update of NEC Decision No. 91/2017. NEC-File-No.-NEC04-1-21.11.17.pdf. Government of Papua New Guinea. This was cited in the 2017 EITI audit.

${ }^{87}$ ExxonMobil has been a leading supporter of the EITI internationally.
} 
The 2016 EITI Report provides vague and contradictory explanations of the structure and materiality of subnational direct payments linked to the extractives. There is also confusion between subnational direct payments, subnational transfers, SOE transactions with provincial governments and private-to-private transactions (with landowner groups). (EITI PNG, 2018, p. 5, PDF note)

There are some challenges that the EITI will continue to face in PNG and include the following as outlined by Sovacool et al (2016):

1. Limited mandate: The EITI, moreover, does not address how those revenues are expended; it merely makes their amounts more precisely known to outside groups. As one commentator. [The EITI is problematic because it focuses] on transparency in government oil revenue, or the financial flows between the oil industry and national treasuries and misses where the corruption is often far worse: in government spending (P. 187).

2. Dependence on strong civil society: Yet in many countries, especially those most prone to corruption, non-governmental organizations remain disorganized, weak, or even non-existent. Moreover, the EITI criterion that civil groups have to be "actively engaged as a participant in the design, monitoring and evaluation of this process and contribute towards public debate" can functionally exclude the process from starting in countries until sufficient civil society capacity exists. (P. 188).

\subsection{Other sources}

Information about the project was not limited to official sources: the research could also draw on the unofficially published documents and other unofficial sources including many on-line media sources and blogs, and anecdotes as well. These are strongest when it comes to politics and administration centred on the government and in Port Moresby. Reporting from the further reaches of the project, for example from Hela in the Southern Highlands, has tended to focus on the public confrontations of local landowners with the project. There is very little available first-hand of the discourse within local communities about the project, particularly in the Highlands, except what is reported by outsiders. The research has relied to some extent on these reports, such as McIlraith (2011) and (2012). 


\subsection{Observations on PNGEITI Validation}

\subsubsection{Pre-validation briefing ${ }^{88}$}

In the pre-validation exercise it was the PNGEITI National Secretariat's role to gather together the various stakeholders, including representatives from the mining and petroleum companies, government departments involved in the extractive industry, NGOs, Transparency International, research institutions and the public (bookings have to be made to attend) and to update them on progress with PNGEITI. The pre-validation exercise was also to prepare the stakeholders for the meeting with the visiting International Team from Oslo who were conducting the validation exercise to move PNG to full Candidate Country Status. The validation is:

... an essential feature of the EITI implementation process. It is intended to provide all stakeholders with an impartial assessment of whether EITI implementation in a country is consistent with the provisions of the EITI Standard. The Validation Report will, in addition, address the impact of the EITI in the country being validated, the implementation of activities encouraged by the EITI Standard, lessons learned in the EITI implementation, as well as any concerns stakeholders have expressed and recommendations for future implementation of the EITI ${ }^{89}$. (Ernst \& Young, 2018, p. 29)

The Head of the PNGEITI Secretariat pointed out that as a Candidate Country: "We are required under the EITI Standard to be validated after 3 years of implementation, in order to determine if we made satisfactory progress to obtain a 'Compliant' status" (Alkan $27^{\text {th }}$ April 2018, Pre-validation presentation). Furthermore, he pointed out to the International EITI Board at its meeting in October 2016 that PNG would undergo a validation under the EITI Standard beginning 1 April 2018. The International EITI Board were impressed with what the PNGEITI had achieved including the production of yearly reports (ibid).

The four areas that pre-validation wanted a focus and discussion on are outlined and discussed below:

\footnotetext{
${ }^{88}$ The researcher participated in this pre-validation briefing for stakeholders held on 27 April 2018.

${ }^{89}$ See: https://eiti.org/document/standard. Annex2 - Terms of reference for EITI validators
} 
(1) Reforms within the extractive sector: A major reform that all the stakeholders wanted to see happen was the conversion of the Department of Petroleum into an Authority. Mr Alkan said that as far as he knows that there are moves underway for this conversion to take place. There was no representative from the DPE to shed light on progress of this reform initiative;

(2) Assess performance and promote dialogue: While the PNGEITI has been on a major awareness exercise broadcasting its work to the public via newspapers, radio outlets and the Television (TV) networks a lot remains to be done. Conrad, a staff member of Oil Search Limited was very passionate about the work that his company was doing to promote awareness and dialogue between the company and the host communities and provincial and local governments. The World Bank representative Dr Wilfred Lus stressed the importance of dialogue. "In a country like PNG, there needs to be a continuous dialogue. You cannot understand what the other parties are thinking or feeling without dialogue. Dialogue will solve a lot of problems before they escalate (Lus, 27 April 2018, Pre-validation presentation). He went on to point out that the Bank has an on-going relationship with the mining sector where funding for alluvial mining and capacity building is an on-going process across the sector with dialogue as key corner stone of the relationship;

(3) Identify opportunities for mainstreaming EITI implementation in government systems. There was a general consensus that either through government directive or through legislation would mainstreaming EITI especially in the key public sector organizations involved with the extractive industry be possible. An NGO activist Martyn Namorong pointed out that there needs to be a shift in culture in thinking, attitude and approach for mainstreaming to be embedded within organizations (Namorong, 27 ${ }^{\text {th }}$ April 2018, Prevalidation presentation);

(4) Safeguard the integrity of the EITI: The integrity of the EITI is very important otherwise everything that is being done is a waste of time. The PNGEITI Secretariat has been very independent although they are housed within Treasury, the same expectation of all companies in the extractive industry is also expected of all government departments and agencies.

Everybody noted the important role expected of EITI and the need for more interaction to share experience and maintain the momentum. 
In the second stage of a validation exercise the International Secretariat visits the country and does initial data collection and stakeholder consultation. In the case of PNG, this stage was led by Alex Gordy who is the Validation Manager. This second stage was for a week where the International met with key government agencies, companies and donor agencies. On the $9^{\text {th }}$ of May 2018, the International Secretariat met with NGOs where I participated and discussed the role of civil society including research institutions. The PNGEITI Secretariat was asked to leave the room.

The main points of validation were to look at the capacity of civil society and whether the PNGEITI was having an impact on the extractive sector, summarised as follows:

- The concern that there were discrepancies with the 2017 EITI Report relating to amounts reportedly paid by companies and amounts received by the state agencies. The International Secretariat noticed the anomaly and queried the discrepancies with government agencies and the companies.

- There were eight main questions asked under civil society engagement. These questions included how restrictive the operations of the CSO is in PNG, if CSO were funded by the PNG government, whether there were examples of collaboration between PNG CSOs and international groups and if there is any evidence of published research by CSOs on EITI and if there are campaigns calling for amendments to laws, closure of mines, and transparency in licence allocation.

\subsubsection{Conclusions drawn from the validation exercise}

The following observations were made of the PNGEITI at the various gatherings between the months of April and May 2018:

- Civil society organisations did not have the capacity to carry out any of the tasks required under the PNGEITI. They were fragmented and tended to pursue their own interest such as the PNG TI and while the PNG Resource Governance Coalition ${ }^{90}$ was doing its bit it was overwhelming to cover all the mining and petroleum projects in the country.

\footnotetext{
${ }^{90}$ Its National Coordinator, Martyn Namorong, has since moved on to a research position in the Office of the Minister for Treasury.
} 
- There was no link or coordination between the civil society organizations at the national level and those at the district and village level. It appeared that a lot of the CSOs were operating in a ad hoc manner and tended to rise to tackle a specific issue and then fade away.

- The dissemination of important information was not being coordinated well, and when important information was provided a lot of the CSOs were unable to do anything because the information was technical or they did not have the resources to mount an awareness exercise or campaign against abuses by actors within the industry.

- It appears that a number of international NGOs were aware of the situation and were trying to assist with resources.

- Most the CSOs were funded by overseas organizations (NGOs, foundations and advocacy groups).

\subsection{Weaknesses in public sector accountability framework}

The next section of this Chapter looks at the performance of the public sector organizations and in particular the Department of Petroleum and Energy and its role in the PNG LNG.

\subsubsection{Auditor-General's oversight}

The public sector organizations in PNG are required by law to provide financial statements to the Office of the Auditor-General annually. According to the Office of the Auditor General's 2016 Report, 60 public offices did not submit their annual financial statements (AuditorGeneral of Papua New Guinea, 2017). The Auditor General pointed out that this year's report's findings are:

... consistent with those in my previous year's reports that highlighted my concerns over the number of entities that do not submit current year financial statements for audit and the overall poor state of the financial management structure in most public entities whose statements are subject to audit and inspection. ... Weaknesses with financial management are contributing to significant wastage of financial resources and indicate a serious lack of transparency and accountability (ibid, p. 15). 
A major weakness pointed out by the IMF (2012) report of the country is the lack of capacity and accountability by public sector organizations who are incapable of delivering goods and services. A major reason is the public sector's inability to manage its financial affairs.

The audit by the Auditor General's Office of PNG revealed significant weaknesses in the control and management of nearly all the entities audited for the various years. As summarised by the 2017 EITI Report (Ernst \& Young, 2018, p. 144, Table 50), the Auditor-General found major management and financial weaknesses in the Internal Revenue Commission for 2014; the Mineral Resources Authority for 2012; Department of Treasury 2014; Department of Finance 2013; Department of Petroleum and Energy for 2013-2014; and the Department of National Planning and Monitoring. He also recorded that some SOEs (including KML) "have amended their enabling Acts to exclude my Office from performing the audit of those entities and appointed their own auditors contrary to the Audit Act." (Ibid., p.145)

The total disregard by many of the public sector organizations for audit requirements weakens the government's ability to ensure compliance and among other things to enforce laws within the extractive industry.

\subsubsection{The Public Accounts Committee (2010 Report on Department of Petroleum)}

The Public Accounts Committee (PAC) remains one of the most powerful parliamentary bodies that has broad oversight into public sector organizations. The 2010 PAC in its enquiry into the operations of the Department Petroleum and Energy has uncovered some very disturbing practices and anomalies which to a certain extent explains some of the problems afflicting the department.

The PAC in its Executive Summary stated that:

The nation has a right to expect that this Department is expertly and lawfully managed and thoroughly accountable for all public monies, property and stores under its control. The Department has, for years, failed to meet those expectations. This Committee makes the following general findings:

Departmental weaknesses and failures:

In so far as its management of public monies is concerned, the Department of Petroleum and Energy is incompetently managed, unaccountable and disorganized. 
The Department is incapable of managing or accounting for its own internal finances to any acceptable level of competence or legality. This situation has existed for years and continues in 2009 .

The Department of Petroleum and Energy has failed to comply with virtually any of the accounting or reporting requirements prescribed by the Public Finances (Management) Act 1995, the Financial Instructions, the Audit Act, the Constitution or the requirements of the Oil and Gas Act 1998 and breaches those Acts on a daily basis.

On the management of the Department of Petroleum and Energy, the PAC reported:

The Head of the Department of Petroleum and Energy has failed to account for or control expenditure of public monies, failed to prevent private individuals from taking unfettered control of huge amounts of public monies outside the Departmental and Government accounting systems and failed to seek or obtain any accountability from those persons and companies.

The Department of Petroleum and Energy has, for years, failed to lawfully or competently manage, administer or account Royalty Trust Accounts in the control of the Department.

Furthermore, DPE's role in managing Trust Accounts was even worse:

The management of all Trust Accounts by the Department of Petroleum and Energy is among the worst and most derelict that this Committee has encountered. The identified failures and frank illegality in the management of Trust Accounts was made worse by reason that five of the Trust Accounts held Royalty monies - the ultimate property of third persons for whose benefit the Department administered the Accounts. In such circumstances a high degree of probity and strict adherence to requirements of Law and/or the Trust Instrument are required.

The discussions the author had with a number of former and senior government officials revealed the need to reform the departments involved in the extractive industry. One former government official who is now a consultant stated that: 
All the key players in the industry know that the DPE is understaffed, does not have the skills and expertise... but it is not their job to go to the government and tell the government, what the government already knows. They just want their licenses given, renewed or extended (and that they are complying with all the laws).

\subsection{Conclusion: How did availability of information influence the discourse?}

The second leg of a transparency initiative is whether in fact greater availability of information has an impact on the accountability of the executive and, in the case of this research, its decisions regarding the distribution of resource revenues from the project. This is harder to substantiate, but impressions gained in this research include the following:

- Information on the government's budgetary policy and its economic effects and specifically about the revenue impacts of the project was a frequent source of discussion in the media and debate in Parliament. Several detailed analyses of revenue impacts also appeared in the media: prominent are the Jubilee Report and the various analyses emanating from the DevPolicy project. The Jubilee Report in particular drew the ire of the Prime Minister.

- From about 2016 onwards, as a result of the publicly available information on actual revenues, confidence in the "bonanza" of the PNG LNG project ebbed rapidly. The Budget papers began to lower expectations and by 2018 the official forecasts of revenues had been scaled back dramatically.

- The information about the UBS loan and the Oil Search shares transactions was widely publicised and leveraged by opposition politicians in repeated attacks on the stewardship of the O’Neill government.

- Publicity given to direct action by landowners and having their issues taken up by MPs and others in Port Moresby probably helped force their agenda into the public arena regarding the delay in receipt of benefits. The Prime Minister was forced to respond by quoting figures for the balances held in trust and despatching officials to Hela to show them to the landowners.

- The influence of the EITI audits seems to have been less direct. Although the EITI Secretariat was able to identify a minimum of nearly 60 articles about EITI in 2017-2018, 
a small minority of these dealt with the findings of the annual audits on revenue generation and distribution. There are also few direct mentions of EITI findings in the Hansard reports inspected. However, the EITI findings are quoted in some of the financial analyses of the project mentioned above and occasionally mentioned in Parliament. 


\section{Chapter 11 Conclusions}

\subsection{Introduction}

Chapter 11 analyses the findings from the case study in relation to the research questions and the underlying propositions about revenue distribution and the role of transparency; makes some observations about the implications of these findings for PNG's future public policy and governance; and suggests directions for future research.

\subsection{How have the research questions been addressed?}

Chapter 5 of the thesis concluded with some propositions about the economic, social, and political effects of revenue from natural resource projects relevant to the research questions. This Chapter first addresses the three research questions directly in the light of these propositions and the evidence from the case study.

\subsubsection{First research question: How have revenues from the PNG LNG project been distributed?}

The principal findings have been that, to date, a disproportionate share of benefits from the project have flowed to foreign investors and the project has made a limited contribution to local development.

\section{Disproportionate share of benefits in hands of foreign investors}

International investors have exported a disproportionate share of the profits from their projects, have left behind significant negative environmental impacts, and have done little to ensure sustainable benefits for the local stakeholders.

\section{Case study findings}

The research confirmed that the resource revenue from the PNG-LNG project is likely to be half or less what was estimated at the time of the Gas Agreement. The implications are obvious: government and landowners were making decisions based on flawed projections and information about the benefits of the project. Although the share accruing to local stakeholders may increase from about 2024, the bulk of the returns to the project is currently being remitted offshore in the form of dividends to overseas companies or servicing of project debt. 
This loss of predicted income has only partially been offset by local expenditure by the project on infrastructure which benefits local communities. The research was not able to contribute to findings on environmental impacts of the project.

\section{Limited contribution to broader-based development}

Minerals and petroleum projects are largely enclaved: they have few linkages to other sectors of the economy and generate few longer-term employment opportunities; they thus contribute little directly to broader-based development.

\section{Case study findings}

A lot of studies have shown that the construction phase of the project had a significant impact on GDP and GNI, on the balance of payments, and on labour markets. There are disagreements, however, on the longer-term effects on the economy. For instance, employment was high during the construction phase but declined rapidly during the production phase. The flow of money within the economy - national and local - also reflected the phases with more demand for goods and services during the construction and a lower demand during the production phase with businesses scaling back operations. The current account deficit reduced as imports fell and exports began to rise, although offset by reducing oil exports and subject to cycling commodity prices. Wage pressure generated by the project reduced but there has been continued pressure on the country's scarce resources of skilled labour from the operational demands of the project.

These effects were largely anticipated in official forecasts both in the Budget and in the Central Bank, and reinforced by advice from international agencies, particularly the IMF.

There is now a general consensus that, since production began, the returns to PNG have been lower than forecast, due mainly to low commodity prices or exchange rate effects, but the government now acknowledges that the fiscal regime for the project also adversely affected the revenue flow to government coffers. The government's apparent net loss (through KPHL) on the off-budget UBS/Oil Search transaction also reduced financial returns. There were also several loans that the government took both domestically and internationally which reduced overall fiscal returns due to repayments made.

The overall effect on the country's economic growth is still debatable. The Jubilee Report concluded that in the early years the net effect has been to depress growth in both GDP and 
GNI compared with a counterfactual of long-run trends, but the Jubilee model has been criticised. The government and Prime Minister Peter O'Neil have pointed out that, without the project, there would be less economic activity in the country. On balance the returns to investors in the form of equity flows to offshore parent companies and principal repayments on project debts have been a windfall while landowners continue to wait for their share of the financial benefits.

\subsubsection{Second research question: What have been the major influences on this distribution?}

The major influences have been the government's fiscal response to expected revenues characterised by the adverse effects of price volatility, a pro-cyclical budgetary response to the commodity cycle, and a pre-commitment of expected resource revenues; and the ongoing political struggles over access to resource rents which have had destabilising effects on local society.

\section{Adverse effects of price volatility}

Economic, financial and fiscal management have all been dominated by the requirement to respond to the effects of volatility of prices for exports of minerals and petroleum products.

\section{Case study findings}

The volatility of commodity prices was an obvious influence on government budget policy. The case study shows that government budgets since production commenced show massive fluctuations of government revenue from petroleum (oil and gas) prices. There has also been continued reference made to commodity prices as a major factor in revenue planning and projections.

The case study also noted the failure of budget forecasts which have been particularly inaccurate in the years from 2014-2016, when revenues were overestimated. Each time the government has blamed commodity prices. The budgetary implications are obvious with huge revenue shortfalls and the government has had to borrow.

\section{Pro-cyclical budgetary response to commodity cycle}

For short-term political reasons, government budgeting has tended to over-commit to new spending during the commodity booms and be forced in the downswings into cutbacks 
damaging to public services and investment or to rapid increases in broadly defined public debt.

\section{Case study findings}

The case study confirms that government budgets were mostly pro-cyclical over the period from 2007-2012, but that the Somare Government, which came to office in 2002, maintained a responsible fiscal approach to budgeting over this period. Budget forecasts were more likely to underestimate revenue growth, but revenue fluctuated significantly with commodity prices. Expenditure was however managed to keep budgets more or less in balance. This changed in 2011 when Peter O’Neill came in as Prime Minister and took an expansionary approach, reflected in the election budget of 2012. Peter O'Neill was returned as Prime Minister after the National Election - and 2013-2017 saw significant over estimation of revenue and continued deficit budgeting with the promise of a balanced budget deferred until 2022.

\section{Pre-commitment of expected resource revenues}

The expectation of significant windfall revenue gains from new extractive industry projects results in governments pre-committing those revenues to new public expenditure projects.

\section{Case study findings}

The case study confirms that the government expectations from the PNG LNG project had a significant effect on fiscal policy and planning. The government was aware of the abandonment of the gas to Queensland pipeline project when the proposal was put to it for a PNG LNG stand alone project. This was against the backdrop of a declining yield from the current oil fields. The enthusiasm can be seen by how fast the government moved to conclude the Gas Agreement, secured its equity through borrowing and settling the benefit sharing arrangement with landowners. Furthermore, the most revealing aspect of the project is the government's reliance on a study and financial analysis commissioned by the licence holders. Even more extraordinary is the projected revenue from the study which the government did not independently verify.

The euphoria and rhetoric surrounding the project's forecast of the revenues flowing to the government and landowners during the construction and operational phases made the government give a lot of concessions. This played into the hands of key decision makers who used the projections in their planning and fiscal stance. For instance, the setting up of the SWF 
was based in part on the projections that were being made and the encouragement from the IMF and other donor agencies. Although the government and its advisors moved to damp down these expectations, the research concludes that they had a marked effect in encouraging precommitment of revenues through an expansionary budget policy, particularly in the budgets from 2013-2016 when deficits grew rapidly. In the most recent budget, the Treasury had cut its forecasts of total revenues by roughly half. The proposed SWF has been put on hold until there is enough money to start it. In part the shortfalls from forecast were due to overestimation of petroleum prices in the years from 2014.

The case study confirmed that the drop in oil and LNG prices contributed substantially to the reduction in revenue. The negative fiscal impact of the UBS / Oil Search transactions also played a part the government's cash flow and revenue reduction. The government in its effort to meet the shortfall borrowed domestically and in the international money markets. The reason it gave was to service its debt and meet some of its contractual obligations. The project was also able to reduce or delay its revenue payments to the government significantly by using fiscal concessions in legislation and the gas agreement.

In summary, the evidence from the case tends to confirm the "presource curse" proposition (Cust \& Mihalyi, 2017b) but in a modified form. Cust and Mihalyi's definition “focuses on what happens in the short period between discovery and the start of production" (2017b, p. 38), when "economic problems can occur if economic behaviour is based on an overly optimistic assessment of the boon from future resource wealth.” (Ibid. p. 39). In contrast, the PNG LNG case indicates that the government's expectations were most strongly influenced long after discovery of the resource, when it had received a specific project proposal along with optimistic forecasts of its benefits. But the moral was the same: not enough attention was given to the downside risks of the revenue projections supplied by the licence holders.

\section{Political struggle for access to and control of resource rents}

Politics, both national and local, has been dominated by the struggle for resource rents, grievances about their distribution, and moral hazard from opportunities for corrupt access.

\section{Case study findings}

The case study found that the politics of access to resource rents have played out in the form of relations between local landholders and the government and in how the executive power has been able to structure access to project revenues nationally. The lack of transparency about the 
use of project revenues, particularly those not accruing directly to the Public Account, means that some of the findings here are based on anecdote and speculation.

The politics of the distribution has been a feature of the extractive industry in PNG. The legislative and institutional arrangement has been used by those in power at the national and provincial level to distribute resource rents. There are those who aspire to hold public office not to perform their duties and responsibilities but to access the office to either distribute the rent or accumulate for personal use.

It is also the case that the neglect of landowners and surrounding communities whose appeal for goods and services are not attended to can be a source of tension. For the government, the legacy of Bougainville and the continued threat of landowner violence and open insurrection, particularly in the Southern Highlands, has been a constant factor. As reported in Chapter 8, landowners, particularly in Hela, have been complaining almost continuously since the UBSA about the legitimacy of existing claims to project benefits.

The government has had to contend with a series of well-publicised incidents of direct action by locals against project facilities in pursuit of their claims. The project operators themselves have complained about the delays in payments and put pressure on the government to meet its obligation to keep project facilities secure. The government itself has moved to reassure, suppress, and pay off local landowners to keep a lid on this discontent. It has attempted to reassure local communities that the money is indeed there and will be paid out once all eligible landowners have been identified. It has increased its security presence in the project areas. Finally, there is at least anecdotal evidence that in Port Moresby officials have been making cash payments to "paper landowners" and, in project areas like Hela, agents on contract to the government have similarly been visiting villages to make payments.

At a national level, the use of political power to influence distribution, particularly for patronage networks, is less clear. There are intermittent claims that money from project revenues is being diverted to service patronage networks or for personal use, but this research has been unable to shed any further light on these allegations. What is clear is that the lack of transparency and accountability of two major recipients of revenues, KPHL and MRDC, gives plenty of scope for moral hazard. Neither of these organisations publishes financial statements. Receipts into KPHL are not treated as public money and the entity is not legally auditable by the Auditor-General. Apart from Treasury records of dividend payments to the Public Account, 
and some IRC information about tax liabilities, there is virtually no information about their expenses. Furthermore, "expenditure or acquisition or disposal of assets" by the Kumul Group must be approved by the National Executive Council. This lack of transparency and accountability clearly came to a head with the use of KPHL, at the direction of the Prime Minister, as a vehicle for the UBS borrowing and the subsequent acquisition and eventual sale at a substantial loss of Oil Search shares, as discussed in Chapter 8.

\section{Destabilising effects on local society}

Local customary relationships have influenced the national politics of resource rent distribution and conversely have been put under pressure locally and fractured by contestation over project impacts and access to benefits.

\section{Case study findings}

The research found that, contrary to the Oil and Gas Act, the social mapping and landowner identification had not been properly done. The failure to identify all the eligible landowners has not only delayed the payments but has also created tensions among the landowners and between the landowners and the developers and the government. The Development Forum remains one of the important forums where all the parties can openly discuss their concern but the research found that just as many people were happy with the forum there are just as many who feel that the forum was hijacked. Landowners not present at the Development Forums have protested at the claims that those who signed the BSAs were not representative and many were "paper landowners" in Port Moresby fraudulently claiming eligibility in licence areas. The landowner identification dragged on for a decade. The government is now claiming that it is complete and final but, given the history of local disputes over land, this seems optimistic. The case study adds to the evidence of the ongoing fracture line between local customary relationships and the formal incorporation of land interests required by the state. Furthermore, the creation of Landowner Incorporation Groups and Landowner Companies appears to have further entrenched power and control of resources in the hands of local big men and their extended families.

In summary, the case study tends to support the persistent findings, mainly from an anthropological perspective (Ballard and Banks 2003; Banks 2008; Filer 2006, 2016; Gilberthorpe and Rajak 2016; and others) of the inevitability of major and continuing local disputes over shares in natural resources arising from the conflict between formal law and 
custom in traditional societies like PNG, and of the various strategies that local individual landowners will use to exploit this conflict to their own advantage.

\subsubsection{Subsidiary question: what effect has there been from the initiatives for financial transparency and accountability associated with the project?}

Although information on the expected and actual flows of revenues from the project, and their disposition, has been incomplete, the available information on resource rents has influenced the political discourse.

\section{Information on resource rents has influenced political discourse}

Transparency: accountability for benefit sharing from major extractive industry projects will be improved by transparency about project agreements and planned and actual payments from the project to stakeholders.

\section{Case study findings}

As discussed in Chapter 10, this research also been a practical experiment to access information about a major extractive industry project and its use to hold government accountable. The research has confirmed the inaccessibility and unavailability of official information from the State. All the major project documents that were used came from other sources. The CDOA which is the original agreement amongst the license holders was not available in any form.

A lot of information including payments made by the project to the government could not be fully verified and confirmed. The EITI was able to trace payments made and payments received but there were still major discrepancies caused in part by two government controlled entities the KPHL and MRDC who cannot fully account for the receipts from the project or for their overall revenues and expenses.

This research found enough project information entering the public discourse and also acknowledgement of this discourse by the government, which shows that when information is available it can influence how government conducts its business and the decisions it makes. The availing of this information for the public has been assisted using social media and other internet platforms to post the information. This is a form of transparency and accountability which the government is aware of and to which it has been forced to respond. 
The official documents that were used included: the Budget Papers which are built on strong fiscal responsibility law and processes; legislation, all publicly available on an independent website supported by the government; and the Hansard record of parliamentary proceedings, available on the parliamentary website until mid-2017 and then discontinued. All were useful raw material used in the research. The local media, social media and blogs have supplemented the official documents accessed.

\subsection{Implications for future PNG governance and policy}

\subsubsection{Reconciling the different decision streams in major projects}

In so far as the PNG LNG project is concerned, it was only in 2009 when there was certainty that project would proceed that the Government, developers and landowners started moving to strengthen their respective positions and exert their influence over the various phases and processes of the project. There were moves for instance to negotiate finance, ownership (equity), and sales and marketing among other areas and things.

The PNG Government while negotiating with the developers was also negotiating "benefit sharing agreements with relevant provincial governments and landowners according to PNG law" (Nelson \& Valikai, 2014, p. 5). The urgency towards meeting the pre-requisites before construction stage of the PNG LNG project was a major influence in how everybody reacted in making decisions, making commitments and signing off on agreements. This is certainly true for the construction phase: "All these processes have shaped the contractual, regulatory, political and socio-economic context within which construction is being undertaken" (ibid).

\subsubsection{Custom versus capitalism in land access}

Another well documented feature that continue to influence and shape the thinking and reaction of the Government and developers is the enclave nature of resource projects and the accompanying tensions and conflicts such projects generate. The World Bank in its recent diagnostic of PNG pointed out that:

The large presence of the enclave-based resource economy has created frictions in Papua New Guinea's social fabric. Conflict over resource rents and revenues is apparent from family to local to central levels, and both inside and outside of government. Resources exist in territorial enclaves, fuelling spatial inequity and conflict between villages, districts, provinces and regions. Resentments develop between adjoining 
districts where one has resource rents and the other does not. As visible around PNG's LNG and mining enclaves, existing territorial relations are transformed: conflict faultlines can deepen or change, disabling previous resolution mechanisms, and enabling the re-emergence of ethnic violence. Outsiders arriving in resource enclaves seeking opportunities can create further tensions, especially as they side with or are protected by local factions. (2018, p. 115)

The position of landowners has been recognized as very critical and important in any major resource projects and the benefits accruing to them in the country. This is certainly true with the PNG LNG project where the developers and the government needed to be very sensitive and careful in how the BSA is being handled with landowners:

The Project recognizes that the consequences of an ineffective or inequitable system of distribution would be inevitably, and adversely, linked to the Project and the reputations of the Project operator and its financial co-venture partners. Conversely, if implementation of the BSAs work well, this will not only reflect well on the government and Project, but will give local communities a greater sense of ownership in the project and hopefully a vested interest in supporting future operations. (Nelson \& Valikai, 2014).

While the process of Development Forums and Benefit Sharing Agreements in the OGA has been much admired, it has fallen down in execution on key issues like proper prior consensus identification of eligible landowners and then being able to honour commitments made in the BSAs. The developers have been honouring their respective commitments as contained in the PNG LNG Gas Agreement, but the PNG Government has not been honouring its agreement with the landowners as contained in the UBSA and LBSA in terms of paying out royalties and other financial benefits. Failure on these aspects has significantly jeopardised government / local landowner relations.

\subsubsection{Disconnecting resource revenues from patronage}

A third major influence is the use of resource rents by respective governments of the day to try to continue to stay in power and weaken key oversight institutions. This is certainly the case in the PNG LNG project: 
The governments have used slush funds to keep backbenchers happy and suppressing votes of no-confidence in the government. Furthermore, “(w)hen political pacts are based on rent-based provisioning, there are strong incentives not to invest in watchdogs or anti-corruption authorities, or citizen accountability mechanisms. On the contrary, the benefiting parties will be inclined to reduce transparency, shifting arrangements into SOE or private sector institutions, where commercial sensitivity can deny scrutiny of patronage practices. (World Bank, 2018, p. 128).

Furthermore, a major influence on the distribution of revenues from the resource sector is the institutionalization of resource rents for instance in the budgets where each local MPs are given K10 million for use in their respective electorates.

Rent based provisioning of MPs has been institutionalized in the District Services Improvement Program (DSIP) and Provincial Services Improvement Program (PSIP) grants systems, which give MPs access to, and wide-ranging autonomy over, millions of Kina, with very limited transparency required in how the funds are utilized. (Ibid.:127).

Finally, countries like PNG are caught up in situations where the local elites can influence the government to serve their interests, for example the awarding of major contracts have tended to benefit the business associates of those in government. This is an arena that is played out through the budget process and through the government tender process. Misappropriation and poor fiscal management reinforce each other and can be crippling when institutions and the lack of compliance and enforcement is poor in PNG.

Revenue streams can create elite arenas of competition, or they can underpin kleptocratic governments ... there are those governments who remain in power only to accrue rents from the oil windfall and who regardless do not even attempt to manage fiscal booms well e.g. the goal is appropriation and not financial management. (Acosta \& de Renzio, 2007, p. 12).

\subsubsection{Reform to the fiscal and regulatory regime}

The National Executive Council (NEC) in early March 2018 approved the PNG Natural Gas policy White Paper that is intended to set in place specific policies to maximise benefits for the country. Prime Minister Peter O’Neil announced this policy initiative which will "guide the 
development and management of the country's growing oil and gas industry". He went on to state that:

The recent PNG LNG development has made PNG a key natural gas producer in the Asia Pacific region with the other developments that are preparing to come into production. The White Paper sets clear the policy direction on the country's management of its natural gas developments. The direction now enables the government's implementing agencies to undertake policy, legislative and regulatory reforms to establish the policies with the agencies to administer and implement the policy directions (PM Office Press Release, March 2018:1)

\subsubsection{Improving public capacity}

Weaknesses in official capacity to analyse and regulate has been a major factor in the PNG LNG project.

There was a lack of internal capacity to evaluate the project and then to secure a balanced regulatory and fiscal regime. The negotiating team relied heavily on the findings of a research commissioned by the developers (ExxonMobil). The ACIL Report was very optimistic in its projections and as it now appears greatly influenced how the government's expenditure was based on future projected revenue. The anticipated revenue as contained in the ACIL Report also influenced the government to borrow heavily from the international money markets. From nearly all the studies and reports that were consulted in the research there was no study commissioned by the State to look at the financial impact of the PNG LNG project.

A further point is the problem of over- and under-forecasting project revenues. To be sure, this is a task bedevilled by the problem of picking turning points in strongly fluctuating commodities markets. The best solution here is to forecast conservatively and be sure that there are contingency plans to respond to sudden shifts in commodity markets. The SWF would clearly be part of the solution to this problem. But forecasting also suffers from a lack of detailed understanding of just how project activity interacts with fiscal and regulatory regimes to affect revenue flows to the government and other project impacts. Again, this is a problem of lack of capacity within the PNG government.

There was indeed a lack of capacity at all levels of government to manage the project of the size as the PNG LNG. This was obvious in how the State negotiated with the developers and 
the landowners. The DPE which is the lead Government Department for the PNG LNG did not have the capacity to facilitate and coordinate the project. This was evident when the Government elevated the Ministerial Committee for Economic Sector (MCES), chaired by the Treasurer, to prepare and plan the Government's position on the PNG LNG project.

The Department of Petroleum under the current departmental/bureaucratic structure will not be able to deliver or implement government policies and directives. The Department would need to be changed into an Authority as is the case with Mining Department which was changed into the Mineral Resources Authority.

\subsubsection{Transparency and accountability}

The EITI has made a significant difference to the quality of information about resource revenues emerging from project developers - albeit with some significant shortcomings like lack of information about true project profitability. But it is still not able to give the same degree or transparency to what government does with the money. The annual EITI audits and the EITI Validation process have pinpointed the areas where improvement is needed, particularly in identifying sub-national distributions of payments but clearly there are major gaps in information simply because some major agencies of government are unwilling or unable to provide the necessary data, together with a lack of confidence in the audit and parliamentary scrutiny of this information, which remains weak to the point of non-existence.

\subsubsection{Strengthening public scrutiny}

This research has been able to scan the media and make use of some detailed and apparently well-informed accounts and analyses of the project, there remains a suspicion that this is a conversation amongst a small urban elite. The poor and marginalized may be left behind as the gathering, analysis, and use of information require a level of literacy, while applying political pressure needs organization. Drawing the wider parts of PNG society outside a few urban centres remains a challenge and may require an enlightened government to fund a clearly independent capacity to manage this stakeholder communication.

\subsection{Scholarly contribution}

The PNG LNG case adds the weight of evidence to several of the propositions in this thesis. 
A major contribution is to analyse in detail the expectations effect of a major resource project: what the extractive industry offered and how a developing country government responded to it. In the case of PNG, the PNG LNG project created an illusion which the Government saw as the panacea for all its problems. The research noted repeatedly that, despite the low stream of revenue from the LNG project, the government continued an expansionary budget including borrowing heavily against high and unrealistic forecasts. This was a case of project capture where the state was captured by a single project and did its planning around it, to the detriment of its institutions and people.

A second contribution is to further develop understanding of the mechanisms by which the state attempts to force land access into a formal code, in this case through the process of social mapping, incorporation of landholder groups, and benefit sharing agreements, and the ongoing mismatch and process of adaptation between state and customary society, in which actual outcomes in terms of benefits depart significantly from policy intentions, and the consequent grievances and tensions are never fully resolved.

Finally, the analysis in this research of the public debate about the PNG LNG project has indicated that, when information about project transactions is publicly available (as it was imperfectly in this case), it can influence the debate and ultimately force the government to respond to it, thus completing the transparency-accountability loop. Conversely, where information has not been readily accessible, as in the case of KPHL and its debt transactions, the government has had much greater latitude to enter into transactions without public accountability.

\subsection{Future areas for research}

The following areas have been identified as areas for future research and include:

- The need to monitor the financial benefits accruing to landowners and how they spend their monies. There, have been hundreds of millions of kina given to landowners by companies operating in the extractive industry over the last four decades but with very little to show for in terms of development outcomes and improvement in peoples' livelihood. While the UNDP PNG Human Development Report of 2014 is very revealing and insightful there is a need to better understand the spending behaviour of landowners especially at the household level. 
- There is a need to look at the provincial and lower level governments of resource rich areas to see how they spend their resources in the communities. A careful assessment of the major resource producing provinces - such as Western (Ok Tedi copper mine), Southern Highlands (Kutubu oil project/PNG LNG), New Ireland (Lihir gold project), Madang (Ramu nickel mine), Enga (Porgera gold mine) - shows very little economic development. Are these projects in these provinces microcosms of what is happening at the national level? Although, Glen Banks (2003) and Collin Filer (2012) looked at the Porgera gold mine and its social impact and its contribution to provincial and lower level governments, there is a need for ongoing studies for the different resource projects.

- There is a need to evaluate the impact of the work of the EITI in PNG and to see in particular the transparency of the monies given by companies and the monies received by the national government and the reconciliation and explanation of any anomalies. The financial transactions within the extractive industry in PNG remains opaque and there is no clear linkage between the revenue received by the government and the amount or the percentage of the amount going into the budgets.

\subsection{Conclusions}

PNG does not have the capacity to negotiate with developers to secure a better deal for the landowners, lower level and provincial governments hosting major resource projects. The government's approach has been to: fast track resource projects to the stage of signing agreements before bringing in landowners and provincial governments; rely heavily on information provided by the developers to sell the project to the landowners and provincial governments and the general public; use the budget as a tool to reward landowners, provincial governments and the elected officials to support the government of the day and worse still raise unrealistic expectations. 


\section{Annex: Sovereign Wealth Fund Rule Changes}

\begin{tabular}{|c|c|c|}
\hline & 2012 Law & 2015 Law \\
\hline \multicolumn{3}{|c|}{ Stabilisation Fund } \\
\hline Deposits & $\begin{array}{l}\text { All mineral and petroleum } \\
\text { revenues } \\
\text { Fund earnings from investments } \\
\text { Other Government contributions }\end{array}$ & $\begin{array}{l}50 \% \text { of mining and petroleum taxes } \\
\text { Maximum } 60 \% \text { of proceeds of sale of State } \\
\text { mining and petroleum interests (balance to go } \\
\text { to Savings Fund) } \\
\text { Transfers from Savings Fund (see below) } \\
75 \% \text { of all dividends from State holding } \\
\text { companies' mining and petroleum interests } \\
\text { (less companies' operating costs) } \\
\text { Balance (35-75\% - decided by Parliament) of } \\
\text { all State dividends from mining and petroleum } \\
\text { non-holding companies after deposit in } \\
\text { Savings Fund } \\
\text { Other Government contributions }\end{array}$ \\
\hline Withdrawals & $\begin{array}{l}\text { Maximum of " } 15 \text { year long-term } \\
\text { moving average of mineral and } \\
\text { petroleum revenues as a share of } \\
\text { non-mining revenue" } \\
\text { Further provisions "not } \\
\text { inconsistent" with the above }\end{array}$ & $\begin{array}{l}\text { Maximum of "five year long-term moving } \\
\text { average of mineral and petroleum receipts as a } \\
\text { share of the non-mineral and non-petroleum } \\
\text { receipts of the State" lagged two years (e.g. } \\
\text { maximum for } 2020 \text { set by moving averages } \\
\text { calculated 2014-2018) }\end{array}$ \\
\hline \multicolumn{3}{|c|}{ Development (Savings) Fund } \\
\hline & 2012 Law (Development Fund) & 2015 Law (Savings Fund) \\
\hline Deposits & $\begin{array}{l}\text { Minimum of "guaranteed } \\
\text { minimum annual allocation as } \\
\text { determined by an Act of } \\
\text { Parliament based on the expected } \\
\text { average PNG LNG Dividends" } \\
\text { Earnings from Fund investments } \\
\text { Other Government contributions }\end{array}$ & $\begin{array}{l}\text { Surplus in Stabilisation Fund above US\$1 } \\
\text { billion } \\
\text { Minimum } 40 \% \text { of proceeds of sale of State } \\
\text { mining and petroleum interests (balance to go } \\
\text { to Stabilisation Fund) } \\
25 \% \text { of all dividends from State holding } \\
\text { companies' mining and petroleum interests } \\
\text { (less companies' operating costs) } \\
25-65 \% \text { (decided by Parliament) of all State } \\
\text { dividends from mining and petroleum non- } \\
\text { holding companies } \\
\text { Proceeds from the sale of any non-mining or } \\
\text { non-petroleum asset } \\
\text { Other Government contributions }\end{array}$ \\
\hline Withdrawals & $\begin{array}{l}\text { Any credit balance required "to } \\
\text { support the development plans of } \\
\text { Government in accordance with } \\
\text { an Act of Parliament" }\end{array}$ & $\begin{array}{l}\text { May not reduce real (inflation-adjusted) capital } \\
\text { of Fund. } \\
\text { May only be made from the Fund's real } \\
\text { income } \\
\text { First withdrawal ten years after establishment } \\
\text { of Board at least equal to the real income of } \\
\text { the Savings Fund earned two fiscal years prior } \\
\text { to the year in which the withdrawal is being } \\
\text { made." } \\
\text { Must be deposited to Stabilisation Fund. }\end{array}$ \\
\hline
\end{tabular}




\section{References}

\section{Note on referencing}

Third party content: In making use of third-party content, I have relied on the permissions granted in the publication by the copyright holders or s. 43(1) of the New Zealand Copyright Act 1994 regarding "fair dealing" for the purposes of research or private study. As requested by the World Bank, Asian Development Bank, and the United Nations Development Programme, I advise that their permissions are generally in terms of a Creative Commons Attribution Licence 3.0 or 4.0.

Page numbering: Where a citation is linked to a reference obtained as a PDF document, page numbers given may be the PDF page number. They may not correspond to the page numbers in the printed text.

\section{Bibliography}

Aaronson, S. A. (2011). Limited Partnership: Business, Government, Civil Society, and the Public in the Extractive Industries Transparency Initiative (EITI). Public Administration and Development, 31, 50-63.

ABC News. (2017a, February 20). Unpaid royalties prompt protest at LNG project near Port Moresby [Text]. ABC News. https://www.abc.net.au/news/2017-02-20/pngprotesters-block-lng-project-near-port-moresby/8286894

ABC News. (2017b, November 29). PNG landowners block access to gas wells in ongoing royalty dispute. ABC News. https://www.abc.net.au/news/2017-11-29/pnglandowners-seize-gas-wells-over-royalty-disputes/9206828

Abel, H. C. (2017). 2018 National Budget. Volume 1: Economic and Development Policies. Government of Papua New Guinea. http://www.treasury.gov.pg/html/national_budget/files/2018/Volume\%201.pdf

Abel, H. C. (2019). 2019 National Budget. Volume 1-Economic and Development Policies. Government of Papua New Guinea.

Acemoglu, D., \& Robinson, J. (2012). Why Nations Fail: The Origins of Power, Prosperity, and Poverty. Crown Publishers (Random House).

ACIL Tasman. (2008). PNG LNG Economic Impact Study: An assessment of the direct and indirect impacts of the proposed PNG LNG Project on the economy of Papua New Guinea (p. 66). Exxon Mobil.

Acosta, A. M., \& de Renzio, P. (2007). Aid, Resource Rents and the Politics of the Budget Process. Centre for the Future State's Development Research Consortium. 
ADB. (2009). ADB Support for Public Sector Reforms in the Pacific: Enhance Results through Ownership, Capacity, and Continuity [Evaluation Study]. Asian Development Bank.

ADB. (2012). Papua New Guinea: Critical Development Constraints (Country Diagnostics Studies). Asian Development Bank.

ADB. (2015). Country Partnership Strategy_Papua New Guinea 2016-2020. https://www.adb.org/sites/default/files/institutional-document/157927/cps-png-20162020.pdf

ADB. (2018). Asian Development Outlook 2018 Update: Maintaining Stability amid Heightened Uncertainty [Asian Development Outlook]. Asian Development Bank. https://doi.org/10.22617/FLS189567-3

Alexeev, M., \& Conrad, R. (2009). The elusive curse of oil. The Review of Economics and Statistics, 91(3), 586-598.

Allen, M., \& Hasnain, Z. (2010). Power, pork and patronage: Decentralisation and the politicisation of the development budget in Papua new guinea. Commonwealth Journal of Local Governance, 6, 7-31.

Alt, J. E., \& Dreyer Lassen, D. (2003). Fiscal transparency and fiscal policy outcomes in OECD countries. EPRU Working Paper Series.

Andrews, M. (2008). The Good Governance Agenda: Beyond Indicators without Theory. Oxford Development Studies, 36(4).

Anoser, K. (2013). The evolution of Benefit Sharing Agreements in Papua New Guinea: What are the lessons learnt and what are the prospects for the future? [Masters Thesis (Development Studies)]. Massey University.

Arezki, R., Ramey, V. A., \& Sheng, L. (2017). News Shocks in Open Economies: Evidence from Giant Oil Discoveries. The Quarterly Journal of Economics, 132(1), 103-155. https://doi.org/10.1093/qje/qjw030

Arezki, R., \& Van der Ploeg, F. (2011). Do natural resources depress income per capita? Review of Development Economics, 15(3), 504-521.

Atkinson, G., \& Hamilton, K. (2003). Savings, Growth and the Resource Curse Hypothesis. World Development, 11, 1793-1807.

Auditor-General of Papua New Guinea. (2017). Report of the Auditor-General 2016: Part IV. Auditor-General's Office of Papua New Guinea.

Auty, R. M. (1990). Resource-based industrialization: Sowing the oil in eight developing countries. Clarendon Press Oxford.

Auty, R. M. (1994). Industrial policy reform in six large newly industrializing countries: The resource curse thesis. World Development, 22(1), 11-26.

Auty, R. M. (2001). The political economy of resource-driven growth. European Economic Review, 45, 839-846.

Auty, R., \& Mikesell, R. F. (1998). Sustainable development in mineral economies. Oxford University Press. 
Auty, R., \& Warhurst, A. (1993). Sustainable development in mineral exporting economies. Resources Policy, 19(1), 14-29.

Avalos, N., Stuva, V. G., Heal, A., Lida, K., \& Okazoe, N. (2015). Papua New Guinea and the natural resource curse. Comparative Economic Studies, 57(2), 345-360.

Axline, W. A. (1993). Governance in Papua New Guinea: Approaches to institutional reform. Institute of National Affairs.

Badeeb, R. A., Lean, H. H., \& Clark, J. (2017). The evolution of the natural resource curse thesis: A critical literature survey. Resources Policy, 51 (2017), 123-134.

Bakani, L. M. (2011). Monetary Policy Statement by the Governor. Bank of Papua New Guinea.

Balkin, J. M. (1999). How mass media simulate political transparency. Cultural Values, 3(4), 393-413. https://doi.org/10.1080/14797589909367175

Ballard, C. (1997). It's the land, stupid! The moral economy of resource ownership in Papua New Guinea. In P. Larmour (Ed.), The governance of common property in the Pacific region (pp. 47-65).

Ballard, C., \& Banks, G. (2003). Resource Wars: The Anthropology of Mining. Annual Review of Anthropology, 32, 287-313. JSTOR.

Bank of PNG. (2015). Quarterly Economic Bulletin. Bank of Papua New Guinea. https://www.bankpng.gov.pg/publications-presentations/quarterly-economic-bulletin/

Banks, G. (2008). Understanding 'resource' conflicts in Papua New Guinea. Asia Pacific Viewpoint, 49(1), 23-34.

Banks, G. (2003). Landowner equity in Papua New Guinea's minerals sector: Review and policy issues. 27, 223-234.

Banks, G., \& Ballard, C. (1997). The Ok Tedi Settlement: Issues. Outcomes and Implications (Australian National University, Canberra).

Bannister, F., \& Connolly, R. (2011). The Trouble with Transparency: A Critical Review of Openness in e-Government. Policy \& Internet, 3(1). www.policyandinternet.org

Barma, Naazneen, Fritz, V., \& Rex, W. (2010). Governance of Natural Resource Management in Lao PDR: A Value Chain Perspective. World Bank.

Barma, Nazneen. (2014). The Rentier State at Work: Comparative Experiences of the Resource Curse in East Asia and the Pacific. Asia \& the Pacific Policy Studies, 1(2), 257-272.

Barma, Nazneen, Kaiser, K., Tuan, M. L., \& Viñuela, L. (2012). Rents to Riches? The Political Economy of Natural Resource-Led Development (No. 65957). The World Bank.

Basedau, M., \& Lacher, W. (2006). A paradox of plenty? Rent distribution and political stability in oil states.

Basedau, M., \& Lay, J. (2009). Resource curse or rentier peace? The ambiguous effects of oil wealth and oil dependence on violent conflict. Journal of Peace Research, 46(6), $757-776$. 
Bates, R. H. (2008). When Things Fell Apart: State Failure in Late-Century Africa. Cambridge University Press.

Bertelsmann Stiftung. (2009). BTI 2010_Papua New Guinea Country Report. http://www.bti2010.bertelsmann-transformation-index.de/

Biersack, A. (2012). Porgera-Whence and Whither? In C. Filer (Ed.), Dilemmas of development: The social and economic impact of the Porgera gold mine (Vol. 1994, pp. 260-279).

Biggs, P. (2007). The Financial Sector in Papua New Guinea-A Good Case of Reform. Economic Round-Up, Winter 2007, 73.

Bleaney, M., \& Halland, H. avard. (2009). The resource curse and fiscal policy volatility. CREDIT research paper.

Bolger, J., Mandie-Filer, A., \& Hauck, V. (2005). Papua New Guinea's health sector: A review of capacity, change and performance issues. European Centre for Development Policy Management.

Bonnell, S. (2012a). Social change in the Porgera Valley. In C. Filer (Ed.), Dilemmas of development: The social and economic impact of the Porgera gold mine (Vol. 1994, pp. 19-87).

Bonnell, S. (2012b). The landowner relocation programme. In C. Filer (Ed.), Dilemmas of Development: The Social and Economic Impact of the Porgera Gold Mine (Vol. 1994, pp. 128-159).

Botten, P. (2007). Oil Search signs cost-sharing agreement to study LNG project. Oil Search Limited. http://www.oilsearch.com/__data/assets/pdf_file/0009/4050/070411-Costsharing-agreement-on-LNG-4fc166c3-5711-444e-91cf-e0e98e8cc790.pdf

Botten, P. (2009, March 16). Media Release: IPIC Exchangeable Bond Agreement 16 March 2009. 3 .

Bourke, R. M., \& Allen, B. (2009). People, Land and Environment. In R.M. Bourke \& T. Harwood (Eds.), Food and Agriculture in Papua New Guinea. ANU E Press.

Bovaird, T., \& Löffler, E. (Eds.). (2003). Public management and governance. Routledge.

Boyle, J. S. (1994). Styles of Ethnography. In J. M. Morse (Ed.), Critical issues in qualitative research methods (pp. 159-185). Sage.

Brower, R. S., Abolafia, M. Y., \& Carr, J. B. (2000). On Improving Qualitative Methods in Public Administration Research. Administration \& Society, 32(4), 363-397. http://dx.doi.org/10.1177/00953990022019470

Brückner, M. (2010). Natural resource dependence, non-tradables, and economic growth. Journal of Comparative Economics, 38(4), 461-471.

Brunnschweiler, C. N., \& Bulte, E. H. (2008). The resource curse revisited and revised: A tale of paradoxes and red herrings. Journal of Environmental Economics and Management, 55(3), 248-264.

Bulte, E. H., Damania, R., \& Deacon, R. T. (2005). Resource intensity, institutions, and development. World Development, 33(7), 1029-1044. 
Burton, J. (2017). Corruption Risks in Mining Awards: Country Report. Transparency International Papua New Guinea.

Business Advantage PNG. (2016, August 10). In brief: 'Clan vetting' the key to resolving PNG LNG royalty issue, says Energy Minister. Business Advantage PNG.

https://www.businessadvantagepng.com/in-brief-clan-vetting-the-key-to-resolvingpng-lng-royalty-issue-says-energy-minister/

Canuto, O., \& Cavallari, M. (2012). Natural Capital and the Resource curse.

Castro, A. P., \& Brokensha, D. W. (2015). Development: Social-Anthropological Aspects. In International Encyclopedia of the Social \& Behavioral Sciences (Second, pp. 301306). Elsevier.

Center for Systemic Peace. (2009). PolityProject. The Polity Project. http://www.systemicpeace.org/polityproject.html

Chand, S. (2002). Deficit bias and debt accumulation to economic crises in Papua New Guinea. Knowledge Sector Initiative (KSI) Conference 2002. openresearchrepository.anu.edu.au

Chand, S. (2004). Papua New Guinea economic survey: Transforming good luck into policies for long-term growth. Pacific Economic Bulletin, 19(1), 19.

Chand, S., \& Yala, C. (2009). Economic policy making. In R J May (Ed.), Policy Making and Implementation: Studies from Papua New Guinea (pp. 41-56). ANU E Press.

Cochrane, G. (1986). Reforming National Institutions for Economic Development. Westview.

Cochrane, L. (2014, March 11). PNG Prime Minister sacks two ministers from cabinet. ABC News. https://www.abc.net.au/news/2014-03-11/an-png-pm-sacks-treasurerpolye/5311526

Collier, P., \& Hoeffler, A. (2004). Greed and grievance in civil war. Oxford Economic Papers, 56(4), 563-595.

Collis, J., \& Hussey, R. (2009). Business research: A practical guide for undergraduate and postgraduate students.

Connell, J. (1992). "Logic is a capitalist cover-up": Compensation and crisis in Bougainville, Papua New Guinea. In S. Henningham \& R. J. May (Eds.), Resources, development and politics in the Pacific Islands (pp. 30-54).

Connell, J., \& Howitt, R. (1991). Mining, dispossession and development. In J. Connell \& R. Howitt (Eds.), Mining and indigenous people in Australasia (pp. 1-17).

Corality. (2019). Features of a cash flow waterfall in project finance.

http://www.corality.com/training/campus/post/cash-flow-waterfall-in-project-finance

Corkery, J. (1995). Civil service reforms: Hurdles and helps. DPMN Bulletin, 3(1), 9-11.

Cotet, A. M., \& Tsui, K. K. (2013). Oil, growth, and health: What does the cross-country evidence really show? The Scandinavian Journal of Economics, 115(4), 1107-1137.

Creswell, J. W. (1994). Research design: Qualitative \& quantitative approaches. Sage Publications, Inc. 
Creswell, J. W. (1998). Qualitative inquiry and research design: Choosing among five traditions. Sage.

Cust, J., \& Mihalyi, D. (2017a). Evidence for a Presource Curse? Oil Discoveries, Elevated Expectations, and Growth Disappointments. The World Bank. https://doi.org/10.1596/1813-9450-8140

Cust, J., \& Mihalyi, D. (2017b). The Presource Curse. Finance \& Development; Washington, 54(4), 36-40.

Daniel, P., Palmer, K., \& Brown, R. (2000). Review of the Fiscal Regimes for Mining and Hydrocarbons [The Bogan Report]. Asian Development Bank and the Papua New Guinea Tax Review.

Davis, G. A. (2013). Replicating Sachs and Warner's working papers on the resource curse. Journal of Development Studies, 49(12), 1615-1630.

Davis, G. A., \& Tilton, J. E. (2005). The resource curse. Natural Resources Forum, 29, 233242.

Deloitte. (2015). Papua New Guinea (PNG) Extractive Industries Transparency Initiative (EITI 'Scoping Study for First EITI Report'). PNG EITI. https://eiti.org/sites/default/files/documents/2015.05.28_-_deloitte_pngeiti_scoping_study_final.pdf

Denoon, D., Ballard, C., Banks, G., \& Hancock, P. (1996). Mining and mineral resource policy issues in Asia-Pacific: Prospects for the 21st Century. Research School of Pacific and Asian Studies, The Australian National University, Canberra.

Department of Petroleum and Energy. (2018). Notes provided to researcher.

Desai, D., \& Jarvis, M. (2012). Governance and Accountability in Extractive Industries: Theory and Practice at the World Bank. Journal of Energy \& Natural Resources Law, 30(2), 101-128. https://doi.org/10.1080/02646811.2012.11435288

Devpolicy. (2019). Devpolicy PNG Budget Database. Development Policy Project, Crawford School of Public Policy, Australian National University.

https://devpolicy.crawford.anu.edu.au/png-project/png-budget-database

DFAT. (2018). Aid Program Performance Report 2017-18: Papua New Guinea. Department of Foreign Affairs and Trade (Australia). https://dfat.gov.au/aboutus/publications/Documents/papua-new-guinea-appr-2017-18.pdf

Dorney, S. (2000). Papua New Guinea: People, politics and history since 1975. ABC Books.

Dove, J., Miriung, T., \& Togolo, M. (1974). Mining bitterness. In P. G. Sack (Ed.), Land in Papua New Guinea's Future (pp. 181-189). ANU Press and Robert Brown and Associates.

Duncan, R. (Ed.). (2011). The Political Economy of Economic Reform in the Pacific. Asian Development Bank.

Duncan, R., \& Hassall, G. (2011). How Pervasive is Clientilist Politics in the Pacific? In R. Duncan (Ed.), The political economy of economic reform in the Pacific. Asian Development Bank. 
Duncan, R., \& Temu, I. (1995). The need for fiscal discipline. Pacific Economic Bulletin, 10(1).

Eisenhardt, K. M. (1989). Building Theories From Case Study Research. Academy of Management Review, 14(4), 532-550.

EITI. (2013). EITI Business Guide. Extractive Industries Transparency Initiative.

EITI. (2019). Extractive Industries Transparency Initiative. Extractive Industries Transparency Initiative. https://eiti.org/

EITI PNG. (2018). Validation of Papua New Guinea. Extractive Industries Transparency Initiative. https://eiti.org/scorecardpdf?filter\%5Bcountry\%5D=46\&filter\%5Byear\%5D=2018

EITI PNG. (2019). Papua New Guinea Extractive Industries Transparency Initiative (EITI). Extractive Industries Transparency Initiative. https://eiti.org/papua-new-guinea

Ekeh, P. P. (1975). Colonialism and the two publics in Africa: A theoretical statement. Comparative Studies in Society and History, 17(1), 91-112.

Ernst \& Young. (2017a). Papua New Guinea Extractive Industries Transparency Initiative (PNG EITI): Report for 2015. https://eiti.org/sites/default/files/documents/2015-pngeiti-report.pdf

Ernst \& Young. (2017b). Papua New Guinea Extractive Industries Transparency Initiative (PNG EITI): Report for 2016. PNG Extractive Industries Transparency Initiative.

Ernst \& Young. (2018). Papua New Guinea Extractive Industries Transparency Initiative (PNG EITI): Report for 2017. PNG Extractive Industries Transparency Initiative. http://www.pngeiti.org.pg/wp-content/uploads/2019/01/PNGEITI-Report-2017-1.pdf

Escobar, A. (1995). Encountering Development: The Making and Unmaking of the Third World. Princeton University Press.

Evans, P. B. (1989). Predatory, Developmental, and Other Apparatuses: A Comparative Political Economy Perspective on the Third World State. Sociological Forum, 4(4), 561-587.

ExxonMobil. (2019). PNG LNG: Project Website. https://pnglng.com/

Fearon, J. D., \& Laitin, D. D. (2003). Ethnicity, insurgency, and civil war. American Political Science Review, 97(1), 75-90.

Ferraro, V. (2008). Dependency Theory: An Introduction. In The Development Economics Reader ed. Giorgio Secondi (pp. 58-64). Routledge.

Filer, C. (1997). Compensation, rent and power in Papua New Guinea. In C. Filer \& S. Toft (Eds.), Compensation for resource development in Papua New Guinea (pp. 156-189).

Filer, C. (2006). Custom, Law and Ideology in Papua New Guinea. The Asia Pacific Journal of Anthropology, 7(1), 65-84. https://doi.org/10.1080/14442210600554499

Filer, C. (2008). Development Forum in Papua New Guinea: Upsides and Downsides. Journal of Energy \& Natural Resources Law, 26(1), 120-150. 
Filer, C. (2012). Local Custom and the Art of Land Group Boundary Maintenance in Papua New Guinea. In J. F. Weiner \& K. Glaskin (Eds.), Customary land tenure and registration in Australia and Papua New Guinea: Anthropological perspectives (Vol. 3, p. 135).

Filer, C. (2016). The Intractable Problem of Landowner Identification in the PNG LNG Project: A Historical Perspective [Powerpoint]. Australian National University.

Filer, C. (2019). Methods in the Madness: The 'Landowner Problem' in the PNG LNG Project. SSRN Electronic Journal. https://doi.org/10.2139/ssrn.3332826

Filer, C., \& McIntyre, M. (2006). Grass Roots and Deep Holes: Community Responses to Mining in Melanesia. The Contemporary Pacific, 18(2), 215-231.

Finel, B. I., \& Lord, K. M. (1999). The surprising logic of transparency. International Studies Quarterly, 43(2), 315-339.

Finney, B. R. (1973). Big-men and business: Entrepreneurship and economic growth in the New Guinea Highlands. Australian National University Press. https://openresearchrepository.anu.edu.au/handle/1885/115049

Flanagan, P. (2018, June 12). Benefit shortfalls of the PNG LNG Project: A response to Mark McGillivray -. Devpolicy Blog from the Development Policy Centre. http://www.devpolicy.org/benefit-shortfalls-of-the-png-lng-project-20180613/

Flanagan, P., \& Fletcher, L. (2018). Double or Nothing: The Broken Economic Promises of PNG LNG. Jubilee Australia Research Centre.

Flick, U. (2002). Qualitative research-state of the art. Social Science Information, 41(1), 524.

Florini, A. (1988). The End of Secrecy. Foreign Policy, 50-64.

Fox, R., Howes, S., Atip Nema, N., \& Schröder, M. (2017). 2017 PNG economic survey. Development Policy Centre, Crawford School of Public Policy. http://devpolicy.org/wp-content/uploads/2017/09/2017-PNG-economic-survey.pdf

Frankel, J. A. (2012). The Natural Resource Curse: A Survey of Diagnoses and Some Prescriptions (HKS Faculty Research Working Paper Series RWP12-014). John F. Kennedy School of Government, Harvard University.

Freedom House. (2019). Freedom in the World. https://freedomhouse.org/reporttypes/freedom-world

Gardner, K., \& Lewis, D. (1996). Anthropology, Development and the Post-modern Challenge. Pluto Press.

Garnaut, R. (2000). The first 25 years of searching for development. Pacific Economic Bulletin, 15(2), 29-36.

Gelb, A. (Ed.). (1988). Oil Windfalls: Blessing or Curse? Oxford University Press.

Gerelmaa, L., \& Kotani, K. (2016). Further investigation of natural resources and economic growth: Do natural resources depress economic growth? Resources Policy, 50, 312321. 
Gerritsen, R., \& McIntyre, M. (1991). Dilemmas of distribution: The Misima gold mine, Papua New Guinea. In J. Connell \& R. Howitt (Eds.), Mining and Indigenous People in Australasia (pp. 35-54). Sydney University Press.

Ghai, Y. (1997). Establishing a Liberal Political Order Through a Constitution: The Papua New Guinea Experience. Development and Change, 28(2), 303-330. https://doi.org/10.1111/1467-7660.00044

Ghai, Y. (2000). Ethnicity and autonomy: A framework for analysis. Autonomy and Ethnicity: Negotiating Competing Claims in Multi-Ethnic States, 1.

Ghai, Y. (2001). Establishing a liberal political order through a constitution: The Papua New Guinea experience. In A. J. Regan, P. Jessop, \& E. L. Kwa (Eds.), Twenty years of the Papua New Guinea Constitution. Lawbook Company, Pyrmont.

Gilberthorpe, E. (2007). Fasu solidarity: A case study of kin networks, land tenure, and oil extraction in Kutubu, Papua New Guinea. American Anthropologist, 109(1), 101-112.

Gilberthorpe, E., \& Banks, G. (2011). Development on whose terms?: CSR discourse and social realities in Papua New Guinea's extractive industries sector. Resources Policy.

Gilberthorpe, E., \& Rajak, D. (2016). The Anthropology of Extraction: Critical Perspectives on the Resource Curse. The Journal of Development Studies, 53(2), 186-204.

Gillham, B. (2000). Case study research methods. Bloomsbury Publishing.

Goldman, D. L. R. (2009). Social Impact Assessment 2008 Papua New Guinea Liquefied Natural Gas Project. Esso Highlands Limited.

Gollwitzer, S. (2010). Budget institutions and fiscal performance in Africa. Journal of African Economies, 20(1), 111-152.

Golub, A. (2007). From Agency to Agents: Forging Landowner Identities in Porgera. In J. F. Weiner \& K. Glaskin (Eds.), Customary Land Tenure and Registration in Australia and Papua New Guinea: Anthropological Perspectives (Vol. 3, pp. 73-96). Australian National University E Press.

Income Tax Act, (1959). http://www.paclii.org/pg/legis/consol_act/ita1959116.pdf

Land Groups Incorporation Act, Pub. L. No. 147 (1974).

http://www.paclii.org/pg/legis/consol_act/lgia1974292/

Constitution of the Independent State of Papua New Guinea, (1975). http://www.paclii.org/pg/legis/consol_act/cotisopng534/

Audit Act, (1989). http://www.paclii.org/cgibin/sinodisp/pg/legis/consol_act/aa198971/aa198971.html?stem=\&synonyms=\&quer $\mathrm{y}=$ Audit

Public Finances (Management) Act, Pub. L. No. 21/1995 (1995). http://www.paclii.org/cgibin/sinodisp/pg/legis/consol_act/pfa1995224/pfa1995224.html?stem=\&synonyms=\& query $=$ Public $\% 20$ Finance

Oil and Gas Act, (1998). http://www.paclii.org/pg/legis/consol_act/oaga199894.pdf

Resource Contracts Fiscal Stabilization Act, Pub. L. No. 33 (2000).

http://www.paclii.org/pg/legis/consol_act/rcfsa2000409/ 
Fiscal Responsibility Act, Pub. L. No. 9 / 2006 (2006).

GoPNG. (2008). PNG LNG Gas Agreement.

https://www.banktrack.org/download/png_lng_gas_agreement/080522_pnglngagreem entexecutionversion.pdf

Land Groups Incorporation (Amendment) Act, Pub. L. No. 29 / 2009 (2009).

GoPNG. (2009a). Recent Changes To The Law On Incorporated Land Groups and Voluntary Customary Land Registration: Information Booklet. , Published by Business Directories.

GoPNG. (2009b). Papua New Guinea Vision 2050.

GoPNG. (2010). Development Strategic Plan 2010-2030. Department of National Planning and Monitoring.

Organic Law on Sovereign Wealth Fund, (2012).

GoPNG. (2014a). National Strategy for Responsible Sustainable Development for Papua New Guinea (StaRS)—2nd Edition. Department of National Planning and Monitoring. http://www.planning.gov.pg/images/dnpm/pdf/StaRS.pdf

GoPNG. (2014b). Background Information on Extractive Industry Transparency Initiative (EITI) and Papua New Guinea EITI. Government of Papua New Guinea. https://www.treasury.gov.pg/html/misc/Special\%20Projects/PNGEITI/Background\% 20on\%20PNGEITI.pdf

GoPNG. (2014c). Financial Arrangements for State Acquisition of Shareholding in Oil Search Limited and State Borrowing (National Executive Council Minute 79/2014). Government of Papua New Guinea.

https://www.scribd.com/document/284157594/The-document-appointing-UBS-asadviser

Organic Law on Sovereign Wealth Fund 2015, (2016).

GoPNG. (2017). Mid Year Economic and Fiscal Outlook Report 2017. Government of Papua New Guinea: Treasury Department.

http://www.treasury.gov.pg/html/national_budget/files/2013/budget_documents/Relat ed $\% 20$ Budget $\% 20$ Documents $/ 2017 \% 20 \mathrm{Mid} \% 20$ Year $\% 20$ Economic $\% 20$ and $\% 20$ Fisc al\%20Outlook\%20Report.pdf

Public Money Management Regularisation Act, Pub. L. No. 17/2017 (2017). http://www.parliament.gov.pg/uploads/acts/17A-17.pdf

GoPNG, \& Government of Australia. (2009). Joint Understanding on PNG LNG Project. https://www.dfat.gov.au/geo/papua-new-guinea/Pages/joint-understanding-on-pnglng-project

GoPNG, Southern Highlands Provincial Government, Local Level Governments, \& Project Area Landowners. (2009a). PNG LNG Project: Angore PRL 11 License Based Benefits Sharing Agreement (p. 34). Government of Papua New Guinea. http://actnowpng.org/sites/default/files/PNG\%20LNG\%20Project\%20Angore\%20PR L\%2011\%20License\%20Based\%20Benefits\%20Sharing\%20Agreement-2010-0129_1.PDF 
GoPNG, Southern Highlands Provincial Government, Local Level Governments, \& Project Area Landowners. (2009b). PNG LNG Project: Hides PDL1 License Based Benefits Sharing Agreement. Government of Papua New Guinea.

http://actnowpng.org/sites/default/files/Hides\%20PDL\%201\%20LBSA\%20Agreemen t_0.pdf

Gummesson, E. (2000). Qualitative methods in management research. Sage.

Gylfason, T. (2001). Nature, power and growth. Scottish Journal of Political Economy, 48(5), $558-588$.

Gylfason, T., \& Zoega, G. (2006). Natural Resources and Economic Growth: The Role of Investment. The World Economy, 29(8), 1091-1115. https://doi.org/10.1111/j.14679701.2006.00807.x

Haber, S., \& Menaldo, V. (2011). Do Natural Resources Fuel Authoritarianism? A Reappraisal of the Resource Curse. American Political Science Review.

Haley, N., \& May, R. (2007a). Conflict and Resource Development in the Southern Highlands of Papua New Guinea (Vol. 3). ANU E Press.

Haley, N., \& May, R. (2007b). Conflict and Resource Development in the Southern Highlands of Papua New Guinea. ANU E Press.

Hancock, G. (2010). Papua New Guinea-Second Mining Sector Institutional Strengthening Technical Assistance Project (No. 93400; pp. 1-1). The World Bank. http://documents.worldbank.org/curated/en/315291468290410871/Papua-NewGuinea-Second-Mining-Sector-Institutional-Strengthening-Technical-AssistanceProject

Haque, S. (1996). The contextless nature of public administration in Third World countries. International Review of Administrative Sciences, 62, 315-329.

Harford, T., \& Klein, M. (2005). Aid and the Resource Curse: How Can Aid Be Designed to Preserve Institutions? World Bank. https://openknowledge.worldbank.org/handle/10986/11223

Harris, B. M. (2007). Papua New Guinea: A Nation in Waiting. The Dance of Traditional and Introduced Structures in a Putative State (p. 64). World Bank (East Asia Environment and Social Division).

Hassall, G. (2017a). Law, culture, and corruption in the Pacific Islands. New Zealand Yearbook of International Law, 15, 9-28.

Hassall, G. (2017b, October 2). Corruption in the Pacific Islands. Multi-Level Responses to Transnational Security Threats: Are We Really All in This Together? CIAR annual symposium, Wellington, Victoria University Faculty of Law.

Hayward-Jones, J. (2016). The future of Papua New Guinea: Old challenges for new leaders. https://apo.org.au/node/62242

Heald, D. (2003). Fiscal transparency: Concepts, measurement and UK practice. Public Administration, 81(4), 723-759.

Hegarty, D. (1983). Electoral politics in Papua New Guinea: Studies on the 1977 national elections. Port Moresby, PNG: University of Papua New Guinea Press. 
Hellman, J. S., Jones, G., Kaufmann, D., \& Schankerman, M. A. (2000). Measuring Governance and State Capture: The Role of Bureaucrats and Firms in Shaping the Business Environment (No. 51; Working Paper). European Bank for Reconstruction and Development. http://www.ssrn.com/abstract=222210

Hellmann, O. (2015). The Institutionalisation of Corruption: The Neglected Role of Power. PSA Annual International Conference Sheffield, 30.

Hodler, R. (2006). The curse of natural resources in fractionalized countries. European Economic Review, 50(6), 1367-1386.

Hogbin, H. I. (1973). Anthropology in Papua New Guinea: Readings from the Encyclopaedia of Papua and New Guinea. Melbourne University.

Horn, M. K. (2019). Giant Oil and Gas Fields of the World. AAPG Datapages: Giant Oil and Gas Fields of the World - Energy Data Exchange (EDX). https://edx.netl.doe.gov/dataset/aapg-datapages-giant-oil-and-gas-fields-of-the-world

HuffPost. (2013, February 13). Shady Stories At The Holiday Inn. HuffPost. https://www.huffpost.com/entry/exxon-mobil-papua-new-guinea_n_2658668

Huntington, S. P. (1996). The Clash of Civilizations and the Remaking of World Order. Simon \& Schuster.

Imbun, B. Y. (2008). Making Sense of an Imposed Industrial Relations System in Papua New Guinea: A Review of Literature $\dagger$. Journal of South Pacific Law, 12(2), 3-14.

IMF. (2010). Papua New Guinea: Staff Report for the 2010 Article IV Consultation.

IMF. (2015). Papua New Guinea: Selected Issues (15/319; IMF Country Reports, p. 32). International Monetary Fund. http://elibrary.imf.org/view/IMF002/229459781513564357/22945-9781513564357/22945-9781513564357.xml

IMF. (2018). 2018 Article IV Consultation. International Monetary Fund.

IMF. (2019). World Economic Outlook Database. World Economic Outlook. https://www.imf.org/external/pubs/ft/weo/2019/01/weodata/index.aspx

Internal Revenue Commission. (2018). A Guide to the Taxation Incentives for Business \& Investment in Papua New Guinea. Government of Papua New Guinea.

International Gas Union. (2018). 2018 World LNG Report: 27th World Gas Conference Edition. https://www.igu.org/sites/default/files/node-documentfield_file/IGU_LNG_2018_0.pdf

Jackson, R. T. (1982). Ok Tedi: The pot of gold. University of Papua and New Guinea, distributed by World Publishing Company.

Jaganathan, J. (2018, August 7). Exxon Mobil's Papua New Guinea LNG export plant offers cargo for... Reuters. https://www.reuters.com/article/papua-lng-idUSL4N1UY2R9

Jreisat, J. E. (1988). Administrative reform in developing countries: A comparative perspective. Public Administration and Development, 8(1), 85-97.

Kaiulo, R. (1997). Report to the Sixth Parliament on the 1997 National Election by the Electoral Commissioner Reuben T. Kaiulo. 
Karl, T. L. (1997). The paradox of plenty: Oil booms and petro-states (Vol. 26). Univ of California Press.

Kaufmann, D., Kraay, A., \& Mastruzzi, M. (2007). Worldwide Governance Indicators Project: Answering the Critics (SSRN Scholarly Paper ID 965077). Social Science Research Network. https://papers.ssrn.com/abstract $=965077$

Kavanamur, D., \& Okole, H. (2004). Understanding Reforms in Papua New Guinea: An Analytical Evaluation. Global Development and AusAid.

Kirsch, S. (1997). Is Ok Tedi a precedent? Implications of the lawsuit. The Ok Tedi Settlement: Issues, Outcomes and Implications, 118-140.

Klitgaard, R. (1988). Controlling Corruption. University of California Press.

Koim, S., \& Howes, S. (2016, December 15). PNG LNG landowner royalties - why so long? Devpolicy Blog from the Development Policy Centre. http://www.devpolicy.org/pnglng-landowner-royalties-long-20161216/

Kolstad, I., \& Søreide, T. (2009). Corruption in natural resource management: Implications for policy makers. Resources Policy, 34(4), 214-226.

Kolstad, I., \& Wiig, A. (2009). Is transparency the key to reducing corruption in resource-rich countries? World Development, 37(3), 521-532.

Kramer, B. (2019, June 7). Real Story Behind the IPIC Deal. Kramer Report.

Kuhn, T. S. (1970). The structure of scientific revolutions. University of Chicago Press.

Kumul Consolidated Holdings. (2017, February 21). Minister Abel Clarifies the Kumul Consolidation Agenda. https://www.kch.com.pg/minister-abel-clarifies-the-kumulconsolidation-agenda/

Kumul Petroleum Holdings Ltd. (2016, December 27). Kroton Equity Unit Application Signing Ceremony. http://kumulpetroleum.com/news-article/kroton-equity-unitapplication-signing-ceremony/

Kumul Petroleum Holdings Ltd. (2019, June 7). Our History. http://kumulpetroleum.com/our-history/

Kuwimb, M. (2010). A critical study of the resource curse thesis and the experience of Papua New Guinea [PhD Thesis]. James Cook Uinversity.

Lakau, A. A. (1997). Customary Land Tenure, customary landowners and the proposals for customary land reform in Papua New Guinea. Anthropological Forum, 7, 529-547.

Lange, G.-M., Wodon, Q., \& Carey, Kevin. (2018). The Changing Wealth of Nations 2018: Building a Sustainable Future. World Bank. https://openknowledge.worldbank.org/handle/10986/29001

Larmour, E. P. (2012). Interpreting corruption: Culture and politics in the Pacific Islands. University of Hawai Press.

Larmour, P. (1998). State and society in Papua New Guinea. Modern Papua New Guinea, 21-30. 
Leftwich, A. (2008). Developmental States, Effective States and Poverty Reduction: The Primacy of Politics [Data set]. United Nations Research Institute for Social Development. https://doi.org/10.1163/1570-6664_iyb_SIM_org_39759

Leite, C., \& Weidmann, J. (2002). Does mother nature corrupt? Natural resources, corruption, and economic growth. Governance, Corruption, and Economic Performance, 159196.

Levine, S. (1997). Culture and conflict in Fiji, Papua New Guinea, Vanuatu, and the Federated States of Micronesia. In M. E. Brown \& S. Ganguly (Eds.), Government policies and ethnic relations in the Asia-Pacific (pp. 457-508). MIT Press.

Lewis, D. (2005). Anthropology and development: The uneasy relationship. In J. G. Carrier (Ed.), A handbook of economic anthropology. Edward Elgar. http://eprints.lse.ac.uk/archive/00000253

Lijphart, A. (1999). Patterns of democracy: Government forms and performance in thirty-six countries. Yale University Press.

Lindlof, T. R. (1995). Qualitative communication research methods. Sage Publ.

Main, M., \& Fletcher, L. (2018). On Shaky Ground: PNG LNG and the consequences of development failure. Jubilee Australia Research Centre.

March, J. G., \& Olsen, J. P. (1989). Rediscovering Institutions: The Organizational Basis of Politics. The Free Press.

Marshall, C., \& Rossman, G. B. (1989). Designing Qualitative Research Sage Publications. Newbury Park, California.

Martinussen, J. (1997). Society, State and Market: A guide to competing theories of development. Zed Books Ltd.

Maxwell, J. A. (2013). Qualitative Research Design: An Interactive Approach. SAGE Publications.

May, R J. (2004). State and Society in Papua New Guinea. ANU Press; JSTOR. http://www.jstor.org.helicon.vuw.ac.nz/stable/j.ctt2jbkfq

May, R J (Ed.). (2009). Policy Making and Implementation: Studies from Papua New Guinea. ANU E Press.

May, Ronald James. (2003). Turbulence and Reform in Papua New Guinea. Journal of Democracy, 14(1), 154-165.

Mayorga Alba, E. (2009). Extractive Industries Value Chain: A comprehensive integrated approach to developing extractive industries. World Bank.

McIlraith, J. (2011). Preliminary review: The PNG LNG Project in the Hela region of Papua New Guinea. National Centre for Peace and Conflict Sudies, University of Otago.

McIlraith, J. (2012). The Community Good: Examining the Influence of the Png Lng Project in the Hela Region of Papua new guinea. National Centre for Peace and Conflict Studies, University of Otago.

Mehlum, H., Moene, K., \& Torvik, R. (2006). Institutions and the resource curse. The Economic Journal, 116(508), 1-20. 
Melhum, H., Moene, K., \& Torvik, R. (2006). Institutions and Resource Curse. The Economic Journal, 116, 1-20.

Meyer, P. (2003). The truth about transparency. ASAE and The Center for Association Leadership.

Mitchell, R. B. (1998). Sources of transparency: Information systems in international regimes. International Studies Quarterly, 42(1), 109-130.

Moore, M. (2004). Revenues, state formation, and the quality of governance in developing countries. International Political Science Review, 25(3), 297-319.

Morgan, M. (2005). Cultures of Dominance: Institutional and Cultural Influences on Parliamentary Politics in Melanesia (State Society and Governance in Melanesia). Research School of Pacific and Asian Studies, The Australian National University.

Munro, W. A. (1996). Power, peasants and political development: Reconsidering state construction in Africa. Comparative Studies in Society and History, 38(1), 112-148.

Namaliu, R. H. S. R. L. (2006). 2007 Budget Speech. Government of Papua New Guinea. https://www.treasury.gov.pg/html/national_budget/files/2007/budget_speeches/2007. Budget.Speech.pdf

Namaliu, R. H. S. R. L. (2007). Budget Strategy Paper-2008. Government of Papua New Guinea.

Nelson, J., \& Valikai, K. (2014). Building the foundations for a long-term development partnership: The construction phase of the PNG LNG Project. Cambridge, MA: The CSR Initiative at the Harvard Kennedy School.

North, D. C. (1993). Nobel Prize Lecture. URL: Http://Www. Nobelprize. Org/Nobel_prizes/Economics/Laureates/1993/North-Lecture. Html.

North, D. C. (1995). Five Propositions about Institutional Change. Washington University.

OECD. (2002). OECD Best Practices for Budget Transparency. Organisations for Economic Cooperation and Development (OECD).

OECD. (2019). IBP - OECD Budgeting Transparency Toolkit. https://www.oecd.org/governance/budget-transparency-toolkit/internationalstandards/list-of-standards/ibp/

O\&G Links. (2018, May 31). Gas landowners known, says Pok. https://oglinks.news/pnglng/news/gas-landowners-known-says-pok

Öge, K. (2016). To disclose or not to disclose: How global competition for foreign direct investment influences transparency reforms in extractive industries. Energy Policy, 98, 133-141.

Oil Search Ltd. (2014). Oil Search to acquire interest in PRL 15 (Elk/Antelope), providing core strategic position in future $L N G$ developments in $P N G$. https://www.asx.com.au/asxpdf/20140227/pdf/42n1rb2r2n39yp.pdf

O’Neill, H. P. (2010). 2011 National Budget. Volume 1: Economic and Development Policies. Government of Papua New Guinea. 
http://www.treasury.gov.pg/html/national_budget/files/2011/budget_documents/Volu me\%201/2011.Budget_volume1.pdf

Osborne, D. (2014). An analysis of the Papua New Guinea Sovereign Wealth Fund's process of formulation and progress towards establishment (Issues Paper No. 9). The National Research Institute (PNG). http://devpolicy.org/pdf/blog/PNGSWF.pdf

Pacific Islands Report. (2017, March 28). PNG Landowners Submit Equity-Sharing Offer For ExxonMobile LNG Project. http://www.pireport.org/articles/2017/03/28/pnglandowners-submit-equity-sharing-offer-exxonmobile-lng-project

Parker, R. S., \& Wolfers, E. P. (1971). The context of political change. In A. L. Epstein, R. S. Parker, \& M. Reay (Eds.), The Politics of Dependence: Papua New Guinea 1968. Australian National University Press.

Petrie, M. (2003). Promoting Fiscal Transparency The Complementary Roles of the IMF, Financial Markets and Civil Society. International Monetary Fund.

PNG IPA. (2008). Final Report to the National Development Summit on the Papua New Guinea National Strategic Plan. PNG Institute of Public Administration.

PNG National Statistical Office. (2013). Final Figures: Papua New Guinea National Population and Housing Census 2011. Government of Papua New Guinea.

PNG Parliament. (2019). Hansard-National Parliament of Papua New Guinea. http://www.parliament.gov.pg/hansard

PNGReport. (2007, February 1). Oil Search scraps PNG pipeline plans. https://www.pngreport.com/news/news/1101647/oil-search-scraps-png-pipeline-plans

Polye, H. D. P. (2011a). Budget Strategy Paper-2012. Government of Papua New Guinea.

Polye, H. D. P. (2011b). 2012 National Budget. Volume 1: Economic and Development Policies. Government of Papua New Guinea. http://www.treasury.gov.pg/html/national_budget/files/2012/budget_documents/Volu me1/volume1.pdf

Polye, H. D. P. (2012). 2013 National Budget. Volume 1: Economic and Development Policies. Government of Papua New Guinea. https://www.treasury.gov.pg/html/national_budget/files/2013/budget_documents/Vol ume1/Vol1.pdf

Polye, H. D. P. (2013). 2014 National Budget. Volume 1: Economic and Development Policies. Government of Papua New Guinea. http://www.treasury.gov.pg/html/national_budget/files/2014/budget_documents/Volu me1/2014\%20Budget\%20Volume\%201.pdf

Post Courier. (2018, October 25). PNG LNG pipeline landowners to receive benefitsMRDC. Post Courier. https://postcourier.com.pg/png-lng-pipeline-landownersreceive-benefits-mrdc/

Post-Courier. (2018, May 2). PM rejects LNG report as utter nonsense. PNG Post Courier. https://postcourier.com.pg/pm-rejects-lng-report-utter-nonsense/

Pruaitch, H. P. (2007). 2008 National Budget: Volume 1-Economic and Development Policies. Government of Papua New Guinea. 
https://www.treasury.gov.pg/html/national_budget/files/2008/budget_documents/Vol ume\%201/Volume\%201.pdf

Pruaitch, H. P. (2008). 2009 National Budget. Volume 1-Economic and Development Policies.

Pruaitch, H. P. (2009). 2010 National Budget. Volume 1: Economic and Development Policies. Government of Papua New Guinea. http://www.treasury.gov.pg/html/national_budget/files/2010/budget_documents/Volu me\%201/Volume\%201_fulldoc.pdf

Pruaitch, H. P. (2014). 2015 National Budget. Volume 1: Economic and Development Policies. Government of Papua New Guinea. http://www.treasury.gov.pg/html/national_budget/files/2015/Vol1 Economic\%20and\%20Development\%20Policies.pdf

Pruaitch, H. P. (2015). 2016 National Budget. Volume 1: Economic and Development Policies. Government of Papua New Guinea. http://www.treasury.gov.pg/html/national_budget/files/2016/Volume1Econ\&DevPolicies.pdf

Pruaitch, H. P. (2017). 2017 National Budget. Volume 1: Economic and Development Policies. Government of Papua New Guinea. http://www.treasury.gov.pg/html/national_budget/files/2017/2017\%20Budget\%20Vol ume\%201\%20Economic\%20and\%20Development\%20Policies.pdf

Radio New Zealand. (2018a, June 15). Perceptions of corruption behind PNG Highlands unrest. RNZ. https://www.rnz.co.nz/international/pacific-news/359680/perceptions-ofcorruption-behind-png-highlands-unrest

Radio New Zealand. (2018b, June 16). Southern Highlands govt suspended in PNG state of emergency. RNZ. https://www.rnz.co.nz/international/pacific-news/359757/southernhighlands-govt-suspended-in-png-state-of-emergency

Ramkumar, V., \& Shapiro, I. (Eds.). (2010). Guide to Transparency in Government Budget Reports: Why are Budget Reports Important, and What Should They Include? International Budget Partnership.

Ramsay, K. W. (2011). Revisiting the Resource Curse: Natural Disasters, the Price of Oil, and Democracy. International Organization, 65(Summer 2011), 507-29.

Reilly, B. (2002). Political engineering and party politics in Papua New Guinea. Party Politics, 8(6), 701-718.

Reilly, B. (2008). Ethnic conflict in Papua New Guinea. Asia Pacific Viewpoint, 49(1), 12 22.

Reinhart, C. M., \& Rogoff, K. S. (2011). From financial crash to debt crisis. American Economic Review, 101(5), 1676-1706.

Reuters. (2016, August 9). ExxonMobil urges end to PNG LNG royalty dispute amid protest. Reuters. https://uk.reuters.com/article/papua-exxon-mobil-protests-idUKL4N1AQ1P3 
Reuters. (2019, January 18). In Papua New Guinea, Exxon's giant LNG project fuels frustration. Reuters. https://www.reuters.com/article/us-papua-lng-exxon-mobilinsight-idUSKCN1PA32M

Rhodes, R. A. (1997). Understanding governance: Policy networks, governance, reflexivity and accountability. Open university press.

Robinson, J. A., Torvik, R., \& Verdier, T. (2006). Political foundations of the resource curse. Journal of Development Economics, 79, 447-468.

Ross, M. L. (2001). Does oil hinder democracy? World Politics, 53(3), 325-361.

Ross, M. L. (2013). The Politics of the Resource Curse: A review. In Handbook on the Politics of Development. Oxford University Press.

Rubin, H. J., \& Rubin, I. (1995). Qualitative interviewing the art of hearing data. Thousand Oaks, CA: Sage.

Ruis, A., \& van der Walle, N. van de. (2003). Political and Cultural Institutions and Economic Polity Reform (Preliminary Draft). A Paper presented to the GDN Workshop on Understanding Reform, Cairo, Egypt (Preliminary Draft).

Sachs, J. D., \& Warner, A. M. (1995). Natural resource abundance and economic growth. National Bureau of Economic Research.

Sachs, J. D., \& Warner, A. M. (2001). The curse of natural resources. European Economic Review, 45(4), 827-838.

Scapens, R. W. (1990). Researching management accounting practice: The role of case study methods. The British Accounting Review, 22(3), 259-281.

Schutt, R. K. (1999). Investigating the social world: The process and practice of research. Sage Publications.

Scott, W. (2001). Institutions and Organizations (Rev. Ed.). Sage.

Shaffer, B., \& Ziyadov, T. (2011). Beyond the Resource Curse. University of Pennsylvania Press.

Sigam, C., \& Garcia, L. (2012). Extractive Industries: Optimising Value Retention in Host Countries. United Nations.

Simons, H. (2009). Case Study Research in Practice. SAGE Publications. https://eprints.soton.ac.uk/388331/

Somare, A. (2017). Power Point Presentation to University of PNG Law Faculty.

Sovacool, B. K., Walter, G., Van de Graaf, T., \& Andrews, N. (2016). Energy Governance, Transnational Rules, and the Resource Curse: Exploring the Effectiveness of the Extractive Industries Transparency Initiative (EITI). World Development, 83, 179192.

Stake, R. E. (2000). Case studies. In N. K. Denzin \& Y. S. Lincoln (Eds.), Handbook of Qualitative Research (pp. 435-454).

Stake, R. E. (2006). The art of case study research. Sage Publ. 
Standish, B. (1994). Papua New Guinea: The search for security in a weak state. Papua New Guinea: Issues for Australian Security Planners. Canberra: Australian Defence Studies Centre, Australian Defence Force Academy, 51-97.

Standish, B. (2007). The dynamics of Papua New Guinea's democracy: An essay. Pacific Economic Bulletin, 22(1).

Stevens, P., Lahn, G., \& Kooroshy, J. (2015). The resource curse revisited [Research Paper]. Chatham House.

Stirton, L., \& Lodge, M. (2001). Transparency mechanisms: Building publicness into public services. Journal of Law and Society, 28(4), 471-489.

Strathern, A. (1993). Voices of conflict (Vol. 14). Ethnology Monographs.

Strathern, A. J., \& Stewart, P. J. (1998). Shifting Places, Contested Spaces: Land and Identity Politics in the Pacific 1. The Australian Journal of Anthropology, 9(2), 209-224.

Strauss, A. L. (1987). Qualitative analysis for social scientists. Cambridge university press.

Subramanian, M. A., \& Sala-i-Martin, X. (2003). Addressing the natural resource curse: An illustration from Nigeria. International Monetary Fund.

Teskey, G. (2013). Governance in PNG: what can donors do? Devpolicy Blog from the Development Policy Centre, 3.

The Australian Pipeliner. (2006). The history of the PNG - Queensland pipeline. The Australian Pipeliner. https://www.pipeliner.com.au/2016/03/16/the-history-of-thepng-queensland-pipeline/

The Australian Pipeliner. (2016, March 15). Elk-Antelope independent certification begins. https://www.pipeliner.com.au/2016/03/15/elk-antelope-independent-certificationbegins/

The National. (2016, June 23). Sonk outlines KPHL's role. The National. https://www.thenational.com.pg/sonk-outlines-kphls-role/

The National. (2018, June 21). Exxon reports damage. The National. https://www.thenational.com.pg/exxon-reports-damages/

The Sydney Morning Herald. (2018, May 12). Oil Search blames PNG government for slow payments. The Sydney Morning Herald. https://www.smh.com.au/business/theeconomy/oil-search-blames-png-government-for-slow-payments-20180511p4zers.html

Tornell, A., \& Lane, P. R. (1999). The voracity effect. American Economic Review, 89(1), $22-46$.

Torvik, R. (2002). Natural resources, rent seeking and welfare. Journal of Development Economics, 67(2), 455-470.

Torvik, R. (2009). Why do some resource-abundant countries succeed while others do not? Oxford Review of Economic Policy, 25(2), 241-256.

Transparency International PNG. (2017). Annual Report 2017. https://www.transparencypng.org.pg/wp-content/uploads/2017/08/2017-AnnualReport.pdf 
Tsui, K. K. (2010). More oil, less democracy: Evidence from worldwide crude oil discoveries. The Economic Journal, 121(551), 89-115.

Turner, M., \& Kavanamur, D. (2009). Explaining Public Sector Reform Failure: Papua New Guinea 1975-2001. In R J May (Ed.), Policy Making and Implementation: Studies from Papua New Guinea (pp. 9-26). ANU E Press.

UNDP. (2015, March). Papua New Guinea National Human Development Report 2014. http://hdr.undp.org/en/content/papua-new-guinea-national-human-developmentreport-2014

UNDP. (2018). Briefing note for countries on the 2018 Statistical Update: Papua New Guinea. United Nations Development Plan. http://hdr.undp.org/sites/all/themes/hdr_theme/country-notes/PNG.pdf

Van Alstine, J. (2017). Critical reflections on 15 years of the Extractive Industries Transparency Initiative (EITI). The Extractive Industries and Society, 4(4), 766-770.

Van Maanen, J. (1983). Qualitative methodology. Sage.

Weiner, J. F. (2007). The Foi Incorporated Land Group: Group Definition and Collective Action in the Kutubu Oil Project Area, Papua New Guinea. In J. F. Weiner \& K. Glaskin (Eds.), Customary land tenure and registration in Australia and Papua New Guinea: Anthropological perspectives.

Weiner, J. F., \& Glaskin, K. (2007). Customary Land Tenure and Registration in Papua New Guinea and Australia: Anthropological Perspectives. In J. F. Weiner \& K. Glaskin (Eds.), Customary land tenure and registration in Papua New Guinea and Australia: Anthropological perspectives. Australian National University, E Press.

Weinthal, E., \& Luong, P. J. (2006). Combating the resource curse: An alternative solution to managing mineral wealth. Perspectives on Politics, 4(1), 35-53.

White, G. (2007). Indigenous Governance in Melanesia. Australian National University, Research School of Pacific and Asian Studies, State, Society and Governance in Melanesia.

Wikipedia. (2019). Exchangeable bond. In Wikipedia. https://en.wikipedia.org/wiki/Exchangeable_bond

Williamson, O. E. (2000). The New Institutional Economics Taking Stock, Looking Ahead. Journal of Economic Literature, XXXVIII, 595-613.

Woolford, D. (2013). Papua New Guinea: Initiation and independence. University of Queensland Press.

World Bank. (1978). Papua New Guinea: Its Economic Situation and Prospects for Development. https://www.jstor.org/stable/2757815?origin=crossref

World Bank. (1999). Papua New Guinea: Improving Governance and Performance (No. 19388-PNG; p. 306). World Bank (Poverty Reduction and Economic Management Sector Unit, East Asia and Pacific Region).

World Bank. (2003). Papua New Guinea: Public Expenditure Review and Rationalization Overview Of Discussion Papers (pp. 10-17). http://www- 
wds.worldbank.org/servlet/WDSContentServer/WDSP/IB/2005/01/12/000009486_20 050112122446/Rendered/PDF/312060PNG0whit1iew0P07979801public1.pdf

World Bank. (2018). Systematic Country Diagnostic: The Independent State of Papua New Guinea. World Bank.

http://documents.worldbank.org/curated/en/360291543468322518/pdf/127800-28-112018-11-12-10-PNGSystematicCountryDiagnosticFinal.pdf

World Bank. (2019a). Total natural resources rents (\% of GDP)| Data. https://data.worldbank.org/indicator/NY.GDP.TOTL.RT.ZS

World Bank. (2019b). World Bank Commodity Price Data-Excel Spreadsheet. World Bank. pubdocs.worldbank.org/en/561011486076393416/CMO-Historical-DataMonthly.xlsx

World Bank. (2019c). World Bank Data: PNG. World Bank. https://data.worldbank.org/country/papua-new-guinea

World Bank. (2019d). Worldwide Governance Indicators (WGI)| Data Catalog. https://info.worldbank.org/governance/wgi/\#home

Yin, R. K. (1984). Case study research: Design and methods (Beverley Hills, CA, Sage).

Yin, R. K. (2003). Case study research: Design and methods. SAGE Publications.

Yin, R. K. (2009). Case Study Research-Design and Methods. Applied Social Research Methods, 5.

Zainal, Z. (2007). Case study as a research method. Jurnal Kemanusiaan, 5(1). 